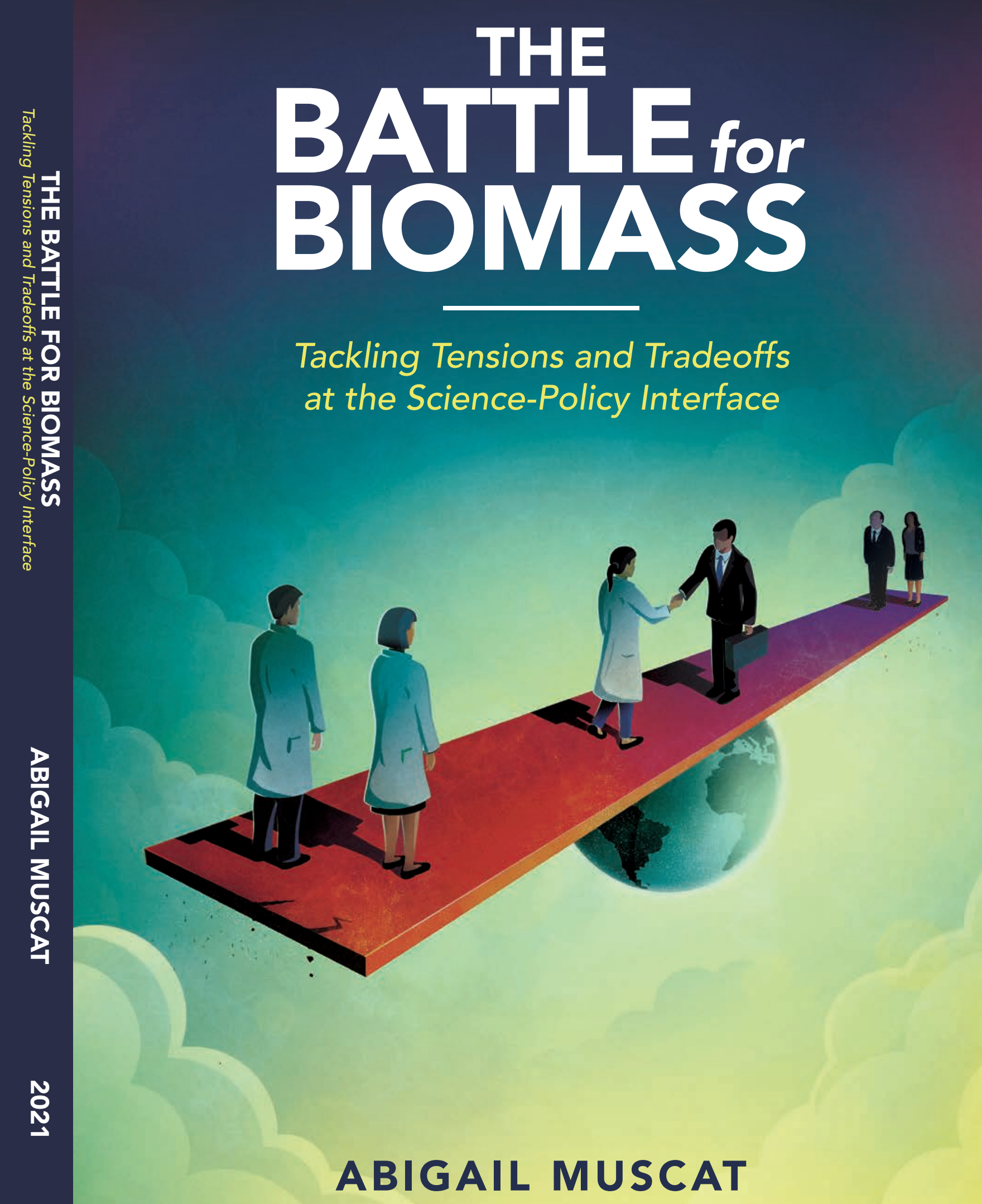




\section{Propositions}

1. Sustainable biomass use needs to be guided by human needs rather than economic value. (this thesis)

2. Embracing ambiguity is essential for successful governance of complex problems. (this thesis)

3. Sustainability science, like history, is doomed to repeat itself.

4. How we apportion scarce resources is fundamentally an ethical question.

5. It's ironic scientists ask politicians to break-up with infinite growth while scientists themselves are still expected to grow in publications, h-index, the number of students, funding etc.

6. Until animals learn how to use guns, violence against animals will continue.

Propositions belonging to the thesis, entitled

'Battle for Biomass: tackling tensions and trade-offs at the science-policy interface'

Abigail Muscat

Wageningen, 21 April 2021 


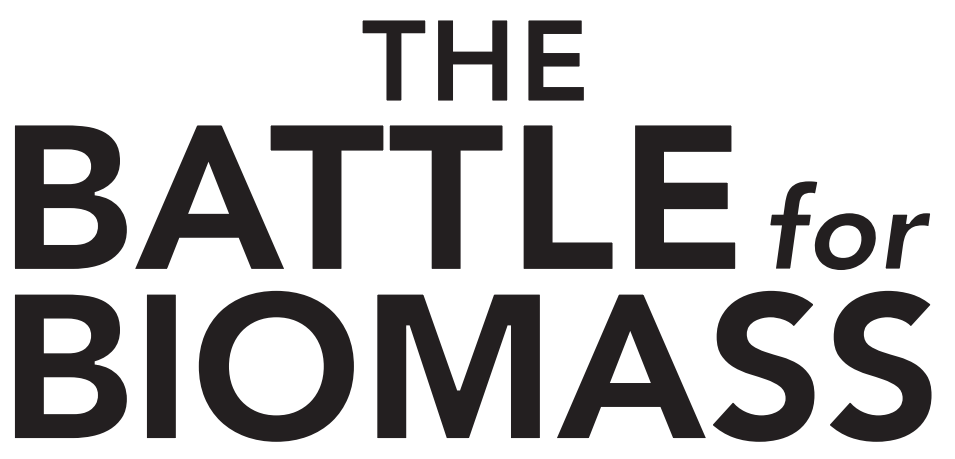

Tackling Tensions and Tradeoffs at the Science-Policy Interface 


\section{Thesis Committee}

\section{Promoters}

Prof. Dr I.J.M. de Boer

Professor of Animal Production Systems

Wageningen University \& Research

\section{Co-promoters}

Dr R. Ripoll Bosch

Researcher, Animal Production Systems Group

Wageningen University \& Research

\section{Dr E.M. de Olde}

Researcher, Animal Production Systems Group Wageningen University \& Research

\section{Other members}

Dr HL. Bos, Wageningen University \& Research

Dr B.S. Elbersen, Wageningen University \& Research

Prof. Dr P.J.M. Oosterveer, Wageningen University \& Research

Prof. Dr R. Strand, University of Bergen, Norway

This research was conducted under the auspices of the Graduate School of Wageningen of Animal Sciences (WIAS) 


\title{
The Battle for Biomass: Tackling Tensions and Tradeoffs at the Science-Policy Interface
}

\author{
Abigail Muscat
}

Thesis

submitted in fulfilment of the requirements of the degree of doctor

at Wageningen University

by the Authority of the Rector Magnificus

Prof. Dr A.J.P. Mol,

in the presence of the

Thesis Committee appointed by the Academic Board

to be defended in public

on Wednesday 21 April 2021

at 11 a.m. in the Aula. 
Muscat, Abigail

The Battle for Biomass: Tackling Tensions and Tradeoffs at the Science-Policy Interface, 192 pages

PhD thesis, Wageningen University, Wageningen, the Netherlands (2021)

With references, with summary in English

DOI: https://doi.org/10.18174/541657

ISBN: 978-94-6395-713-7 


\section{Abstract}

Humanity's growing demands for food, feed, bioenergy and biomaterials put pressure on agroecosystems and the biosphere. If these trends continue, the capacity of agroecosystems to feed the planet while also providing for humanity's energy and material needs is at risk. These demands cause interactions and trade-offs between different biomass uses, competition for biomass and other natural and economic resources. Governing these interactions is difficult, because of the inherent complexity of these interactions but also due to the diversity of biomass resources, the diversity of policy domains and institutions that are needed to govern them. This thesis, therefore, aims to advance the theoretical and empirical understanding of the governance of biomass with the ultimate aim of improving the governance process at the science-policy interface, taking the EU as a case study. By conducting a systematic review, this thesis finds that, overall, the majority of the interactions between food, feed fuel uses of biomass found in the scientific literature are tradeoffs e.g. increasing bioenergy leading to increased resource use consumption as well as higher food prices and land rents. Furthermore, the solutions recommended to address these tradeoffs were diverse, addressing production or consumption of biomass, losses and wastes along supply chains or governance. Each set of solutions set different priorities for biomass, resulting in incoherencies. To dig further into these incoherencies, a policy coherence study was conducted across five policy domains (agro-food, bio-based industry, waste, energy and environment). Utilising a survey and focus groups, this thesis finds that policies are largely considered consistent or synergistic. However, there was considerable uncertainty and context dependencies in the scientific knowledge-base, particularly concerning waste and bio-based industry domains which arise from different incommensurable ways of framing a problem and vagueness which leaves concepts undefined. This thesis examined one such ambiguous concept: the term 'marginal land', a solution that is recommended to overcome competition for biomass between food, feed and fuel uses. Through an analysis of European policies and debates, this thesis finds that the ambiguity around marginal land is a type of uncertainty that results from multiple ways of framing an issue, leaving no clear idea of what is the problem or what should be done about it. Issues of policy incoherence, ambiguity and vagueness can be handled in multiple ways. First, acknowledging the interactions between different policy goals across the different sectors and avoiding 'silo-thinking'. Overcoming vagueness in policies, by having clear definitions where possible, such as having clear cascading guidelines for biomass. Where this is not possible, embracing ambiguity becomes essential. Deliberative approaches are needed where different scientific and policy frames around complex problems can form the starting point. To connect the different perspectives on biomass, this thesis suggests an integrated framework for biomass, based on five ecological principles: 1) safeguarding and regenerating the health of our agroecosystems; 2) avoiding the production of non-essential products and waste of essential ones; 3) using biomass streams for basic human needs; 4) utilising and recycling all by-products of agroecosystems, and 5) prioritising renewable energy and minimising energy use. By involving stakeholders, leaving room for ambiguity, having an ambitious vision for change and a mix of top-down and bottom-up governance approaches, these principles can be operationalised. 


\section{Table of Contents}

$\begin{array}{lll}\text { Chapter } 1 \quad \text { General Introduction } & 9\end{array}$

$\begin{array}{lll}\text { Chapter } 2 & \text { The battle for biomass: } & 21\end{array}$

a systematic review of food-feed-fuel competition

Chapter $3 \quad$ Food, energy or biomaterials? 53

Policy coherence across agro-food and bioeconomy policy domains in the EU

Chapter 4 The Promised Land:

81

contrasting frames of marginal land in the European Union

Chapter 5 Towards a circular, bio-based economy:

107

principles, barriers and opportunities

$\begin{array}{lll}\text { Chapter } 6 & \text { General Discussion } & 123\end{array}$

$\begin{array}{ll}\text { Bibliography } & 141\end{array}$

$\begin{array}{ll}\text { Summary } & 175\end{array}$

$\begin{array}{ll}\text { Acknowledgements } & 179\end{array}$

$\begin{array}{ll}\text { About the Author } & 183\end{array}$

$\begin{array}{ll}\text { Publications } & 185\end{array}$

$\begin{array}{ll}\text { Education Certificate } & 189\end{array}$

$\begin{array}{ll}\text { Colophon } & 191\end{array}$ 

Chapter 1

General Introduction 


\section{Background}

Biomass forms the basis of agroecosystems. It is the basis of food systems and the bioeconomy. Humans do not just utilise biomass for food, but they also use biomass to produce feed for animals and bio-materials such as fibre, biochemicals, bioplastics and bioenergy. Over the last century, humans have appropriated more biomass than ever before, contributing to land-use change, biodiversity loss, climate change, water pollution and land degradation (Helmut Haberl et al., 2014a; Krausmann et al., 2013; Poore and Nemecek, 2018; Smil, 2012). Demands for biomass are growing due to population growth, a shift towards diets rich in animal-source food (ASF) (Foley et al., 2011) and bioeconomy policies pushing increased production of bioenergy and bio-based products (European Environmental Agency (EEA), 2018). Given these increasing demands, pressure on agroecosystems will increase. The capacity of agroecosystems to feed the planet while also providing for energy and material needs is ultimately limited by its biophysical boundaries or 'planetary boundaries' (Erb et al., 2016; Smil, 2012; Steffen et al., 2015) and forms the option-space in which socio-economic goals must be achieved (Fischer et al., 2007; Raworth, 2017). In the next sections, we will look at how growing biomass demands cause pressure on and competition for resources, and how this poses a challenge for governance.

\subsection{Growing biomass demands}

Humans use biomass for a multitude of products and have been harvesting increasingly larger shares of biomass from the biosphere for some time. Over the last 50 years, the use of biomass has increased substantially, for the large part due to population growth and socio-economic development (Alexandratos and Bruinsma, 2012). As the global population is expected to increase to about 10 billion by 2050 (Melorose et al., 2015), upward trends in biomass demands are expected to continue. Three major drivers are associated with these growing demands. First, larger and richer populations will consume more food (Alexandratos and Bruinsma, 2012). Since measurements started in 1961, the average calorie supply has increased globally (FAOSTAT, 2016), with large disparities between richer and poorer regions in calorie supply. Particularly, rising incomes and urbanisation have induced a 'nutrition transition' characterised by a shift from staple foods to increased consumption of ASF (Alexandratos \& Bruinsma 2012; Drewnowski \& Popkin 1997). Between 1950 and 2009, the average ASF consumption doubled. The consumption of fish follows a similar trend (FAO, 2012). Should these trends continue until 2050, the consumption of ASF will double compared to current levels (UNEP, 2012).

To support this increased intake of ASF a greater amount of feed is needed to grow and maintain farm animals (referring to both livestock and fish). The demand for feed is expected to grow from about 7 Gton in 2010 to about 8.3 Gton in 2050 if ASF consumptions patterns are not changed 
(Bos and Broeze, 2020). Despite this demand for feed crops may seem modest, in resource terms, feeding livestock currently requires approximately $77 \%$ global farmland (including both grazing and cropland) (approximately 40 million square kilometres), while producing only $37 \%$ of the world's protein (Poore and Nemecek, 2018).

Second, in response to climate change and concerns around fossil depletion, governments around the world have pushed to increase the share of bioenergy in the energy mix. This is seen as an important step in the pathway towards a low-carbon future (European Commission, 2011; Executive Office of the President, 2013; Ros et al., 2011; Valentine et al., 2012). Bioenergy is a significant global energy source, accounting for over $70 \%$ of renewable energy production. Although renewable energy is expected to be supplied by other renewables, such as solar and wind, bioenergy is expected to continue to be an important part of the energy mix and thus demand is still expected to increase (IEA, 2017).

Third, the shift from fossil to biomass is not likely to be limited to energy. Given the challenges of climate change, fossil depletion and plastic pollution (Chae and An, 2018; Eriksen et al., 2014; Sarker et al., 2020), more products and sectors are expected to become bio-based (Bos and Broeze, 2020; European Commission, 2018; European Environmental Agency (EEA), 2018). Bio-based materials can come in many shapes and formats; from traditional material uses, such as paper, pulp and furniture, to fossil-replacements, such as biochemicals, bioplastics and textiles. Many of these bio-based industries are expected to grow in the future, in comparable magnitudes to growth in food and feed (Bos and Broeze, 2020). Bioplastics, for example, currently representing approximately $1 \%$ of the total production of plastics are expected to grow further in the coming 5 years (Bioplastics Europe, 2019).

\subsection{Pressure on the planet's biophysical boundaries}

These growing demands for biomass put pressure on the planet's biophysical boundaries and induce competition for natural and economic resources (Erb et al., 2016; Smil, 2012). Land-based biomass production is responsible for more than $30 \%$ of anthropogenic greenhouse gas (GHG) emissions (of which 5\% for non-food products)(Poore and Nemecek, 2018). The food system alone is responsible for one-third of global terrestrial acidification and the majority of global eutrophication (Bouwman et al., 2002; Poore and Nemecek, 2018). Biomass production systems furthermore occupy about $43 \%$ of the world's ice- and desert-free area (of which $5 \%$ for non-food products) (Poore and Nemecek, 2018). Competition for biomass refers to the tensions and tradeoffs between different alternatives uses of resources between different biomass end-uses, such as for food, feed, fuel, fibre etc. Particularly, competition has been observed between food-fuel uses (HLPE, 2013), food-feed (Mottet et al., 2017) and between bio-based products and other uses (Searchinger et al., 2020). 
The global food price crisis around 2007/2008 led, among others, to increased awareness of the competition between food and feed (Chakravorty et al., 2009). The crisis spurred scientific research and debate on the contribution of biofuel mandates, particularly in the United States and the European Union (EU) on the price of food and other agricultural commodities. Biofuels, such as ethanol and biodiesel, made from food and feed crops, such as corn and rapeseed, were thought to increase competition for land, water, and other resources by pushing out crops meant for food or feed (Chakravorty et al., 2009; Rulli et al., 2012). Additionally, the crisis highlighted the environmental effects of biofuels, such as increased GHG emissions through indirect land-use change (Ahlgren and Di Lucia, 2014; Don et al., 2012). This also spurred research on the pressure on water, energy and land, highlighting the 'nexus' between water, energy and food systems (Damerau et al., 2016; Gerbens-Leenes, 2017; Gerbens-Leenes et al., 2009; Mirzabaev et al., 2015; Rulli et al., 2016). In response to this crisis, second-generation or advanced biofuels were put forward as a solution. Advanced biofuels are biofuels made from dedicated energy crops (e.g. grasses, short-rotation coppice) or wastes and residues (e.g. animal fats, unused cooking oil, crop residues). However, advanced biofuels do not entirely avoid issues of competition for resources; for example, biogas feedstocks can compete directly with animal feed uses (Styles et al., 2015; Tonini et al., 2016; Van Stappen et al., 2016).

The competition for resources is also of concern for the food system (Willett et al., 2019) as many of the food system's environmental impacts and resource burdens are largely related to the production of ASF (Poore and Nemecek, 2018). As mentioned in section 1.1, the contribution of the livestock sector versus the resources needed to produce ASF is imbalanced and can result in resource trade-offs between food and feed uses. The tensions and trade-offs between using crops and resources to feed animals as opposed to feeding humans directly are known as foodfeed competition (Banerjee, 2011; Ben Fradj et al., 2016; Mottet et al., 2017; Van Zanten et al., 2016b). Competition can occur either directly or indirectly. Direct competition is when humanedible crops or caught fish are consumed by farm animals rather than humans, while indirect competition is when the resources needed for their production, such as water, labour, capital and ecosystem services are used for growing feed for farm animals (Muscat et al., 2020). However, such resources are needed for more than just for humans or farm animals. Land, for example, can also be utilised for nature conservation, rewilding, urbanisation and renewable energy. In a world of limited resources, this can exacerbate competition even further.

As highlighted in section 1.1, due to bioeconomy policies formed in response to climate change and fossil depletion, biomass demands for chemicals and materials are likely to increase and put pressure on resources. This is already happening in the case of forest resources where the use of wood for bioenergetic uses over material uses induces additional GHG emissions (Searchinger et al., 2020, 2018). 
Studies highlighting the nexus across different resources (food, energy, water etc) have shown that pressure on these resources can lead to trade-offs between different goals. For example, increased energy production and GHG mitigation from biofuels can come at the expense of increased water demand (Holmatov et al., 2019). On the one hand, these trade-offs may sometimes be difficult to predict or to avoid due to the complex nature of the interlinkages between different systems. On the other hand, interlinkages may imply that synergies are possible, i.e. making progress towards one goal can improve the other. For example, the reduction of ASF in human diets may lead to both planetary and human health benefits (Willett et al., 2019). The interlinkages between different systems will nevertheless mean that careful governance is needed for trade-offs to be minimised and synergies increased.

\subsection{Governing biomass dilemmas}

Achieving responsible governance of the dilemmas surrounding biomass competition comes with its own policy challenges. The concept of the bioeconomy has been utilised, particularly in EU policy, to attempt to address sustainability issues that cut across different agroecosystems and different economic sectors. However, the fact that the bioeconomy links primary sectors, such as the agricultural, aquaculture and forestry sector, with industrial and processing sectors, such as the chemical, energy and biotechnology sectors, poses a challenge for the governance of the bioeconomy (Kelleher et al., 2019) and can result in policy incoherence. To avoid this policy incoherence and mitigate trade-offs across different goals, a collective effort will be needed across different institutions in a diversity of policy domains (Ronzon and Sanjuán, 2020). Furthermore, governance is challenged by the complexity of biomass competition itself. Biomass resources are diverse (e.g. food, feed and energy crops, forestry felling), yet come from interconnected agroecosystems that can cause unexpected effects. Complexity or complex problems, such as biomass competition, are characterised by several features; namely uncertainty, ambiguity, open-ended systems, self-organisation and emergence (Orsini et al., 2019). These concepts are explained further in section 2. Complexity thus poses a challenge for governance systems, particularly because the science that can guide governance systems can only provide incomplete, uncertain or conflicting knowledge. This relates not just to how the problem is represented, as is the case of biomass competition, but also to how solutions are represented. In other words, if complex problems lead to a multiplicity of representations, then the solutions to these problems are also subject to such a multiplicity of representations. For example, the circular economy has been suggested as a solution to reduce or eradicate waste and reduce the pressure on resources. However, the circular economy is also vaguely defined and refers to different solutions to different stakeholders (Kirchherr et al., 2017; Kovacic et al., 2019b). Marginal lands, for example, are widely advocated as a solution to land-use competition and biomass competition dilemmas, by shifting any non-food biomass production to these lands. However, marginal lands are often ambiguously defined in scientific literature and represented differently in policy. Definitions of 
marginal lands may contain unexamined assumptions (Shortall, 2013), yet policy relies on such scientific definitions and assessments of the quantity and location of marginal lands. Ways forward are therefore needed for governance in the context of scientific ambiguity and uncertainty.

\subsection{Pathways to better biomass use}

The intractable dilemmas surrounding rising biomass demands and the ensuing competition for resources has led to calls for a systems-view of such dilemmas, whether in science (Al-Saidi and Elagib, 2017; van Berkum et al., 2018; Weitz et al., 2017) or in policy (European Environmental Agency (EEA), 2017a). The connections across different systems and the difficulty in balancing goals, minimising trade-offs and promoting synergies require a systems-perspective that can acknowledge these interlinkages. One such approach is the concept of the 'nexus', which looks at the interconnections of resource-use between different sectors. The concept of the nexus can refer both to the actual interdependencies between natural resources, such as water, food and energy and the integrated governance of these resources (Zhang et al., 2018). In particular, circular food systems have been put forward as a way to address a number of the issues mentioned above; namely food-feed competition, competition for resources and resource scarcity, and food security (Bos and Broeze, 2020; de Boer and Van Ittersum, 2018; Jurgilevich et al., 2016). Recommendations for food systems under a circular concept, for example, include, inter alia, feeding livestock only with by-products and biomass from marginal lands (Van Kernebeek et al., 2016; Van Zanten et al., 2019), the utilisation of unused biomass residues (Bos and Broeze, 2020; Van Zanten et al., 2019) and the recycling of phosphorus from human excreta (Van Kernebeek et al., 2018). However, many biomass dilemmas face agroecosystems as a whole, not just those systems delivering food. Furthermore, to alter our relationship with the biosphere we will require a deep societal transformation. However, research around the social, cultural and economic elements to achieve such a transformation is largely missing.

In conclusion, growing demands for biomass results in pressure on resources and competing claims for resources. The complex nature of biomass competition results in several debates and dilemmas. In many ways, Europe stands at the centre of a great deal of these dilemmas and debates. For one, the disproportionate consumption pattern of Europeans has a great effect on the resource demand in other countries (Erb et al., 2009; Mayer et al., 2015; Weinzettel et al., 2013). At the same time, the EU has sought to be a diplomatic leader in climate change, to improve policy coherence (Nilsson et al., 2012), to increase bioenergy production globally and has pushed for bioeconomy policies across its member states (European Comission, 2018). To illustrate, the bioeconomy is one of the largest components of the EU economy (Scarlat et al., 2015) and bioenergy is the biggest contributor to renewable energy in the EU and accounts for $64 \%$ of the total share of primary renewable energy production (Eurostat, 2016). Largely due to this role, the EU has also been at the centre of debates about bioenergy, the effects of land- 
use change and the conflicts around land use. The highly technical nature of these debates has meant studying the relationship between science and policy in dealing with these dilemmas is both inevitable and fruitful. Naturally, the challenge respecting planetary boundaries is global, and biomass dilemmas play out in different ways depending on geography and time (Dixon et. al, 2010).

Below, I sketch out my theoretical frame, primary research gaps that this thesis addresses, where they lie in these dilemmas and how this thesis addresses them.

\section{Theoretical framework Governance under complexity}

The competition for biomass is a complex problem. Complex problems are characterised by certain unique features which present challenges for governance. First, complexity implies openendedness or open systems, which means that systems interact with the wider environment. This means that policy has to operate in an increasingly networked, multi-scaled and interconnected world. However, these interconnections also come with increased unpredictability. A second characteristic is self-organisation, meaning there is no clear authority on these interconnections and non-linear interactions can create multiple feedback loops. A third characteristic is emergence, which is the emergence of unexpected processes and outcomes. Governing, and possibly finding solutions to biomass competition, therefore, is not straightforward. In this context, the traditional model of the science-policy interface as one where science 'speaks truth to power', where science can reduce reality to actionable facts, may not be up to the task (Kovacic et al., 2019a; Pielke, 2004).

\section{Nexus and policy coherence}

In response to this complexity, the concept of the 'nexus' became popular. As mentioned above, the concept of the nexus looks at the interdependencies between natural resources, such as the water-energy-food nexus. However, the nexus is not only a scientific heuristic but also a policy category. Particularly in light of a growing awareness of the complexity of governing issues, such as biomass competition and the adoption of integrative policies like the Sustainable Development Goals (SDGs), there was a call to overcome policy 'silos'. Policy silos are isolated policies that deal with only one topic at a time and are a result of a history of institutional specialisation within governments. Due to this, 'policy coherence' also became an important governance goal, both internationally (OECD, 2004) and also for the EU (Nilsson et al., 2012). The call to move away from 'silo thinking' to more integrative, systems or a 'nexus' way of thinking to solve policy coherence issues also became a subject of study in itself across several disciplines and fields (Weitz et al., 
2017). Policy coherence can be defined as reinforcing policy goals across government ministries, departments and agencies (OECD, 2004). It is 'an attribute of policy that systematically reduces conflicts and promotes synergies between and within different policy areas to achieve the outcomes associated with jointly agreed policy objectives' (Nilsson et al., 2012). On the one hand, the nexus and policy coherence are policy goals that everyone can agree on and bring different stakeholders to the table. On the other hand, it remains unclear how nexus policies and policy coherence can be achieved. This may invoke ambiguity.

\section{Ambiguity}

Complexity can also lead to the proliferation of ambiguous ideas in policy-making. Ambiguous ideas in policy-making have been widely studied in the social science and governance literature under several theoretical umbrellas, particularly in the governance under complexity literature (Kovacic and Di Felice, 2019; Stirling, 2010) and are sometimes referred to as 'polysemic ideas' (Hannah, 2020). Examples of such ideas include 'sustainability', 'circular economy' or 'energy security'. Ambiguity can emerge if the problem is urgent and, simultaneously, if there are unresolved (or irresolvable) uncertainties in the evidence base (Zahariadis, 2008). Ambiguous ideas fulfil several aims in the policy-making process, such as building coalitions amongst different stakeholders and opening the option-space when there is uncertainty which technology or policy intervention will work (Beck and Mahony, 2018; Hannah, 2020; Kovacic and Di Felice, 2019; Stirling, 2010). Such ambiguous ideas are crucial to understand, especially in their role in finding a way out of complex such as land-use competition.

\section{Framing}

Given the importance of understanding ambiguous ideas, this begs the question of how such ideas are communicated. To understand this, we use the concept of 'framing' or 'frames'. This concept has been utilised across several disciplines, including communication science, psychology and political science. While the exact definition of a frame can change depending on the discipline, frames, in general, can be defined as the selection of 'some aspects of a perceived reality....in such a way as to promote a particular problem definition, causal interpretation, moral evaluation, and/or treatment recommendation' (Semetko and Valkenburg, 2000, citing Entman, 1993: p. 53). In short, frames are the structures that influence how reality is perceived and how it is then communicated. There are several reasons why such a concept is useful. On the one hand, how an ambiguous idea is framed can lead to a narrative that has 'performative power' (Beck and Mahony, 2018). In other words, it can bring about technologies, pathways or solutions into being. Frames can have a considerable impact on the policy process and the institutionalisation of ideas (Béland and Cox, 2016; Felt et al., 2007; Hannah, 2020). 
On the other hand, frames may also give the impression of action where there is none, thus obfuscating ineffectiveness (Candel et al., 2014; Hannah, 2020; Kovacic and Di Felice, 2019).

\section{Knowledge gaps and research aims}

Understanding the food-feed-fuel-fibre debate as a complex problem, this section focuses on the key knowledge gaps and how the research aims of this thesis address them. this thesis aims to advance the theoretical and empirical understanding of the governance of this problem with the ultimate aim of improving the governance process at the science-policy interface in the European Union.

The scientific community has produced a considerable body of literature that explores various ways to achieve singular goals, such as food security (Godfray et al., 2010) and agricultural productivity (Tilman et al., 2011) or energy efficiency (Pelletier et al., 2011). Such assessments, which focus on the success of one goal, may miss on trade-offs that may occur between different goals (Obersteiner et al., 2016). Section 1 highlighted that biomass demands for food, feed, fuel and materials are growing and that these demands put pressure on natural resources. Above, we discussed some of the driving factors behind these growing demands, such as rising incomes and government policies. However, details about which key driving factors affect trade-offs between different biomass uses are not yet connected. Furthermore, we do not yet have a map of the trade-offs and possible synergies between food, feed and fuel uses; for example, how do rising demands for ASF affect bioenergy availability?

Given the above our first research aim is to analyse how science looks at the problem of biomass competition and what solutions it recommends. This thesis connects these key factors with trade-offs and synergies. It furthermore looks at the solutions that science recommends in addressing these trade-offs and organises them into different scientific perspectives. We finally attempt to bring together multiple scientific perspectives in chapters 2 and 5.

Given the complexity of balancing these different demands, the governance of biomass, particularly for the future bioeconomy will be challenging. However, we do not know whether policies and the scientific knowledge-base are robust enough to deal with this challenge. Trade-offs may be created between policy domains due to silo-thinking within policy institutions, while uncertainty and incommensurability in the scientific knowledge-base may arise to the complexity of the issue itself. This entails understanding the role of scientific knowledge in complexity as well as understanding the degree of policy coherence across different sectors of the bioeconomy, agriculture and food. The literature on policy coherence has so far focused on finding inconsistencies between stated goals in policy documents (Harahap et al., 2017; Kalaba et al., 2014; Kelleher et al., 2019) or finding out how goals are interconnected (Huttunen, 2015; Huttunen et al., 2014; McCollum et al., 2018). However, 
policy coherence studies do not yet focus on the role of scientific expertise in these assessments.

To fill this gap, our second research aim is to assess the level of policy coherence in the governance of biomass competition. The study on policy coherence can be found in chapter 3. This thesis addresses this using scientific expertise to map out uncertainties and confidence levels. Methodologically, this expands on the policy coherence literature by using the coherence score created by Nilsson et al. (2012), a seven-point Likert scale, in both a survey and focus group setting. The inclusion of both agreement and confidence of expert assessments is related to the governance under complexity literature (Kovacic and Di Felice, 2019).

Ambiguous or polysemic ideas may arise at the centre of an intractable debate at the science policy-interface, particularly when there are uncertainty and incommensurability in the scientific knowledge-base. As mentioned in section 2.1, ambiguous ideas may both arise from complexity as well as provide the way forward when clear-cut solutions cannot be found. To understand the role of scientific knowledge in policymaking further and particularly the role that ambiguous ideas play in the policy-making process, we take the example of marginal lands. The literature has found that the multiple representations of marginal lands that exist can contain problematic assumptions (Shortall, 2013) and that landowners and farmers are rarely consulted about what they believe marginal lands should be used for (Shortall et al., 2019a; Skevas et al., 2016). However, we do not yet understand the role that marginal lands may play in the science-policy interface. In particular, the literature has not yet focused on how such ambiguous or polysemic ideas may follow a preset narrative or frame. Examining how such concepts may fall into frames may reveal what role such ideas play and whether the solutions or policy interventions different actors suggest may be conflicting or coherent. This can help clarify the discussions around suggested solutions to biomass competition.

Our third research aim is to examine the role of ambiguous ideas in the governance of biomass competition. This case study on marginal lands can be found in chapter 4 .

The need for a societal transformation to avoid exceeding the planet's biophysical limits is widely recognised (Steffen et al., 2015). The circular economy and circular food concepts have been proposed to achieve this transformation (de Boer and Van Ittersum, 2018; Jurgilevich et al., 2016). However, an integrated framework is still required that prioritises biomass for basic human needs, including food, fibre (textiles), pharmaceuticals, functional biochemicals and bio-energy. Current frameworks for directing biomass rely on an economic and market-based theory of value (BosBrouwers et al., 2012). This thesis suggests a framework for connecting biophysical limits to human well-being. This thesis emphasises the connection between natural and social systems further by identifying how transformation can be achieved. The literature so far has focused on identifying the social, economic, cultural barriers to the transformation to achieving circular systems (Kirchherr et 
al., 2018), few address how these barriers may be overcome.

Our fourth research aim, therefore, is to develop a theoretical framework to guide sustainable biomass use from both a biophysical and socio-economic perspective. This thesis attempts to address that gap by suggesting best practices and by suggesting frameworks that can help create and measure progress. This theoretical framework can be found in chapter 5 .

Chapter 6 synthesises the findings and insights of the previous chapters, placing them in a wider perspective and gives the conclusions of the thesis. 



\section{Chapter 2}

\section{The battle for biomass:}

\section{A systematic review of food-feed-fuel competition}

A. Muscat ${ }^{a}$, E.M de Oldea, I.J.M de Boera , R. Ripoll-Bosch ${ }^{a}$

aAnimal Production Systems group, Wageningen

University \& Research, PO Box 338, $6700 \mathrm{AH}$

Wageningen, the Netherlands

Global Food Security, 25 (2020) 100330 


\section{Abstract}

We review 75 studies on the competition for biomass and production resources such as land, water, labour and capital across food, feed and fuel production. We identified seven factors that are key to the availability and effective use of biomass and production resources. These ranged from ones related to production, such as crop yields to ones related to policy. Many of these factors resulted in trade-offs across different uses of biomass. Studies had different perspectives (e.g. economic, biophysical) on setting priorities for biomass and suggested different solutions to address competition (e.g. marginal lands). To connect these perspectives, we suggest a framework that prioritises biomass and production resources for the use of human food before its use as feed or bioenergy. 
The Battle for Biomass | Abigail Muscat

A systematic review of food-feed-fuel competition

\section{Introduction}

Humanity faces the challenge of feeding a growing population and supplying its energy needs without exhausting the biological and physical resources of the planet, as articulated in the Sustainable Development Goals (SDGs) of the United Nations (UN General Assembly, 2015). Achieving food and nutrition security is central to the SDGs. As the global population grows and becomes wealthier, the demand for food, especially animal-source food will increase particularly in developing countries (Alexandratos and Bruinsma, 2012). Increasing demand for animal-source food, moreover, is intrinsically associated with an increasing demand for feed (Thornton, 2010).

Besides food security, clean and renewable energy is also central to the achievement of the SDGs (UN General Assembly, 2015). The European Union (EU), for instance, has launched ambitious goals to incentivise the use of renewable energies. The EU Renewable Energy Directive sets targets to achieve at least $20 \%$ of its total energy use with renewables by 2020 , and $32 \%$ by 2030 (European Parliament and Council, 2009). Biomass is the most common form of renewable energy, and its demand is expected to increase further (IEA, 2017). About $60 \%$ of EU renewable energy, for instance, originates from biomass, such as wood and biofuel crops (Scarlat et al., 2019).

A key question is whether we can produce enough biomass to produce all the food, animal feed and bioenergy needed for our future population. The capacity of the planet to produce biomass is limited by its biophysical boundaries (Erb et al., 2016; Smil, 2012) and by socio-economic and policy constraints (European Environmental Agency (EEA), 2017b). The challenge is, therefore, the competition between food, feed and fuel for biomass. About $40 \%$ of all global cropland is currently used to produce high quality feeds, some of which are cereals which humans could also consume (Mottet et al., 2017) resulting in feed-food competition. Around $30 \%$ of the global cropland dedicated to cereals is used to grow livestock feed. Direct consumption of these cereals by humans is more resource-efficient than consumption of animal-source food produced by animals fed with these cereals (Garnett, 2009; Goodland, 1997). The use of biomass edible for humans or farm animals for bioenergy production further complicates the competition for resources. Currently, about $13 \%$ of global cropland is used to produce biofuels and textiles (Poore and Nemecek, 2018).

There seems to be wide agreement that food, feed and fuel production compete intensively for limited resources, such as land, water, labour and capital (Persson, 2013; Rulli et al., 2016). To mitigate this competition for biomass and avoid increasing the pressure on natural resources 
and ecosystems, strategies are needed to manage the use of biomass more effectively (Garnett et al., 2015; Haberl et al., 2014b; Karlberg et al., 2015; Smith et al., 2010).

One strategy to manage biomass more effectively is based on the concept of circularity in agricultural production, as proposed in food systems research (de Boer and Van Ittersum, 2018). This concept aims to reduce food losses and food waste, using biomass for human consumption first and then recycle any by-products back into the system. Livestock here plays an important role as converters of biomass not suitable for human consumption into food (Van Zanten et al., 2016a). In policy, various frameworks exist to guide the effective use of biomass. These frameworks differ in values underlying the cascading of biomass, (e.g. the Waste Hierarchy and Moerman's ladder), such as economic benefits or resource-use efficiency (e.g. the Value Pyramid or cascading use) (Rood et al., 2017). Such frameworks have been applied to connect bioenergy policies to concepts of circularity or circular economy (European Environmental Agency (EEA), 2018).

Despite this interest in managing biomass more effectively, we argue that a coherent framework that connects the ideas of circularity with the multiple goals for biomass, such as food, feed and bio-energy, is lacking. More importantly, we argue that a coherent discussion of these multiple goals is lacking, and it is important to discuss priorities for these goals. Similarly lacking is the examination of trade-offs when pursuing different goals for biomass and what factors influence these trade-offs. It is important to discuss what the most effective use of biomass is because setting priorities for one biomass use over another depends on different perspectives (Garnett et al., 2015). Some studies had a food perspective and prioritised biomass used for food production, whereas other studies had a bioenergy perspective and prioritised biomass use for bioenergy production. This sometimes resulted in competing claims for the same resource. Making these perspectives explicit is the first step to effective use. Furthermore, these perspectives are inherently limited by biophysical boundaries, especially in the context of increasing pressure on resources.

The aim of this paper, therefore, was to systematically review the state of the art of the use of biomass for food, feed and bioenergy production, and to what extent studies suggest strategies for effective use of biomass. To that aim, we first identified the factors that are key to the availability and effective use of biomass. Second, we mapped the trade-offs and synergies associated with changes in these key factors. Third, we explored whether solutions suggested to meet the increasing demand for biomass will mitigate or increase the competition for biomass and the resources needed for its production. While acknowledging that biomass can be directed to a wide range of uses, we choose to focus on the three main uses of biomass (food, feed, fuel) and exclude biomaterials and biochemicals. We argue that this is because food security 
and renewable energy are the main challenges facing humanity in the short to medium-term. Finally, the scope of our paper is limited to the implications of European biomass demand in a global context. We finalise by summarising the main research gaps and uncertainties.

\section{Material and methods}

We applied a systematic review approach (Boland et al., 2014) aiming to provide a complete summary and synthesis of the literature. Our selection was based on three phases: 1) an identification phase where records were obtained from three scientific databases, 2) a screening and eligibility phase where records were removed based on pre-selected criteria 3) a final inclusion phase where records were read in full to determine eligibility. Once the screening process was complete, final records were coded in a database for a number of variables on methodology (i.e. objective, conclusion, study approach, name of model, method used, and spatial scale), content and outcomes, and solutions recommended. We chose to focus on Europe as the EU is an important global player in the demand for bioenergy (Banse et al., 2011), while simultaneously being dependent on land from outside the EU to feed livestock (de Visser et al., 2014; European Environmental Agency, 2017). The scope of our conclusions is therefore largely applicable to Europe. Further information on our approach is presented in the supplementary material.

\section{Results}

The final selection included a total of 75 studies. The studies spanned the years 1996 to 2017 , with most studies included in the study being published in 2016 (Figure 1). The relations most examined in the studies was the one between food and fuel, representing $47 \%$ of the studies, followed by the one between all three uses, representing $32 \%$ of all the studies. This is not surprising, given the controversy surrounding the competition between food and biofuels sparked by the $2007 / 2008$ world food price crisis (Nebehay, 2007). This controversy brought about a number of studies that explored the effects of biofuel policies around the world on agricultural commodity prices (Persson, 2015). Studies represented in Fig. 1 increasingly make a distinction between food and feed, reflecting greater concern for the role of livestock in food system sustainability. The inclusion of all three uses of biomass started appearing more frequently from 2009 onwards, indicating a shift towards more integrative studies. 


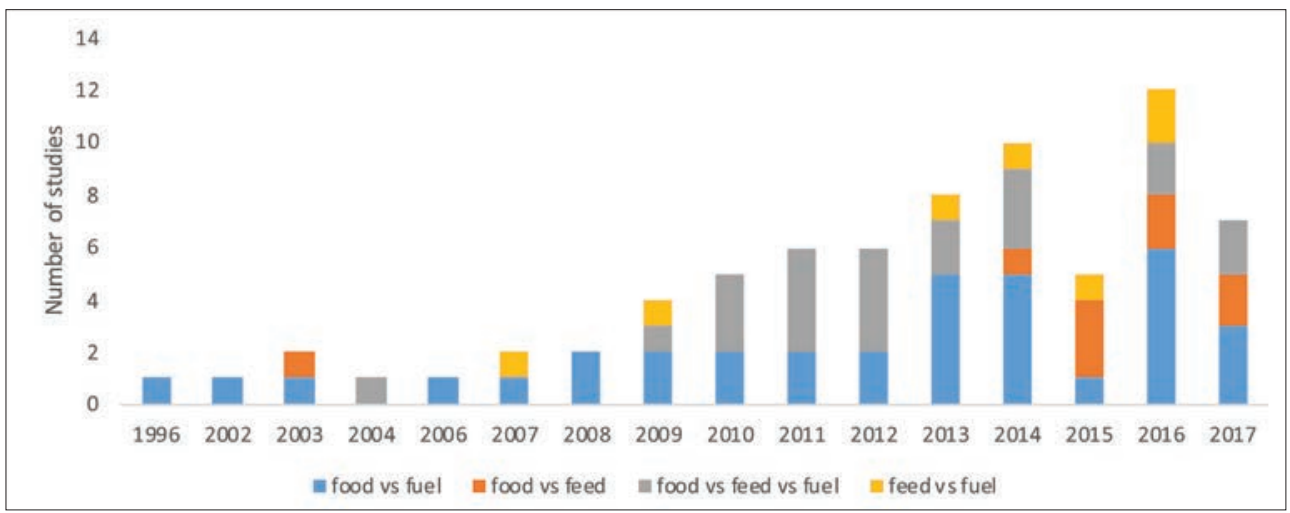

Fig. 1. The number of studies that look at the four relationships across years (1996 to 2017)

Figure 2 summarises the scale, methodology, biomass source and the competitions addressed by the different studies. Most studies (40\%) were conducted at a global level, where Europe was included as a region. Many studies that looked at the competition between food and fuel uses of biomass were conducted at a global level. However, the majority of the studies that looked at all three uses of biomass were conducted at a country level, possibly indicating the higher level of detail required to understand the relationship between all three uses of biomass. The 75 studies encompassed a wide range of methodologies, from economic approaches to more biophysical approaches, reflecting the complexity of the problem and the need for different approaches. Most studies used a biophysical modelling approach.

With regard to competition around $27 \%$ of the studies focused on the direct competition for the biomass itself, i.e. the potential of that biomass to be used for another purpose. The majority of the studies (67\%), however, focused on the competition for the land needed to produce the biomass and the fact that productive land is becoming a scarce resource. Although many studies employed economic approaches, such as general and partial equilibrium models, few studies looked at the effects of allocation of capital and labour to the production of food, feed or bioenergy. The majority of studies examining the general equilibrium effects were again concerned with direct competition for biomass and land use competition. Studies that included bioenergy mostly focused on $1^{\text {st }}$ generation feedstocks, made up of starch, oil and sugar crops. Studies looking at forest biomass were lacking. This was unexpected as around $92 \%$ of bioenergy in the EU is generated by forest biomass and is used to generate heat and power, while the remaining $8 \%$ comes from agriculture to be used as biofuels in the transport sector (Gurría et al., 2017). One possible explanation is that there is no direct competition for biomass for food, feed and fuel uses, but indirect competition for land. In fact, $45 \%$ of studies considered competition for land between food, feed and fuel uses and forest conservation. 
The Battle for Biomass | Abigail Muscat

A systematic review of food-feed-fuel competition
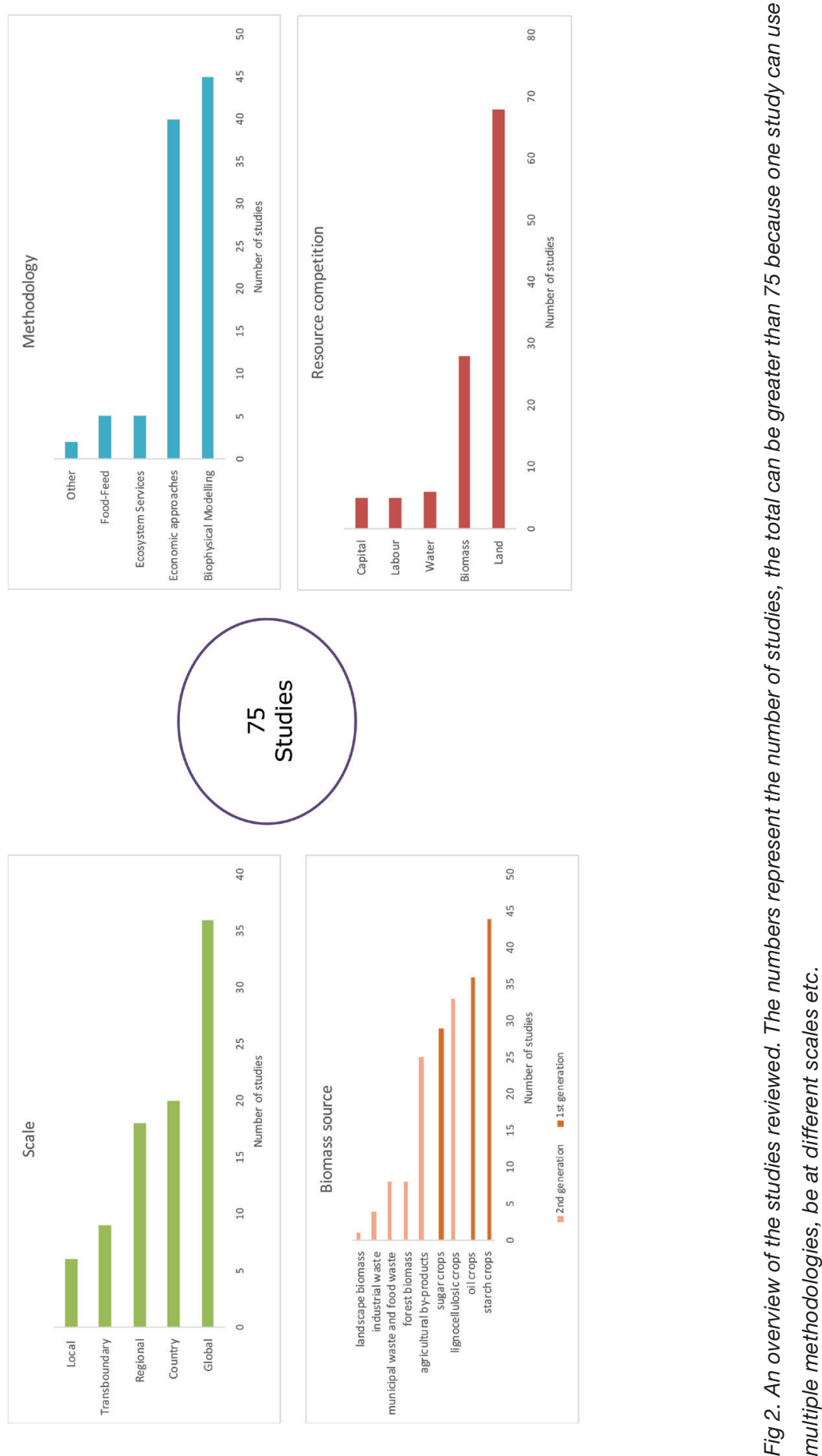
The majority of studies considered livestock in their study, especially to account for agricultural land use. Although $81 \%$ of all studies included livestock in their analysis, only $41 \%$ included information about livestock species and only $28 \%$ distinguished different livestock production systems (e.g. landless, grass-based, mixed or broiler chicken, laying hen). The majority (52\%) of studies did not consider the effect of trade in their studies. Of those studies that did, $59 \%$ said demands for food, feed and fuel will have to be met by trade, with $90 \%$ of those saying either food, feed or bioenergy will have to be imported. Around $10 \%$ said demand will also indirectly depend on non-domestic water, land, capital or labour.

\subsection{Factors that determine the effective use of biomass and associated trade-offs}

We identified seven factors that are key to the availability and effective use of biomass (Table 1). A specific factor can increase or reduce the availability of biomass for end- uses and can have positive implications (synergy) or negative implications (trade-off) for resource use or sustainability issues. Sustainability issues identified ranged across all three pillars of sustainability (Fischer et al., 2007), from environmental (e.g. land use, greenhouse gas emissions), economic (increase in food prices, high cost of subsidies) to social (decrease in food availability or energy security). Key factors identified were:

1) Increasing demand for bioenergy $(n=37)$ has been associated with a number of sustainability issues, from higher food prices (Hertel et al., 2013) to increased water consumption (Damerau et al., 2016). In our review, the increased demand for bioenergy presented many trade-offs between bioenergy, and food and feed production.

The majority of implications reported in Table 1 are trade-offs. For "increased bioenergy demand", for instance, current literature acknowledged 12 potential trade-offs, whereas only four synergies were reported. Increasing bioenergy demand would have negative implications for the use of biophysical resources (e.g. increased land use and land-use change, increased water consumption, increased nitrogen demand, etc.), for socio-economic aspects (e.g. increased food prices and agricultural commodities, higher land rents, increased shadow prices for irrigation water, competition etc.) and for environmental performance (higher greenhouse gas emissions from land-use change, decrease in ecosystem services, such as habitat services, aesthetic values and carbon storage). In contrast, the synergies found were related to the utilisation of co-products from bioenergy production as livestock feed. Other synergies emerged from moving to advanced biofuels, which would decrease competition for land, and ultimately reduce food-feed competition, or eventually even improve ecosystem services. Some of the implications listed for this first factor, 
however, can be perceived both as trade-off or synergy. For instance, the "need of high rates of technological improvement" was seen as synergy because it could generate new findings and solutions but was seen also as a trade-off because of the need for economic investment or the dependency on technology. Moreover, studies reported some contradictory findings in whether the increased demand for biofuels, whether $1^{\text {st }}$ generation or $2^{\text {nd }}$ generation, would lead to deterioration or improvement of ecosystem services.

2) Increase in crop yields $(n=7)$. Increasing crop yields on the same amount of agricultural land have been suggested as a strategy to meet the growing demand for biomass while avoiding further agricultural expansion (Godfray et al., 2010).

Some studies found that increasing crop yields met food and feed demands, leaving land available for other uses, such as bioenergy. However, other studies found that even with high yields, landbased bioenergy always hampered food availability. An additional trade-off showed that the advantages of yields can be reversed by climate change and increased competition for biomass. 3) Increase in the use of human-edible ingredients as livestock feed $(n=7)$. The introduction of high-quality feed in livestock diets has been a common strategy to improve livestock productivity and efficiency (Van Zanten et al., 2018). However, most high-quality feeds are also edible by humans. Hence, this practice can trigger competition for natural resources between feed and food production and impair the contribution of livestock to global food security (Mottet et al., 2017).

Increased number of human-edible components in livestock feed was associated with less food availability and poorer environmental performance, especially regarding land use Under a number of future scenarios considering different levels of ASF production, decreasing the number of human-edible feedstuffs led to synergies, by not only increasing food availability but also by having improved environmental performance (Röös et al., 2017; Schader et al., 2015).

4) Increase or decrease in the share of animal-source food in the diet $(n=7)$. The amount of animalsource food in the diet and the livestock production system is key to determine the total amount of food produced and the resources needed for its production (Erb et al., 2016).

Increased animal-source food resulted in a trade-off with bioenergy potential, as production resources such as land were used for livestock production. Decreased animal-source food in human diets brought synergies, such as a reduction in land demand and associated GHG emissions.

5) Increased efficiency of food supply chains $(n=4)$. Gains in efficiency can be achieved through reduced losses and wastes throughout the chain and/or better integration between food and bioenergy supply chains. Reducing food wastage and food losses along the production chain have been identified as a promising strategy to increase the availability of food, use resources 
more efficiently and reduce the environmental burden of food production (Scherhaufer et al., 2018; Van Zanten et al., 2014).

"Increased the efficiency of food supply chains" was the only factor showing synergies only and no trade-offs. Reducing losses along the chain resulted in improved food security, enhanced selfsufficiency of food production and reduced land use, which could be eventually used for the bioenergy sector. Furthermore, using co-products of $1^{\text {st }}$ generation biofuel production, such as distiller's dried grains with solubles, and maize stover as animal feed avoided the need to grow more feed and replaced feeds that were competitive with human consumption.

6) Type of feedstocks used for bioenergy $(n=10)$. The choice of feedstock is an important determinant of the sustainability of bioenergy (Dale et al., 2011). This depends on a number of factors, such as whether the feedstock competes with food or feed production, what was the initial use of the biomass, where and how the feedstock was produced and whether the production of the feedstock and/or its conversion to bioenergy generates valuable co-products.

Studies in this group reported both trade-offs (2) and synergies (3) as resulting effects were highly dependent on the feedstock used and on whether the initial use of the feedstock changed. Tradeoffs were related to impacts from changing the initial use of biomass. When crops and by-products used for food and feed were shifted to energy, studies reported a higher environmental burden. However, the use of manure or $2^{\text {nd }}$ generation feedstocks grown on marginal lands provided opportunities not just for improved environmental performance but also for increasing a country's sufficiency on domestic feedstocks.

7) Land-use policies ( $n=13)$. Many land-based policies constrain the management intensity of the land and the total amount of land available for certain uses. For instance, regulations regarding lands for nature conservation, but also the sustainability criteria in the EU Renewable Energy Directive (European Parliament and Council, 2009), climate mitigation activities in the Land Use, Land-Use Change and Forestry (LULUCF) sector or limiting bioenergy to marginal lands.

In relation to the implementation of land-use policies, interventions resulted in synergies (4) as well as trade-offs (5). This may reflect the complexity of the food-feed-fuel competition in itself, the difficulty to design and implement efficient land-use policies with the current body of literature (with sometimes contradictory points of view) and the challenge to foresee all unintended effects (i.e. trade-offs) of any particular intervention. 
The Battle for Biomass | Abigail Muscat

A systematic review of food-feed-fuel competition

Table 1. Reported list of trade-offs [T] and synergies [S] organised by the main influencing factors. Citations are all 75 studies included in the review. Further details on the 75 studies are included in the supplementary material.

Influencing Factors Ref

\section{Increased bioenergy demand led to:}

[T] increased land use and consequently higher land rents and higher GHG emissions from land use change

[T] loss of forest and pasture converted to arable land

[T] increased food prices or agricultural commodity prices

[T] reduced food consumption in developing countries

[T] increased water consumption and increased shadow prices for irrigation water

[T] increased nitrogen demand

[T] countries unable to meet bioenergy targets with domestic feedstocks thereby reducing energy security

[T] a decrease in ecosystem services, notably food provision, but also habitat services, aesthetic values, and carbon storage

[T] less land available for livestock production

[T] higher competition for residues/wastes which are of high-value in countries with developed economies

[T] intensification of agricultural production towards more high-input production systems (e.g. fertilisers and pesticides)

[T] production of bioethanol and biodiesel, which used land and water that competed with food production

[S] generation of bioenergy by-products suitable as feed for livestock, which dampened effects of land use and price [S] planting $2^{\text {nd }}$ generation bioenergy, which improved ecosystem services

[S] planting $2^{\text {nd }}$ generation bioenergy on non-competitive land, thereby reducing food-fuel competition

[S] opportunities for an increase in supply if energy efficiency is increased and energy demand is reduced $[\mathrm{S} / \mathrm{T}]$ need for high rates of technological improvement $[\mathrm{S} / \mathrm{T}]$ decreased animal-source food consumption
(Banse, M; Junker, M; Prins, AG; Stehfest, E; Tabeau, A; Woltjer G; van Meijl, 2014; Ben Fradj et al., 2016; Beringer et al., 2011; Bryngelsson and Lindgren, 2013; Burgess et al., 2012; Damerau et al., 2016; Gardebroek et al., 2017; Gissi et al., 2016; Grundmann and Klauss, 2014; Hertel et al., 2013; Hoogwijk et al., 2003; Ignaciuk et al., 2006; Konadu et al., 2015; Lajdova et al., 2016; Langeveld et al., 2014; Larsen et al., 2017; Lotze-Campen et al., 2010, 2014; Lywood et al., 2009; Nonhebel, 2012; Özdemir et al., 2009; Rulli et al., 2016; Russi, 2008; Scarlat et al., 2013; Schmidt et al., 2012; Simon and Wiegmann, 2009; Smeets et al., 2007; Sorda and Banse, 2011; Steubing et al., 2010; Strapasson et al., 2017; Stürmer et al., 2013; Taheripour et al., 2010, 2011; Thrän et al., 2010; Timilsina et al., 2012; Winchester and Ledvina, 2017; Wise et al., 2014) 


\section{Increased crop yields led to:}

[S] freed up land for bioenergy and reduced food-feed competition

However:

[T] even with high yields, scenarios with no bioenergy production fed more people

[T] yields will be hampered by climate change, increasing competition for land for food, feed, fuel and ecosystem services
(Brinkman et al., 2017; Davis et al., 2014; Erb et al., 2012; Haberl et al., 2011; Hertel et al., 2013; Manceron et al., 2014; Röös et al., 2017)

\section{Increase of human-edible feed led to:}

[T] increased food-feed competition However:

[S] improved feed conversion ratio in livestock and reduced food-feed competition over time [S] reducing human edible feedstuffs improved environmental performance

\section{4.a. Increased animal-source food in human diets led to:} [T] limited bioenergy potential because the production resources were used for livestock production

4.b. Decreased animal-source food in human diets led to: [T] no land available for crop-based bioenergy when the gap between the highest and lowest calorie diets was closed

[S] reduced greenhouse gas (GHG) emissions and reduced land demand [S] more people fed when current uses of food and fuel were assumed and when the gap between the highest and lowest calorie diets was closed

\section{Increased efficiency of food supply chains led to:} [S] freed-up land for bioenergy without displacing other uses

[S] reduction of waste of animal-source food and thereby reduced food-feed competition which fed more people [S] efficiency of the food sector combined with utilisation of wastes which increased domestic bioenergy potential
(Davis et al., 2014; Ertl et al., 2016, 2015; Mottet et al., 2017; Röös et al., 2017; Schader et al., 2015; Wirsenius, 2003)

\section{(Davis et al., 2014; Davis and D'Odorico, 2015; Erb et al., 2012; Fazeni and Stein-}

müller, 2011; Haberl et al., 2011; Röös et al., 2017; Van Kernebeek et al., 2016)
(Brinkman et al., 2017; Davis and D'Odorico, 2015; Röös et al., 2017; Welfle et al., 2014) 


\section{Promotion of certain bioenergy feedstocks led to:}

[T] subsidies to promote maize for energy production which resulted in more competition between food and energy sector

[T] shifting use of industrial by-products from feed to fuel meant a higher environmental burden across all indicators such as deforestation and land use

[S] small biogas plants on farm fed with manure meant synergy between energy and livestock sector

[S] use of marginal lands for 2 nd generation crops

[S] using 2nd generation crops, which increased countries' self-sufficiency rate for bioenergy feedstocks and reduced imports to meet bioenergy demand

\section{Implementation of Land Use Policies led to:}

[T] high sustainability criteria that account for indirect land use change reduced bioenergy potential

[T] continued expansion of cropland into nature, even with sustainability criteria

[T] high societal cost to incentivise producers to plant only on marginal, less productive land

[T] increased food prices and increase water scarcity when climate change mitigation through bioenergy and high forest conservation were coupled

[T] constrained future land and limited bioenergy when Land-Use, Land-Use Change and Forestry (LULUCF) strategies based on storing carbon in soil and vegetation were applied

[S] land zoning which protected high-value nature land from bioenergy expansion

[S] planting on marginal lands which avoided food vs fuel competition

[S] more efficient agricultural production when LULUCF strategies were applied

[S] high sustainability criteria that accounted for indirect land use change avoided food vs fuel competition
(Akgul et al., 2012; Bartoli et al., 2016; Demartini et al., 2016; Nonhebel, 2004, 2007; David Styles et al., 2015; Tonini et al., 2016; Tufvesson et al., 2013; Van Stappen et al., 2016; Van Zanten et al., 2016b)

(Beringer et al., 2011;

Brinkman et al., 2017; Bryngelsson and Lindgren, 2013; Callesen et al., 2010; Elbersen et al., 2013; Erb et al., 2012; Forsell et al., 2013; Gielen et al., 2002; Gillingham et al., 2008; Hertel et al., 2013; Popp et al., 2011; Treesilvattanakul et al., 2014; Warner et al., 2013) 
The different studies analysed were performed at different spatial scales and study areas, used different methodologies, and adopted different assumptions and definitions of concepts (such as the definition of "marginal land"). Moreover, studies had a different starting point, research question or narrative to check. These differences determined the trade-offs and synergies presented. This also led to different solutions for the problem of biomass competition, which may be conflicting across studies. Such important differences between the studies are further explained in the solutions section below and placed in the larger context of scientific literature in the discussion.

\title{
3.2 Solutions
}

As a final step in this review, we tracked solutions suggested to avoid food-feed-fuel competition. Around $37 \%$ of papers did not recommend a solution. The rest recommended a wide range of solutions. Solutions fell into four categories: production-side solutions, governance solutions, consumption-side solutions and solutions addressing food losses and waste. Most solutions suggested were production-side strategies (Figure 3).

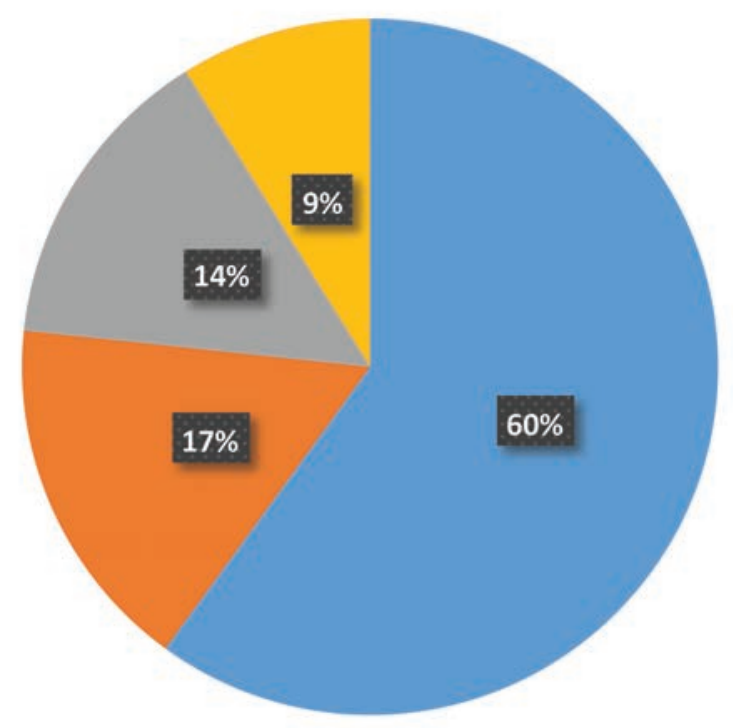

\author{
= Production \\ - Governance \\ - Consumption \\ n Losses and Waste
}

Fig. 3. The shares of recommended solutions 
The Battle for Biomass | Abigail Muscat

A systematic review of food-feed-fuel competition

\section{Production-side solutions}

Production-side solutions urged to avoid competition for resources at the production level and often focused on minimising competition between food and bioenergy production. The options to solve the competition between food, feed and fuel reflected a sometimes difficult debate, in which some argue for intensive production whereas others suggest extensive production. For example, many papers considered it important to increase the lifetime productivity of the herd. (e.g. Burgess et al., 2012; Erb et al., 2012; Schader et al., 2015). Other papers, however, suggest to feed livestock on leftovers from arable land (e.g. crop residues, industrial by-products) and grass resources, and avoid the use of human-edible feeds, such as grains, to mitigate competition with food production (e.g. Ertl et al., 2015; Nonhebel, 2004; Özdemir et al., 2009; Schader et al., 2015). The availability of these biomass streams determines the boundary of livestock production and consumption (Van Zanten et al., 2018). These apparently contrasting solutions are based on differences in underlying values and assumptions. The first group argues that to meet the increasing demand for food, and especially animal-source food, we need to produce more with a lower impact on the environment and feed demand whereas the second group argues that livestock can contribute to net food security by converting biomass that is inedible for humans into valuable food. Some studies in both groups suggested that these solutions would reduce overall land-use, thereby leaving room for planting bioenergy crops.

Another option explored to alleviate the competition between food production and bioenergy production was planting bioenergy crops on land not suitable for food production or 'marginal lands'. However, there is no consensus on the definition and characterisation of marginal lands, which also include grasslands (see further explanation in the discussion section). As such there might be an opportunity cost related to using marginal land for bioenergy production: not all biomass from marginal land can be considered "free" for bioenergy production. So far, however, there appears to be no agreement on the best use of marginal lands (grazing livestock, advanced biofuels or biodiversity conservation), or whether they can be used at all.

\section{Governance Solutions}

Governance solutions were the second-largest group of recommended solutions after productionside solutions. This shows the importance of addressing the competition for biomass from a policy perspective. The main governance solutions were 1) more equitable trade policies that would allow for better distribution of food (Davis and D'Odorico, 2015) 2) More emphasis on economically viable supply chains and market structures for bioenergy producers (Gissi et al., 2016) 3) Working with local stakeholders for better biomass management (Gissi et al., 2016; Steubing et al., 2010) 4) Being aware of the local context when making decisions about important trade-offs (Grundmann 
and Klauss, 2014; Van Stappen et al., 2016).

\section{Consumption-side solutions}

The impact of livestock production on the environment has received a lot of attention lately (Garnett, 2016; Poore and Nemecek, 2018; Willett et al., 2019). Hence, the most common solution suggested was to decrease the consumption of animal-source food in human diets in high-income countries (e.g. Beringer et al., 2011; Fazeni and Steinmüller, 2011). Besides eating less animal-source food in high income countries, the solution to eat a balanced diet (Davis et al., 2014; Davis and D'Odorico, 2015), i.e. if all people were to consume enough nutrients but not more than they needed, would help to mitigate food-feed-fuel competition and enable feeding more people globally.

\section{Losses and waste solutions}

Food loss and food waste are considered to be one of the critical issues affecting the sustainability of the global food system (FAO, 2011). Consequently, reducing food waste is also considered as an important strategy to ease the burden on production resources, such as land and water, to achieve food security and to attain ambitious bioenergy targets (e.g. Brinkman et al., 2017; Burgess et al., 2012; Davis et al., 2014). The emphasis of solutions within this category was to improve resource-use efficiency by combining cascade utilisation principles of biomass, waste management strategies and consumption-side strategies.

\section{Discussion}

Humanity faces the challenges of feeding a growing population and supplying its energy needs within biophysical boundaries (Haberl et al., 2013). Within a context of greater pressure on resources, meeting these two challenges will require the effective use of biomass (Haberl and Geissler, 2000). This means introducing greater circularity into how we use biomass, setting priorities for its use and making the values underlying these priorities explicit. We argue that a discussion that brings together the multiple goals for biomass is needed. In this paper we argue for 'effective' rather than efficient use of biomass following Garnett et al. (2015) to make explicit that directing biomass towards its most 'high-value' use is a matter of perspective. Directing biomass towards food may be a priority for one scientific domain while directing biomass towards bioenergy may be a priority for another. Societal values and contexts may also change these priorities. Increasingly the aim of the agricultural system is changing from producing as much food as possible to producing sustainable and nutritious food within the 
boundaries of the planet (Willett et al., 2019). Future developments may change these priorities, such as the proliferation of bio-based products in response to call for a circular bioeconomy (Zabaniotou, 2018) or future foods, such as cultured meat and insects that may shift diets away from traditional animal-source food (Parodi et al., 2018). We argue that effective use should direct biomass towards food first, and avoid losses and wastes before these are used for feed and/or fuel (de Boer and Van Ittersum, 2018). We do this following Fischer et al's. (2007) 'hierarchy of considerations', with biophysical limits representing the ultimate boundary of sustainability. We assessed how the literature takes elements of effective use of biomass into account, particularly acknowledging competition for biomass within biophysical boundaries, suggesting more circular use of biomass and setting priorities for biomass. We looked at the factors that are key determinants of biomass availability and effective use and looked at the ensuing trade-offs. However, as brought forward in this review, multiple perspectives on how to best use biomass exist. Below, we discuss the research gaps before moving on to our framework that connects these multiple perspectives.

Overall, the number of studies looking at relationships across all three biomass uses shows the state of the art's awareness of the complexity in directing biomass towards its most effective use. Over time, an increasing number of studies considered the inclusion of feed and its complex relationship with food and bioenergy. The key factors influencing biomass use are diverse and related to production (increasing bioenergy, crop yields, use of humanedible feed), consumption (consumption of animal-source food), supply chains (losses and food waste) and policy (promotion of feedstocks and land use policy). A large number of tradeoffs shows the scale of the challenge in achieving effective use of biomass. Together, these present the best entry points for intervention for the effective use of biomass. However, while solutions suggested by studies were equally diverse, the overwhelming emphasis remained on the production side. Emphasis should be made on a more systemic approach to effective biomass use that goes beyond tweaking production (Willett et al., 2019).

So far, only a few studies paid attention to the competition for socioeconomic resources, i.e. capital and labour, suggesting a gap in research. Only four studies included substitution between capital and labour in their models (Banse et al., 2011; Ignaciuk et al., 2006; Taheripour et al., 2011; Timilsina et al., 2012), but only the study by Ignaciuk et al. (2006) explicitly considered the competition for capital and labour between bioenergy, food and feed production. The most important socio-economic effects of increasing bioenergy production are the potential diversion of capital and labour away from other primary production sectors, such as agriculture (Persson, 2015), hence, impairing food production. Similarly, high levels of subsidies for bioenergy can divert capital from other agricultural sectors and may prove to be an overall social cost. Some studies expect that bioenergy production may displace more labour-intensive production, such as livestock rearing (Trink et al., 2010). The relative labour 
and capital intensity of a particular bioenergy system will determine whether it generates positive socio-economic effects or whether it displaces other sectors (Persson, 2013). Hence, it is important to better integrate biophysical models which consider environmental limits (i.e. availability of natural resources), with economic models which consider labour and capital (i.e. availability of economic resources). For a fuller picture, the different modelling approaches will need to be integrated to determine what is both environmentally and economically sustainable (Plantinga, 2015). For that, harmonisation and integration of different disciplines is a must, as well as the need to acknowledge that socioeconomic and biophysical limits exist under increased biomass demand.

The role of livestock and their potential to utilise low-opportunity-cost biomass also requires further research. Livestock can convert biomass with low opportunity for direct human consumption (e.g. grass products, crop residues, food processing by-products, and food losses and wastes) into valuable food and manure. Livestock then recycle nutrients into the food system (Garnett et al., 2015), and contribute to net food security. Reducing the amount of food-competitive feedstuffs in animal diets not only increases food security (Davis et al., 2014; Davis and D'Odorico, 2015), but also improves environmental performance in terms of land use (Schader et al., 2015; Van Kernebeek et al., 2016), nitrogen surplus, phosphorus surplus, greenhouse gas (GHG) emissions, non-renewable energy use, freshwater use, pesticide use, deforestation and water-induced soil erosion (Van Zanten et al., 2018). Hence, there will be a need to assess availability, safety and nutritional values of low-opportunity cost biomass as feed for livestock. We need better insights into questions, such as "which animal species or systems are most suitable to upcycle what low-opportunity-cost biomass" (Van Hal et al., 2019a) and "which biomass streams are most suitable for bioenergy production or for maintaining soil fertility". Although a few studies explored the role of livestock to achieve more sustainable use of biomass, the majority of food-feed-fuel research lacks the detail to explore cascading of biomass use across food, feed and fuel production.

Another research gap was the importance of trade on the competition for resources which poses a challenge for the effective use of biomass. The increasing scarcity of resources can trigger a global rush for the desired resources (e.g. biomass), but also for the resources required for its production (e.g. land, water, nutrients, capital or labour) (Rulli et al., 2012). The EU is dependent on land and water from elsewhere for its domestic production and consumption of food, feed and fuel (Tukker et al., 2014) and in an increasingly interconnected world, this dependency is expected to grow. This dependency on external resources can shift the environmental impact of biomass production to other regions outside the EU. This phenomenon has been described in literature as externalisation, burden-shifting, displacement or leakage effect (Giampietro et al., 2014; Meyfroidt et al., 2010) which can induce effects such as land displacement (Weinzettel et al., 2013), land grabbing (Rulli et al., 2012) and 
negative impacts on food security and ecosystem services (Naylor et al., 2005; Porkka et al., 2013). This leads to the question at which spatial scale should effective use of biomass be adopted. The answer will largely depend on the priorities we place for biomass and resource use sustainability.

Critical uncertainties about some of the solutions, such as the use of marginal lands and advanced feedstocks remain. Studies from the livestock domain and the bioenergy domain had different perspectives on the aims of the agricultural system and therefore what were the best use of marginal land and of advanced feedstocks.

From the perspective of studies within the livestock domain, marginal lands unsuitable for food crop production ought to be used for livestock production to ease competition with food crop production. Often, this means using them as grazing lands for livestock. While this may reduce the dependency of livestock on arable land, it may still come at the expense of GHG emissions (Garnett et al., 2017). From the perspective of studies within the bioenergy domain, marginal lands are a key solution to growing bioenergy crops without impacting food production. The viability of such a solution depends on the levels of productivity achievable in marginal lands. This remains uncertain since some authors link marginal lands to intrinsic low productivity (Bryngelsson and Lindgren, 2013) others suggest that marginal lands do not necessarily entail low productivity (Gopalakrishnan et al., 2011; Meehan et al., 2017). If marginal lands are defined as ones with low productivity, studies indicated that the solution could prove to be costly to the government or bioenergy consumers. This is because payments would be needed to keep farmers from planting bioenergy on more productive land or limiting the productivity of their land (Bryngelsson and Lindgren, 2013). However, both domains do not consider any other functions these lands may fulfil. For example, there is limited information on the potential natural value of these marginal lands (Immerzeel et al., 2014) and for the social and cultural functions of land which deliver important services for rural people's livelihoods (Rossi and Lambrou, 2008). It should be said that these various claims on marginal lands are not necessarily mutually exclusive. However, to successfully utilise marginal lands it is important to consider their diverse uses to avoid unintended impacts on rural communities, livestock production and nature conservation.

The potential of advanced biofuels to replace conventional biofuels is also uncertain. Many studies cited this is as a way to increase bioenergy without competing with food or feed production. However, currently, the contribution of advanced biofuels to energy production in the EU is marginal. Bioenergy is almost entirely produced from forest biomass or from energy crops in the agricultural sector (Gurría et al., 2017). The little penetration of advanced biofuels can be explained because the technology still lags behind $1^{\text {st }}$ generation biofuels in terms of production, many advanced biofuels are still concepts or pilot studies, there are high costs for 
implementation and scaling-up, and they face challenges in commercialisation (Bourguignon and Vandenbussche, 2013). The uncertainty in devising which advanced biofuel will develop to a commercial-stage and which production efficiency might attain makes the estimation of its potential at large scale difficult. Defining what is a "second-generation" or "advanced" feedstock is also difficult. For example, the inclusion of "straw" as an advanced feedstock has accrued a debate of the multiple uses straw might have (e.g. as bedding for livestock or return to the soil as organic matter). The use of new second-generation feedstocks will require determining the most sustainable primary use of biomass. The application of biomass cascade principles could provide better management guidance on new feedstocks, such as food wastes (Dahiya et al., 2018). However, there is a need to assess which biomass uses should be prioritised to allow for more effective use.

To connect the various perspectives mentioned above, we propose a framework that connects ideas from food systems research (de Boer and Van Ittersum, 2018; Van Zanten et al., 2018) to broader ideas of circular biomass use (Figure 4). While biomass can be used for many uses, we consider food security to be the highest priority. From this priority, we propose a number of principles adapted from de Boer and Van Ittersum (2018). First, that biomass should aim for food for humans first. The same principle is applied to the resources needed for biomass production, namely water, land, capital and labour. In other words, these resources should be used for biomass production for food for humans. Second, that by-products, wastes and losses should be avoided then recycled back into the system as food, feed and bioenergy, in that order (de Boer and Van Ittersum, 2018). Third, that livestock can be used to valorise biomass that humans cannot or are not willing to eat. Our framework builds on top of that of de Boer and Van Ittersum, (2018) by expanding it from the food system to also include bioenergy. Secondly, we argue that competition does not only refer to competition for biomass or land, but also other production resources such as water, capital and labour. Third, as shown in Fig. 4 opposite, we also expand it by explaining the factors that influence available biomass and create synergies and trade-offs across the goals we want to achieve with that biomass, such as achieving food and bio-energy security etc. These principles of circularity in combination with the production resources define what biomass can be most effectively used for food, feed and fuel.

Available biomass is determined by influencing factors, of which we have identified seven from the literature, and by production resources. As these resources are limited, there will be trade-offs as well as synergies. Circular principles set limits for biomass for more sustainable resource use, prioritising human consumption of biomass first.

From a circular perspective, using biomass, land, water, capital and labour for human consumption first will bring a number of benefits. Namely, that livestock will no longer consume large quantities 
of human-edible food. In a zero human-edible concentrate feed scenario for 2050 , Schader et al., (2015) find that greenhouse gas emissions could be reduced by $18 \%$, land occupation by $26 \%$ and $\mathrm{N}$-surplus by $46 \%$ compared to the reference scenario while still providing sufficient food.

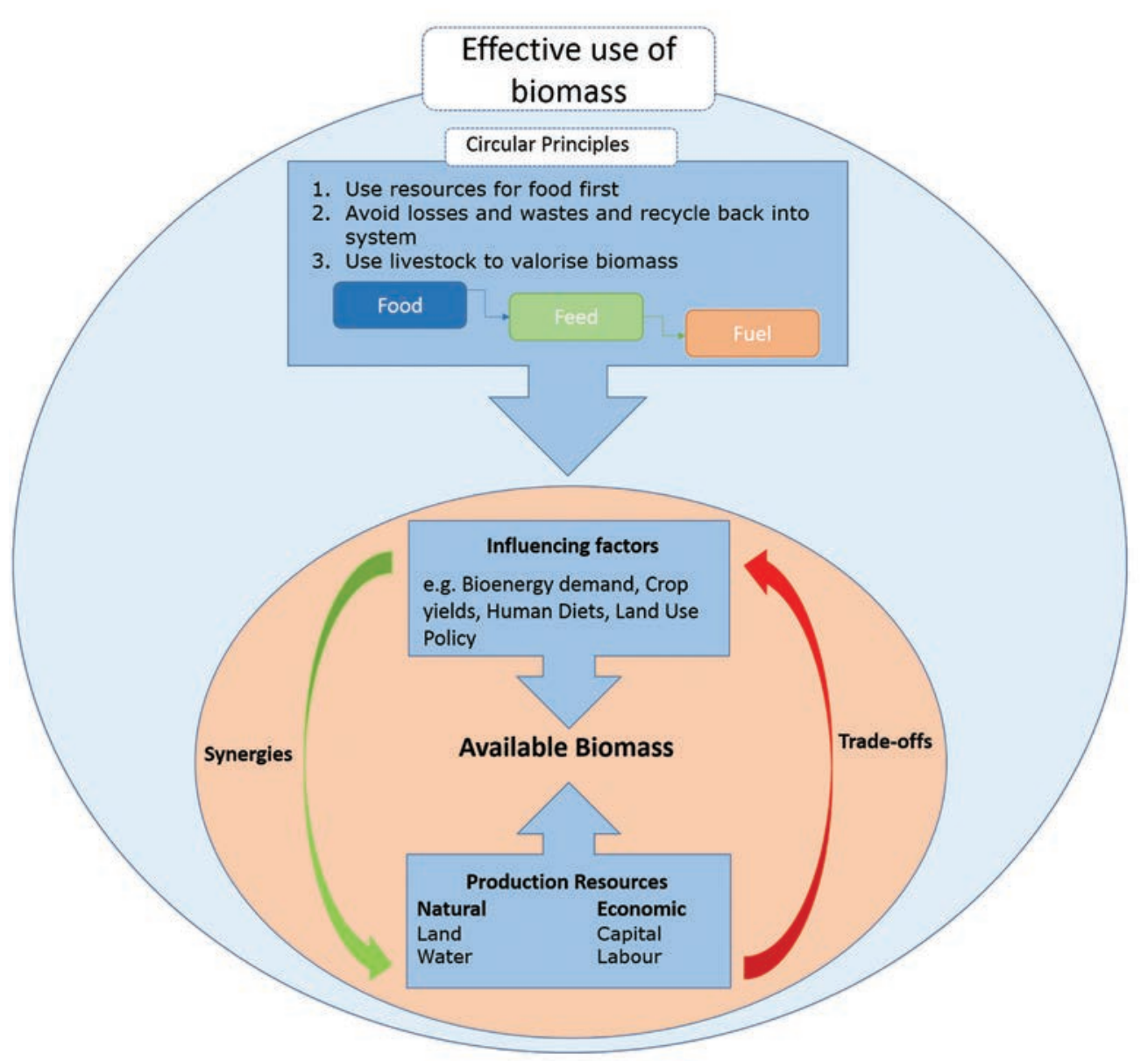

Fig. 4. Presents our framework for effective biomass use.

This would also free up arable land rendering it available for other purposes such as nature conservation. Avoiding wastes and recycling by-products can provide equally powerful effects. Davis and D'Odorico, (2015) estimate that feed crop calories required to support global consumer waste of animal source food could feed an additional 235 million people. Finally, using livestock to valorise biomass that humans cannot and will not eat can reduce overall land use, even more than 
diets with no animal-source food. This is because livestock convert crop residues and by-products from crop production that would otherwise go unused into edible food (Van Kernebeek et al., 2016; Van Zanten et al., 2018).

Many solutions suggested by studies are aligned with our framework, from using livestock to upcycling biomass, avoiding human-edible feedstuffs in feed, reducing consumption of animalsource food, using by-products feedstocks for livestock feed or bioenergy and using marginal lands. However, there is no prioritisation over the best use of biomass and the resources needed for its production between these solutions. Prioritisation is important, particularly in the case of deciding the best use of by-products and co-products of the agro-food industry, which are seen as potential feedstocks for bioenergy. However, many of these feedstocks already have a use as animal feed. For example in the study of Van Zanten et al., (2014), using beet tails as dairy cattle feed instead of a feedstock for anaerobic digestion for the production of on-farm biogas, resulted in a reduction of $239 \mathrm{~kg} \mathrm{CO}$ eq per ton beet tails and a decrease of $154 \mathrm{~m}^{2}$ land. Similar results were observed with other agro-industrial products, such as oilseed cake and wheat middlings when use was shifted from feed to anaerobic digestion at farm-level (Styles et al., 2015; Tonini et al., 2016; Tufvesson et al., 2013; Van Stappen et al., 2016). This review, therefore, raises awareness of potential feed-fuel competition in the bioeconomy.

An important finding of this review is that food, feed and bioenergy do not just compete for biomass and land but also for water, capital and labour. Therefore, our prioritisation framework should also apply here; this would help bridge perspectives between livestock and bioenergy domains on the best use of marginal land. Furthermore, it would help guide policy to prioritise food and material uses first and energy uses last, avoiding the negative knock-on effects of displacing capital, labour and resources away from food production.

Inevitably relying on sidestream biomasses that do not compete with food production for feed will likely result in lower consumption of animal-source food and lower levels of bioenergy. Studies indicate that livestock fed with only such 'low-opportunity cost feeds' can provide 9-23g of animal protein per person per day, while the average animal protein supply in Europe stands at around $51 \mathrm{~g}$ of animal protein per person per day (Van Zanten et al., 2018). However, this would potentially free up a quarter of global arable land (Van Zanten et al., 2018) besides providing benefits for human health and environment (Willett et al., 2019). 'Food first' estimations of bioenergy potentials using only crop residues and wasted crops show it is possible to produce $491 \mathrm{GL}$ of bioethanol per year (Kim and Dale, 2004), where in 2017 global ethanol production was 127 GL per year (OECD/ FAO, 2018). However, such high estimations do not consider other potential uses of this biomass, besides other factors such as climate change and yields (Haberl et al., 2011).

An important question remaining is at which scale should these circularity principles be pursued. 
From our reviewed studies, $48 \%$ argued that domestic biomass would be needed to be supplanted with imports, whether of actual or virtual resources, if food, feed, fuel needs are to be met. So far, research has not provided a clear answer as to at which scale, nutrients cycles should be recycled, and wastes and by-products returned to the system.

In future work, this framework can be expanded in two ways; firstly, by including other uses of biomass, such as incorporation into the soil for carbon sequestration, fertilisers, biochemicals and biomaterials. Secondly, the framework can be expanded by including other important functions of land associated with the production of biomass, such as nature conservation. We have so far focused on the three main uses of biomass (food, feed, fuel) because we argue that achieving food security and clean and renewable energy within planetary boundaries remain the main challenges facing humanity in the short to medium-term.

We believe such a framework setting priorities for the effective use of biomass is important because the various uses for biomass are inherently limited by biophysical boundaries, especially in the context of increasing pressure on resources (Fischer et al., 2007). This framework, therefore, argues that biophysical boundaries should be the guiding principles for effective biomass use, which does not necessarily entail directing biomass to its highest economically valuable use. Using such a framework is also useful to trigger new research questions, such as thinking about the availability and best use of biomass by-products that can be reused, the role of livestock in recycling these by-products and the role we give to trade in fulfilling these biomass uses.

\section{Conclusion}

This review finds that food, feed and fuel do not just compete for limited land but also compete for other resources such as water, labour and capital. The key influencing factors that affect the amount of biomass available for food, feed, fuel purposes related to bioenergy demand, crop yields, amount of human-edible feed fed to livestock, amount of animal source-food in human diets and food supply chain efficiency. Availability of biomass was also particularly affected by which feedstocks policy encouraged to be used for bioenergy and which land-use policies were put in place to discourage food-fuel competition. Important gaps identified in the literature related to the competition or displacement of economic resources when biomass demand is changed, the role of livestock in valorising biomass with low opportunity costs and the role of international trade in the competition for resources.

The reviewed studies had different priorities on how biomass should be directed, for food, feed or bioenergy. These different priorities resulted in contrasting or piecemeal solutions to solve competition for biomass, land and other resources, such as using by-products of the agro-food 
industry for livestock feed or bioenergy. We set a framework with three principles for the circular use of biomass, using a systems approach and the findings from our review, to help overcome this. By setting priorities directing biomass and the resources needed for its production towards food first, a number of trade-offs across food-feed-fuel uses of biomass can be addressed.

\section{Acknowledgements}

The authors would like to thank the Information Specialists at Wageningen University \& Research Library for their help with formulating the search queries. This project has received funding from the European Union's Horizon 2020 Research and Innovation Programme under grant agreement No.689669. The present work reflects only the authors' views and the Funding Agency cannot be held responsible for any use that may be made of the information it contains. 


\section{Appendix 2.1}

\section{Material and Methods}

This study applied a systematic explicit and transparent method to review the scientific literature (Boland et al., 2014). Literature searches were carried out using selected keywords and Boolean operators (AND, OR, NOT). Several iterations of scoping searches were tested in Scopus to ensure inclusion of relevant papers. Three queries were finalised to be used in three scientific databases: SCOPUS, Web of Science and CAB Abstracts. See below for the exact queries. The figure below shows the order and flow of our approach.

The queries were run on 15/10/2018 and yielded the following results: SCOPUS 2034 records, Web of Science 1823 records and CAB Abstracts 340 records. The citations were then exported into bibliographic software. Only peer-reviewed articles or reviews in English were imported. Book chapters, conference proceedings and grey literature were excluded from the review. See below for more details on the import procedure.

Duplicates were removed following a systematic procedure. See below for details on the deduplication procedure. After the deduplication procedure was applied, 3001 records remained. Two rounds of screening were applied to the remaining records. The procedure was partially based on the recommendations of Bramer et al. (2017). We started by scanning titles and abstracts, and subsequently full records. The relevance of the papers was based on the following selection criteria:

First, the paper established a relation or interaction between at least 2 of the three uses of biomass (for food, for feed and for bioenergy). Based on this criterion, papers that address the direct competition for biomass are included (e.g. studies that quantify the amount of human-edible ingredients in livestock feed), as well as studies that address the indirect competition between production resources, such as competition for natural or human resources among feed, food or fuel production. In this study, we tracked the four most critical resources needed for the production of food, feed and fuel: land, water, labour or capital. We have defined these resources as natural resources (land and water) and economic resources (labour and capital). Modelling studies that included a 'food first paradigm' (setting aside land or biomass for food and feed production) as an assumption when calculating bioenergy potential were also included.

Second, this review aimed to explore the implications of competition between food, feed and bioenergy for the European context, therefore only studies with European countries as case 
studies, at European scale or global studies with Europe as a world region were included. The boundaries of Europe were confined to the European Economic Area, including Switzerland. We chose to focus on Europe as the EU is an important global player in the demand for bioenergy (Banse et al., 2011), while simultaneously being dependent on land from outside the EU to feed livestock (de Visser et al., 2014; European Environmental Agency, 2017b).

Third, the study quantified biophysical relations. This was set as a selection criterion as this review defines the problem of biomass competition as defined by inherently biophysical limits, such as limited land or limited sustainable harvestable biomass, even if resource allocation is also governed by economic drivers. Economic studies were included if they examined biophysical relations alongside economic ones.

Fourth, studies were excluded for other reasons, such as not having access to the full paper, the paper being retracted or the paper not having data on or not being clear on how the conclusions were reached.

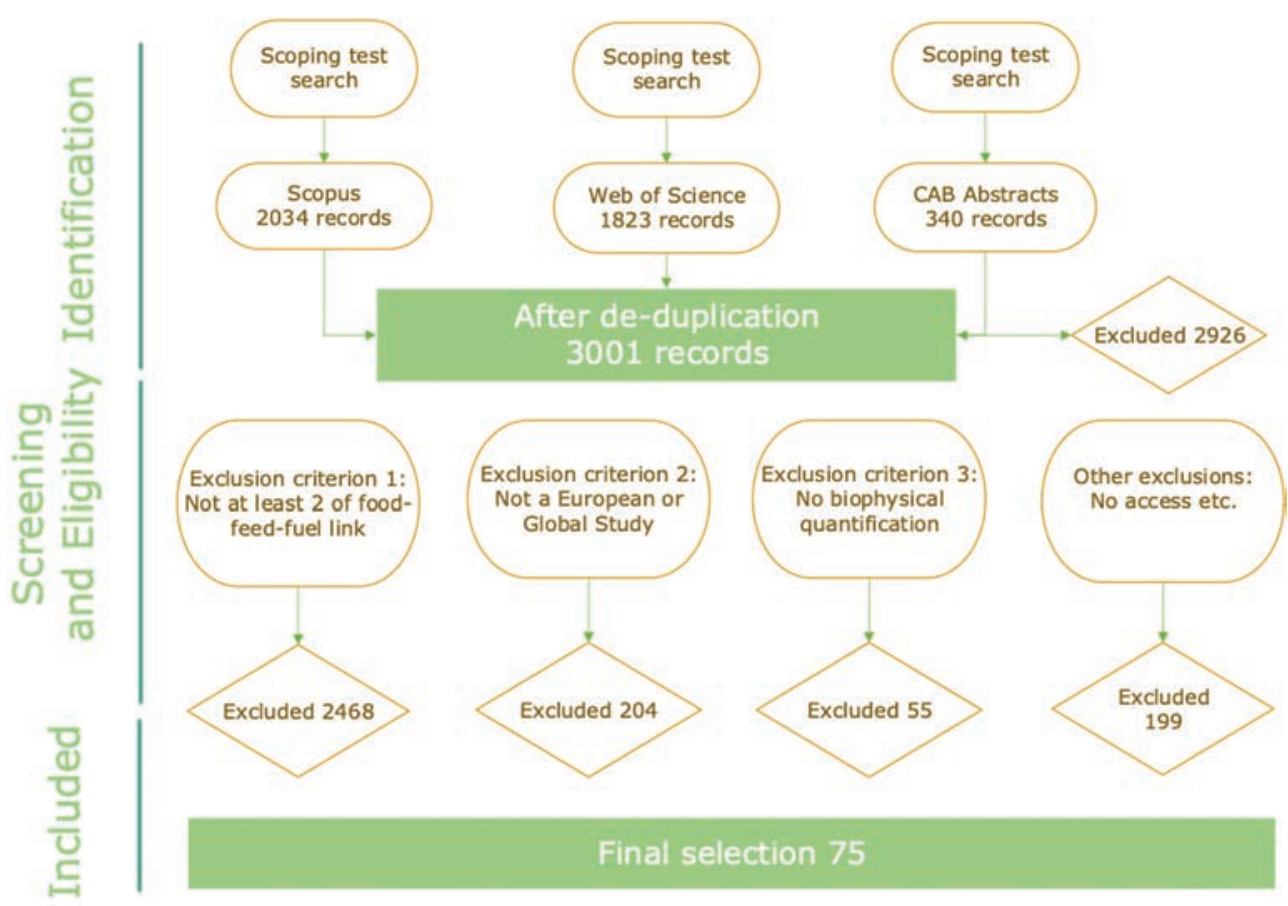

S1. An illustration of the selection process of our review. During the identification phase searches were tested in Scopus first, after which queries were finalised and used to identify the first three databases; during the screening and eligibility phase, duplicates were removed, and exclusion criteria applied, leaving the final selection of 75 papers 
Once the screening process was complete, final records were coded in a database for a number of variables on methodology (i.e. objective, conclusion, study approach, name of model, method used, and spatial scale), content and outcomes, and solutions recommended. Papers were categorised based on food-fuel, food-feed, feed-fuel, food-feed-fuel links. See the Excel file in supplementary material for the full list of variables coded and for the full database of records in the final selection.

To get an overview of the methods used in the papers, we categorised methods used into the following groups: a) biophysical modelling, b) economic approaches, c) ecosystem services approaches, d) food-feed competition studies that use measures of feed or land efficiency to assess whether feeding livestock is in contradiction with feeding the largest amount of people, e) other approaches not covered by the above.

To gain insight into at which scale studies look at effective biomass use, we categorised studies into different spatial scales, these were: a) global b) transboundary c) country d) regional e) local levels. The transboundary level included studies encompassing a range of EU countries or EU aggregates, such as the EU-25, EU-28 etc. Studies looking at the supply chain level of a product were also coded as transboundary.

Details about biomass generation, biomass source and bioenergy types were also collected. In this review we categorised biomass generation into $1^{\text {st }}$ and $2^{\text {nd }}$ generation, depending on whether the biomass source is a food crop $\left(1^{\text {st }}\right)$ or not $\left(2^{\text {nd }}\right)$ and included feedstocks, such as perennial grasses, short-rotation coppice, by-products and wastes.

Livestock are an essential component to consider when looking at the appropriation of biomass as they are important consumers, producers and recyclers of biomass (Wirsenius, 2003). Livestock are also important when looking at competition for resources, especially considering that the production of meat, aquaculture, eggs and dairy use about $83 \%$ of agricultural land globally (Poore and Nemecek, 2018). In this study, we looked at whether the study included livestock, information on livestock species or types if aggregated, livestock farming system and feed.

Trade is another essential component when considering the effective use of biomass as the source of this biomass is increasingly disconnected from its point of consumption (Kastner et al., 2014; Tukker et al., 2014). This is also critical for the competition of resources, as the resource burden of such biomass is also disconnected from its point of consumption (Tukker et al., 2016). In this study, we gathered information on whether trade is considered and if there is a dependency on imports to meet demand.

We coded the main factors mentioned in the studies that influence the use of biomass and 
identified the implications (synergies or trade-offs) when pursuing different biomass uses or goals. The implications were categorised as a) trade-off, meaning that they are conflicting, and making progress on one goal decreases another, b) synergistic, meaning that making progress on one goal can aid another or c) neutral meaning that there is no effect (trade-off nor synergy) or the outcome is unclear. Examining trade-offs is critical to the problem of food-feed-fuel competition (Dixon et. al, 2010; Mirzabaev et al., 2015) since under current rates of resource consumption it will become difficult to balance the goals of food security, climate mitigation and energy security. Queries SCOPUS (

TITLE-ABS-KEY(AGRI* OR AGRO* OR LIVESTOCK OR CROP*)

AND TITLE-ABS-KEY(FOOD AND FEED)

OR TITLE-ABS-KEY(FUEL OR BIOENERGY OR BIOFUEL AND FOOD)

OR TITLE-ABS-KEY(FUEL OR BIOENERGY OR BIOFUEL AND FEED)

OR TITLE-ABS-KEY(FOOD AND FEED AND FUEL OR BIOENERGY OR BIOFUEL)

AND TITLE-ABS-KEY(BIOMASS OR LAND*)

AND TITLE-ABS-KEY(“TRADE-OFF”OR COMPET* OR IMPACT* OR RELAT OR EFFECT*)

AND NOT TITLE-ABS-KEY (*ALGA*)

)

AND DOCTYPE(ar OR re)

AND LANGUAGE(ENGLISH)

AND SUBJAREA(AGRI OR ENV OR EART OR ENER OR SOCI OR ECON OR MULT OR ENGI)

WEB OF SCIENCE

$\# 1$ TS=(AGRI ${ }^{*}$ OR AGRO* OR LIVESTOCK OR CROP*)

\#2 TS=(BIOMASS OR LAND*)

\#3 TS=("TRADE-OFF" OR “TRADE-OFFS" OR COMPET* OR IMPACT* OR RELAT* OR EFFECT*)

\#4 TS $=\left({ }^{*} A L G A^{*}\right)$

\#5 TS=(FOOD)

\#6 TS=(FEED)

\#7 TS=(FUEL* OR BIOENERGY OR BIOFUEL*)

\#1 AND \#2 AND \#3 NOT \#4 AND ((\#5 AND \#6) OR (\#5 and \#7) OR (\#6 AND \#7) OR (\#5 AND \#6 AND \#7))

Excluded research areas: ETHICS OR GENETICS HEREDITY OR ENGINEERING INDUSTRIAL OR CHEMISTRY APPLIED OR COMPUTER SCIENCE INTERDISCIPLINARY APPLICATIONS OR GEOGRAPHY PHYSICAL OR FISHERIES OR BIOCHEMISTRY MOLECULAR BIOLOGY OR SPECTROSCOPY OR MANAGEMENT OR CHEMISTRY ANALYTICAL OR LAW OR TOXICOLOGY OR BIOCHEMICAL RESEARCH METHODS OR PHYSIOLOGY OR PUBLIC ENVIRONMENTAL OCCUPATIONAL HEALTH OR PARASITOLOGY OR PLANT SCIENCES OR MICROBIOLOGY 
OR HUMANITIES MULTIDISCIPLINARY OR ENGINEERING MECHANICAL OR CHEMISTRY PHYSICAL OR ARCHAEOLOGY OR ZOOLOGY OR ENGINEERING CIVIL OR MEDICINE GENERAL INTERNAL OR GEOCHEMISTRY GEOPHYSICS OR IMAGING SCIENCE PHOTOGRAPHIC TECHNOLOGY OR ENGINEERING AEROSPACE OR URBAN STUDIES OR DEMOGRAPHY OR CONSTRUCTION BUILDING TECHNOLOGY OR OCEANOGRAPHY OR CELL BIOLOGY OR EVOLUTIONARY BIOLOGY OR HISTORY OF SOCIAL SCIENCES OR ELECTROCHEMISTRY OR HISTORY OR MARINE FRESHWATER BIOLOGY OR GEOLOGY OR NUCLEAR SCIENCE TECHNOLOGY OR ENGINEERING MANUFACTURING OR ENTOMOLOGY OR ENGINEERING ELECTRICAL ELECTRONIC OR ENGINEERING BIOMEDICAL OR ORNITHOLOGY OR EDUCATION SCIENTIFIC DISCIPLINES OR MECHANICS OR DEVELOPMENTAL BIOLOGY OR CHEMISTRY ORGANIC OR CHEMISTRY MEDICINAL OR NUTRITION DIETETICS OR LIMNOLOGY OR CHEMISTRY INORGANIC NUCLEAR OR BIOLOGY OR ARCHITECTURE OR CHEMISTRY MULTIDISCIPLINARY OR HISTORY PHILOSOPHY OF SCIENCE OR ALLERGY OR VETERINARY SCIENCES

AND EXCLUDED PROCEEDINGS PAPER OR BOOK CHAPTER

OVIDSP:CAB Abstracts

1 BIOMASS OR LAND*

2 "TRADE-OFF?" OR COMPET* OR IMPACT* OR RELAT* OR EFFECT*

3 ALGA*

4 FOOD CROPS/ OR EXP FOOD PRODUCTION/ OR FOOD SECURITY/ OR FOOD SUPPLY/

5 FEEDS/

6 BIOFUELS/ OR BIOENERGY/ OR FUEL CROPS/

71 AND 2 AND ((4 AND 5) OR ( 5 AND 6) OR (4 AND 6) OR ( 4 AND 5 AND 6)) NOT 3

8 Limit 7 to English language

98 and "Journal article" [Publication type]

Deduplication procedure

Recommended to Display in the EndNote library window before de-duplication:

$\leftarrow$ Author

$\leftarrow$ Year

$\leftarrow$ Title

$\leftarrow$ Secondary Title (Journal)

$\leftarrow \quad$ Name of database

$\leftarrow$ Pages 


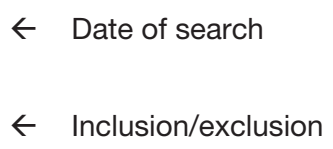

Follow in this order
A. Author | Year | Title | Secondary Title (Journal)
B. Author | Year | Title | Pages
C. Title | Volume| Pages
D. Author | Volume | Pages
E. Year|Volume | Issue | Pages
F. Title
G. Author | Year

Import Procedure

When importing from SCOPUS we imported Citation information, Bibliographical information, and Abstract and Keywords. When importing from Web of Science we imported the Full record and Cited References. When importing from CAB Abstracts we imported the complete reference. 
The Battle for Biomass | Abigail Muscat

A systematic review of food-feed-fuel competition 



\section{Chapter 3}

\section{Food, energy or biomaterials?}

\section{Policy coherence across agro-food and bioeconomy policy domains in the EU}

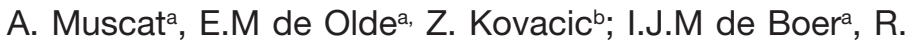
Ripoll-Bosch ${ }^{\mathrm{a}}$

${ }^{a}$ Animal Production Systems group, Wageningen University \& Research, PO Box 338, $6700 \mathrm{AH}$ Wageningen, the Netherlands

${ }^{b}$ Centre for the Study of the Sciences and the Humanities (SVT), University of Bergen, Universitetet i Bergen, Senter for vitskapsteori, Parkveien 9, 5007 Bergen, Norway

Under Review 


\section{Abstract}

The European Union (EU) envisions a shift towards a bioeconomy to address climate change, to reduce dependence on non-renewable resources, to manage natural resources sustainably and to achieve food and nutrition security. As a result, biomass will become an increasingly important resource in the bioeconomy and will require careful and sustainable management. A key challenge is how to balance the increasing demand for non-food materials with food security; especially because biomass comes from a wide variety of economic sectors and is governed by different policies. The bioeconomy will require coherence between many different policy domains. However, little is known how policy goals in these domains interact and how these interactions may play out in different contexts. Given the above, this study aims to assess coherence between bioeconomy and agro-food policies by assessing the interactions between bioeconomy and agro-food goals (i.e. trade-offs, synergies) and by unravelling key uncertainties and knowledge gaps underlying these interactions. We conducted a qualitative content analysis of $41 \mathrm{EU}$ policy documents across 5 policy domains, namely agro-food, bio-based industry, waste, energy and environment. We explored how policies interact, using a survey and focus groups based on expert opinion across scientific fields. We find that bioeconomy policy goals and agro-food policy goals are largely considered to be consistent and that synergies outweigh trade-offs, both in quantity and in strength. However, all bioeconomy policy domains show some trade-offs with agro-food policy. We furthermore find uncertainty and disagreement in scientific knowledge-base, particularly concerning waste and bio-based industry. Disagreement surrounds the feasibility of some policy goals, such as decoupling economic growth from the environment. We conclude that a shift towards a bioeconomy will have to acknowledge the interactions between different policy goals across the different sectors and avoid 'silo-thinking'. This can be achieved through overcoming vagueness in policies, such as having clear cascading guidelines for biomass. 


\section{Introduction}

Humans use biomass for multiple purposes, such as the production of food, livestock feed, bioenergy and bio-based materials (e.g. bio-plastics, cellulose fibres, pharmaceuticals). Due to the growth of the global population and changing patterns of consumption, humans are appropriating more biomass than ever before (Krausmann et al., 2013; Smil, 2012). Food demand is expected to increase by $50 \%$ between 2012 and 2050 (FAO, 2017) and the increasing demand for animal-source food will entail higher animal feed demands and will increase pressure on agricultural resources (Thornton, 2010). Bioenergy, already an important source of renewable energy, representing $64 \%$ of all renewable energy in the EU (Eurostat, 2016) is also expected to increase as the EU seeks to meet $20 \%$ of its gross energy consumption through renewables. As economies shift to become more bio-based, demands will also increase for bio-based products such as bioplastics, biolubricants and biochemicals (Scarlat et al., 2015). If these trends remain unchanged, it will become increasingly difficult to meet growing demands without increasing pressure on water, land and other natural resources (Muscat et al., 2020). Competing uses for biomass pose a challenge of how to meet biomass demand while also managing natural resources sustainably (Godfray et al., 2010). Several studies have so far assessed the potential biomass available now and in the future to meet human demands (Daioglou et al., 2019; Scarlat et al., 2011; Verkerk et al., 2019). However, these studies often focus on only one or two biomass uses (for food, feed, fuel, materials etc.) without considering systems-level connections between food-systems, energy-systems and other bio-based systems (e.g. forestry). This results in science recommending either piecemeal or inconsistent solutions that lead to several trade-offs (Muscat et al., 2020).

In 2012, the European Union (EU) adopted the bioeconomy strategy to meet the challenges of mitigating climate change, moving away from non-renewable resources, managing resources sustainably and achieving food and nutrition security. The EU defines the bioeconomy as 'the production of renewable biological resources and the conversion of these resources and waste streams into value-added products, such as food, feed, bio-based products and bioenergy' (European Commission, 2012a). The bioeconomy encompasses all economic sectors where biomass is extracted and recovered, linking primary sectors, such as the agricultural, aquaculture and forestry sector, with industrial and processing sectors, such as the chemical, energy and biotechnology sectors (Kelleher et al., 2019). Biomass streams within the bioeconomy can range from food, feed and energy crops, to forestry felling, municipal solid waste and industrial residues. However, the diversity of biomass streams and the economic sectors where biomass is sourced poses a challenge for the governance of the bioeconomy (Kelleher et al., 2019). This is because it requires cooperation between several policy domains and a collective effort to mitigate the impact of trade-offs across different policy goals (Ronzon and Sanjuán, 2020). This will not just mean balancing demands for biomass for different uses but also implies balancing other goals; 
both within the bioeconomy (e.g. sustainable resource use) but also outside (e.g. maintaining and regenerating biodiversity)(European Environmental Agency (EEA), 2018).

In light of the adoption of the Sustainable Development Goals (SDGs) and the need to overcome policy 'silos', policy coherence itself has become an important governance goal for the EU (Nilsson et al., 2012). The Bioeconomy Strategy (European Commission, 2012a) aims to facilitate coherence and synergies and attempts to address trade-offs emerging from the competing uses of biomass. Policy coherence has been defined as going beyond 'do no harm strategies' to fostering synergies across policy domains; identifying trade-offs across spatial scales and over time (OECD, 2016). The complexity involved in balancing goals has spurred research interest into policy coherence by looking at the interactions between policy goals and how likely they are to reinforce (create synergies) or cancel each other (create trade-offs) (International Council for Science, 2017). The call to move away from 'silo thinking' to a more integrative, systems or 'nexus' way of thinking to solve policy coherence issues has echoed across a multitude of disciplines and fields (Weitz et al., 2017). The prominent role of the agro-food system in the production, provision and utilisation of biomass means that the bioeconomy presents a unique opportunity to move towards a sustainable agrofood system. This can be achieved by fostering new technologies, circular use of resources and moving away from fossil fuels. However, it may also create conflicts between sustainability goals and may place additional demands on natural resources (OECD and Diakosavvas, 2018). Studying the potential interactions between the bioeconomy and agro-food goals can find pathways to reduce conflicts and foster synergies. Given the bioeconomy is a relatively new concept, little is known how these interactions may play out, therefore finding knowledge gaps, highlighting uncertainties and disagreement is also key.

The contrasting solutions recommended by science (Muscat et al., 2020) as well as the lack of integration between policy domains and governance bodies represents both a gap in the research and a challenge for governance and policy. It is, therefore, imperative that the complexity of interactions between policy domains is well understood. Previous policy coherence studies have addressed policy domains such as energy, climate change and forestry (Antwi-agyei et al., 2017; Harahap et al., 2017; Kalaba et al., 2014; Lindstad et al., 2015). To our knowledge, policy coherence studies have not yet addressed concepts such as the bioeconomy, particularly concerning its potential effect on agricultural and food goals. Furthermore, many do not consider key uncertainties in the knowledge-base by including measures of agreement and confidence between experts. Our aim for this study is to assess coherence between bioeconomy and agrofood policies in the EU by assessing the interactions between bioeconomy and agro-food goals (i.e. trade-offs, synergies) and showing where key uncertainties and knowledge gaps lie regarding these interactions. We do this by measuring confidence levels, range of coherency scores and expand on survey results using focus groups to highlight uncertainties and other key aspects. 


\section{Material and Methods}

\section{Policy coherence: definition}

Policy coherence has been defined in multiple ways. It has been defined as reinforcing policy goals across government ministries, departments and agencies (OECD, 2004) and also across policy areas or domains (Gauttier, 2004). It has also been defined as 'an attribute of policy that systematically reduces conflicts and promotes synergies between and within different policy areas to achieve the outcomes associated with jointly agreed policy objectives' (Nilsson et al., 2012: 396). In this study, we follow the definition of Nilsson et al. (2012) and define coherence as the promotion of synergies across policy areas or domains, rather than across institutional bodies such as government departments. Assessing the interactions, and their induced impacts and effects between various policy areas is possible across domains and spatial/administrative scales (Lenschow et al., 2018). In this study, we focus on horizontal and external coherence, which is the examination of coherence across one administrative scale (EU) but across different policy domains (bioeconomy vs agro-food). Furthermore, while many definitions have been provided for a policy domain, for our study we define it as a substantive topic such as environment or climate change under which policy goal-setting takes place, irrespective of the governmental institution. Studies focusing on policy coherence argue that incoherence can emerge from the tendency to make use of specialist policy knowledge within policy domains with little integration of knowledge from other domains (Tosun and Leininger, 2017). We define policy incoherence for the bioeconomy as not just emerging from a lack of integration but the complexity involved in balancing competing biomass uses with biophysical and ecological limits (Muscat et al., 2020).

\section{Selection of documents and policy goals}

The first stage of our analysis involved qualitative content analysis of policy documents. To find relevant documents, we utilised documents referenced in three key documents defining the bioeconomy: the 2012 Bioeconomy Strategy and the 2018 update to the Bioeconomy Strategy (European Commission, 2018) and the European Environmental Agency (EEA) report "The circular economy and the bioeconomy: Partners in sustainability"(European Environmental Agency (EEA), 2018). We further conducted searches in EURLEX, using keywords such as "food", "feed", "fuel", "bioenergy", "biofuel”, "land", "fisheries", "waste”, "forest”, "biomass", "bioeconomy”, "bio-based", "agriculture". We included several types of policy documents, such as regulations, directives and communications, but excluded non-strategic or goal-setting documents. Our selection included 41 documents related to 5 policy domains: waste, bio-based industry, environment, renewable energy and agro-food (Supplementary Material). These policy domains were chosen based on their importance to the bioeconomy, particularly as they govern economic sectors that provide 
biomass, utilise biomass or contain important goals for the bioeconomy (European Environmental Agency (EEA), 2018).

From these 41 documents, multiple goals could be identified for each policy domain, as presented in Table 1. To make the final selection of goals, we conducted qualitative content analysis (Flick, 2014), using the qualitative data analysis software Atlas.ti version 8.4.4 (Friese, 2012). EU policy documents were coded for goals as stated in the document. Goals were selected based on their relevance to the research questions, particularly policy goals needed to be related to biomass production, utilisation or consumption. Selected goals stated the objective or target clearly and were delineated as such to be the purpose of the policy within the document. Goals mentioned more than once in the same or different documents were excluded. This process resulted in an overview of EU policy goals domains from 15 policy documents (Table 1) and was used to assess the coherency.

Table 1. Selected policy goals for presentation to experts across 5 policy domains. All domains were scored against EU Agro-food policy goals.

\begin{tabular}{|c|c|c|c|}
\hline $\begin{array}{l}\text { POLICY } \\
\text { DOMAIN }\end{array}$ & CODE & GOAL & EXPLANATION \\
\hline \multicolumn{4}{|c|}{ EU Waste policy domain } \\
\hline & Waste1 & Reduce waste & $\begin{array}{l}\text { Adhere to the waste hierarchy and reduce waste } \\
\text { generation }\end{array}$ \\
\hline & Waste2 & $\begin{array}{l}\text { Cascade } \\
\text { biomass }\end{array}$ & $\begin{array}{l}\text { Encourage the cascading principle taking into } \\
\text { account all biomass-using sectors utilising } \\
\text { biomass in the most resource-efficient way }\end{array}$ \\
\hline & Waste3 & $\begin{array}{l}\text { Energy from } \\
\text { non-recyclables }\end{array}$ & $\begin{array}{l}\text { Recover energy only from non-recyclable } \\
\text { materials }\end{array}$ \\
\hline & Waste4 & $\begin{array}{l}\text { Ban } \\
\text { biodegradable } \\
\text { landfilling }\end{array}$ & Ban landfilling of biodegradable waste by 2025 \\
\hline \multicolumn{4}{|c|}{ EU Bio-Based Industry policy domain } \\
\hline & $\mathrm{BIO1}$ & $\begin{array}{l}\text { Sustainably } \\
\text { scale biomass }\end{array}$ & $\begin{array}{l}\text { Develop sustainable scaling up of biomass } \\
\text { supplies }\end{array}$ \\
\hline & $\mathrm{BIO2}$ & $\begin{array}{l}\text { New bio-based } \\
\text { products }\end{array}$ & Develop new bio-based products and materials \\
\hline & $\mathrm{BIO3}$ & $\begin{array}{l}\text { Utilise unused } \\
\text { residues }\end{array}$ & $\begin{array}{l}\text { Encourage innovation to exploit currently } \\
\text { unused crop residues and marine biomass }\end{array}$ \\
\hline & $\mathrm{BIO4}$ & $\begin{array}{l}\text { Replace fossil- } \\
\text { with bio-based } \\
\text { products }\end{array}$ & $\begin{array}{l}\text { Replace fossil-based products with bio-based, } \\
\text { recyclable and marine-degradable products }\end{array}$ \\
\hline
\end{tabular}


Policy coherence across agro-food and bioeconomy policy domains in the EU

\begin{tabular}{|c|c|c|}
\hline BIO5 & $\begin{array}{l}\text { Develop } \\
\text { biorefineries }\end{array}$ & $\begin{array}{l}\text { Facilitate the development of new sustainable } \\
\text { biorefineries }\end{array}$ \\
\hline BIO6 & $\begin{array}{l}\text { Healthy and } \\
\text { sustainable diets }\end{array}$ & $\begin{array}{l}\text { Changes in consumption promoting healthier } \\
\text { and more sustainable diets }\end{array}$ \\
\hline \multicolumn{3}{|c|}{ EU Renewable Energy policy domain } \\
\hline Energy1 & $\begin{array}{l}32 \% \text { renewable } \\
\text { energy }\end{array}$ & $\begin{array}{l}\text { Achieve } 32 \% \text { of overall gross energy } \\
\text { consumption by } 2030 \text { from renewable energy }\end{array}$ \\
\hline Energy2 & $\begin{array}{l}14 \% \text { renewable } \\
\text { energy in } \\
\text { transport }\end{array}$ & $\begin{array}{l}\text { Achieve } 14 \% \text { of transport (road and rail) from } \\
\text { renewable energy }\end{array}$ \\
\hline Energy3 & $\begin{array}{l}\text { More advanced } \\
\text { biofuels }\end{array}$ & $\begin{array}{l}\text { Incentivise biofuels made from advanced } \\
\text { feedstocks through double-counting their } \\
\text { energy content }\end{array}$ \\
\hline Energy4 & $\begin{array}{l}\text { Halt indirect- } \\
\text { land use change }\end{array}$ & $\begin{array}{l}\text { Halt 'high indirect land-use change' biofuels by } \\
2030\end{array}$ \\
\hline Energy5 & $\begin{array}{l}\text { Biofuels on } \\
\text { marginal land }\end{array}$ & $\begin{array}{l}\text { Encourage biofuels grown on abandoned, } \\
\text { severely degraded and contaminated land }\end{array}$ \\
\hline \multicolumn{3}{|c|}{ EU Environment policy domain } \\
\hline ENV1 & Decoupling & $\begin{array}{l}\text { Decouple environmental impacts from a growing } \\
\text { economy }\end{array}$ \\
\hline ENV2 & No net land take & No net land take by 2050 \\
\hline ENV3 & Water quality & $\begin{array}{l}\text { By } 2020 \text { achieve good status (quality, quantity } \\
\text { and use) of waters in all EU river basins }\end{array}$ \\
\hline \multicolumn{3}{|c|}{ EU Agro-food policy domain } \\
\hline Agro1 & Food security & $\begin{array}{l}\text { Food security: access to safe, sufficient, } \\
\text { nutritious food at all times }\end{array}$ \\
\hline Agro2 & Healthy soils & $\begin{array}{l}\text { Preventing soil degradation, restoring soil at } \\
\text { least with consistent with the current or intended } \\
\text { use }\end{array}$ \\
\hline Agro3 & $\begin{array}{l}\text { Domestic and } \\
\text { organic fertiliser }\end{array}$ & $\begin{array}{l}\text { Incentivise organic fertiliser production from } \\
\text { domestic sources }\end{array}$ \\
\hline Agro4 & $\begin{array}{l}\text { Domestic protein } \\
\text { crops }\end{array}$ & $\begin{array}{l}\text { Increase domestic protein crop production } \\
\text { especially for livestock feed }\end{array}$ \\
\hline Agro5 & $\begin{array}{l}\text { Reduce food } \\
\text { waste }\end{array}$ & Reduce food losses and waste \\
\hline Agro6 & $\begin{array}{l}\text { Resource } \\
\text { efficiency }\end{array}$ & Resource efficiency and nutrient cycling \\
\hline
\end{tabular}




\section{Assessing coherence}

To assess the coherence between bioeconomy policies and agro-food policies we used expert opinion through an online survey followed by a round of focus-groups for each policy domain.

We first presented the selected policy goals (Table 1) in an online survey to obtain expert opinion on interactions (synergies, neutral or trade-offs) between bioeconomy vs agrofood goals. Experts were chosen based on snowballing referrals. All experts were from an academic background and belonged to different scientific disciplines, aligned with the policy domains. The online survey was sent to a total of 40 experts. Experts were presented with the goals in Table 1. Experts were asked to score the effect of one policy domain of their expertise (waste, bio-based industry, environment, renewable energy) on agro-food policy goals. To assess the level of coherency between policy domains we employed the scoring framework used by Nilsson and colleagues, (see e.g. International Council for Science, 2017; Nilsson et al., 2018, 2012) (See Fig. 1 below).

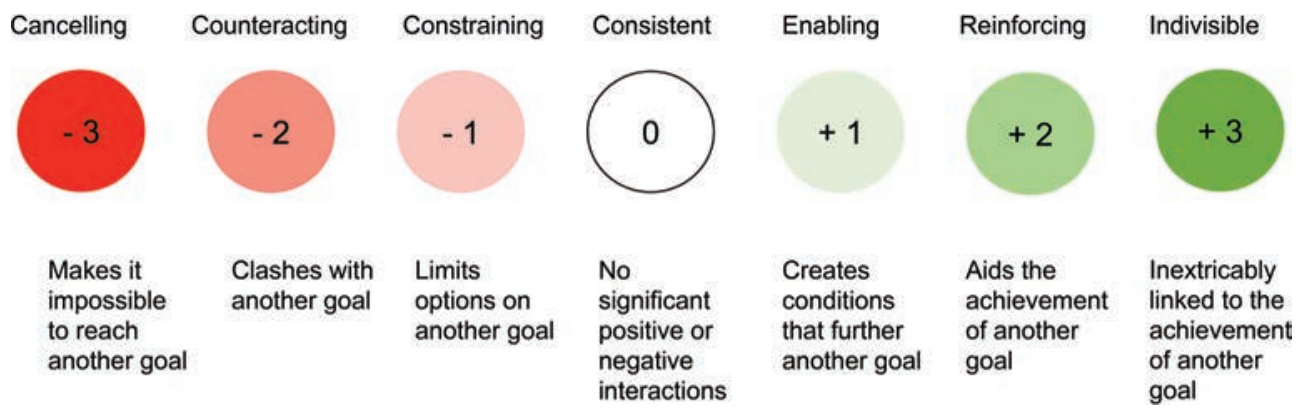

Fig 1. Coherency Scoring system (adapted from Nilsson, 2017)

The coherency scoring system is a 7 point scale where interactions between policy goals can be scored as positive $(+3$ to +1$)$, meaning that the goals can positively contribute to one another, negative ( -1 to -3$)$ meaning the goals negatively affect each other, and neutral $(0)$, where two goals are independent of each other and no interaction is known. Inspired by the 'NUSAP' approach, a system for the communication of uncertainty in science, (Van Der Sluijs et al., 2005), experts were also asked to indicate the confidence level (i.e. low, medium or high confidence) in the assessment of each goal interaction. Further, additional 
space for qualitative comments was provided. We received a total number of 24 responses ( $n=4$ for waste, $n=5$ for bio-based industry, $n=10$ for environment, $n=5$ for renewable energy). The online survey aimed to score a large number of policy interactions and consider each interaction thoroughly. A total of 108 possible policy interactions were scored by every respondent in the online survey.

After the survey, responses were gathered, the data was summarised with the median and range of the coherency score and the median of the confidence score (1 equal to 'low confidence and 3 equal to 'high confidence'). These results were then presented to experts in a focus group. A separate focus group was held per policy domain with 3-4 experts attending per focus group along with a facilitator and note-taker. We presented the interactions from the survey where experts agreed or disagreed the most (highest range), as the interactions where experts agree or disagree the most are likely to be the most insightful. The focus groups lasted for 1 to $1,5 \mathrm{~h}$, were audio-recorded and notes were taken. The data was then analysed using thematic content analysis. The interactions between policy domains and agro-food policy, the result of the survey and outcomes of the expert workshops are presented in Figure 2, 3 and Table 2 overleaf.

\section{Interactions between bioeconomy and agro-food goals}

This section first presents the results of the online survey (Figure 2 and 3), before presenting the results from the focus groups. (Table 2). Figure 2 shows the results from the survey considering the median score for coherency only. In this case, results indicate that bioeconomy policy goals are perceived to be largely consistent (meaning two goals do not interact) or synergistic (meaning two goals interact positively) with agro-food policy goals. While all four policy domains register synergies across all three possible synergistic scores (enabling +1 , reinforcing +2 , indivisible +3 ), trade-offs are weaker in strength. All policy domains have some trade-offs, with all policy domains having some goals that may be 'constraining' on agro-food policy. However, only the energy policy domain had some interactions that were counteracting. No two policy goals were found to be so incoherent as to be cancelling each other out. All policy domains also had many interactions that were considered to be consistent, meaning that the policy goals do no interact either positively or negatively. Waste policy has the largest potential for synergies with agro-food policy, while energy has the least potential. 


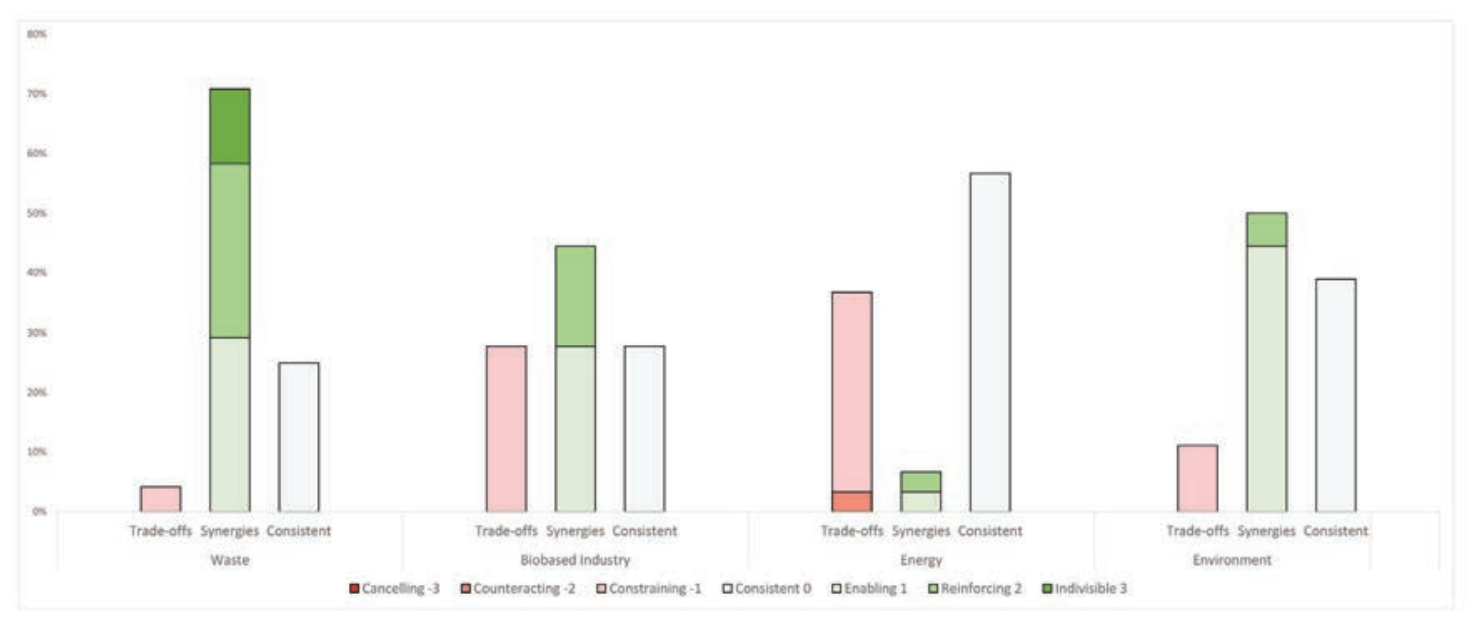

Fig. 2. Interactions (trade-off, synergy or consistent) between policy domains and agro-food policy. Size of bars shows the percentage of interactions with a given score while colour shows strength (positive/ negative) of the coherency score.

Figure 3 presents the results of the survey by presenting the coherency score, the range of scores and the confidence score for each pair of goals across the different policy domains. Figure 3 indicates that the agro-food goals of 'Food security', 'Reduce food waste' and 'Resource efficiency' have the most synergistic effects, showing the more positive coherency scores than other agro-food goals. To reduce food waste, the waste goals 'Reduce waste' and 'Cascade biomass' have the most potential, with scores of 3 and 2.5 respectively. To improve resource efficiency, bio-based industry goals, such as 'Ban biodegradable landfilling', 'Utilising unused residues', can have synergistic effects. Decoupling environmental impacts from a growing economy was also assessed to have a synergistic effect on resource efficiency in the agro-food system. The agro-food goals with the most trade-offs were 'Domestic and organic fertiliser' and 'Domestic protein crops'. Both goals entail increasing domestic supplies of biomass i.e. within the EU.

However, digging further into the results from the survey shows gaps and uncertainties in the knowledge-base. While the coherency scores show that bioeconomy and agro-food goals interact positively or do not interact at all, looking into the range of coherency scores (which measures expert disagreement) and the confidence scores (which measures expert confidence) gives a different picture. Figure 3 below shows that relying on the coherency score alone may be misleading. The coherency scores frequently had large ranges even for interactions and policy domains that were scored with high confidence, for example, the effect of cascading biomass (Waste2) on healthy soils (Agro2). The reverse was also true, where 
experts all scored the same score but with low to medium levels of confidence (e.g. Bio2 on Agro3). Concerning the range, there were only a few interactions where all experts converged to the same score, these were: Bio2 'New bio-based products' on Agro3 'Domestic and organic fertilisers', Energy4 'Halt indirect land-use change' on Agro5 'Reduce food waste' and Energy 5 'Biofuels on marginal land' on Agro 5 'Reduce food waste'. Nevertheless, ranges of scores for most policy domains were particularly high within the environment policy domain, particularly for Env1 goal of 'Decoupling and for the Waste and Bio-based industry policy domains concerning Waste2 'Cascade biomass' and Bio6 'Healthy and sustainable diets'. Hence, and despite the median would show a consistent coherency score, the ranges provide a wider and sometimes conflicting picture. This could be because there is a great deal of uncertainty around the feasibility of achieving some goals (e.g. decoupling) or to different interpretations of the goals and imaginaries on how to achieve those goals. This is further discussed below in Section 4.

Concerning the confidence score, the policy domains with the highest confidence were waste, energy bio-based industry, particularly when assessing the effects of such policies on food security and reducing food losses and waste. This may reflect that scientific knowledge surrounding these politically high priority goals may be higher than for newer and more specific goals such as Agro3 'Domestic and organic fertiliser. This may also reflect the large knowledge-base, particularly in the case of energy, regarding the conflict between bioenergy production and food security and conflicts around biomass more broadly. However, both waste and bio-based industry were the only policy domains that had interactions with low confidence; concerning the effect of promoting domestic and organic fertilisers. When speaking to experts, it became clear that this was because the knowledge-base concerning bio-based industry is still limited (Table 2)

To gain insight into possible explanations from experts about the ranges in coherency scoring and the certainty in the answers we organised focus groups that presented the interactions from the survey where experts mostly agreed (low range) or disagreed (high range). Table 3 presents the results of the focus groups. The focus groups revealed that a complex set of interactions is often taking place between two goals that could not be fully captured with the coherency score. As explained above and shown in Figure 2, overall interactions were synergistic or consistent when considering coherency scores only. 

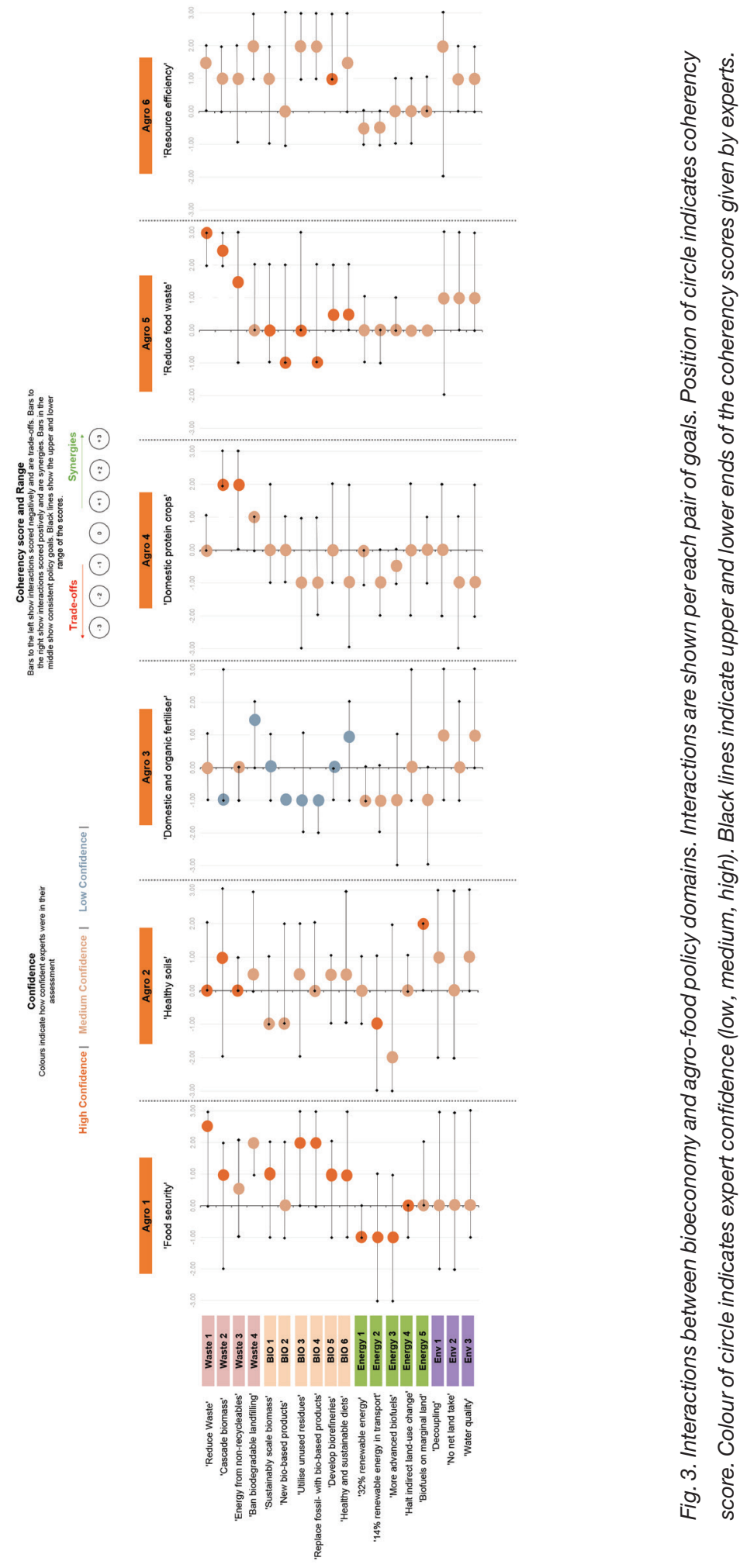
However, digging into the interactions with experts revealed that some goals may interact in multiple, sometimes opposing ways. Even for pairs of policy goals that were scored as consistent, interactions were identified that could potentially change the coherency score if the context would change in the future. For example, in the case of the effect of the biobased industry goal 'Changes in consumption promoting healthier and more sustainable diets' on the agro-food goal 'Increase domestic protein crop production especially for livestock feed', was highly dependent on the degree to which sustainable and healthy diets could be achieved in the future. It furthermore depended on how a healthy and sustainable diet is defined and the amount of animal-source food in the diet. This revealed that coherency scores depended on several factors. Firstly, it revealed uncertainties, particularly about resource use or consumption patterns into the future. Other uncertainties concerned the feasibility of some solutions which remain, as yet, unproven or disputed. The focus groups furthermore revealed context dependencies: the agriculture practice or agricultural system, the temporal or geographical, or biophysical scale within which a policy is implemented. Furthermore, focus groups revealed some interactions were difficult due to the vagueness in the definition of policy terms. We address such wider issues in turn below.

Table 2. Results of the focus groups. Qualitative descriptions of the interactions assessed between each policy domain (waste, bio-based industry, environment, renewable energy) and its effect on an agro-food goal.

\section{Goals}

Effect of

Waste1

'Adhere to the waste

hierarchy and reduce

waste generation'

Interactions identified

On

Agro4

'Domestic protein crops'

Agro5

'Reduce food waste'
Reducing waste might free up land that could be used for protein crops but only to a very limited extent. If the land is to be freed for protein crops, incentives are needed for efficient land use.

The waste hierarchy states that wastes should be avoided and reduced, therefore there is a strong synergy between adhering to the waste hierarchy and reducing food losses and wastes. 


\begin{tabular}{ll}
\hline Waste2 & Agro2 \\
'Encourage the & 'Healthy soils' \\
cascading principle & \\
taking into account & \\
all biomass-using & \\
sectors utilising & \\
biomass in the most & \\
resource-efficient & \\
way'
\end{tabular}

Agro3

'Domestic and organic fertiliser'

Agro4

'Domestic protein crops'

Agro5

'Reduce food waste'
Cascading biomass may result in more byproducts being directed to livestock feed and bioenergy over composting. The resulting products, manure and digestate prove easier to transport back to the soils where nutrients are needed.

However, if a high market value is placed on a biomass stream such as crop residues, this could threaten soil conservation. This is dependent on the practices applied to prevent soil degradation and under what type of farming system: organic, agroecological, circular etc.

Cascading biomass may mean using more waste biomass as livestock feed and bioenergy, resulting in manure and digestate but at lower quantities and in a less stable state than composting.

However, this is dependent on the priority that the cascading principle would place on organic fertiliser.

Reducing waste will free up land that could be used for protein crops but to a very limited extent. Freeing up land for protein crops requires incentives for efficient land use. In addition to above, protein-rich by-products should be directed to livestock feed under a cascading principle. If a cascading principle puts a priority on directing residual biomass towards feed, this may potentially improve feed security. It would also not be enough to address the current feed dependency.

Cascading biomass would mean that certain biomass streams will be utilised, translating into fewer food wastes and losses. There is a strong synergy between the cascading principle and reducing food losses and wastes. 


\begin{tabular}{|c|c|c|}
\hline $\begin{array}{l}\text { Waste3 } \\
\text { 'Recover energy only } \\
\text { from non-recyclable } \\
\text { materials' }\end{array}$ & $\begin{array}{l}\text { Agro2 } \\
\text { 'Healthy soils' } \\
\text { Agro3 } \\
\text { 'Domestic and } \\
\text { organic fertiliser' }\end{array}$ & $\begin{array}{l}\text { This is dependent on whether biomass is } \\
\text { considered a recyclable material. Since it } \\
\text { is likely a recyclable material, this may limit } \\
\text { bioenergy and incentivise the use of biomass } \\
\text { for soil fertilisation. }\end{array}$ \\
\hline $\begin{array}{l}\text { Waste } 4 \\
\text { 'Ban landfilling of } \\
\text { biodegradable waste } \\
\text { by } 2025 \text { ' }\end{array}$ & $\begin{array}{l}\text { Agro1 } \\
\text { 'Food security' }\end{array}$ & $\begin{array}{l}\text { Banning biodegradable waste may mean that } \\
\text { there is an incentive for these biomass streams } \\
\text { to be converted into food and feed, which may } \\
\text { help food security. However, if these biomass } \\
\text { streams are incinerated than there is no link to } \\
\text { food security. }\end{array}$ \\
\hline Goals & & Interactions identified \\
\hline Effect of & On & \\
\hline $\begin{array}{l}\mathrm{BIO} 2 \\
\text { 'Develop new bio- } \\
\text { based products and } \\
\text { materials' }\end{array}$ & $\begin{array}{l}\text { Agro3 } \\
\text { 'Domestic and } \\
\text { organic fertiliser' }\end{array}$ & $\begin{array}{l}\text { The development of new bio-based materials } \\
\text { may compete with the production of organic } \\
\text { fertiliser, particularly because in the initial } \\
\text { phases of development of bio-based products, } \\
\text { the more raw material is needed. }\end{array}$ \\
\hline $\begin{array}{l}\text { BIO4 } \\
\text { 'Replace fossil-based } \\
\text { products with bio- } \\
\text { based, recyclable and } \\
\text { marine-degradable } \\
\text { products' }\end{array}$ & $\begin{array}{l}\text { Agro3 } \\
\text { 'Domestic and } \\
\text { organic fertiliser' }\end{array}$ & $\begin{array}{l}\text { The development of new bio-based materials } \\
\text { may compete with the production of organic } \\
\text { fertiliser, particularly because in the initial } \\
\text { phases of development of bio-based products, } \\
\text { the more raw material is needed. Developing a } \\
\text { bio-based product that is marine degradable } \\
\text { may also need more raw material in the initial } \\
\text { phases of development. }\end{array}$ \\
\hline $\begin{array}{l}\text { BIO5 } \\
\text { 'Facilitate the } \\
\text { development of } \\
\text { new sustainable } \\
\text { biorefineries' }\end{array}$ & $\begin{array}{l}\text { Agro3 } \\
\text { 'Domestic and } \\
\text { organic fertiliser' }\end{array}$ & $\begin{array}{l}\text { The development of new biorefineries may } \\
\text { create competition across different biomass } \\
\text { applications, such as with the production of } \\
\text { organic fertiliser, particularly because in the } \\
\text { initial phases of development of bio-based } \\
\text { products, the more raw material is needed. }\end{array}$ \\
\hline
\end{tabular}




\begin{tabular}{|c|c|c|}
\hline $\begin{array}{l}\text { BlO6 } \\
\text { 'Changes in } \\
\text { consumption } \\
\text { promoting healthier } \\
\text { and more sustainable } \\
\text { diets }\end{array}$ & $\begin{array}{l}\text { Agro4 } \\
\text { 'Domestic } \\
\text { protein crops' }\end{array}$ & $\begin{array}{l}\text { Given current consumption patterns, increasing } \\
\text { domestic protein crop production while } \\
\text { maintaining the same levels of animal-source } \\
\text { food consumption will likely come with negative } \\
\text { environmental effects. On the other hand, if } \\
\text { the production of domestic protein crops is } \\
\text { matched with lower livestock demand, such for } \\
\text { example, feeding livestock only by-products of } \\
\text { crop production, these goals may be coherent. }\end{array}$ \\
\hline
\end{tabular}

\begin{tabular}{ll} 
Effect of & On \\
\hline ENV1 & Agro1 \\
'Decouple & 'Food security' \\
environmental impacts & \\
from a growing & \\
economy &
\end{tabular}

Agro2

'Healthy soils'

Agro5

'Reduce food

waste'

Agro6

'Resource

efficiency'
Food production has so far been closely

linked with environmental impact. However, food security encompasses more elements than production, such as access. Decoupling would, therefore, have no interaction with these elements of food security.

Decoupling growth from environmental impacts would have a positive impact on soils as production, even if increased, would have a limited environmental impact.

If the economy is to decouple from environmental impacts then a reduction in food losses and waste will be beneficial as this can mitigate several environmental impacts (e.g. water use)

If the economy is to decouple from environmental impacts then increased resource efficiency and improved nutrient cycling are essential. Economic development must come from the reuse and recycling of materials rather than the extraction of new materials. 


\begin{tabular}{|c|c|c|}
\hline \multirow[t]{2}{*}{$\begin{array}{l}\text { ENV2 } \\
\text { 'No net land take by } \\
2050 \text { ' }\end{array}$} & $\begin{array}{l}\text { Agro1 } \\
\text { 'Food security' }\end{array}$ & $\begin{array}{l}\text { To feed a growing population, increased land may } \\
\text { be needed, particularly if current consumption } \\
\text { patterns do not change. However, food security } \\
\text { is also about access and distribution, therefore } \\
\text { no net land may not have a large effect on } \\
\text { food security. Furthermore, if increased food } \\
\text { production is needed, many avenues are } \\
\text { possible to improve productivity. The protection } \\
\text { of land may safeguard important ecosystem } \\
\text { services, which may be more important in the } \\
\text { long-run. }\end{array}$ \\
\hline & $\begin{array}{l}\text { Agro2 } \\
\text { 'Healthy soils' }\end{array}$ & $\begin{array}{l}\text { If higher yields are needed on the same amount } \\
\text { of land, this goal may negatively impact soils as } \\
\text { this may imply land-use intensification. However, } \\
\text { this is highly dependent on the current use and } \\
\text { projected use of land. }\end{array}$ \\
\hline
\end{tabular}

\section{Effect of}

Energy1'

Achieve $32 \%$ of

overall gross energy

consumption by

2030 from renewable

energy'
Agro1

'Food security'

Agro3'

Domestic and

organic fertiliser'
This depends highly on the renewable energy source. If the $32 \%$ target is met with bioenergy, the potential constraints on land and therefore food are very high. The trade-off is expected to be far less with solar or wind.

It is likely that if organic fertilisers are produced from domestic sources, these will be the same feedstocks that could be used for biogas production to produce energy and reach the overall target and the transport target. This may limit the available option space for one goal or another. However, the use of agricultural wastes (e.g. forest felling) or organic fraction of municipal waste for biogas can have a dual purpose, for bioenergy and fertiliser.

Agro6 This goal can be achieved by recycling 'Resource efficiency' resources by converting biowastes to energy. However, closing nutrient cycles will be difficult. For example, ashes can be returned to soil from burnt biomass or digestate from digested biomass. However, this may be bulky. 


\begin{tabular}{lll}
\hline $\begin{array}{l}\text { Energy2 } \\
\text { 'Achieve 14\% of } \\
\text { transport (road and } \\
\text { rail) from renewable } \\
\text { energy }\end{array}$ & $\begin{array}{l}\text { Agro5 } \\
\text { 'Reduce food } \\
\text { waste' }\end{array}$ & $\begin{array}{l}\text { Food losses and wastes may be utilised to } \\
\text { produce biogas. }\end{array}$ \\
& $\begin{array}{l}\text { Agro6 } \\
\text { 'Resource } \\
\text { efficiency' }\end{array}$ & $\begin{array}{l}\text { This goal can be achieved by recycling } \\
\text { resources by converting biowastes to energy. } \\
\text { However, closing nutrient cycles will be difficult. }\end{array}$ \\
& & $\begin{array}{l}\text { For example, ashes can be returned to soil } \\
\text { from burnt biomass or digestate from digested } \\
\text { biomass. However, this may be bulky. }\end{array}$ \\
& & $\begin{array}{l}\text { If the transport target is met with advanced } \\
\text { biofuels, removing residues to make these }\end{array}$ \\
\hline $\begin{array}{l}\text { Energy3 } \\
\text { 'Incentivise biofuels } \\
\text { made from advanced } \\
\text { feedstocks through } \\
\text { double-counting their } \\
\text { energy content' }\end{array}$ & Agro2 & \\
\hline
\end{tabular}

\section{Uncertainty, knowledge gaps and context dependencies}

Despite finding that bioeconomy policy and agro-food policy is largely consistent or synergistic when considering the coherency score only (Fig 2.) It is also clear that there is significant uncertainty and disagreement amongst experts, particularly for some policy goals such as 'Domestic and organic fertiliser' and domains such as environment. This means that policies surrounding the bioeconomy are considered coherent for the most part in trying to balance the various biomass applications but many uncertainties and questions remain.

The focus groups revealed three uncertainties; first the feasibility of decoupling environmental impacts from economic growth, second, the future use of land and third, future human diets. Decoupling can be defined as either relative when economies grow faster than the rate of resource use and environmental impact, or absolute, when resource use and associated impacts decline in absolute terms irrespective of economic output (Ward et al., 2016). The range of score reflected disagreement on the possibility and extent to which decoupling is feasible, particularly on the debate on whether relative or absolute decoupling is possible (UNEP, 2014). Experts believed that so far, economic growth, material use and environmental impacts have gone hand-in-hand 
(O'Neill et al., 2018) and it is difficult to imagine a future where decoupling, particularly the absolute decoupling of environmental impacts from economic growth, would be possible. Such discussions reflect current scientific debates around the possibility of decoupling (Hatfield-Dodds et al., 2015; Ward et al., 2016), which have a long history in the wider question of whether environmental and economic goals can ever be reconciled. However, all experts agreed that if decoupling could be achieved, it would benefit all agro-food goals, particularly food security, soil health, reducing food losses and wastes and improving resource efficiency.

The future use of land was another source of uncertainty, where experts cited that this depended on future consumption patterns and the possibility of sustainable intensification and improved crop productivity. Projected future land use is at the heart of many agricultural, energy and climate models (Alexander et al., 2017; Prestele et al., 2016). It is also often cited as a key uncertainty in these models as land use depends on several factors, such as socio-economic and political aspects, consumption patterns and crop productivity (Holman et al., 2017). In the case of sustainable intensification, experts argued that this could reduce overall land-use but could come with trade-offs, such as impacting soil quality. In the case of improved crop productivity, experts cited considerable improvements in crop productivity in past years (Ritchie and Roser, 2019) and questioned the degree to which such a trend could continue (Ray et al., 2013; Zhao et al., 2017).

Closely related to land use, the successful implementation of some goals depended to a large extent on future human diets and consumption patterns, particularly the amount of animal-source food (ASF) in human diets. The transition to sustainable and healthy diets and its relation to increasing domestic feed crops for livestock in Europe, for example, (Bio6 on Agro4), depended to a large degree on the amount of ASF in human diets. Diets high in ASF are associated with higher land use (Gerbens-Leenes and Nonhebel, 2002; Ranganathan et al., 2016; Van Kernebeek et al., 2016; Van Zanten et al., 2019, 2018) and would therefore likely reduce the amount of land available to plant protein crops. Meeting livestock feed demands with domestic resources would be particularly difficult because the EU livestock sector is dependent on feed imports (de Visser et al., 2014; Lywood et al., 2009). However, a key opportunity for synergy between these two goals could be achieved if consumption patterns shift away from animal-source foods. If livestock are fed with by-products from food production and grasses, this could reduce land use and provide a domestic source of protein for livestock (Van Zanten et al., 2019).

It is difficult to overcome many of these uncertainties as they often depend on socio-economic and political drivers, particularly in the case of human consumption patterns, which may be difficult to predict. Nevertheless, these uncertainties point towards knowledge gaps in research. For example, it remains largely unknown how decoupling can be achieved, particularly in the context of the bioeconomy because it reintroduces increased dependence on natural resources (Giampietro, 2019). Moreover, knowledge is still limited on how the livestock sector can contribute 
to the bioeconomy; potential exists for scoping domestic sources of feed that improve nutrient cycling and reduce land use but further research is needed (Van Zanten et al., 2019).

As governments around the world and international organisations aim for increased coherence to meet multiple sectoral goals, science will be called upon to provide a robust knowledge-base. However, this will mean that both science and policy will have to contend with increased complexity as they seek to govern systems that cannot be predicted by studying the components that make up these systems (Geyer, 2012; Kovacic et al., 2019a; Strand, 2002). This will entail dealing with uncertainty, of which we identify different types following Kovacic et al., (2016), namely technical uncertainty, which is uncertainty emerging out of practical issues, methodological uncertainty, having to do with how phenomena are analysed, and epistemic uncertainty, having to do with how knowledge is framed and defined.

The uncertainties presented in this study are linked to different context dependencies namely implementation, temporal scale, geographical scale, and definition which we relate to different types of uncertainty. The policy goals presented above are stated goals in policy documents, however, implementing these goals will require a range of different agricultural and environmental practices. The degree to which these practices are implemented points towards technical uncertainty, as there is no guarantee whether or how these practices may be implemented. To prevent soil degradation and restore soils, for example, many different practices may be employed, such as crop rotation and no-till practices (Bai et al., 2018). Experts also emphasised that the interaction between goals will operate differently depending on the agricultural system. While some goals may be conflicting under current agricultural systems this may not be the case in the future if systems move towards other forms of farming, e.g. organic farming, circular food systems or farming based on agroecological principles (de Boer and Van Ittersum, 2018; FAO, 2016).

Temporal scale, that is the time over which two policy goals may interact, was also considered as important. Experts believed that some policy goals, such as preventing soil degradation, will become more important in the future, particularly if current rates of soil degradation continue (Gomiero, 2016). In the case of soils, experts believed that many other goals depended on healthy soils, particularly food security. The extent of soil degradation, currently and into the future, similar to projected land use, is a key source of uncertainty in predicting future food systems (Gomiero, 2016). Temporal scale will be particularly important for those interactions that do not take place in the short-to-medium term but appear after a significant time lag. Policy interactions also depend on the geographical scale, both in terms of implementation and in terms of effects. Firstly, interactions depend on where the policy goals would be implemented. For example, experts argued that while the Netherlands may have enough manure available to meet both energy and soil fertility needs, this might not be the case elsewhere in Europe. Experts also doubted whether the effects of EU policies outside of the EU should be considered in the assessment. Experts 
argued the production of food waste in EU countries and their notable role in food trade (Porkka et al., 2013), affects the food security of countries elsewhere by externalising the environmental impacts of food production (Chaudhary and Kastner, 2016; Lambin and Meyfroidt, 2011; Meyfroidt et al., 2010), thereby degrading agricultural resources needed to produce food for local markets. However, the knowledge base of the effect of food waste in developed countries on the food security of food-producer countries in the Global South is still under-researched but some studies indicate lower-food waste in developed countries may provide economic benefits in developing countries (Ishangulyyev et al., 2019). Furthermore, food that is unwanted in EU countries due to consumer preferences may be exported to developing countries where they disturb local markets (Murphy and Hansen-Kuhn, 2019).

For some domains, particularly that of energy, experts felt that while policies could be coherent at a local level, once upscaled, any synergistic effects may be reversed. In the context of waste and residue-based biofuels, synergies could be observed at a local scale. For instance, waste and residue-based biofuels or 'advanced biofuels' have the potential to avoid sustainability issues associated with conventional, food and feed crop-based biofuels, such as land-use change, increased greenhouse gas emissions and induced higher food prices (Persson, 2013; Popp et al., 2014; Steinbuks and Hertel, 2016). In the case of conversion of wastes, such as municipal wastes and manure, into biogas, this can have the dual advantage of providing both energy and organic fertiliser and offsetting greenhouse gas emissions from manure storage (Bidart et al., 2014; Parajuli et al., 2018; Tonini et al., 2016). However, the degree to which the renewable energy target can be supplied by advanced biofuels is limited. This is due to several factors, such as the limited supply of wastes and residues, other competitive uses for these residues (David Styles et al., 2015; Tufvesson et al., 2013) (e.g. feed, application to soil) and high energy and infrastructural requirements to collect wastes and residues. Furthermore, experts questioned whether bioenergy should be based on wastes and residues, given that following the waste hierarchy, the first incentive should be to avoid the production of wastes.

We found a wide range of scores associated with terms with unestablished definitions, such as the 'cascading principle'. Issues of definition point towards uncertainty of an epistemological nature where how the scientific analysis or policy goal is framed determines the knowledge acquired. This can be seen for example in the interaction between 'Encourage the cascading principle taking into account all biomass-using sectors utilising biomass in the most resource-efficient way' and 'Preventing soil degradation'. While the general principle behind the cascading principle is understood as utilising biomass at its highest utility, there is uncertainty about what highest utility may imply, particularly which biomass use corresponds to the highest utility. The strong synergy between the waste hierarchy and the reduction of food losses and wastes (Waste1 on Agro5) may indicate that having a clearly defined order for the utilisation of biomass (waste in this case), can have beneficial effects. This also points towards the vagueness in the definition of policy 
goals, which means that effects largely depend on context and implementation rather than the coherency between different policy domains. Confidence levels, for example, were particularly low for waste and bio-based industry policy domains when scored against Agro3 'Domestic and organic fertiliser'. The lack of clarity regarding what it means to cascade biomass (Waste2), sustainably scale biomass supplies (Bio1) or develop biorefineries (Bio5) led to low scores of confidence. Issues of scale, temporal, geographical and biophysical depend greatly on the nature of the analysis, particularly with the challenges of estimating interactions separated by time and space. Issues of scale, therefore, point towards methodological uncertainty.

\section{Discussion}

The aim of our study was twofold: to assess the effect of bioeconomy policy domain on agrofood policy by presenting whether they are coherent (trade-offs, synergies) and mapping out key interactions and uncertainties. Figure 2, 3 and Table 2 present the results of our survey and focus groups conducted with experts. The overall results indicate that when considering the coherency score, policies can be considered coherent and that synergies largely outweigh trade-offs. However, digging further into the range of scores and confidence levels by experts, the picture becomes more complex. The inclusion of both range of scores and confidence levels allowed us to see both where there are knowledge gaps and uncertainties (confidence) and where experts may have high confidence but disagree (range). We suggest that these measures of uncertainty and disagreement be included in future assessment of policy coherence. The knowledge base regarding policies is more certain around high-priority goals such as food security and the reduction of food waste, particularly between the waste, energy and bio-based policy domains. Our results show that key knowledge gaps remain in the waste and bio-based policy domains, particularly due to the gaps in the knowledge-base around biorefineries, bio-based products and how to increase domestic organic fertiliser. Experts particularly disagreed regarding the possibility of decoupling economic growth from environmental impacts and the possible impacts or benefits of healthy and sustainable diets.

However, sometimes disparity in expert opinion could be explained through the lack of definition and vagueness of terms/goals. We have shown that this vagueness makes it difficult to assess the coherency of these policy goals as their coherence depends on several context dependencies such as temporal and geographical scale which will affect implementation. This raises the question, what does policy coherence mean in the context of this study? We argue that assessing policy coherence is not as straightforward as matching policy goals with scientific evidence (International Council for Science, 2017; McCollum et al., 2018). To this end, frameworks have been proposed such as the 'water-energy-food' nexus to overcome silo, top-down, linear governance models. While initiatives to break down silos and apply more integrative approaches such as the 'nexus' approach 
should be lauded, initial evidence indicates that more will be needed to overcome these silos in institutional settings (Voelker et al., 2019). This indicates that overcoming such silos will require more than technical fixes (Voelker et al., 2019). As argued below, this will mean overcoming vague terms for better assessment. Other studies have shown how undefined terms in policy may aid the political process (Candel et al., 2014; Kovacic and Di Felice, 2019), however, a distinction needs to be made between ambiguity and vagueness. Our study has found both ambiguity rising out of uncertainty and vagueness; following Kovacic and Di Felice, (2019), we differentiate between vagueness in policy goals, which may serve political purposes, and ambiguity, which arises necessarily out of the complexity, uncertainty and incommensurable frames in scientific knowledge. Vagueness should be overcome with better definitions. Ambiguity, on the other hand, may broaden the space for a multitude of stakeholders and innovations to take hold (Kovacic and Di Felice, 2019; Termeer and Metze, 2019). However, this may go against the expectations of some institutional actors who may expect quick, deep, top-down transitions (Termeer and Metze, 2019) and may explain why 'overcoming silos' has so far not been fully successful (Voelker et al., 2019).

\section{Insights and recommendations for science and policy}

The presence of trade-offs between bioeconomy policy domains and agro-food policy domains shows that scientists and policy-makers will need to overcome 'silo-thinking' to find integrative solutions. However, our results point towards silo-thinking being difficult to overcome since policy success will depend greatly on how goals are defined and particularly on context-dependencies such as temporal and geographical scale. Science is furthermore either replete with uncertainty regarding some issues (e.g. potential effects of bio-based industry) or with disagreement (e.g. decoupling). It is therefore imperative that specific policy domains are designed with potential interactions with other policy goals in mind. Furthermore, increased awareness is needed that overcoming 'silo-thinking' is more than a technical issue as argued above. The best way forward may be in overcoming vagueness, by better defining terms, and embracing ambiguity, which allows for different stakeholders to take part in a transition towards a bioeconomy.

Vagueness, for example, can be overcome in the case of the cascading principle. While the EU has clear guidelines for the various uses of waste biomass, there are no such clear guidelines for biomass in general. The waste hierarchy, as defined in the Waste Framework Directive (Directive 2008/98/EC, 2008), states that waste biomass must be utilised for different purposes before being used for energy. The cascading principle, which aims to direct biomass towards its highest utility use to boost resource-use efficiency, does not yet have a clear definition. More importantly, incentives in renewable energy policy, particularly in the Renewable Energy Directive (European Parliament, 2009), direct biomass to energy use first. Furthermore, the double-counting 
mechanism, which double-counts the energy content of biofuels made from wastes and residues towards the renewable target, similarly incentivises biomass towards energy use before other uses (Birdlife Europe and European Environmental Bureau, 2014; Dammer and Essel, 2015). In practice, this may lead to competition issues between other uses of residues, e.g. crop residues could be utilised to maintain and improve soil health. There is a clear trade-off between making a goal-specific, allowing for clear implementation and assessment and making a goal broader to gain political agreement and allow space for various solutions (Candel et al., 2014; Kovacic and Di Felice, 2019). However, from this assessment, it is clear that some terms would benefit better definition and better integration between the various policy domains. The EU would benefit from having general guidelines for the cascading of biomass, beyond that specifically related to waste. Our results show, that if well implemented, proper cascading use of biomass could create synergies and improve soils, food security and reduce food losses and wastes.

Furthermore, increased awareness is needed about the limitations of some solutions. While waste and residue-based biofuels, or 'advanced biofuels' have the potential to avoid sustainability issues associated with conventional biofuels the degree to which the renewable energy target can be supplied by advanced biofuels is limited. It is therefore imperative that the scale to which technologies can solve sustainability issues is communicated between science and policy.

Finally, our results have relevance for governance as policy shifts away from silo approaches and to more integrative policy-making, such as the Sustainable Development Goals or the water-energyfood nexus. The multiple sources of uncertainty, spanning across different types of uncertainty, namely technical, methodological and epistemic, mean that the relationship between science and policy should not be treated as a puzzle-solving exercise. Instead, a more flexible approach should be taken to decision-making that adapts to difference scales, contexts and practices. The sciencepolicy interface under a 'silo' approach was characterised by a linear relationship between science and policy, where science presents the facts and policy defines goals accordingly. However, recognising the interlinkages between different policy sectors means that governance will have to take place under uncertainty and thereby complexity (Kovacic et al., 2019a).

\section{Conclusions}

Our research shows that considering the coherency score only, bioeconomy and agro-food policy could be considered either synergistic or not interacting by experts. Overall, the waste policy domain provided the most opportunity for synergies with agro-food goals. The agro-food goals of food security and reducing food waste have the most potential for synergies if other goals such as reducing waste, using underutilised residues and cascading of biomass are achieved. Our inclusion of experts' disagreement, confidence, as well as focus groups, however, revealed that 
policy interactions may be more complex. The knowledge base is more certain around goals such as food security and reducing food waste but less so around the increase of domestic organic fertiliser. Particularly, our policy coherency analysis revealed key uncertainties such as projected future land use, future human diets and the feasibility of decoupling. This left room for ambiguity and vagueness. We argued that ambiguity was largely associated with the complexity of the issues, while vagueness with undefined policy terms. We conclude that vagueness in policy may be overcome through better definition of terms, particularly that of the cascading principle, which has a high potential for synergies with agro-food policy. However, "nexus" policy requires also working within uncertainty and adapting policy to different contexts, temporal and geographic scales, and implementation practices, rather than pursuing universal fixes.

\section{Acknowledgements}

This project has received funding from the European Union's Horizon 2020 Research and Innovation Programme under grant agreement No. 689669. The present work reflects only the authors' views and the Funding Agency cannot be held responsible for any use that may be made of the information it contains. The authors would like to thank all the experts who participated and contributed to this study and to thank Dr Ali Leylavi Shoushtari for help with the design of the figures. 
Appendix 2.1. 41 documents across the 5 policy domains included in this study

\begin{tabular}{|rl|}
\hline EU Waste Policy \\
\hline 1. & Waste Framework Directive (Directive 2008/98/EC) \\
\hline 2. & $\begin{array}{l}\text { Commission Communication Towards a circular economy: A zero waste programme } \\
\text { for Europe (2014) }\end{array}$ \\
\hline 3. & Commission Communication Roadmap to a Resource Efficient Europe (2011) \\
\hline 4. & $\begin{array}{l}\text { Commission Communication Closing the Loop-An EU action plan for the Circular } \\
\text { Economy (2015) }\end{array}$ \\
\hline 5. & $\begin{array}{l}\text { Commission Communication A European Strategy for Plastics in a Circular Economy } \\
(2018)\end{array}$
\end{tabular}

\section{EU Bio-Based Industry Policy}

6. Commission Communication A lead market initiative for Europe (2007)

7. Commission Communication A Stronger European Industry for Growth and Economic Recovery (2012)

8. Commission Communication Innovating for sustainable growth: a bioeconomy for Europe (2012)

9. Commission Communication For a European Industrial Renaissance (2014)

10. Commission Communication A sustainable bioeconomy for Europe: strengthening the connection between economy, society and the environment (2018)

\section{EU Renewable Energy Policy}

11. Commission Communication Biomass Action Plan (2005) [included for background info only]

12. An EU Strategy for Biofuels (2006) [included for background info only]

13. Cleaner fuels for road transport (Directive 2009/30/EC)

14. Commission Communication Energy Roadmap 2050 (2011)

15. Commission Communication Accounting for land use, land use change and forestry (LULUCF) in the Union's climate change commitments (2012)

16. Commission Communication European Energy Security Strategy (2014)

17. Commission Communication A Framework Strategy for a Resilient Energy Union with a Forward-Looking Climate Change Policy (2015)

18. Indirect Land-Use Change Directive (Directive (EU) 2015/1513)

19. Commission Communication Accelerating Europe's transition to a low-carbon economy (2016)

20. REGULATION OF THE EUROPEAN PARLIAMENT AND OF THE COUNCIL on the Governance of the Energy Union (2017) 
21. Renewable Energy Directive Final Compromise Text (2018)

\section{EU Environment Policy}

22. Water Framework Directive (Directive 2000/60/EC)

23. Commission Communication Thematic Strategy on the sustainable use of natural resources (2005)

24. Commission Communication Our life insurance our natural capital: an EU biodiversity strategy to 2020 (2011)

25. Seventh Environment Action Europe 'Living well, within the limits of our planet' (2013)

\section{EU Agro-food Policy}

26. Commission Communication Thematic Strategy for Soil Protection (2006)

27. Commission Communication Tackling the challenge of rising food prices Directions for EU action (2008)

28. Commission Communication Addressing the challenges of deforestation and forest degradation to tackle climate change and biodiversity loss (2008)

29. Commission Communication The CAP towards 2020: Meeting the food, natural resources and territorial challenges of the future (2010)

30. Commission Communication An EU policy framework to assist developing countries in addressing food security challenges (2010)

31. Increasing the impact of EU development policy: an agenda for change (2011)

32. Commission Communication Reform of the Common Fisheries Policy (2011)

33. Commission Communication Blue Growth Opportunities for marine and maritime sustainable growth (2012)

34. Commission Communication A new EU Forest Strategy: for forests and the forestbased sector (2013)

35. Commission Staff Working Document Multi-annual Implementation Plan of the new EU Forest Strategy (2015)

36. Joint Communication International ocean governance: an agenda for the future of our oceans (2016)

37. Joint Statement THE NEW EUROPEAN CONSENSUS ON DEVELOPMENT 'OUR WORLD, OUR DIGNITY, OUR FUTURE' (2017)

38. Encouraging the production of protein and leguminous plants in the European agriculture sector $(2017 / 2116 \mathrm{INI})$

39. Commission Communication: The Future of Food and Farming (2017)

40. Legislative Train Schedule, Review of the Fertilising Products Regulation, (2018)

41. CAP Strategic Plans -Proposal for a regulation COM (2018) 392 



\title{
Chapter 4
}

\section{The Promised Land:}

\section{Contrasting frames of marginal land in the European Union}

\begin{abstract}
A. Muscat ${ }^{a}$, E.M de Olde ${ }^{a}$, J.J.L. Candel ${ }^{b}$, I.J.M de Boer ${ }^{a}$, R. Ripoll-Boscha
\end{abstract}

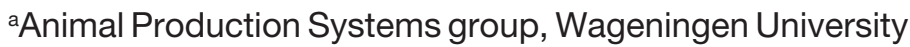
\& Research, P.O. Box 338, $6700 \mathrm{AH}$ Wageningen, the Netherlands

bPublic Administration and Policy group, Wageningen University \& Research, P.O. Box 8130, 6700 EW, Wageningen, the Netherlands 


\section{Abstract}

Appropriating marginal land is seen as a way to overcome a wide range of land-use debates such as food-feed-fuel competition, avoiding land abandonment, and preserving nature. As a result, there is growing interest in policy and academic communities to identify, define and measure the potential of marginal land to overcome these debates. However, multiple definitions of marginal land exist due to the various ways of framing the problems and solutions marginal land can address. To explore the competing claims on marginal land in these frames, we performed a framing analysis of EU policy debates about marginal land. Through this analysis, we find that different actors have conflicting ways of framing what problem marginal land can address and what course of action to take. These frames do not overcome but form part of contested land-use debates already present in Europe. Exact definitions or estimations of marginal land are unlikely to overcome land-use debates because land-use decisions are subject to the same competing claims and hence normative decisions as land-use decisions around productive land. These marginal land frames reflect a vision for how land should be used; for food, feed, fuel or nature. Given the potential policy impact of these visions, we argue that deliberative science-policy relationships are needed to deal with ambiguity. 


\section{Introduction}

Land is a finite and scarce natural resource. Increased demands for food, feed, bioenergy and biobased products, as well as other competing claims on land, exacerbates this land scarcity (Giller et al., 2008; Muscat et al., 2020). Land is needed, for example, to preserve habitats, regenerate ecosystems and sequester carbon to address challenges such as biodiversity loss and climate change (Bryan et al., 2016; Usubiaga-Liaño et al., 2019). This, along with other drivers such as urbanisation or infrastructure development, results in many competing claims for land and causes competition with food production. This competition, in turn, is associated with sustainability issues, such as induced greenhouse gases through land-use change (LUC) and rising food prices (Fargione et al., 2010; HLPE, 2013; Lapola et al., 2010; Timilsina et al., 2012). These interlinked challenges have led to debates about the most sustainable use of land.

Debates about more sustainable use of land in the European Union (EU) have centred on several issues. Since the 2008 food price crisis, where biofuel production was thought to be contributing to rising food prices and food insecurity (Rosegrant and Msangi, 2014), these land-use conflicts have taken centre stage in EU policy-making. The 2008 fears surrounding the effect of biofuels on food security and development, led to discussions of moving away from food-and-feed-crop-biofuels (e.g. maize-based ethanol) to dedicated energy crops and waste-based biofuels. This was thought to avoid competition with food production and avoid food price impacts. However, controversy remained around the potential effect of these biofuels on LUC and greenhouse gas (GHG) emissions, particularly in the revision of the Renewable Energy Directive (Di Lucia et al., 2012a). Besides moving away from food-based biofuels, incentives were introduced to grow bioenergy feedstock on marginal land.

In the run-up to the release of the EU's Green Deal and the Farm to Fork Strategy, debates also surfaced about the pathways to sustainable food systems, in both science and policy. Both scientists and policy-makers debated the relationship between food consumption, livestock and land use (Foote, 2020; Kollenda, 2020). Alongside these debates, other trends in Europe such as land abandonment in rural areas, biodiversity loss and climate change have reinvigorated debates about the need to preserve land for rural development, nature conservation or carbon sequestration, all while avoiding competition with food production (Benayas and Bullock, 2015; Garnett et al., 2017). Such issues resurfaced particularly in the context of how to align the Common Agricultural Policy (CAP) with the Green Deal (Schebesta and Candel, 2020). Marginal land often featured in these discussions as a solution.

In response to the competition for land, making use of marginal land is often advocated as a solution to achieve these bioenergy, biodiversity or carbon sequestration goals without impacting 
food production (Shortall, 2013). The importance of these issues in policy agendas, both inside and outside EU institutions, has sparked academic interest in defining, identifying and testing the viability of marginal land as a solution. Despite these efforts, marginal land remains poorly or ambiguously defined (Shortall, 2013). Furthermore, formulations around marginal land can be contradictory. For example, some definitions frame marginal land as ideal for bioenergy crops while others argue bioenergy crops are not suitable for such land (Andersen et al., 2005). Definitions may focus on biophysical limitations, such as soil quality or economic limitations such as distance from key markets. Furthermore, such definitions may include many different types of land, from abandoned agricultural land to degraded land or grasslands (Shortall, 2013). This ambiguity allows for different expert communities and policy stakeholders to lay claim to marginal land as a solution (Muscat et al., 2020).

To this end, we are interested in understanding the role of marginal land at the centre of these debates by examining how different actors in science and EU policy-making frame this land. We particularly focus on the EU given its prominent role in land-use debates (Di Lucia et al., 2012b; Gamborg et al., 2012). Our aim for this paper is to better understand the multiple frames of marginal land by analysing how different actors frame both the problems and solutions surrounding marginal land.

Previous studies have highlighted the complicated assumptions that underlie definitions and spatial mapping of marginal land (Nalepa and Bauer, 2012a; Shortall, 2013) and focused on stakeholder views of marginal land (Helliwell, 2018; Shortall et al., 2019b; Skevas et al., 2016). However, these have so far not focused on analysing the ambiguous idea of marginal land around set narratives and related these to current policy discussions. This paper, therefore, contributes to ongoing discussions about the role of ambiguity and frames in policy-making. The paper is thereby organised as follows: in section 2, we delineate our theoretical framework focusing on the role of framing and ambiguous ideas in policy-making. Section 3 sets out the EU policy context, addressing the key policy debates in which the frames we present in section 5 are placed. Section 4 sets our methodological approach and section 5 presents the results organised in eight frames surrounding marginal land. Finally, in section 6 we discuss our results and present our conclusions. We argue that exact estimations of marginal land are unlikely to fix controversies on land-use due to the inherent ambiguity of marginal land. We conclude with a critical reflection on the marginality of land and by discussing how to deal with contested frames and ambiguity in policy-making.

\section{Framing marginal land}

The multiple framings and representations of marginal land that are produced by different actors reinforce the construction of land-use competition as a challenge to be governed. Despite the many attempts to define marginal land, the concept remains elusive (Nalepa and Bauer, 2012b; Shortall, 
2013). According to Dewulf et al. (2005), ambiguity emerges from different ways of framing an issue; this makes it unclear what the problem is as well as who and how it needs to be addressed. Ambiguity has also been defined as a source of uncertainty or as a form of uncertainty itself. Ambiguity can be distinguished from other forms of uncertainty, such as variability uncertainty, which relates to the inherent changeability of a given system, and epistemic uncertainty relating to imperfect knowledge which can be reduced through better research practices (Brugnach et al., 2008; Klinke and Renn, 2002; Walker et al., 2003).

Ambiguous ideas in policy-making have been widely studied in the social science and governance literature under several theoretical umbrellas, particularly in the governance under complexity literature (Kovacic and Di Felice, 2019; Stirling, 2010). Ambiguity can be a problem in governance as much as serve multiple purposes. For example, ambiguous ideas may act as coalition builders (Hannah, 2020) or act as 'consensus frames' (Candel et al., 2014). This means that ambiguous ideas can build coalitions amongst different stakeholders when political solutions need to be found, leaving the option-space open when there is uncertainty about the appropriate technology or policy intervention (Beck and Mahony, 2018; Hannah, 2020; Kovacic and Di Felice, 2019; Stirling, 2010). Consensus frames are powerful concepts that can act as a rallying cry for collective action, even if they may hide disagreements (Mooney and Hunt, 2009). Additionally, ambiguous ideas may help find solutions in cases where science may not be able to provide clear-cut answers due to the complex nature of the problem, leading to uncertainty and incommensurability in the knowledgebase, especially when there are equally valid but competing frames and values.

Frames have been shown to have a considerable impact on the policy process and the institutionalisation of ideas (Béland and Cox, 2016; Felt et al., 2007; Hannah, 2020). Particularly, the role of ambiguous ideas as narrative or frame is important to understand given their 'performative power' (Beck and Mahony, 2018) in bringing about technologies, pathways or solutions into being. Such ambiguous ideas are crucial to understanding their role in finding a way out of 'wicked problems' such as land-use competition. However, they may also obfuscate inaction and ineffectiveness by giving the impression something is being done (Hannah, 2020; Kovacic and Di Felice, 2019).

The concept of frames has been utilised across several scientific disciplines, such as communication science, psychology and political science. While the exact definition of a frame can change depending on the discipline, frames, in general, can be defined as the selection of 'some aspects of a perceived reality... in such a way as to promote a particular problem definition, causal interpretation, moral evaluation, and/or treatment recommendation' (Semetko and Valkenburg, 2000), citing also Entman, 1993: p. 53). Two approaches to framing can be distinguished: cognitive framing and interactional framing (Dewulf et al., 2009). While cognitive approaches focus on mental models or cognitive structures an individual may have of a given situation, interactional framing 
focuses more on the communicative and discursive process by which meaning is produced (Isendahl et al., 2009). In this paper, we focus on interactional framing.

Frames can be operationalised by a frame package, which is a set of logical devices that serve as an identifier for that particular frame (Van Gorp, 2006). An entire frame package can contain a core frame, linguistic devices, such as vocabulary, metaphors or images, and reasoning devices. In this study, we were primarily interested in reasoning devices. Reasoning devices are the explicit or underlying statements that connect causes with consequences in order and essentially trace out causal reasoning (Van Gorp and van der Goot, 2012). These devices can trace the cause of the problem as well as potential solutions.

\section{EU policy and research context}

Frames do not take place in isolation but often relate to wider scientific and policy discussions. The framings on marginal land found in this paper relate to four discussions which are taking place within the EU policy context, namely i) biofuels and indirect land-use change (ILUC); ii) the impact of biofuels on development; iii) land abandonment and rural development; and iv) livestock and sustainable food systems.

\section{i) Biofuels and indirect land-use change}

The utilisation of marginal land has been suggested as one potential solution for the problem of indirect land-use change. In 2003, the EU established a biofuels policy, primarily to reduce GHG emissions in the transport sector. Critics accused the policy of inducing both direct and indirect land-use change (ILUC). Direct land-use change is when land is converted from one use to another, in this case, for bioenergy production. Indirect-land use change is when land-use changes take place due to bioenergy production, but the land-use changes are geographically disconnected due to a complex cascade of effects. These land-use changes are associated with the release of GHG emissions and may therefore reduce the climate mitigatory effects of biofuels (Berndes et al., 2015). However, while NGOs pushed the EU Commission to ban ILUC-inducing biofuels, the biofuels industry argued that it created many jobs in European rural areas (European Bioeconomy Alliance, 2020; Kent, 2016). In 2012, the European Commission presented a legislative proposal to address some of these concerns while preserving existing investments. It proposed capping food-based biofuels and promoting advanced biofuels (non-food and feed biofuels) made from wastes and dedicated energy crops. After several years of deliberations and controversies, the revised Renewable Energy Directive (The European Parliament and the Council of the European Union, 2018) entered into force in 2018, introducing caps on food-based biofuels and encouraging incentives for advanced biofuels, especially if grown on marginal land. The directive remains a 
bone of contention between different stakeholders, with the bio-based industry arguing policy is too harsh and too changeable and environmental NGOs warning that not enough has been done to address the negative environmental effects of biofuels (Pilgrim and Harvey, 2010). Particularly, the question remains whether marginal land can prove to be a solution to ILUC.

\section{ii) Biofuels and development}

Another controversy surrounding bioenergy and land-use is the effect of biofuels on development, particularly on food prices, food security and rural development outcomes in low-income countries. Biofuels are thought to contribute to rural development in low-income countries by providing additional income to farmers and creating new jobs in rural areas. Incomes can be particularly improved in marginal land where lower-productivity means lower incomes. However, the increase of prices in agricultural commodity prices in 2007/2008 led to discussions about revisiting the EU 2003 biofuel policy and later on to the revised Renewable Energy Directive (RED) which contains caps for food-based biofuels. Many NGOs argued that there should be a complete ban on biofuels as in reality they do not bring rural development but induce a rush for land and land grabbing. While marginal land is considered a solution to avoid high food prices, some NGOs argued that marginal land is utilised to justify further land grabbing (Borras Jr et al., 2017).

\section{iii) Land abandonment and rural development}

Marginal farmland in Europe is at increased risk of abandonment. Farmland abandonment has been a key issue in CAP discussions for many years and has been discussed in both policy and scientific circles. Land abandonment refers to the abandonment of land that was previously used for crops or pasture and has multiple causes, such as areas with natural constraints limiting economic viability or economic migration to urban centres (Munroe et al., 2013). It is assumed that in the EU, approximately $11 \%$ of all farmland is at risk of abandonment (Joint Research Centre, 2018). The loss of farmland is seen as a problem given the impact on rural communities, where primary income from farming for people living in rural areas is lost, as well as traditional forms of farming which may be 'High Nature Value' (Lomba et al., 2020). High Nature Value farming is a term often utilised in this frame to refer to low-intensity farming systems spanning large rural areas and has become a term that is enshrined in EU policies such as the Birds and Habitats directives and the CAP. Policies and subsidies, such as Less Favoured Areas (LFAs) subsidies (LFAs-Regulation 1257/1999), have been designed to support farmers in marginal areas and prevent farmland abandonment. Others argue that rewilding in marginal land could be a solution to European farmland abandonment, which may yield additional benefits for biodiversity (Benayas and Bullock, 2015). 


\section{iv) Livestock and sustainable food systems}

Increasingly, there is an interest in food systems approaches, both in science and in policy (Fanzo et al., 2020; FAO, 2018). As part of a move towards looking at food and agricultural sustainability from a systems-wide perspective, a discussion formed about the role of livestock, particularly concerning land-use and GHG emissions (Van Zanten et al., 2018). Marginal land in such discussions often come up as a way to by-pass the high land use of livestock systems (Mottet et al., 2017; Van Zanten et al., 2018).

Within EU policies, such discussions appeared in the EU Green Deal; particularly within the Farm to Fork Strategy (European Commission, 2020) which was released in 2020 to make food systems fair, healthy and environmentally-friendly. The strategy was released in part as a response to calls from NGOs and scientists to create a common food policy that looked at the entire food system and went beyond the CAP (De Schutter et al., 2020; Schebesta and Candel, 2020). The Farm to Fork Strategy was also a result of long ongoing discussions some of which centred around the role of livestock in a sustainable food system. The Strategy itself aims to direct consumers towards alternative proteins and strictly re-assess coupled support for livestock production, focusing only on the most sustainable forms of livestock production. Within food systems research, livestock systems are considered as a source of competition for resources between food for humans and feed for livestock (Mottet et al., 2017). Marginal land is largely recommended as a way to avoid the effects of food-feed competition while utilising biomass from marginal land.

These discussions may in turn reflect wider paradigms and themes that characterise discussions about land, food and agriculture in general (Sexton et al., 2019; Shortall et al., 2019a). In the results section, we place these frames in these wider discussions, looking at which actors utilise these frames while in the discussion we delineate how these frames reproduce wider paradigmatic discussions about land, food and agriculture.

\section{Material and Methods}

\subsection{Document Selection}

To better understand how marginal land is framed in debates about land use, we collected policy documents from EU institutions and other important stakeholders such as NGOs and farmers groups as well as scientific documents. We utilised the keyword 'marginal land' for all databases used. For policy and stakeholder documents, we used the EU databases EURLEX and Knowledge 4 Policy. As we were also interested in how marginal land is framed in broader EU policy debates, 
not just within EU institutions, we also included news articles from LexisNexis and position documents from NGOs and lobby groups, which were searched via Google. Only the first 10 pages of hits were included in the search. For scientific documents, we used Scopus as well as websites of EU-funded projects about marginal land from Google searches and snowballing technique (expanding document list by utilising references in original documents). In Scopus, we used the queries "marginal" AND land". Only the first 200 results were collected from Scopus, as in the course of document analysis (section 3.2) no new themes were being added beyond this point. We ordered these results based on the following criteria: only English, published after the year 2000, only results with a European location were displayed, only papers and book chapters, and results were ordered by relevance. Following data saturation guidelines for qualitative research (Saunders et al., 2018), we furthermore ensured data saturation by looking for data that we may have missed by looking at key citations in the field and diversifying our list of actors. Documents were selected based on the following selection criteria: a) must form part of EU policy debates by referring to EU land issues or policies; b) must contain a full causal narrative, i.e. identifies what the problem is that the use of marginal land is addressing, the proposed solution and proposed use for the land; c) contains some definition of what is marginal/why it is considered 'available'; $d$ ) must be in English and e) must be after the year 2000. The final selection yielded a total of 82 documents across several actors (Table 1).

Table 1. Final selection of documents. Type of documents, number of documents and source of documents

\begin{tabular}{lll}
\hline Document & Number & Source \\
\hline Scientific papers & 37 & Scopus \\
EU project communications & 13 & Google Search, Project websites \\
EU Commission Communications & 12 & EURLEX, Knowledge4Policy \\
Actor position papers groups websites, & 10 & Google Search, NGO/Farmer's \\
News Articles & 6 & $\begin{array}{l}\text { Google search, LexisNexis, News } \\
\text { Cobsites }\end{array}$ \\
European Parliament Resolutions & 1 & Google search, EURLEX \\
Court of Auditors reports & 2 & EURLEX \\
& 1 & EURLEX
\end{tabular}




\subsection{Document Analysis}

To analyse the documents, we utilised a frame package analysis (Van Gorp and van der Goot, 2012) and analysed them in qualitative analysis software, Atlas.ti (Friese, 2012). To achieve this, we coded the documents for the problem definition (what problems do marginal land solve or not solve), what land is considered marginal, which goals can using marginal land help achieve, how can these goals be achieved (e.g. which policy interventions or agricultural practices), nonsolutions (e.g. when an actor identifies a previous solution as not working) and who is making the statement. The coding structure used a combination of deductive and inductive coding through a preset codebook relating to the criteria mentioned above as well as emerging themes (Fereday and Muir-Cochrane, 2006). We furthermore assessed the solutions and non-solutions to address key conflicts between frames, using conflict matrices.

\section{Results}

In this section, we present the results of the framing analysis. Our analysis yielded a total of eight frames that are utilised to talk about marginal land in the European science and policymaking arena. An overview of these frames and their associated actors are presented in Table 2 below. We find that the proponents of the Sustainable Bioenergy frame represented the majority of the actors. Many frames had diverse actors, coming from both science and policy stakeholder groups. Only two frames (Marginal land Critique, Low-Cost Livestock) were used by scientific actors alone.

Table 2. Breakdown of actors by frame. Number and type of actors and percentage of the total amount of actors per frame

\begin{tabular}{lll}
\hline Frame & Who & $\begin{array}{l}\text { How many (\% of } \\
\text { total actors) }\end{array}$ \\
\hline Sustainable Bioenergy & $\begin{array}{l}\text { EU Commission (1), EU projects (1), } \\
\text { Scientific papers (25), Nature and } \\
\end{array}$ & $41(60 \%)$ \\
& $\begin{array}{l}\text { Environment NGOs (4), National Politician } \\
\text { (1), Bio-Based Industry (1), Farmer's }\end{array}$ \\
& groups (1), EU projects (4), Scientific \\
& lobby (1),
\end{tabular}




\begin{tabular}{|c|c|c|}
\hline Rural Development & $\begin{array}{l}\text { Farmer's Groups (1), Social Enterprises } \\
\text { (1), EU Commission (1), EU news portals } \\
\text { (1), Scientific papers (2), European } \\
\text { Parliament (1), Court of Auditors (1) }\end{array}$ & $8(12 \%)$ \\
\hline Ecosystem Restoration & EU projects (2), Scientific papers (4) & $6(9 \%)$ \\
\hline Precautionary Principle & $\begin{array}{l}\text { Nature and Environment NGOs (1), } \\
\text { Consultancies (2), Green MEP (1) }\end{array}$ & $4(6 \%)$ \\
\hline Low cost Livestock & Scientific papers (3) & $3(4 \%)$ \\
\hline Marginal Land Critique & Scientific papers (2) & $2(3 \%)$ \\
\hline Food Security & EU Commission (1), Scientific papers (1) & $2(3 \%)$ \\
\hline Land Rights & $\begin{array}{l}\text { Nature and Environment NGOs (1), Land } \\
\text { Rights NGOs (1) }\end{array}$ & $2(3 \%)$ \\
\hline
\end{tabular}

A more detailed insight into the frames is provided in Appendix 1. The eight frames found have different problem statements, different starting points and feed into different scientific and policy discussions. Below we describe each frame and the differences between them in turn. The frames are clustered into which wider policy and scientific discussions they feed into. Finally, we discuss the key conflicts between the frames where we look at conflicts between different solutions presented by the frames and between solutions and 'non-solutions'.

\section{Frames that address the Biofuels and ILUC debate}

\section{Sustainable Bioenergy}

The Sustainable Bioenergy frame revolves around the idea that shifting bioenergy to marginal land is one of the key solutions to addressing sustainability issues such as competition with food production and direct and indirect land-use change that has plagued bioenergy in the past. This frame defines the problem as concerning the definition, assessment and mapping of marginal land as well as the lack of its careful management. Advocates of this frame emphasised that overcoming this barrier may result in win-win-win situations, particularly in cases where marginal 
land is used for forest bioenergy:

In many of our semi-natural forest ecosystems, this unused potential reduces biological diversity and increases the risk of natural disasters such as fires and wind damage. The use of forest biomass will therefore create a "win-win-win" situation because the production of bio-energy decreases the risk of forest fires and increases producers' incomes, which allows for further investments into sustainable forest management. (Joint position on the promotion of bioenergy from forests, CEPF and ELO, 2007)

The debates that surrounded the revision of the RED separated actors that advocated for a way out of these sustainability issues and those that would argue that the risk of ILUC may negate the benefits of biofuels altogether (see Precautionary Principle below). For the proponents of this frame, biofuels still have potential as a climate mitigation strategy. Actors within this frame were diverse, spanning from the EU Commission, the bioenergy industry to science and environmental NGOs. The majority of actors utilising this frame were scientific actors, either through scientific papers or, as in one case, through a temporary scientific lobby group, which lobbied for more sustainable bioenergy policy. The majority of actors within this study utilised this frame.

The solutions recommended by this frame largely related to income support for farmers to plant bioenergy crops such as subsidies based on the farming area dedicated to bioenergy cropping. These solutions conflict with several other frames, particularly those frames that do not consider marginal land a solution (Marginal land Critique, Land Rights) or those that want to decouple payments from crop production (Ecosystem Restoration). Nevertheless, proponents of this frame consider subsidies do not take into account the variety inherent to marginal land as a non-solution.

\section{Precautionary Principle}

The Precautionary Principle frame is careful with recommending marginal land as a solution to the problem of ILUC and argues that demand for bioenergy itself may need to be reduced along with the utilisation of marginal land. Marginal land can be a solution to land-use change problems by avoiding land that would be used for food production but proponents of this frame are quick to point out that it is a limited solution. Proponents of this frame utilise, albeit indirectly, a form of the 'precautionary principle'; a philosophical and legal principle enshrined in Treaty of the Functioning of the European Union (European Commission, 2012b) that allows for decision-makers to adopt precautionary measures when scientific evidence is unclear and the problem being addressed is characterised by considerable uncertainty (Stirling, 2007). Proponents of this frame argue that given there is no clear way out of this uncertainty and that in practice biofuels have come with considerable impacts, precautionary measures are needed. The overall growth of the bio-based 
sector should therefore be kept in check:

We cannot push for excessive growth in all bio sectors - bio-energy, biofuels, bio-based plastics and chemicals - without increasing land scarcity, competing with food supply and causing biodiversity loss. (Eickhout, 2015)

Proponents of this frame tended to be environmental NGOs or actors with green political credentials and were often pushing the European Commission to set strict criteria for avoiding ILUC. The solutions are therefore to reduce demands that cause land scarcity in the first place, such as reducing demand for bioenergy and utilising already biomass for higher-value uses such as chemicals and materials rather than energy. If bioenergy cropping on marginal land still has to take place then strict environmental safeguards are needed. Similar to the Sustainable Bioenergy frame, the main non-solution is undifferentiated subsidies to grow bioenergy on marginal land.

\section{Marginal Land Critique}

The Marginal Land Critique frame outrightly rejects that marginal land could provide a pathway to sustainable bioenergy. The problem is seen to be inherent to the idea of planting crops on marginal land: growing crops on marginal land is theoretically possible but will always be too inefficient and expensive compared to growing crops on productive land. This is particularly the case for bioenergy. Critics of marginal land argue that bioenergy itself is an inefficient way to make energy on a large-scale and utilising marginal land would make it even more so. Under this definition, whether the land is marginal for economic or biophysical reasons, this will mean that planting crops on marginal land will always entail more resources, whether economic or biophysical, in comparison to productive land. The use of marginal land is considered inefficient for two reasons, firstly it would entail a great bureaucratic effort to monitor land use:

Owners of land too productive for bioenergy production would have very strong economic incentives to cheat and grow bioenergy crops anyway, or to reduce the productivity of their land, to get access to the bioenergy market. There would be a need of a bureaucracy of monstrous proportions and with super national authority in order to control such a policy (Bryngelsson and Lindgren, 2013)

And secondly, it would always be costly to use marginal land and would thus never reach industriallevel production without significant environmental impacts. Proponents of this frame who largely took a combined biophysical and economic approach, do not dismiss the possibility of planting bioenergy on marginal land but rather the possibility of it being economically viable on an industrial scale. Proponents of this frame therefore present no solutions and consider utilising public funds 
to incentivise farmers to plant on marginal land as a waste of resources. This frame, therefore, conflicts with the Sustainable Bioenergy frame which suggests subsidies for crop cultivation.

\section{Frames that address the impact of biofuels on development}

\section{Food Security}

The Food Security frame considers marginal land as an opportunity for rural development in developing countries. It is, therefore, one of two frames (see Land Rights frame below) that is primarily focused on marginal land outside of the EU. It argues that biofuels could potentially bring incomes to marginal areas with challenges in food security by providing additional income. The 2008/2007 food price crisis revealed biofuels could increase food prices and negatively affect food security, however, there was a disparity in food security outcomes between rural and urban dwellers (IFPRI-CGIAR, 2008; Kline et al., 2017). The food security frame argues that higher food prices could benefit farmers. In contrast to all other frames, this frame considers higher food prices from bioenergy as potentially good news for some rural producers in developing countries:

Rising prices offer new income-generating opportunities for farmers and could enhance the contribution of agriculture to economic growth, although several factors may slow down this adjustment. High agricultural prices provide incentives for public and private investments and programmes to improve productivity, reinforce infrastructure, spread production to marginal land and enhance the efficiency of agricultural markets. (Tackling the challenge of rising food prices, European Commission, 2008)

The problem is a lack of investment in these lands and the solution is, therefore, to find a way to make marginal land more productive by investing in infrastructure and on-farm machinery. Non-solutions are anything that may hinder these investments, such as distorted government incentives that may discourage rural producers from investing in production rather than moving towards urban centres. The Food Security frame stands in opposition to the Land Rights frame because it considers marginal land to be a pathway to development rather than a hindrance. This frame identifies the problem not as land-use competition or land scarcity but rather that populations living on marginal land in developing countries are often food insecure.

\section{Land Rights}

The Land Rights frame views marginal land as a way to obfuscate the land grabbing effects of biofuels. According to this frame, planning bioenergy crops on marginal land is unlikely to solve 
issues of land grabbing as marginal land is already valuable resources. The Land Rights frame is one of two frames that does not consider marginal land to be a solution to land-use competition as the frame questions the idea of 'marginality' itself, arguing that so-called marginal land, particularly in developing countries, are vital resources for local communities:

Most land labelled as 'marginal' is in reality already being used by small-scale farmers, herders, hunters or foragers, often without official land titles. Such land provides vital functions for communities, and the loss of such land damages their food security and livelihoods. (Friends of the Earth Europe, 2010)

The problem, according to this frame, is that the idea of 'marginality' itself is problematic and can cause unwanted consequences such as land grabbing:

International Land Coalition (ILC) calls the assumption that abundant 'unused' land is available a "myth" often perpetuated by host governments trying to attract investors. Evidence suggests that there is very little genuinely 'marginal' land and that many communities have been displaced and their livelihoods destroyed (Friends of the Earth Europe, 2010)

Proponents of this frame were more likely to be from civil society organisations and were producing a counter-narrative to the story that Jatropha (a drought-resistant energy crop) can be planted on marginal land to produce energy, reduce carbon emissions, bring biodiversity benefits and improve rural development. Proponents of this frame did not recommend as many solutions as other frames and spent more time debunking frames that propose energy crops on marginal land. The solution recommended was to avoid using marginal land completely and instead intercrop drought-resistant energy crops next to food crops on a small-scale. This would avoid any incentives for land grabbing communal land. This frame potentially conflicts with the Food Security frame which encourages investment into marginal land areas that may cause land grabbing.

\section{Frames that address land abandonment and rural development}

\section{Rural Development}

The Rural Development seeks to improve the farmer livelihoods, maintain traditional forms of farming and maintain biodiversity by utilising marginal land. It considers land abandonment and a lack of rural development to be the primary problem. Land abandonment is seen to cause biodiversity loss and disintegration of the rural fabric via young people moving away from rural 
to urban areas. Another problem is minimal opportunities for farmers to gain viable livelihoods in marginal land. Marginal land, on the other hand, is seen as a way to preserve traditional modes of farming and rural landscapes. In this sense, marginal land lands are seen as both the problem and the solution. The challenge of land abandonment and rural livelihoods is well encapsulated in the following quote:

Traditional and extensive agriculture systems in areas with natural constraints and marginalised areas should be promoted throughout the EU, since they are hit hardest by the effects of land abandonment in rural areas. (COPA-COGECA, 2020)

Marginal land should therefore be used for, High Nature Value farming, planting bioenergy crops and afforestation (often for bio-based applications). This diversity of actors is reflected in this frame as farmer's groups, the European Commission and scientists made use of this frame.

The primary solution to this is direct income support for farmers in marginal land areas and to help farmers adapt to marginal conditions e.g. through appropriate livestock breeds. The primary non-solution to this frame is for afforestation projects to be given to international investors rather than farmers. This is seen to defeat the primary purpose i.e. to ensure income to farmers for providing a service. This potentially risks land grabbing and may induce further land abandonment. This may potentially conflict with the Ecosystem Restoration frame as it recommends afforestation as a key goal, particularly if large afforestation projects are achieved through wide-scale non-farmer investment.

\section{Ecosystem Restoration}

The Ecosystem Restoration frame considers marginal land as an opportunity to deal with the global threats of biodiversity loss, climate change and soil degradation. It notes that land is being abandoned and considers this as an opportunity for rewilding and ecosystem restoration. The main aim for marginal land is therefore achieving environmental sustainability rather than rural development, though this can be a welcome effect. Proponents of the Ecosystem Restoration frame argue that abandoning land and 'letting nature take over' and rewilding may improve biodiversity. In this sense, it is the only frame where some actors suggested that marginal land be utilised for non-human purposes. Nevertheless, most actors in this frame suggested that increased biodiversity would also lead to benefits for humans through ecosystem services. Proponents of the Ecosystem Restoration frame reject common perceptions around land abandonment and the best use of marginal land:

contrary to the common perception, traditional agriculture practices were not environmentally friendly and that the standards of living of rural populations were low. We suggest that current policies to 
maintain extensive farming landscapes underestimate the human labor needed to sustain these landscapes and the recent and future dynamics of the socio-economic drivers behind abandonment (Navarro and Pereira, 2012)

While the Ecosystem Restoration frame takes part in discussions on land abandonment and rural development, it also touches upon wider themes of the role of agriculture in improving biodiversity. For example, it addresses the so-called 'land-sparing/land-sharing debate': a debate that centres around whether agriculture should either intensify production with possible detrimental effects on biodiversity or extensify production and interweave agriculture and biodiversity. Multifunctionality of land and rewilding are presented as a way to connect these two approaches.

The solutions suggested by this frame, besides rewilding, include low-input farming and afforestation to address these problems and this could be achieved through policy instruments such as payments for carbon storage or payments for farm-land abandonment. In terms of solutions, the Rural Development frame and the Ecosystem Restoration frame are at odds as one frame wants to pay farmers to stop abandonment and the other to increase it. This reflects calls to utilise financial support for Areas of Natural Constraints for rewilding (Merckx and Pereira, 2015) and a network of green areas and High Nature Value farms (European Commission, 2000). The Ecosystem Restoration frame also rejects the notion of the Rural Development frame that extensive farming system typical in marginal land are more biodiverse. It also rejects the notion that marginal land is:

A mere dormant natural resource waiting to be used, since it may provide multiple benefits and services to society relating to wildlife, biodiversity or carbon sequestration. (Gerwin et al., 2018a)

This frame thereby rejects that land necessarily has to be used for renewable energy as a solution to climate change but argues that the aim should be achieving multiple benefits. The second difference is that while proponents of the Rural Development frame consider land abandonment to lead to biodiversity loss, the Ecosystem Restoration frame considers land abandonment to be an opportunity for restoration of the ecosystem.

\section{Frames that address livestock and sustainable food systems}

\section{Low-Cost Livestock}

The Low-Cost Livestock frame considers marginal land as a solution to the problem of foodfeed competition and as a pathway to produce sustainable animal-source food. This is largely 
achieved through the grazing of marginal land.

It argues that current food systems utilise resources, particularly land, ineffectively. It recognises that livestock production has so far caused considerable environmental effects. Particularly, it considers the phenomenon of food-feed competition as a key environmental issue and a misuse of agricultural resources. Food-feed competition implies feeding human-edible crops or fish to livestock and fish. It also refers to utilising land for the production of animal feed that could also be utilised for the production of human food (Mottet et al., 2017). To avoid foodfeed competition, livestock should be fed only leftovers from arable cropping and biomass from marginal land i.e. grassland that is not suitable for the production of food crops. The Low-Cost Livestock frame tends to emphasise a systems-oriented view and talks of livestock within a wider food system, arguing that resource-use should be as effective as possible:

If we want to use livestock for what they are good at, namely converting leftovers from arable and grass products into valuable food and manure, we suggest that we should no longer focus on reducing footprints of (animal) products per kg of product. ...Instead, we should focus on improving the efficiency with which livestock recycle biomass unsuited for human consumption back into the food system. (Van Zanten et al., 2018)

The frame gains its name from the argument that livestock should be fed only with waste and leftover streams that are not edible or needed by humans and frame proponents often place themselves between two solutions to sustainability problems in food-systems: those who argue for making livestock production more efficient through 'sustainable intensification' (Petersen and Snapp, 2015) methods (getting more food with fewer inputs) and those who argue that consumption of livestock products should be reduced. Proponents of the LowCost Livestock frame present themselves as a third way, arguing that both solutions are needed and that marginal land provides one way of leaving livestock in the food system while improving sustainability. As coupled support for livestock products may be questioned under the Farm to Fork Strategy, the Low-Cost Livestock frame presents itself as a way to produce livestock products while using resources sustainably. The Low-Cost Livestock frame is one of two frames along with the Marginal Land Critique frame that was only used by scientists.

The solution under this frame is to utilise biomass from marginal land to feed livestock. Grazing these marginal land is also seen to provide additional benefits, such as maintaining biodiversity. Grazing may potentially conflict with the Ecosystem Restoration frame solution of rewilding if no space for domesticated animals is left in this vision. 


\section{Discussion and conclusions}

The use of marginal land is recommended as a way to overcome a multitude of land-use debates by both scientists and policy-makers; from the role of biofuels on land-use change to finding a balance between human use and biodiversity. However, marginal land is often defined ambiguously. Our aim for this paper was to better understand the multiple frames of marginal land by analysing how different actors frame the problems and solutions surrounding marginal land.

We found a total of eight frames, each defined the key problems and solutions differently, and contributed to a variety of scientific and policy debates taking place in the EU. The fact that all frames had a different problem statement and addressed different debates shows the wide variability of frames being utilised around marginal land. Unlike consensus frames, which have the same starting point but may differ on the course of action, the frames found here addressed entirely different debates (Candel et al., 2014). This could be due to the diversity of actors and stakeholders that utilise these frames and the ideological differences between them (Emilsson et al., 2020). For example, the Rural Development frame was utilised by farmer's groups while the Land Rights frame was utilised by development NGOs interested in land rights. The European Commission, on the other hand, featured in many of the frames, reflecting both the internal diversity between different Commission directorates but also reflecting the bridging role of the European Commission across other EU institutions such as the EU Council and the EU parliament (Skogstad and Wilder, 2019). This corresponded to the findings of Candel et al.(2014) who found that the EU Commission utilised a multitude of food security frames in the post-2013 CAP reform. This leads to a situation where multiple equally valid frames about marginal land exist, resulting in a state of ambiguity, i.e. a state in where it is not clear what the problem is, who should solve it or how it should be solved (Brugnach et al., 2011). Particularly for some frames, such as the Sustainable Bioenergy frame, this ambiguity produced by both the scientific and wider EU policy communities on marginal land continue to reinforce the idea of land-use competition as a challenge that can be solved using marginal land. This is because marginal land is seen by many frames as 'spare' and 'free' and thus not subject to the same conflicts as productive land. In other words, the uncertainty surrounding challenges such as ILUC reinforced the idea of marginal land as the solution that needs defining. Some frames, such as the Land Rights frame, challenged this idea of marginal land as spare land.

Based on our results we draw three conclusions. First, we conclude that as the frames have different starting points and problem statements, this creates ambiguity and we argue this is a type of uncertainty. Following research on uncertainty at the science-policy interface we claim that the various frames found in this paper can be due to different types of uncertainty: variability uncertainty, epistemic uncertainty (Walker et al., 2003) and ambiguity (Brugnach et al., 2008; 
Kovacic and Di Felice, 2019; Stirling, 2007). Variability uncertainty arises from the unpredictability of a system, which applies to complex issues such as ILUC, the relationship between biodiversity and agriculture, land abandonment and sustainability of food systems which are addressed by the frames found in this paper. For example, the uncertainty around whether biofuels on marginal land would successfully avoid ILUC led to three different frames largely due to the inherent complexity in modelling complex social and natural systems. Reviews of ILUC models show this difficulty in dealing with such uncertainty (Ahlgren and Di Lucia, 2014; Di Lucia et al., 2012a). Proponents of the Precautionary Principle advocated for careful management based on variability uncertainty. Epistemic uncertainty relates to imperfect knowledge, which may be reduced through more and better research or better research framing. Proponents of the Sustainable Bioenergy frame argued for more and better research on marginal land. However, the differing frames clearly show that a third type of uncertainty is playing out: ambiguity that arises from different ways of defining the boundaries of the problem. In this sense, marginal land frames represent a situation of uncertainty as defined by Brugnach et al., (2008) "the situation in which there is not a unique and complete understanding of the system to be managed". With the various frames of marginal land, there was also disagreement about what exactly is to be managed: biofuels and ILUC, land abandonment, food security or biodiversity? Policy solutions will therefore likely need to be nuanced and locally adapted; for example, subsidies could both exist to preserve traditional ways of farming in areas at risk of land abandonment with rich cultural heritage (corresponding to the Rural development frame) and in some areas it might make more sense to incentivise abandonment where environmental values matter more (corresponding to the Ecosystem Restoration frame).

This leads to our second conclusion, which is that these frames ultimately lead marginal land-use to be subject to the same competing claims as for productive land, even though it is largely intended to avoid them. It is therefore unlikely that better definitions or accurate estimations of marginal land that attempt to reduce epistemic uncertainty will fix the problem, as they will inevitably fall into value-based and normative decisions about the best use of land. In this sense, marginal land is not 'free'. There should also be an acknowledgement that marginality is itself a frame and we should recognise the inherent anthropocentrism and productivism in such a definition. This applied even to frames such as the Ecosystem Restoration frame, which was still based on the assumption marginal land should be used and any benefits from rewilding can be assessed in terms of ecosystem services. This acknowledgement of marginality as a frame is important if marginal land definitions contain problematic assumptions (Nalepa and Bauer, 2012a; Shortall, 2013). Marginal land can be used to push paradigms of resource productivism that may ignore human-environment relationships and ecosystem services that currently remain undervalued (Nalepa and Bauer, 2012a) or ignore the wishes of farmers completely (Helliwell, 2018; Shortall et al., 2019a; Skevas et al., 2016). The overarching frame is that if land is available it should be used (otherwise it would be wasted) and that it should be used for human purposes and/or benefit. No frame outrightly denied this assumption, even when rewilding was suggested as in the Ecosystem 
Restoration frame, rewilding was a way to get ecosystem services that ultimately benefit humanity.

Third, we conclude that making frames clear can be a way to deal with ambiguity by feeding them into deliberative processes in science and governance. As marginal land frames largely reproduce the contestations around land they are trying to avoid, ambiguity surrounding marginal land may need to be maintained to avoid the normative choice of some scientific facts over others, e.g. having singular definitions of marginal land that exclude its many potential uses. How can science and policy deal with ambiguity? Some have suggested different pathways that decision-makers may take to deal with ambiguity, such as rational problem-solving, persuasion and dialogue (Brugnach et al., 2011). However, others have suggested that leaving conflicting ideas or frames ambiguous may mean no concrete path of action is determined (Candel et al., 2014) and that emphasising too much inclusivity in frame-deployment may mean actionable ideas are ignored. Losers may have to be shut out and political bargains struck (Hannah, 2020). This is particularly problematic when ambiguity blocks legal definitions from being formed and progress slowed (de Olde and Valentinov, 2019). In these cases, authors argue that difficult trade-offs ought to be made. Nevertheless, while we agree that trade-offs need to be made to reach material gains, we argue that a democratic deliberative process is needed whenever there is uncertainty due to ambiguity, rather than variability or epistemic uncertainty (Stirling, 2010, 2007). This means that making differences as explicit and transparent as possible and revealing the underlying frames and how they conflict and contrast can be part of this process. These can contribute to more formalised methods such as participatory modelling or Quantitative Story-Telling (Saltelli and Giampietro, 2017) which can explore the biophysical and economic viabilities of different frames. In EU policy-making, this could mean plural and conditional advice at critical points where science interacts with policy (e.g. EU Horizon projects, EU scientific committees and working groups).

Future policy-making will therefore have to contend with these contested visions, as without this policies may be repealed (Shortall et al., 2019b). Given the EU's push for a strong bioeconomy and the revision of the Renewable Energy Directive which encourages the use of marginal land for biofuels, the continued interest in defining marginal land is likely. Multiple EU projects have already sought to define and map marginal land (Gerwin et al., 2018b; Gomes et al., 2018), which are likely to come out with conflicting outcomes. The frames also have implications for the Farm to Fork Strategy and the CAP given some of the frames' call for rewilding Europe, limiting livestock and using CAP rural development payments to support farmers and nature. While our results have shown how some frames contrast in their solutions or non-solutions, they are not necessarily mutually exclusive. The recognition that the option-space surrounding marginal land are frames rather than mutually exclusive 'scientifically objective' stories is the step needed to discuss what we want to do with land, whether marginal or not. In this sense, marginal land as a concept is not useful if utilised as a panacea concept to overcome wider land-use debates such as land-use change or food-feed competition. 


\section{Acknowledgements}

This project has received funding from the European Union's Horizon 2020 Research and Innovation Programme under grant agreement No. 689669. The present work reflects only the authors' views and the Funding Agency cannot be held responsible for any use that may be made of the information it contains. 

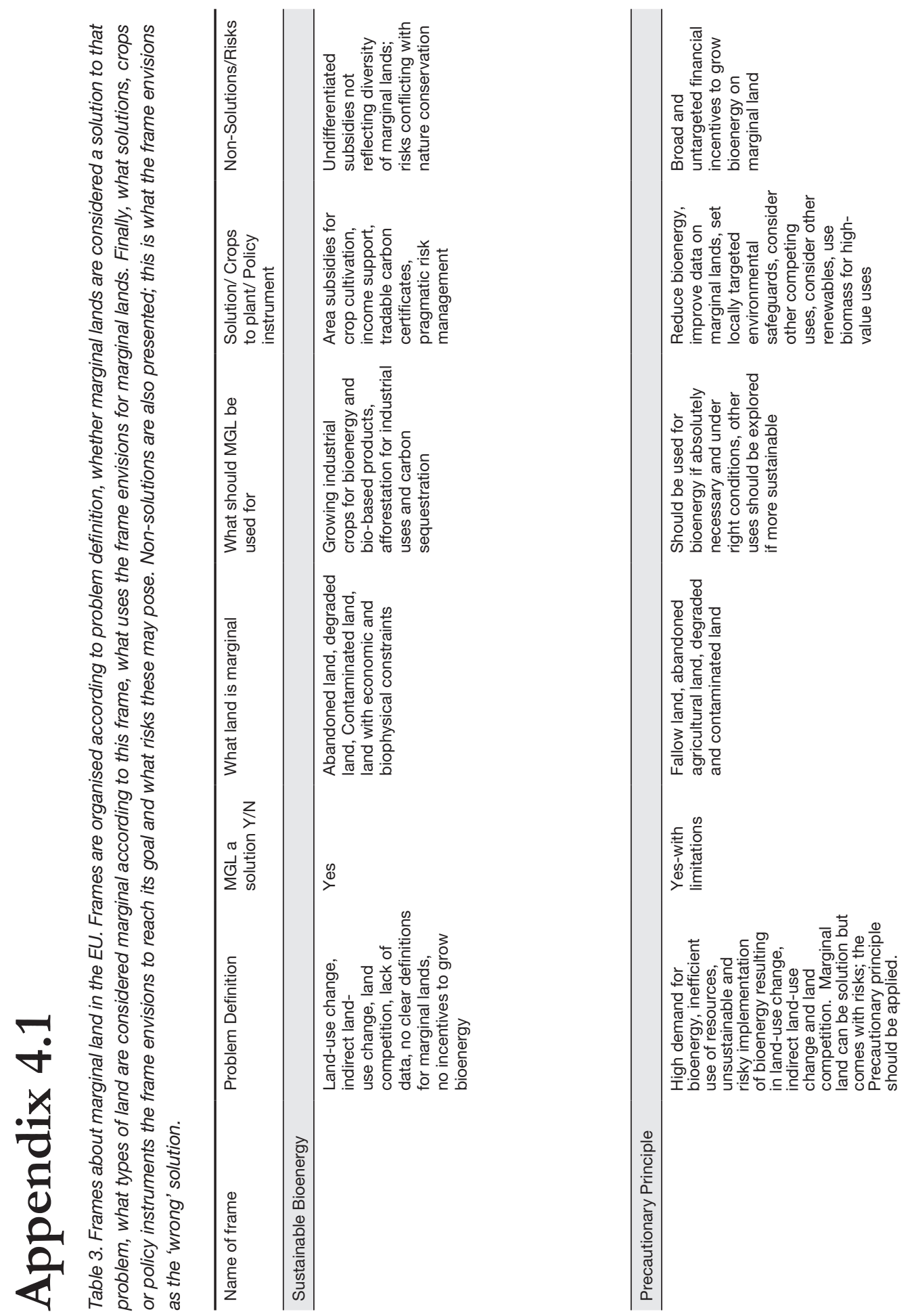


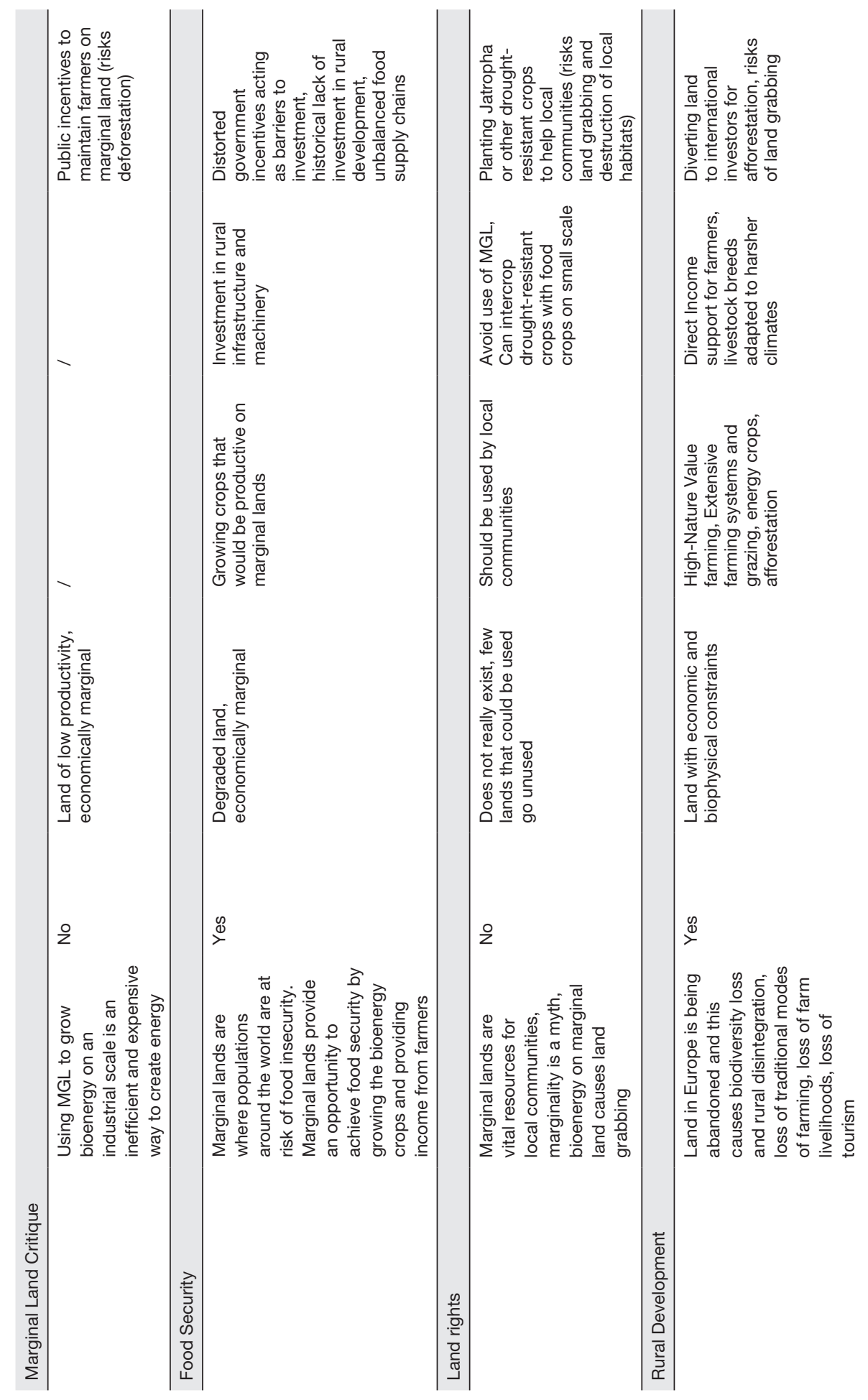




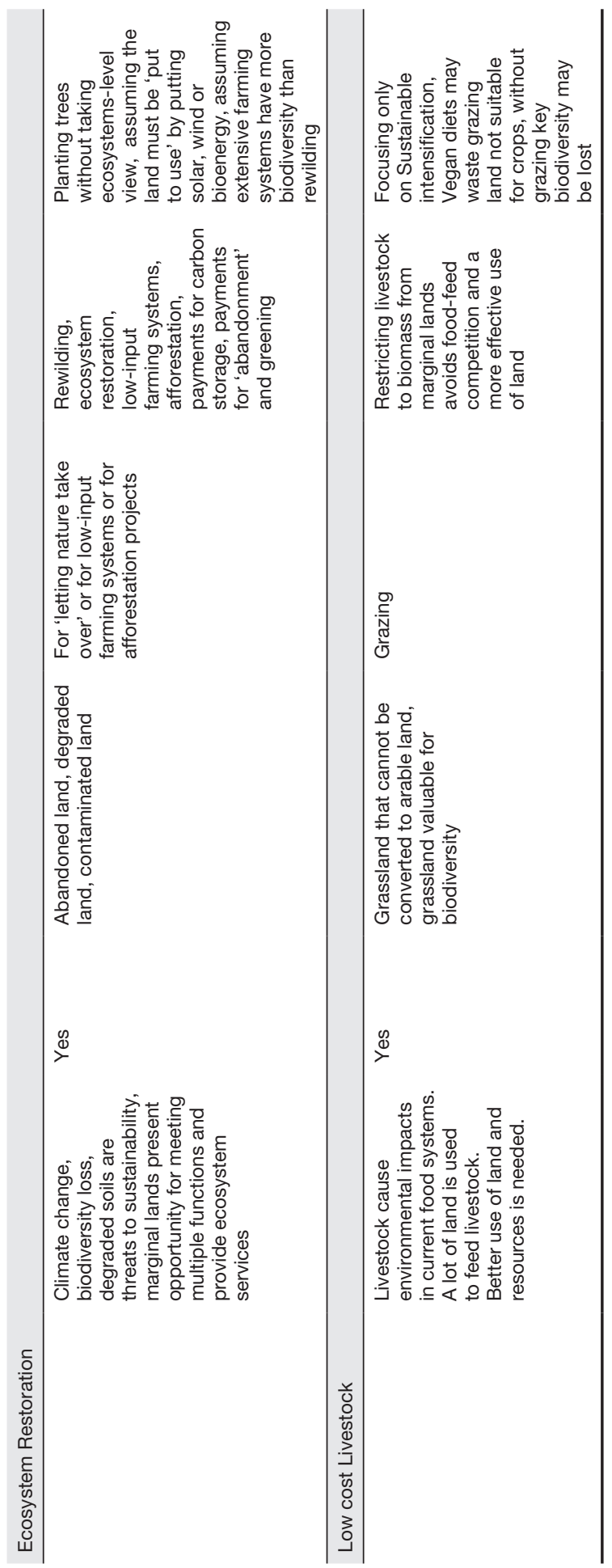





\title{
Chapter 5
}

\section{Towards a circular, bio-based economy: Principles, barriers and opportunities}

\begin{abstract}
A. Muscat ${ }^{a}$, E.M de Oldea , R. Ripoll-Boscha , H.H.E van Zanten $^{\text {b }}$, T.A.P. Metze ${ }^{c}$, C.J.A.M Termeer ${ }^{c}$, M.K. van Ittersum ${ }^{\text {, }}$ I.J.M de Boera

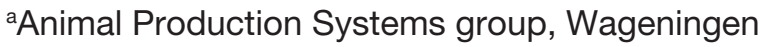
University \& Research, PO Box 338, $6700 \mathrm{AH}$ Wageningen, the Netherlands
\end{abstract}

bFarming Systems Ecology group, Wageningen University \& Research, PO Box 430, 6700 AK Wageningen, the Netherlands

'Public Administration and Policy group, Wageningen University \& Research, P.O. Box 8130, 6700 EW, Wageningen, the Netherlands

dPlant Production Systems group, Wageningen University \& Research, P.O. Box 430, 6700 AK Wageningen, the Netherlands

Under Revision 


\section{Abstract}

Biomass is fundamental to human life. Humans utilise biomass to feed themselves and farm animals, to produce energy and, increasingly, to produce innovative bio-based products such as bioplastics. Rising global demand means more biomass is being harvested than ever before. Coupled with our current linear economic model, these demands will have detrimental effects on the earth's ability to provide a safe operating space for humanity. A circular, bio-based economy could provide the pathway to ensuring a sustainable future. Here we present five ecological principles to guide biomass use towards a circular bioeconomy: 1) safeguarding and regenerating the health of our agroecosystems; 2) avoiding the production of non-essential products and waste of essential ones; 3) using biomass streams for basic human needs; 4) utilising and recycling all by-products of agroecosystems, and 5) prioritising renewable energy and minimising energy use. We also determine what is needed to stimulate the application of these principles to achieve the transformation towards a circular bioeconomy. Institutional, technological, organisational, behavioural, cultural and market barriers that may halt the required transformation are identified and opportunities for change indicated. By introducing an integrative view on biomass via five ecological principles and identifying barriers and opportunities, this perspective provides a basis for stimulating the essential transformation to a circular bioeconomy. 


\section{Introduction}

Biomass is the basis of our food system and our future bioeconomy. In addition to food and feed production, humans utilise biomass to produce bio-materials such as fibre, biochemicals, bioplastics and bioenergy. More biomass has been appropriated over the last century than ever (Haberl et al., 2014b; Krausmann et al., 2013), leading to land-use change, biodiversity loss, climate change, water pollution and land degradation. As demand for biomass grows due to population growth, a shift towards diets rich in animal-source food (Foley et al., 2011) and a desire to move towards a bioeconomy (European Environmental Agency (EEA), 2018), these problems are likely to worsen.

The need to transform the economy to avoid exceeding the Earth's biophysical limit is widely recognised (Steffen et al., 2015) and the circular economy is proposed as one of the ways to achieve this. While scholars have translated the concept of a circular economy to the food system (de Boer and Van Ittersum, 2018; Jurgilevich et al., 2016) existing work applying circular concepts to biomass has yet to address its use for functions other than food. An integrated framework is still required that prioritises biomass for basic human needs, including food, fibre (clothes), pharmaceuticals, functional biochemicals and bio-energy, within planetary boundaries. Addressing this gap is crucial given the competition for biomass between different uses (Muscat et al., 2020): direct competition for biomass between food, feed, fuel and materials production, and indirect competition for the resources needed for production, such as land, water, capital and labour (Muscat et al., 2020).

While many studies touch upon the multitude of social, economic, cultural barriers to the transformation to a circular bioeconomy (Kirchherr et al., 2018), few address how these barriers may be overcome. Departing from an ecological food-systems perspective, this paper addresses these knowledge gaps and presents a circularity framework for food and non-food biomass use based on five ecological principles that can help guide policy-makers, businesses, communities and individuals. There are institutional, technological, organisational, behavioural, cultural and market barriers to implementing these principles, however. In discussing these barriers we identify opportunities to stimulate this transformation by placing solutions in the context of systems thinking (Meadows, 2009).

\section{Principles for guiding circular biomass use}

Five principles are presented for circular biomass use based on the concept of circularity and its roots in disciplines such as industrial ecology (Saavedra et al., 2018), ecological economics (Giampietro, 2019; Korhonen et al., 2018), agroecology (FAO, 2016) and general systems theory 
(Bertalanffy, 1950). More recently circularity has been combined with concepts of regenerative design, cradle-to-cradle and biomimicry (Ellen MacArthur Foundation, 2015). In Figure 1 we define agroecosystems as any human-managed system of biomass production, encompassing land-based agriculture, fisheries \& aquaculture and forestry, including both managed and natural elements of the ecosystems.

The first four principles deal with biomass flows in these agroecosystems while the fifth acknowledges that a circular bio-based society cannot be achieved without addressing the role of renewable energy and thermodynamic limits.

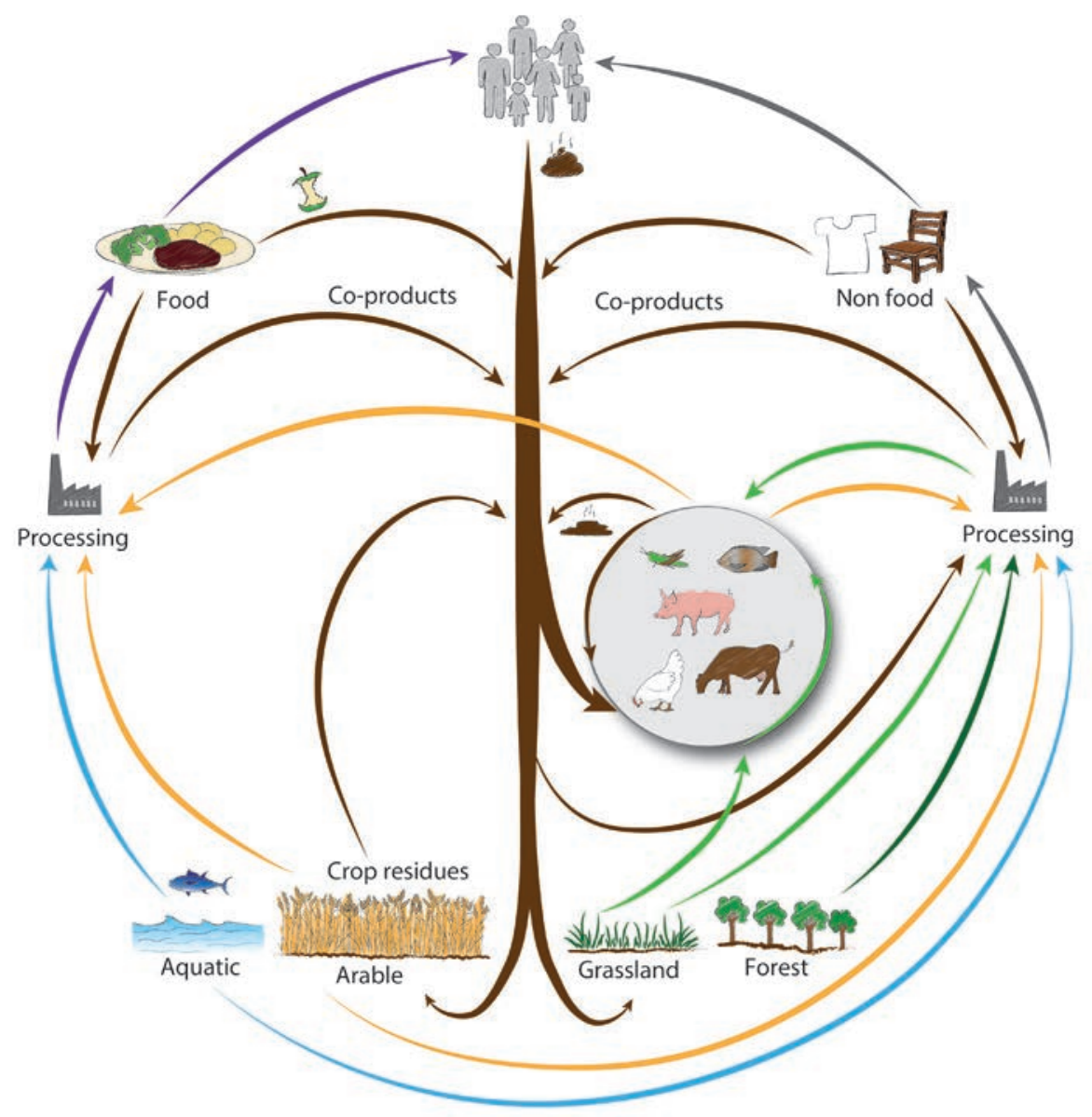

Figure 1. Biomass flows in a circular bioeconomy. Biomass from aquatic, arable, grassland and forest production systems are processed or consumed. By-products and wastes are recycled back into the system. 
The Battle for Biomass | Abigail Muscat

Principles, barriers and opportunities

\subsection{Safeguard}

Biomass is the basis of the circular bioeconomy, and its production depends on the health of our aquatic, arable, grassland and forest production agroecosystems. To safeguard the health of these agroecosystems, agricultural, fisheries and forestry practices are needed that utilise natural resources at a rate that does not exceed their regenerative and absorptive capacity. This means ensuring that natural resources remain completely and indefinitely available.

Based on this, our first principle argues that production practices should contribute to the conservation and regeneration of the health of agroecosystems and the natural resources they provide. For example, humans should not harvest wood or fish at a rate exceeding the growth rate of the forest or fish stock and must maintain soil health. The safeguard principle also implies minimising or ideally halting the consumption of finite resources like phosphate rock or fossil fuels and stimulating the use of regenerative ones (solar and wind energy).

Not exceeding the absorptive capacity means that waste or losses are emitted at a rate not higher than the assimilation capacity of agroecosystems. For instance, greenhouse gas (GHG) emissions should not exceed the sink capacity of our agroecosystems. Forests, for example, act as a carbon sink as well as a valuable source for paper and pulp, textile or bioenergy industries. The capacity of our agroecosystems to act as sinks should be protected.

Biodiversity plays an essential role in providing a variety of buffering capacities (Jørgensen and Nielsen, 1996) and contributing to the ecosystem's resilience now and in the future. In practice, goals to protect this role need to both conserve the natural ecosystems that are left (e.g. zero deforestation targets) and regenerate or restore degraded agroecosystems (e.g. regenerate soil health, encourage biodiversity-enhancing practices) (Willett et al., 2019).

Moving towards a circular bioeconomy, therefore, entails more than a simple reduction of throughput flows of natural resources: it also implies continuous regeneration of resource quality. In the absence of technologies and strategies that reduce emissions or replace the absorptive capacity of ecosystems (e.g. carbon capture and storage systems that act as artificial sinks) a circular bioeconomy means a greater dependency on the speed of natural cycles.

\subsection{Avoid}

Conserving and regenerating healthy agroecosystems also implies questioning wasteful production systems and focusing on essential products for humans that need to be produced. Our second principle, therefore, addresses the use and production of non-essential bio-based products, and 
the avoidance of losses and waste of essential ones.

Avoiding non-essential products, losses and waste can prevent the exploitation of natural resources (Potting et al., 2016). Moreover, emissions to air, water and soil (Scherhaufer et al., 2018; Van Kernebeek et al., 2018) are avoided by preventing the impact of production processes further upstream. The question then arises: what are essential and non-essential products and what is waste?

Food is essential and yet we currently throw away one-third of all food globally each year and discard a third of the global fisheries catch for not being the target species (FAO, 2011). These estimates do not even include consumption above nutritional requirements (van den Bos Verma et al., 2020). People in high to middle-income countries have a higher intake of calories than needed, resulting in more deaths linked to obesity than to being underweight (WHO, 2019). One may also question the value of ultra-processed foods with their low nutritional value and negative impact on health (Rico-Campà et al., 2019; Srour et al., 2019).

Waste is paradigmatic around production systems for other human needs such as housing and clothing. Consumption patterns, in particular, have sped up and the lifetime of our products greatly reduced, generating more waste in shorter periods. The rise of fast fashion has reduced the average lifespan of a garment to around three years (Daystar et al., 2019). Determining which products are essential and non-essential and what is waste rather than a by-product will entail answering challenging questions within a discussion between different sectors of society (section 3 ).

\subsection{Use}

As the growing demand for biomass means natural resources supporting production need to be used effectively, our third principle refers to the order of priority for its use. We argue that priority should start with basic human needs (food, pharmaceuticals, clothes) and sectors without sustainable alternatives like the chemical industry (PBL Netherlands Environmental Assessment Agency, 2014). Energy, for example, can be produced directly from solar, wind, hydro or thermal sources.

Biomass is not currently used effectively to meet food requirements. Some $40 \%$ of global arable land produces high-quality feed for livestock, much of which is human-edible. Similarly, most fish that end up in fishmeal are of food-grade quality (Cashion et al., 2017). Direct human consumption of these human-edible feeds would be more resource-efficient (Garnett, 2009; Goodland, 1997). Livestock and farmed fish, however, can contribute significantly to a sustainable supply of nutrients, especially highly bio-available ones such as protein and iron, or nutrients largely absent in plant-sourced food, like vitamin B12 and long-chain essential fatty acids (Van Hal et al., 2019a; Van Zanten et al., 2018). 
Following the use principle, these livestock and fish would only consume leftovers from arable land or fisheries and grass resources (recycle principle), not human-edible biomass. In the near future, biorefineries can also upgrade leftover inedible biomass streams like cultivated grass into proteins which humans can eat (Bos-Brouwers et al., 2012). People can also sustainably harvest and consume a larger diversity of aquatic foods from aquatic production systems, each in proportion to its natural production capacity (Zhou et al., 2019) (safeguard principle).

Biomass is also required for essential non-food biomaterials that cannot be produced sustainably, such as clothing. Availability and resource efficiency can be maximised through the biomass cascading principle (Haberl and Geissler, 2000), used multiple times before being converted to energy. Directing biomass towards material rather energy uses may sequester carbon for longer periods of time (Suominen et al., 2017) and prevent the appropriation of additional biomass (Vis et al., 2016). Here we argue for prioritising non-food materials like furniture and housing (Churkina et al., 2020) that also sequester carbon if used sustainably.

Current policy incentives in the EU and US do not take such biomass cascades into account and direct biomass to bioenergy before material uses (Keegan et al., 2013). Such cascades should also be directed by social norms. We believe biomass cascades are best informed by frameworks of human needs (Doyal and Gough, 1991; Max-Neef, 1992) and resource efficiency rather than the economics that are leading to current cascade frameworks such as the value-pyramid (BosBrouwers et al., 2012). The production of bioenergy, for instance, is then only desirable or effective for biomass streams that are not safe for recycling. Reframing biomass cascades will entail rethinking which products are essential for human development.

\subsection{Recycle}

Even if the waste of food and non-food bioproducts is avoided, the production and consumption of essential food and non-food bio-based products result in by-products such as manure and slaughterhouse waste from animal production. Our fourth principle sees inevitable and unavoidable nutrients and carbon in by-products recycled back into the bio-based system, prioritising basic human needs over other purposes.

Based on the avoidance principle, the first priority is not producing human-edible by-products such as the middlings from white and brown bread. Inevitable and unavoidable by-products like straw or animal/human excreta do contain valuable nutrients and carbon. Recycling them into our agroecological systems (Fig. 1) can enrich the soil, fertilise crops, feed farm animals and produce bio-materials. 
As we've seen, such by-products are recycled back into the system following the cascade principle to meet basic human needs. But care must first be taken to ensure they are safe to recycle and do not cause harmful effects to humans, animals and the environment. Decisions as to what is inevitable, inedible and harmful will have to be taken on a case-by-case basis and be context-dependent. For example, while plant-based human-inedible food waste can be immediately fed to farm animals, animal-contaminated food waste must be heat-treated to deactivate potential diseases before being fed to pigs, poultry, fish and insects. That said, recycling may entail a trade-off between food safety and additional energy and transport (Sandin and Peters, 2018).

\subsection{Entropy}

The driving force behind the recycling of nutrients and carbon in our agroecosystems is energy. While biogeochemicals, like nutrients and carbon, are cycled through ecosystems, energy flows and cascades from useful to less useful forms of energy(Korhonen et al., 2018) as during each energy transformation process, entropy, or disorder, increases. Increased circularity and recycling costs energy and a fully circular bioeconomy is difficult given the losses in each consecutive cycle (Castro et al., 2007; Korhonen et al., 2018). Our fifth principle advocates minimising energy use by working with nature, moving towards renewables and effectively utilising the rare metals on which current renewable technologies depend.

Following ecological engineering or design principles, a system can maximise the use of freeflowing energy from natural sources, particularly the sun. This allows energy systems to be designed that 'work with nature' to minimise energy use (Bergen et al., 2001). A good example is farming systems such as silvopastoral systems or multispecies aquaculture, which are based on ecological principles that minimise energy inputs and are still productive. They show how it is better to conserve energy in ecosystems by prioritising material uses over energy use (via the principle of cascading) than to increase the use of biomass for bioenergy.

Given the above, as well as the need to move away from fossil fuels, the future circular bioeconomy will need to be based on renewable energy. However, current technologies depend on finite metals and minerals to produce solar panels or wind turbines (Vidal et al., 2013). This implies that technologies need to be designed in such a way that finite nonrenewable materials (e.g. lithium and cobalt) can be recycled easily (Grandell and Höök, 2015; Kovacic et al., 2019b). 


\section{Pathways to transformation: barriers and opportunities}

Building a circular economy based on our five principles requires a deep understanding of both the main institutional, technological, organisation, behavioural, cultural and market barriers to change as well as the opportunities (Fig. 2). There is a clear gap between barriers and opportunities in terms of how solutions can be operationalised (Termeer and Metze, 2019). Bridging this gap will involve stimulating a transformation of societal behaviour and attitudes via an ambitious vision on the circular bioeconomy - such as our five principles - which all stakeholders involved can target. This can be achieved by maintaining some ambiguity and leaving room for bottom-up as well as top-down approaches (Termeer and Metze, 2019) (national policy strategies vs. citizenled initiatives). Possible strategies include the accumulation of 'small wins': radical initiatives with concrete results that can amplify and accumulate into transformative change (Termeer and Metze, 2019).

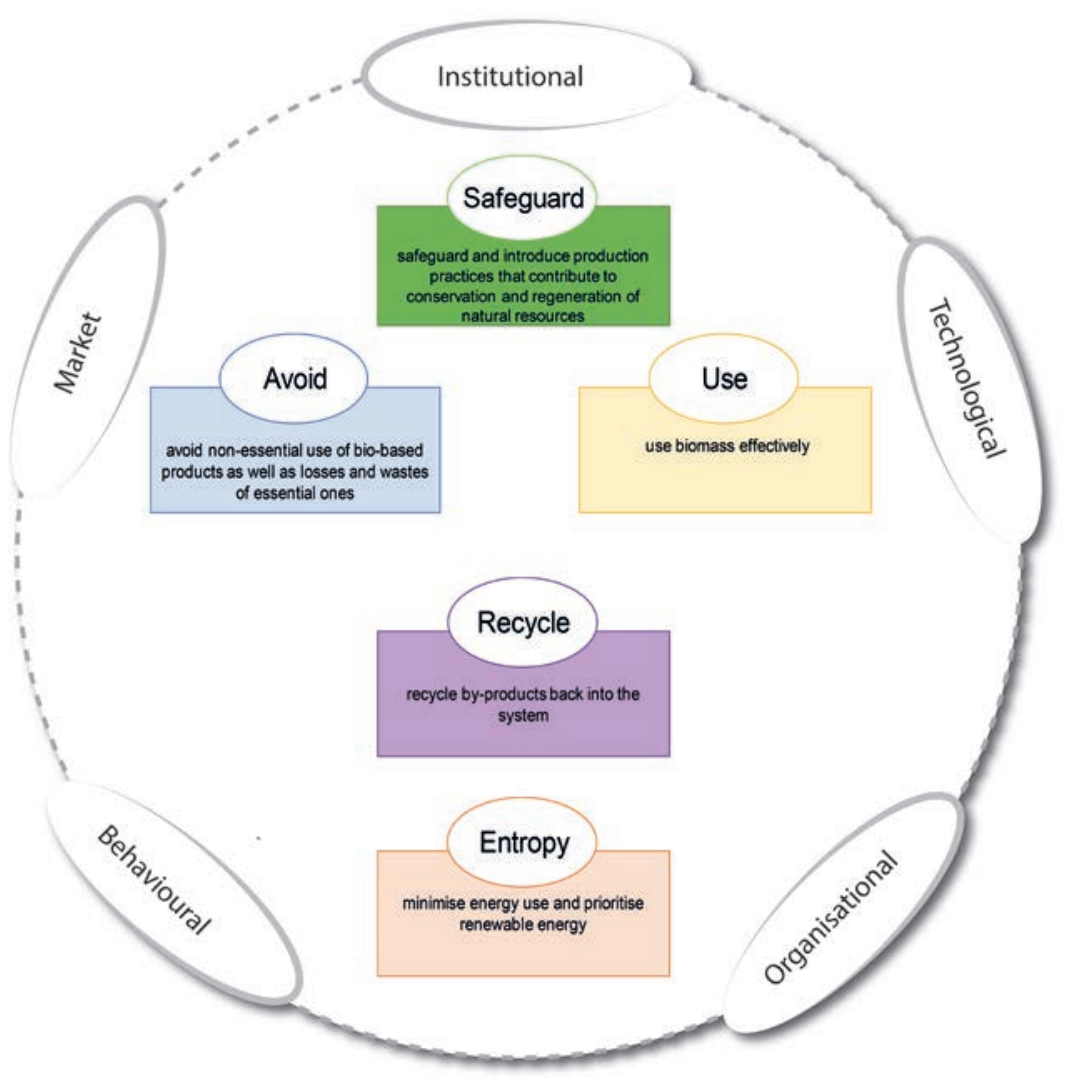


Figure 2. Ecological principles and barriers that need to be overcome for a circular bio-based economy. Implementing the ecological principles highlighted here will not come without various types of barriers; identifying these barriers also helps open up opportunities for change.

\subsection{Institutional}

Institutional barriers are those set by political, governing and legislative bodies, including within the governance process itself. Recent experiences have shown the need for an integrated rather than a 'silo' perspective to governance if we are to move towards a circular, bio-based society. An integrative perspective that acknowledges interactions across institutions is particularly required for biomass as it is produced and used by many different economic sectors, interlinking primary production sectors with industrial sectors (e.g. processing, retail) and households (Fig. 1).

At present, biomass is often governed by different policy domains at different stages of the supply chain, creating conflicting or incoherent claims on biomass. For instance, most biomass in the EU is directed towards energy first (Birdlife Europe and European Environmental Bureau, 2014; Dammer and Essel, 2015) due to renewable energy policies despite cascading principles being in place which favour material uses first. Following the above-developed use principles, resourceefficient cascading can be applied to all biomass while removing distorted policy incentives.

Policy processes, however, are complex and the adoption of ambitious goals is often difficult (European Court of Auditors, 2017). This is why it is crucial to determine which policy measures are more effective from the perspective of the entire bio-based system and to aim for stronger 'leverage' points that go beyond isolated fixes (Abson et al., 2017). Some policies that support increased circularity may find limited political support, such as interventions to reduce animalsource food consumption (e.g. taxation) or feeding livestock with potentially health-hazardous animal-contaminated food wastes. This can result in vicious cycles that inhibit change (Nyborg et al., 2016).

If we are to move beyond the 'silo' approach, change is also necessary in the governance system. Circularity can be achieved with systems thinking that combines top-down and bottomup approaches (Termeer and Metze, 2019; Villas-Bôas et al., 2002) and replaces top-down governance models. Policies will need a strong systems-perspective to maintain coherency across different sectors that govern biomass and protect against undesirable consequences. Policy will also require a vision to maintain stable market incentives and funding for innovation. In short, overcoming institutional barriers in the transformation to a circular bioeconomy also means transforming the governance model itself and involving diverse stakeholders with the production and consumption of biomass. 


\subsection{Technological}

Technological barriers relate to the availability and rate of developments for solving or addressing key circularity issues. These can be technical bottlenecks, a lack of data and information or cost barriers which stop technology from reaching commercialisation.

A circular bioeconomy requires new technologies as well as the redesign of existing ones. These can reduce our dependence on the speed of natural cycles by lowering resource use and emissions or replacing the absorptive capacity of ecosystems. Examples include carbon capture and storage technologies, plants bred for improved photosynthesis and more effective solar power (see safeguard principle). The redesign of existing technologies and products is necessary for a circular bioeconomy (Sumter et al., 2020) to improve the lifespan, repairability (de Fazio, 2019) and recyclability of products. Environmental impacts can be greatly reduced if circularity is taken into account at the product design stage (Velenturf et al., 2019).

Currently, product redesign is inhibited by the widespread obsolescence of products (e.g. fast fashion) in combination with a lack of skills, investment and incentives for redesign, product recycling and remanufacturing infrastructure (Van Eijk, 2015). In addition, many bio-based products are coated or mixed with technical materials, such as construction wood, wooden furniture, and textiles, hindering their safe return to the biosphere (European Environmental Agency (EEA), 2018). Similar to conventional plastics, non-biodegradable bioplastics cannot be easily returned as this requires a complex collection and recycling infrastructure (Cho, 2017). This process could be sped up with open databases of tried and tested bio-based materials ("Materiom," 2018).

\subsection{Organisational}

Organisational or inter-organisational barriers are those that exist for an organisation, such as a business or NGO, and include issues related to supply chains, access to and supply of feedstocks, organisational culture and access to information.

A major organisational barrier to circular biomass is the inherent heterogeneity and seasonality of biomass. This leads to a dispersed and unstable supply base and swift degradation of biomass. Industries have to work together to produce, deliver and process biomass, especially streams such as inedible, unavoidable food waste from the food processing industry. This stream may be far more homogenous than feedstock streams further down the chain such as consumer waste (Teigiserova et al., 2019).

While entailing many challenges, solutions include moving away from economies of scale, which 
prioritise increasing specialisation, volume and efficiency, to economies of scope, which can exist independently of volume and allow multiple products to be produced together. Economies of scope can create multiple sources of income, lower overall costs (Teigiserova et al., 2019) and be combined with multi-product cascading biorefineries, using waste from one process as feedstock for another. A network of biorefineries within proximity can create an economy that minimises waste by avoiding the risk of biomass degradation, overcoming the cost of transport and utilising wastes from nearby production processes (Teigiserova et al., 2019).

Such an economy of scope may mean reconnecting areas where biomass is largely consumed (cities and urban environments) to areas where biomass is produced (rural and agricultural areas). Closing the gap between these areas could improve circularity, by potentially reducing food waste (Ackerman et al., 2014) or recycling waste such as human excreta - a rich source of mineral phosphorus that would reduce dependence on mineral fertiliser (Van Kernebeek et al., 2018).

Organisational barriers also relate to end-of-life options for bio-based products. Safe collection of such products requires adequate labelling, consumer awareness, and infrastructure and clear definitions and standards for what is considered biodegradable under which conditions.

\subsection{Behavioural and cultural}

Behavioural barriers are values or biases inherent to individuals or institutions which prevent the implementation of desirable changes in their behaviour or conduct. Some are inherent to culture, related to attitudes, cognitive biases and social values. Cultural barriers halt any paradigmatic shift in a society's culture usually due to a widely-held, ingrained cultural perspective. Research is increasingly recognising the role that behavioural and cultural factors play in sustainable behaviour (Gifford and Nilsson, 2014; Nyborg et al., 2016; Steg and Vlek, 2009). Access to information and knowledge about sustainable practises is not enough to change behaviour (Kollmuss and Agyeman, 2002). Behavioural and cultural barriers will have to be overcome to shift consumption patterns so they remain within planetary boundaries.

High-demands for animal-source food, energy and plastics are often associated with behavioural and cultural factors such as gender, lifestyle and identity (Rothgerber, 2013; Shove et al., 2015) as well as psychological biases. For example, a 'psychological distance' bias may be created when plastic waste is exported to other countries. This can result in a perception that plastic pollution has been solved, increasing its use (Barnes, 2019). What is seen as waste is furthermore culturally and behaviourally mediated (Richter, 2017) and there is growing recognition that the causes of food waste, particularly at a consumer level, relate to cultural factors such as peer pressure and value-perceptions around waste (Aschemann-Witzel et al., 2015; Schanes et al., 2018). 
Behavioural science studies in how to enact behavioural change on behalf of sustainability provide many avenues, including identifying social norms and their tipping points, vicious and virtuous cycles of behaviour (Nyborg et al., 2016), meaningful memories and emotional experiences (Maiteny, 2010), and appealing to social identities (Byrkjeflot et al., 2013). These can be coupled with formal institutional methods, such as streamlining food labelling (Priefer et al., 2016) or eco-labels, supermarket ratings and campaigns to normalise sustainable choices (Behavioural Insights Team, 2012). Changing the 'choice environment' may, in particular, be more effective than addressing internal aspects like values and identity (Ölander and Thøgersen, 2014). For example, sub-optimal foods such as 'ugly' fruit and vegetables that end up as food waste can be tackled in the 'food environment' via changes in retail practices and consumer awareness.

Change is needed at the individual level as well as among communities, culture and society at large. The latter will, however, require a widespread paradigmatic shift. Structural change can be achieved through nudging strategies that alter individual behaviour and small wins such as community initiatives and socio-technological innovations (Geels and Schot, 2007; Velenturf et al., 2019). Upscaling, deepening and broadening these niche innovations can lead to widespread transformations (Termeer and Metze, 2019).

\subsection{Market}

Market barriers reduce or block the economic viability of circular products or business models, including barriers to market access and environmentally harmful subsidies that inhibit competition.

These barriers are often considered some of the most urgent to overcome (Kirchherr et al., 2018). Investment costs to move from non-renewable to biobased products are high as competing products (often petrochemical-based) remain cheap compared to their bio-based alternatives due to environmental or social costs being external to prices.

As we've seen, there is considerable uncertainty of supply when biomass is the primary feedstock for production due to its heterogeneity. Other uncertainties around the raw material supply of biomass may come from changes in the market itself. For example, avoiding waste may ultimately disrupt business plans that rely on waste-biomass as a feedstock. Furthermore, using food waste and residues from the food processing industry may provide more stable feedstocks. Dietary shifts may, however, alter these biomass streams.

Some products get locked in and retain their market value despite not being circular. The cost of virgin biomass materials currently remains low, while the cost of collection of waste biomass remains high. Changing this will require market incentives such as taxes on virgin raw materials 
(Söderholm, 2011). For a fair playing field between bio-based and petrochemical products - and internationally across different production areas - environmental impacts should be internalised within the final market price. Furthermore, bio-based alternatives can replace petrochemical products that already have an established market. These products are called 'drop-ins' and can be considered an example of a 'small win'. In the case of bioplastics, products that are an improvement on their petrochemical counterparts are 'smart drop-ins' (Carus et al., 2017) which can help overcome the initial barrier of finding a niche in the market.

\section{Discussion}

Shifting towards a circular bioeconomy requires deep transformations, varying from how we cascade biomass and measure progress to the type of economic model we pursue.

Translating the concept of a circular economy into biomass use requires cascading frameworks that direct biomass towards its highest value to make the most effective use of the limited resources available (Haberl and Geissler, 2000). The principles presented above have various implications for existing bioeconomy cascading frameworks for biomass. We suggest that cascading frameworks be informed by human needs frameworks accounting for resource efficiency, implying that 'higher value' is determined by higher need value rather than economic value. Frameworks such as the value pyramid, for example, direct biomass towards higher economic value products such as cosmetics (Bos-Brouwers et al., 2012).

Our principles also have implications for circularity concepts such as those of the Ellen MacArthur Foundation, which keep technical and biological cycles separate in theory (Ellen MacArthur Foundation, 2015). In practice, these two cycles are inherently intertwined as they both contain organic and inorganic elements. Complete separation of technical and biological materials is likely unrealistic (Velenturf et al., 2019).

Once the right frameworks are in place, new metrics will be needed to measure progress. Circularity metrics for bio-based products, for example, will have to address their appropriation of virgin materials and natural resources, clear definitions of biodegradability and measures of toxicity for end-of-life options (Spierling et al., 2019). This will require clear definitions of biodegradability in different environments. Most importantly, circularity metrics must address the complexity and circularity of agroecosystems and the interlinkages in the system such as feed-food-fuel competition (Muscat et al., 2020; Van Zanten et al., 2019). Metrics have to measure resourceefficiency and energy efficiency from the entire bio-based system, such as the land-use ratio (Van Zanten et al., 2016) or measures aimed at the most exergetically efficient energy use, such as combined heating and power systems (Korhonen et al., 2018; Odegard et al., 2012; Zabaniotou, 
2018). Current product footprints fall short in addressing these aspects.

Besides product-based metrics, metrics are needed that define the maximum amount of emissions that can be absorbed by (agro)ecosystems in each region. Such regional ceilings avoid collectively placing an excessive strain on the environment. A transition towards a circular system, therefore, requires a smart combination of metrics at different scales (e.g. product, farm and region). This will entail deciding the scale at which recycling should be pursued and nutrient cycles closed. This, in turn, involves regional considerations about agroecological conditions as much as a discussion on trade and global equity, since achieving increased sustainability in one country may come at the expense of another (Mayer et al., 2015; Mayer, 2005).

While circularity can contribute to all three pillars of sustainability (Korhonen et al., 2018), it mainly addresses staying within planetary boundaries. But a truly, sustainable circular bioeconomy requires us to respect the social foundation (O'Neill et al., 2018; Raworth, 2017). This foundation includes essential rights for humans and animals, such as the right to healthy and safe food, labour protections and the possibility for farm animals to express their species-specific behaviour.

Together, the planetary and social boundaries of our food and bio-based systems define a safeand-just-operating space where human, animal and planet wellbeing are assured. Transitioning towards this space will require a change in the way we value products and services and how they are governed. This will likely mean a rethink of our definition of prosperity as we embrace new measures of social progress such as Gross National Happiness, Genuine Progress Indicator or Human Development Index (Costanza et al., 2009; Kubiszewski et al., 2013). It also opens up a series of questions about which economic model to pursue and how to achieve and measure it. It will require sustained effort to close the loop in our agroecosystems but achieving this potential could set humanity on a path towards socio-economic and planetary prosperity.

\section{Acknowledgements}

This project has received funding from the European Union's Horizon 2020 Research and Innovation Programme under grant agreement No. 689669. The present work reflects only the authors' views and the Funding Agency cannot be held responsible for any use that may be made of the information it contains. 

Chapter 6

General

Discussion 


\section{Introduction}

Humanity's increasing demands for food, feed, bioenergy and biomaterials have induced considerable negative environmental effects on agroecosystems and the biosphere (Krausmann et al., 2013; Poore and Nemecek, 2018; Smil, 2012). If these trends continue, the capacity of agroecosystems to feed the planet while also providing energy and materials for humanity's needs is at risk. This pressure on the planet's biophysical boundaries causes competition for resources, unexpected interactions and trade-offs between different biomass uses. Governing these interactions is difficult because of the inherent complexity of these interactions, but also due to the diversity of biomass resources and the diversity of policy domains and institutions that are needed to govern them. This thesis, therefore, aims to advance the theoretical and empirical understanding of the governance of this problem with the ultimate aim of improving the governance process at the science-policy interface.

This discussion chapter is organised as follows: in section $2 \mathrm{I}$ address the problem of biomass competition by looking at the central interactions, trade-offs and synergies between the various biomass uses found in this thesis. I defined interactions as neutral interconnections; trade-offs as when a goal has a negative impact on another goal and synergies as two goals mutually reinforcing each other. In section $3 \mathrm{I}$ address how both science and policy can deal with the complexity of biomass use and competition. I end the section by suggesting different models of science-policy relationships that can deal with complex issues. Finally, in section 4 , I discuss how to make a transition towards more sustainable use of biomass and a circular bio-based economy before providing the central conclusions of this thesis in section 5 .

\section{Battle for biomass: interactions, trade-offs and synergies}

The interactions between different biomass uses is characterised by complexity. Multiple crosscutting interactions, trade-offs and synergies can be identified, as biomass use is both inherently connected with environmental as well as with socio-economic outcomes. For example, while utilising agricultural by-products for bioenergy can avoid competition with food, these by-products could also be used as livestock feed. More land is therefore needed to replace the displaced livestock feed (chapter 2). Governing this complexity is challenging for two reasons; first due to the interconnected nature of resource use and second due to these connections requiring coherence between policy domains and policy goals (chapter 3). Chapter 2 and 3 analysed the interactions, trade-offs and synergies across food, feed, fuel, fibre uses of biomass and revealed a 
wide number of interconnections. Three key findings, however, are essential for more sustainable use of biomass. First, that high demands, particularly for bioenergy and animal-source food (ASF), reduce the 'biophysical option space', thereby making it harder to meet other demands, such as for other food and fibre. Second, the findings of this thesis suggest that diverting biomass streams from high value uses (such as livestock feed) to lower value uses (such as bioenergy) lead to negative environmental impacts. This highlights the importance of considering a cascading principle, which I come back to in terms of policy trade-offs in chapter 3 and where I presented ecological principles to address cascading in chapter 5 . Third, there is considerable disagreement and uncertainty around solutions, such as utilising marginal land (chapter 4) and advanced biofuels, which are recommended to avoid competition between biomass uses.

\section{High demands reduce the option-space}

Chapter 2 showed that the effect of the increased demands for biomass, for food, feed and fuel, has been extensively studied by the literature. The findings of chapter 2 indicate that high demands for bioenergy as well as diets with higher amounts of ASF can shape the 'biophysical option space'. Increased bioenergy demand negatively affects food prices (Persson, 2013) as well as forest loss (Lapola et al., 2010), greenhouse gas emissions, nitrogen demand (Beringer et al., 2011) and on ecosystem services (Burgess et al., 2012; Howe et al., 2014). Pressure on resources is also further increased with higher demands of ASF, particularly if this also means higher portions of human-edible products are included in animal feed (Schader et al., 2015). Increasingly, studies are looking to the 'option-space' and how these increased demands affect future scenarios for agroecosystems (Erb et al., 2016; Gerten et al., 2020). Three factors found in chapter 2 can help ease the pressure of increased demand, namely: higher crop yields, an improvement in the feed conversion efficiency and a waste reduction. However, not all factors are equally effective in easing this pressure.

Improving crop yields is considered preferable to putting more land into production (Foley et al., 2011) and globally, crop yields, particularly for major crops such as wheat, maize, rice and soybean have been steadily increasing since the 1960 s. However, global agricultural production will have to increase between $60 \%-110 \%$ by 2050 if current trends in population growth and demands for ASF continue (Alexandratos and Bruinsma, 2012; OECD/FAO, 2018; Tilman et al., 2011), making it unlikely to be an effective solution on its own. As a rebound effect, higher crop yields may also increase demand for richer diets in ASF, thereby counteracting any land-sparing effects that increasing crop yields may have. Furthermore, while crop yields remain an important leverage point to ease pressure on resources, their estimation remains a source of uncertainty (Haberl et al., 2011). 
The efficiency with which animals convert feed into ASF has improved significantly in highincome countries. However, these gains have been largely achieved by the increasing use of feed ingredients that could be consumed by humans also (Foley et al., 2011). Feed production requires around $40 \%$ of global arable land (Manceron et al., 2014; Mottet et al., 2017). Human-edible products in livestock feed create competition for land between food and feed. The findings of chapter 2 suggest it is more resource-efficient, especially in terms of land, to eat the crop directly rather than giving it to livestock, despite improved efficiency. Reducing the amount of foodcompetitive feedstuffs for livestock may reduce land use (Schader et al., 2015; Van Kernebeek et al., 2016). A combination of reducing human-edible and reducing overall ASF consumption would result in less pressure on land and decreased competition for biomass resources (Erb et al., 2016). For example, taking optimal land use as a starting point, about one-third of dietary protein from ASF in the per capita diet would represent the optimal use of land (Van Zanten et al., 2018). Both, however, imply a reduction in shares of ASF in the diet from current levels of consumption in highincome countries. It is now widely established that a reduction in ASF would bring considerable benefits to planetary and human health (Behavioural Insights Team, 2012; Willett et al., 2019).

Reductions in food waste along the food supply chains can create several synergies with the bioenergy sector (Muscat et al., 2020). Besides improving food security and self-sufficiency, reducing losses along the chain means a reduced burden on land thus freeing up of land other uses (Welfle et al., 2014).

The above indicates that a combined approach of production and consumption-side strategies for addressing biomass competition is needed. Elsewhere, such strategies are effective in avoiding trade-offs across sustainability goals (Obersteiner et al., 2016) and can present a 'noregret' solution with minimal trade-offs with other policy goals (Van Zanten et al., 2019). Chapter 5 therefore suggests combinations of production and consumption-side solutions by closing biomass and nutrient loops.

\section{The value and use of a biomass stream}

The results of chapter 2 and 3 emphasise the interlinkages between bioenergy, food and agricultural systems. They, for example, interact through competition between feed and fuel uses. This means that bioenergy by-products and waste are used as animal feeds, while agricultural by-products and waste can be utilised as bioenergy. However, the use of waste and by-products for bioenergy entail trade-offs. Many studies find that switching the use of by-products of agricultural production from animal feed to bioenergy has negative environmental effects (Nonhebel, 2007, 2004; David Styles et al., 2015; Tonini et al., 2016; Tufvesson et al., 2013; Van Stappen et al., 2016; Van Zanten et al., 2014). These impacts are associated with the additional land to compensate for the lost feed 
as well as greenhouse gas (GHG) emissions as a consequence of land-use change.

Trade-offs and synergies between feed and fuel are dependent on the rate and scale of resource use. This requires knowledge of the most resource-efficient solution, such as what the best initial use of waste, by-products might be and under what conditions. Integrating food and bioenergy chains can provide benefits. Using by-products of biofuel production, such as distiller's dried grains with solubles, and maize stover as animal feed can replace feeds grown elsewhere. Results from chapter 2 indicate that utilising such by-products eased the burden on land as a resource and reduced the risk of indirect land-use change (Brinkman et al., 2017). While giving credit to biofuel by-products may reduce the land use impact of biofuels, this ignores the fact that using food crops for biofuels may nevertheless have considerable environmental and socio-economic impacts (Fargione et al., 2010; Persson, 2015) and that food crops should be used for food uses before biofuel uses from a food security perspective. Lack of consensus continues to exist on the extent to which the use of biofuel by-products as feed mitigates the impacts of biofuels (Malins, 2017; Shurson, 2017). This raises the question as to which uses (food, feed, fuel, material uses) should biomass be directed for effective resource use. This points towards a need for a cascading principle. The principle of cascading remains a concept under debate (Stegmann et al., 2020; Vis et al., 2016). There are several definitions which can be clustered in three ways: directing biomass towards its highest value use; making full use of a feedstock as possible via co-production of multiple products (e.g. as in an integrated biorefinery), and the sequential use of biomass (Stegmann et al., 2020). As defined in this thesis, cascading is defined as directing biomass towards its highest value use. However, this approach requires discussion of what uses can be considered 'high-value', particularly it raises the question of what is considered valuable for whom. In section 4 below I argue that asking these questions may open up much-needed discussions about the value in the bioeconomy.

A cascading principle is set as a key goal of circular economy and bioeconomy policy in the EU (Stegmann et al., 2020), yet it remains without a clear definition. As set-out EU policy, cascading only means the processing of biomass into a bio-based product that is utilised more than once for material or energy use (European Commission, 2020). Despite the lack of definition or guidance, this thesis (chapter 3 ) identified possible interactions with other EU policy goals and showed where a better definition could be central to improve the coherency between the bioenergy and food systems and address some of the trade-offs between these systems. In chapter 3 , the coherency between agro-food and bioeconomy policy goal was assessed utilising expert knowledge. For example, the cascading principle may affect the EU goal of healthy soils and increasing domestic and organic fertiliser. If the cascading principle does not include soil health as part of its definition, it may run the risk of diverting biomass streams to livestock feed and bioenergy rather than to composting or leaving residues on the field. This is particularly the case if a high market value is placed on these residues or incentives are put in place to utilise residues, such as straw, for 
bioenergy. Currently, such incentives are in place in the revised Renewable Energy Directive (European Parliament, 2009) to utilise these residues for so-called 'advanced biofuels' or biofuels based on non-feed/non-food crops. Synergies are also possible. Chapter 3 shows that the goals of resource efficiency and reduce food waste could be potentially synergistic if waste streams are used for the production of biogas and digestate is used to close nutrient cycles. However, this would only be beneficial if these waste streams are not better used for other purposes before bioenergy. The combination of the cascading principle and the goal of reducing food losses and waste, however, have a strong synergy, as the cascading principle may lead to more effective use of these waste.

As shown above, the findings of this thesis show switching from high-value (market and application value) agricultural by-products such as livestock feed, to lower value uses, such as energy, often entails environmental impacts. This points towards the need for a cascading principle and prioritisation framework for biomass. However, a cascading principle in EU policy remains without a clear definition. Without a clear definition, a cascading principle may result in policy incoherencies. I address how the vagueness of this concept can be addressed in section 4 below.

\section{Uncertain solutions}

Two solutions are often recommended to overcome biomass competition issues (chapter 2 and 3); first, the use of advanced biofuels or biofuels made from waste, by-products and energy crops that are non-food and feed crops. Second, the utilisation of marginal lands, often defined as land that is less productive or economically viable for food production. In both cases, the principle lies in avoiding resources that might compete with food production. However, there is still considerable uncertainty around such solutions.

It is currently difficult to estimate the potential of advanced biofuels to replace conventional biofuels (IRENA, 2019). Currently, advanced biofuel production in the EU is marginal and bioenergy is almost entirely produced from forest biomass or energy crops in the agricultural sector (Gurría et al., 2017). This may be due to technical barriers, many advanced biofuels are still concepts or pilot studies, as well as to economic barriers, such as high implementation costs for implementation (Bourguignon and Vandenbussche, 2013). Experts in chapter 3 questioned advanced biofuels due to several factors, such as the limited supply of waste and residues and technical difficulties to collect waste and residues. Some residues are also incorrectly classified as waste or value-less, as some residues are already used as livestock feed (David Styles et al., 2015; Tufvesson et al., 2013)

Marginal lands were often suggested as a solution to avoid land-use competition by planting bioenergy crops or utilising them for feed crops or grazing. However, as shown in chapter 2 and 4 , 
there is no consensus on the definition of marginal lands as they were often framed from entirely different starting points and perspectives. The viability of marginal lands was questioned either due to the inherent uncertainty of future productivity and the potential costs involved (Bryngelsson and Lindgren, 2013) or due to the possible impacts on rural communities, and nature conservation. Furthermore, there was no consensus on which problems marginal lands can address. I discuss how the lack of consensus can be addressed in section 3 .

To conclude, it is clear that there are considerable trade-offs but also some synergies between different biomass uses. Due to the inherent connections between biomass uses and agricultural production systems, this also presents a challenge for EU policy coherency. It is therefore not surprising that both science and policy provide a multitude of perspectives and solutions on what the problem is and how it can be solved. In the next sections, we focus on how science and policy can deal with this complexity.

\section{How can science and policy deal with complexity, ambiguity and uncertainty?}

\section{The role of complexity at the science-policy interface}

In section 2 above, we highlighted some of the complexity that arises from biomass competition and the policy (in)coherencies that may arise. However, what role does complexity play at the sciencepolicy interface? In chapter 3 , we found considerable uncertainty and context dependencies when experts were asked to assess policy coherence. Experts disagreed on the level of policy coherence between goals and had varying confidence in their scores. From a methodological point of view, it is clear that policy coherence studies in the future would benefit from clarifying where experts disagree and where experts are uncertain. This is important because defining i) the different types of uncertainty ii) and the difference between ambiguity and vagueness is key to better policy advice.

Is it always possible or desirable to reduce uncertainty? This thesis has identified five types of uncertainty: technical, methodological, epistemic, variability and ambiguity uncertainty (Brugnach et al., 2008; Kovacic et al., 2016). As defined in chapter 3, technical uncertainty emerges from technological viability, methodology uncertainty from the limitations of the methods used and epistemic uncertainty from a lack of knowledge. Between these different types of uncertainty, 
some uncertainties may be reduced through technical breakthroughs (technical uncertainty), through methodological breakthroughs, such as more data or better models or framing the question that is appropriate for the problem (methodological or epistemic uncertainty). However, other uncertainties cannot be fully reduced (Ahlgren and Di Lucia, 2014; Di Lucia et al., 2012a; Kovacic et al., 2016), such as variability uncertainty, which has to do with the inherent variability of a system, and ambiguity, which largely arises from multiple incommensurable ways of framing a problem. I have argued, in chapter 4, that ambiguity requires a different approach and it entails making the frames surrounding these problems clear, rather than present frames as a sort of zero-sum game where only one is right or all are wrong. In this sense, the ambiguity emerging from the different ways of framing marginal lands in chapter 4 should not (or rather, cannot) be overcome by better and more accurate definitions of marginal lands, as each frame had a different starting point and set of causal reasoning. Moreover, local communities may not consider marginal lands to be free for use or are not willing to use them for bioenergy (Helliwell, 2018; Skevas et al., 2016).

In chapter 3 we concluded that it is important to distinguish between vagueness and ambiguity. However, it is also important to identify the possible pitfalls of maintaining ambiguity. We defined vagueness as leaving policy goals undefined to serve political purposes, and ambiguity as arising from different frames (chapter 3). The vagueness of policy goals made it difficult to assess policy coherence as coherence depended on too many context dependencies such as temporal and geographical scale, which in turn may affect implementation. In this sense, vagueness stands as a barrier to adequate policy assessment.

Ambiguity, on the other hand, is seen as serving advantageous roles in the policy process. Within the EU for example, Zahariadis, (2008) finds that rather than standing in opposition to policy-making, ambiguity is an integral part of the policy-making process, particularly when there are conflicting interests and fragmented bureaucracies. Ambiguous ideas have been referred to by a multitude of names in the policy literature, such as 'polysemic ideas' (Hannah and Baekkeskov, 2020), or 'multidimensional ideas' (Skogstad and Wilder, 2019). When utilised to form a narrative about an issue, they have been referred to as consensus frames (Candel et al., 2014; Mooney and Hunt, 2009) or normative, explanation and justification narratives (CadilloBenalcazar et al., 2020). Ambiguous ideas have been shown to create coalitions between a diversity of stakeholders (Hannah and Baekkeskov, 2020), and to maintain openness to different kinds of solutions (Beck and Mahony, 2018; Stirling, 2010). They can also help find solutions when the scientific knowledge-base is uncertain or when solutions inherently involve trade-offs (Kovacic and Di Felice, 2019). Particularly when goals are ambiguous, this can limit conflict. The ambiguity of policy instruments or means can leave the option-space open; particularly if the role of organisations is unclear and it is difficult to determine who should take responsibility (Matland, 1995). However, other authors argue that it is precisely this lack of clarity on responsibility that 
fails to bring material results, particularly if the institutional culture and set-up act as blocks (Hannah and Baekkeskov, 2020). Despite ensuring consensus, ambiguous ideas may halt a clear course of action is determined and block legal definitions from being formed (Candel et al., 2014; de Olde and Valentinov, 2019).

\section{What sort of scientific advice do we need?}

It is now recognised that the traditional model of scientific advice needs to change (Felt et al., 2007; Kovacic, 2018; Kovacic et al., 2019b; Stirling, 2010). Calls have been made that the model of 'speaking truth to power' (the process of finding facts and choosing the only logical conclusion based on those facts) can be replaced with other forms of science-policy relationships, ones that are more humble, deliberative and transparent (Stirling, 2007). Despite decades of suggestions to 'make sense together' (Hoppe, 1999) new policy ideas such as the circular economy or the bioeconomy are approached with the traditional model of scientific advice (Kovacic et al., 2019b), leading to misguided attempts to reach a definitive answer to halt controversial debates. There is also the danger that without communicating uncertainty or discussing alternatives, it may make scientific claims susceptible to political pressure (Beck and Mahony, 2018; Stirling, 2010).

In chapter 2, our results showed that when science came to suggesting solutions to biomass competition, these were often wide-ranging and often came from a specific disciplinary perspective. Animal scientists and bioenergy modellers, for example, disagreed about what marginal lands should be used for. In chapter 4 , we furthermore argued that making underlying frames behind policy solutions clear is one step in which scientific advice and policy discussions can be improved. This forms part of a wider call to make the narratives underlying policy more explicit (Cadillo-Benalcazar et al., 2020). The central role that scientific narratives play in shaping the problems studied, the solutions and interventions recommended and their impact on policy has been extensively shown (Candel et al., 2014; Howden et al., 2014; Kovacic and Di Felice, 2019; Lazarevic and Valve, 2017). Particularly, they have been shown in research on sociotechnical imaginaries (collectively held visions of how future technologies can be used) (Jasanoff and Kim, 2015; Verschraegen et al., 2017) and policy framing analyses (Candel et al., 2014). These narratives can have a 'performative power' (Beck and Mahony, 2018) in the sense that through studying certain technologies, pathways or solutions, policy-relevant science has the potential to bring these pathways into being. They may, however, exclude other solution pathways that may be available to policy (Beck and Mahony, 2018). Furthermore, by virtue of scientific assessment, scientific narratives may make explorations of solutions seem politically feasible even though feasibility itself may be contested (Low and Schäfer, 2020). More importantly, when narratives are not made explicit, the role of science in policy-making can become confused. Cadillo-Benalcazar et al., (2020) find with respect to biofuels in the Netherlands, the why (should we have biofuels), 
the what (goals should be achieved through biofuels), and the how (which policy solutions are needed to achieve these goals) get jumbled up. In other words, the 'solutions may end up chasing problems' (Kovacic et al., 2019: pg. 54).

So, given the potential potency of narratives and the problems they may engender, what sort of scientific advice do we need? At the most general level, it requires a science that embraces complexity and humility when the knowledge-base cannot be resolved to come to one singular answer (Stirling, 2010). On a more practical level, it can mean alternative roles for numbers and metrics in governance which are more reflexive, equitable and assessed for quality (Kovacic, 2018; Voelker et al., 2019). It can also mean embedding the precautionary principle in scientific deliberation (Stirling, 2007) and not cutting out 'uncomfortable knowledge' (alternative framings of a policy solution) that may fall outside of the scientific narrative (Saltelli and Giampietro, 2017). Several methodological approaches have been developed to deal with this uncertainty, such as the NUSAP system (notational system for the management and communication of uncertainty in science for policy) that helps communicate uncertainty and risk (Van Der Sluijs et al., 2005). Another approach is Quantitative Story-Telling (Cadillo-Benalcazar et al., 2020; Saltelli and Giampietro, 2017), an approach where different frames or narratives are presented, along with associated measurements, rather than a singular way of looking at the problem. Particularly when the stakes are very high, such as with wide-scale deployment of bioenergy or other bio-based products, scientific outcomes may need to be held up to democratic scrutiny (Beck and Mahony, 2018). The framings around marginal lands found in Chapter 4 led to ambiguity that could not be reduced as different actors disagreed on the problem (land-use change, land abandonment, biodiversity loss) as well as the solutions (subsidies for bioenergy on marginal land, rewilding). Rather than attempting to reduce these frames to a singular frame, I argue that deliberative processes are needed as these frames were largely ambiguous due to social and normative reasons. Deliberative processes that have long been used are stakeholder participation through interactive modelling, scenario workshops and GIS mapping (Stirling, 2010, 2007). Designing and embedding these deliberative processes presents new challenges in governance such as how to deal with input from a diversity of stakeholders as well as how to avoid the pitfalls of group dynamics and power struggles.

Governing complex interactions will require a degree of adaptability. Kovacic et al., (2019) have suggested that governance needs to take place in complexity rather than governance of complexity. In essence, this means that actors recognise themselves as constantly adapting to changing processes rather than steering these processes. This aims for smaller, localised and context-based interventions. The benefits of such approaches are multiple: it ensures solutions are realistic and democratic as well as can better foresee or adapt to new developments. The smallwins governance framework is one example of a framework that can operate within complexity and that can make productive use of ambiguity (Termeer and Metze, 2019). By energising actors 
with concrete examples, tempered ambition and embracing ambiguity that encourages multiple actors, it can overcome uncertainty paralysis while remaining realistic.

\section{Scientific advice in times of uncertainty}

At the time of writing, many countries around the world are experiencing a second wave of coronavirus. Many people, even when infected with the virus, still deny its existence or its severity. Many also deny the existence of climate change despite overwhelming evidence. Talk of humility in science, ambiguity and uncertainty in science may therefore seem inappropriate or even risky when many are denying its claims (even when their health is at stake as in the case of the coronavirus). Nevertheless, while this distrust in science cannot be fully attributed to scientists' themselves, I do believe that we, as scientists, have failed to communicate uncertainty and have not taken full responsibility for how science is utilised.

I would like to end with a short reflection on the role of science in society concerning sustainability. This thesis was not initially written with a Science and Technology Studies (STS) frame in mind, however many of the insights are inspired by this interdisciplinary field. Here I would reiterate what STS scholars have been saying for decades: that we all need to collectively accept that science is inevitably embedded in a political process and that scientists will have to take some responsibility for what is done with their results. Furthermore, science has so far had a very restricted vision of nature and has marginalised alternative visions of nature (as well as the people who hold them). This remains a huge stumbling block in achieving sustainable use of biomass and sustainability in general, despite efforts by many to include indigenous knowledge in ecological assessments (IPBES, 2019). As philosopher Bruno Latour has argued; if scientists were transparent about how science really functions as a social process in which people, politics, institutions and peer review play key parts, scientists would have an easier time convincing people of scientific claims (Latour, 2018).

\section{Towards a circular bio-based economy}

Given the challenge in balancing the complexity of biomass uses with varying policy goals, what practical steps can be made towards more sustainable use of biomass? As highlighted in section 2 of this discussion and chapters 2 and 3, biomass trade-offs cut across the boundaries of food and energy systems as well as those of different policy domains. Given these interconnections, I argue the first step is to take a more integrated view of biomass that connects different biomass uses. Currently, resource accounting frameworks rely on semantic differentiation between flows, accounting, for example, for all waste or food in the system. However, if we are to move towards 
a more sustainable and circular bioeconomy, where flows are (re)cycled, it will be important to make a distinction between flows depending on more relevant factors, such as virginity of material, stage in the supply chain, end-use or purpose of flow, resource and energy investments into a material flow, or the number of times a material flow has been recycled, amongst others. Flows may be distinguished into primary, secondary or tertiary flows, rather than whether it is food, feed or fuel. These can be defined depending at which stage flows enter the economy and the number of times a material has been recycled (Giampietro, 2019). In practical terms, this can also mean taking a nexus approach to resource assessment (Giampietro et al., 2013; Obersteiner et al., 2016; Zhang et al., 2018) and zooming out of product-based environmental assessments to system-level assessments (Van Hal et al., 2019b).

As I argued above in section 2, a cascading principle is needed. I also pointed out that as it stands currently in EU policy, a cascading principle remains vague, resulting in trade-offs between agricultural and bioeconomy policy goals. In chapter $5 \mathrm{I}$, therefore, proposed five ecological principles for a more circular bio-based economy that can address the current vagueness of cascading principle found in chapter 3 . Here I defined the order of ecological principles as 1) safeguarding and regenerating the health of our agroecosystems; 2) avoiding the production of non-essential products and waste of essential ones; 3) using biomass streams for basic human needs; 4) utilising and recycling all by-products of agroecosystems, and 5) prioritising renewable energy and minimising energy use. As these ecological principles are general, I delineate several practical implications if these principles are followed. First, it implies livestock is fed only biomass inedible or unsuitable for direct human consumption (Muscat et al., 2020; Van Zanten et al., 2019). This, however, also implies that the quantity of production and consumption of ASF is determined by the availability of such biomass streams and the carrying capacity of ecosystems. Second, it implies that biomass is directed towards material use above bioenergy whenever possible. EU policy-incentives often direct biomass towards energy before material use; only once biomass is classified as waste, does it follow cascading principles (Birdlife Europe and European Environmental Bureau, 2014; Dammer and Essel, 2015; Keegan et al., 2013). This can be corrected if biomass is treated more integratively in policymaking by avoiding policy 'silos' and providing generalised guidelines for cascading use. Third, biomass streams that are currently under-utilised or wasted, such as grass, food by-products (e.g. beet leaves or wheat bran), insects and food waste, are used higher up in cascading frameworks (Van Hal et al., 2019a). Fourth, a differentiation between a processed product and one that is directly consumed would be helpful. A product may serve the same purpose, but processing will mean additional resources such as energy and water, both due to the processing and due to likely need for transportation (Adhikari and Ozarska, 2018; Giampietro, 2019; Giampietro et al., 2013; Milani et al., 2011). Fifth, as chapter 4 shows, marginal lands cannot be considered 'free' as they are ultimately subject to the same contestations as productive land i.e. arguments around whether they are best used for biodiversity, bioenergy, food production or whether they should be utilised at all. Given this, marginal lands should also be 
considered a resource that requires careful management.

The second step would be to reimagine what are 'valuable' biomass uses in the context of sustainability. Sustainability elsewhere has been defined as formed by three equally important pillars: the economic, the social and the environmental. However, given that the capacity of agroecosystems to support our energy and material needs is ultimately limited by its biophysical boundaries or 'planetary boundaries' (Erb et al., 2016; Smil, 2012; Steffen et al., 2015), I argue, following Fischer et al., (2007) that these biophysical boundaries form the ultimate boundary of sustainability (chapter 5 ). The degree to which humanity respects these boundaries forms the option-space in which socio-economic goals must be achieved (Fischer et al., 2007; Raworth, 2017). Resources should therefore be used more effectively than is currently the case. In the case of biomass, the cascading principle/hierarchy is utilised to direct biomass towards highervalue uses and material uses before energy (Haberl and Geissler, 2000; Sirkin and Houten, 1994). As it has been utilised so far in the literature on bioeconomy, high-value uses are defined as 'higher economic value' e.g. the value pyramid (Bos-Brouwers et al., 2012). However, as this framework may not address all three pillars of sustainability (environmental, economic and the social) I suggest that higher value uses should instead be defined by a framework of human needs.

Given considerable pressure on the planet's biophysical boundaries, the relationship between sustainability and human resource-use can be re-examined through a different frame: that of human-needs and ultimately, human well-being. It is important to look at human-wellbeing if human needs which rely on biomass resources are to remain balanced with planetary boundaries and the social foundation respected (see below). For this reason, along with the planetary boundaries concept, others have suggested the concept of the social foundation as a set of wellbeing criteria that must be met (Raworth, 2017). Little research has so far focused on human-wellbeing in resource-use assessments; traditionally allocation of resources is instead determined by market value. However, there is now a growing body of literature that is embedding discussions of humanneeds and human well-being into assessments of resource use (Brand-Correa and Steinberger, 2017; Millward-Hopkins et al., 2020; Rao and Min, 2018). This forms part of a wider discussion to explore the meaning of value in our economies (Pirgmaier, 2021; Raworth, 2017), shifting to a definition where 'use-value' i.e. its contribution to human-wellbeing is separate from its exchange value. In other words, the economy serves human and ecological well-being rather than the opposite. Of course, what exactly human needs are, entails making normative choices and this will depend highly on what we value as a society. However, human societies are always engaging in these normative choices around value by how economies are structured (Pirgmaier, 2021). The emphasis on human needs and value in directing biomass is a way to make these choices more explicit, in the hope that the perspective or frames (chapter 4) utilised by science and policy are made clear. It would also open up the question of whether such anthropocentrism is justified and whether animal wellbeing should also be considered. 
Finally, even if we define the ultimate boundaries of sustainability as being biophysical, we need to pay more attention to the social foundation and the social processes that are needed to achieve it. The findings of chapter 2 indicate that there is still a need for biophysical disciplines to be married with social science disciplines. Social science can contribute in two ways, in understanding how the transition can be supported and in understanding how sustainability can be achieved while also providing for human-wellbeing. This is particularly important because so far planetary and human well-being have gone in opposite directions (O'Neill et al., 2018). It is also important to acknowledge, amid reports of severe biodiversity decline (IPBES, 2019) that the starting point that the focus on only human-wellbeing is anthropocentric. Given our impact on other species and the possibility that harvesting energy from the biosphere leaves little for other species (Haberl and Geissler, 2000), humanity can make room for other species' wellbeing.

\section{Conclusions}

This thesis illustrates that the problem of biomass competition is characterised by interactions, trade-offs and synergies. In short, it is a complex problem that will require careful governance by using an integrated approach to biomass and an emphasis on policy coherence. The following conclusions can be drawn from this thesis:

- Biomass competition is a complex problem and leads to a multitude of interactions, tradeoffs and synergies. High demands for resource-intensive products, such as animal-source food and bioenergy, reduce the biophysical option space. Bioenergy and agricultural systems are closely interconnected and high-value biomass streams being diverted to bioenergy can cause negative environmental impacts.

- Marginal land is subject to the same debates about the best use of land (e.g. should it be used for biodiversity, bioenergy or food production) as for more productive land. Marginal land is therefore not 'free for use' or 'surplus' land. Marginal land should therefore be treated as a resource that requires careful management like arable land

- When assessing policy coherence, it is not enough to only measure policy coherence; one also needs to measure disagreement and confidence of experts in assessing policy interactions

- The cascading principle is vaguely defined in the EU policy literature; we have defined five ecological principles, whose implementation could lead to potential synergies between the bioeconomy and the agro-food policy domains.

- It is important to distinguish between different types of uncertainty when dealing with complexity as this determines the course of action one needs to take. This thesis distinguished 
between five types of uncertainty namely the technical, methodological, epistemic, variability and ambiguity. Ambiguity arises from incommensurable ways of framing the problem and this means that deliberative approaches in science and governance are needed, as opposed to accurate definitions. Vagueness and ambiguity should be distinguished. Vagueness of policy goals can be addressed while ambiguity needs to be embraced.

- A transition towards a circular bio-based economy requires involving stakeholders, leaving room for ambiguity, having an ambitious vision and a mix of top-down and bottom-up governance approaches.

- To achieve more sustainable use of biomass, it is important to take a more integrated view of biomass that connects different biomass uses. One should define what is a 'highvalue' biomass use through a human-needs framework directed towards human wellbeing. 
The Battle for Biomass | Abigail Muscat

General Discussion 


\section{Bibliography}

Abson, D.J., Fischer, J., Leventon, J., Newig, J., Schomerus, T., Vilsmaier, U., von Wehrden, H., Abernethy, P., Ives, C.D., Jager, N.W., Lang, D.J., 2017. Leverage points for sustainability transformation. Ambio 46, 30-39. https://doi.org/10.1007/s13280-016-0800-y

Ackerman, K., Conard, M., Culligan, P., Plunz, R., Sutto, M.P., Whittinghill, L., 2014. Sustainable food systems for future cities: The potential of urban agriculture. Econ. Soc. Rev. (Irel). 45, 189-206.

Adhikari, S., Ozarska, B., 2018. Minimizing environmental impacts of timber products through the production process "From Sawmill to Final Products." Environ. Syst. Res. 7. https://doi. org/10.1186/s40068-018-0109-x

Ahlgren, S., Di Lucia, L., 2014. Indirect land use changes of biofuel production - a review of modelling efforts and policy developments in the European Union. Biotechnol. Biofuels 7, 35. https://doi.org/10.1186/1754-6834-7-35

Akgul, O., Shah, N., Papageorgiou, L.G., 2012. Economic optimisation of a UK advanced biofuel supply chain. Biomass and Bioenergy 41, 57-72. https://doi.org/10.1016/j. biombioe.2012.01.040

Al-Saidi, M., Elagib, N.A., 2017. Towards understanding the integrative approach of the water, energy and food nexus. Sci. Total Environ. 574, 1131-1139. https://doi.org/10.1016/j. scitotenv.2016.09.046

Alexander, P., Prestele, R., Verburg, P.H., Arneth, A., Baranzelli, C., Batista e Silva, F., Brown, C., Butler, A., Calvin, K., Dendoncker, N., Doelman, J.C., Dunford, R., Engström, K., Eitelberg, D., Fujimori, S., Harrison, P.A., Hasegawa, T., Havlik, P., Holzhauer, S., Humpenöder, F., Jacobs-Crisioni, C., Jain, A.K., Krisztin, T., Kyle, P., Lavalle, C., Lenton, T., Liu, J., Meiyappan, P., Popp, A., Powell, T., Sands, R.D., Schaldach, R., Stehfest, E., Steinbuks, J., Tabeau, A., van Meijl, H., Wise, M.A., Rounsevell, M.D.A., 2017. Assessing uncertainties in land cover projections. Glob. Chang. Biol. 23, 767-781. https://doi.org/10.1111/ gcb. 13447

Alexandratos, N., Bruinsma, J., 2012. WORLD AGRICULTURE TOWARDS 2030 / 2050 The 2012 Revision. Food Agric. Organ. United Nations 146. https://doi.org/10.1016/S0264$8377(03) 00047-4$

Andersen, R.S., Towers, W., Smith, P., 2005. Assessing the potential for biomass energy to contribute to Scotland's renewable energy needs. Biomass and Bioenergy 29, 73-82. https://doi.org/10.1016/j.biombioe.2005.04.004

Antwi-agyei, P., Dougill, A.J., Stringer, L.C., 2017. Assessing Coherence between Sector Policies and Climate Compatible Development : Opportunities for Triple Wins 1-16. https://doi. org/10.3390/su9112130

Aschemann-Witzel, J., de Hooge, I., Amani, P., Bech-Larsen, T., Oostindjer, M., 2015. 
Consumer-related food waste: Causes and potential for action. Sustain. 7, 6457-6477. https://doi.org/10.3390/su7066457

Bai, Z., Caspari, T., Gonzalez, M.R., Batjes, N.H., Mäder, P., Bünemann, E.K., de Goede, R., Brussaard, L., Xu, M., Ferreira, C.S.S., Reintam, E., Fan, H., Mihelič, R., Glavan, M., Tóth, Z., 2018. Effects of agricultural management practices on soil quality: A review of longterm experiments for Europe and China. Agric. Ecosyst. Environ. 265, 1-7. https://doi. org/10.1016/j.agee.2018.05.028

Banerjee, A., 2011. Food, Feed, Fuel: Transforming the Competition for Grains. Dev. Change 42, 529-557. https://doi.org/10.1111/j.1467-7660.2011.01704.x

Banse, M; Junker, M; Prins, AG; Stehfest, E; Tabeau, A; Woltjer G; van Meijl, H., 2014. Global impact of multinational biofuel mandates on land use, feedstock prices, international trade and land-use greenhouse gas emissions. Landbauforschung 64, 59-72. https://doi. org/10.3220/LBF_2014_59-72

Banse, M., van Meijl, H., Tabeau, A., Woltjer, G., Hellmann, F., Verburg, P.H., 2011. Impact of EU biofuel policies on world agricultural production and land use. Biomass and Bioenergy 35, 2385-2390. https://doi.org/10.1016/j.biombioe.2010.09.001

Barnes, S.J., 2019. Out of sight, out of mind: Plastic waste exports, psychological distance and consumer plastic purchasing. Glob. Environ. Chang. 58, 101943. https://doi.org/10.1016/j. gloenvcha.2019.101943

Bartoli, A., Cavicchioli, D., Kremmydas, D., Rozakis, S., Olper, A., 2016. The impact of different energy policy options on feedstock price and land demand for maize silage: The case of biogas in Lombardy. Energy Policy 96, 351-363. https://doi.org/10.1016/j. enpol.2016.06.018

Beck, S., Mahony, M., 2018. The politics of anticipation: The IPCC and the negative emissions technologies experience. Glob. Sustain. 1, 4-11. https://doi.org/10.1017/sus.2018.7

Behavioural Insights Team, 2012. A Menu for Change: using behavioural science to promote sustainable diets around the world. https://www.bi.team/wp-content/uploads/2020/03/ BIT_Report_A-Menu-for-Change_Webversion_2020.pdf.pdf

Béland, D., Cox, R.H., 2016. Ideas as coalition magnets: coalition building, policy entrepreneurs, and power relations. J. Eur. Public Policy 23, 428-445. https://doi.org/10.1080/13501763. 2015.1115533

Ben Fradj, N., Jayet, P.A., Aghajanzadeh-Darzi, P., 2016. Competition between food, feed, and (bio)fuel: A supply-side model based assessment at the European scale. Land use policy 52, 195-205. https://doi.org/10.1016/j.landusepol.2015.12.027

Benayas, J.M.R., Bullock, J.M., 2015. Rewilding European Landscapes, Rewilding European Landscapes. Springer International Publishing, Cham. https://doi.org/10.1007/978-3-31912039-3

Bergen, S.D., Bolton, S.M., Fridley, J.L., 2001. Design principles for ecological engineering. Ecol. Eng. 18, 201-210. https://doi.org/10.1016/S0925-8574(01)00078-7 
Beringer, T., Lucht, W., Schaphoff, S., 2011. Bioenergy production potential of global biomass plantations under environmental and agricultural constraints. GCB Bioenergy 3, 299-312. https://doi.org/10.1111/j.1757-1707.2010.01088.x

Berndes, G., Ahlgren, S., B??orjesson, P., Cowie, A.L., 2015. Bioenergy and Land Use Change-State of the Art. Adv. Bioenergy Sustain. Chall. 2, 249-271. https://doi. org/10.1002/9781118957844.ch16

Bertalanffy, L. Von, 1950. An outline of general system theory. Br. J. Philos. Sci. https://doi. org/10.1093/bjps/l.2.134

Bidart, C., Fröhling, M., Schultmann, F., 2014. Livestock manure and crop residue for energy generation: Macro-assessment at a national scale. Renew. Sustain. Energy Rev. 38, 537550. https://doi.org/10.1016/j.rser.2014.06.005

Bioplastics Europe, 2019. Bioplastics: facts and figures. https://doi.org/10.1016/S00027138(09)61887-2

Birdlife Europe, European Environmental Bureau, 2014. Cascading use of biomass : opportunities and obstacles in EU policies 2013-2016. Available at: http://www.birdlife. org/sites/default/files/attachments/cascading_use_memo_final.pdf

Boland, A., Cherry, M.G., Dickson, R., 2014. Doing a systematic review: a student's guide, Second edi. ed. SAGE. https://doi.org/10.1007/s13398-014-0173-7.2

Borras Jr, S.M., Seufert, P., Backes, S., Fyfe, D., Herre, R., Michele, L., Mills, E., 2017. Land Grabbing and Human Rights: The role of EU Actors Abroad. FIAN Int. 40.

Bos-Brouwers, H., Langelaan, B., Sanders, J., 2012. Chances for biomass. Available at: https:// edepot.wur.nl/248866).

Bos, H.L., Broeze, J., 2020. Circular biobased production systems in the context of current biomass and fossil demand. Biofuels, Bioprod. Biorefining bbb.2080. https://doi. org/10.1002/bbb.2080

Bourguignon, D., Vandenbussche, T., 2013. Advanced biofuels: Technologies and EU policy.

Bouwman, A.F., Van Vuuren, D.P., Derwent, R.G., Posch, M., 2002. A global analysis of acidification and eutrophication of terrestrial ecosystems. Water. Air. Soil Pollut. 141, 349-382. https://doi.org/10.1023/A:1021398008726

Bramer, W.M., Milic, J., Mast, F., 2017. Reviewing retrieved references for inclusion in systematic reviews using EndNote. J. Med. Libr. Assoc. 105, 84-87. https://doi.org/10.5195/ JMLA.2017.111

Brand-Correa, L.I., Steinberger, J.K., 2017. A Framework for Decoupling Human Need Satisfaction From Energy Use. Ecol. Econ. 141, 43-52. https://doi.org/10.1016/j. ecolecon.2017.05.019

Brinkman, M.L.J., Wicke, B., Faaij, A.P.C., 2017. Low-ILUC-risk ethanol from Hungarian maize. Biomass and Bioenergy 99, 57-68. https://doi.org/10.1016/j.biombioe.2017.02.006

Brugnach, M., Dewulf, A., Henriksen, H.J., van der Keur, P., 2011. More is not always better: Coping with ambiguity in natural resources management. J. Environ. Manage. 92, 78-84. 
https://doi.org/10.1016/j.jenvman.2010.08.029

Brugnach, M., Dewulf, A., Pahl-Wostl, C., Taillieu, T., 2008. Toward a relational concept of uncertainty: About knowing too little, knowing too differently, and accepting not to know. Ecol. Soc. 13. https://doi.org/10.5751/ES-02616-130230

Bryan, B.A., Runting, R.K., Capon, T., Perring, M.P., Cunningham, S.C., Kragt, M.E., Nolan, M., Law, E.A., Renwick, A.R., Eber, S., Christian, R., Wilson, K.A., 2016. Designer policy for carbon and biodiversity co-benefits under global change. Nat. Clim. Chang. 6, 301-305. https://doi.org/10.1038/nclimate2874

Bryngelsson, D.K., Lindgren, K., 2013. Why large-scale bioenergy production on marginal land is unfeasible: A conceptual partial equilibrium analysis. Energy Policy 55, 454-466. https:// doi.org/10.1016/j.enpol.2012.12.036

Burgess, P.J., Rivas Casado, M., Gavu, J., Mead, A., Cockerill, T., Lord, R., Van Der Horst, D., Howard, D.C., 2012. A framework for reviewing the trade-offs between, renewable energy, food, feed and wood production at a local level. Renew. Sustain. Energy Rev. 16, 129-142. https://doi.org/10.1016/j.rser.2011.07.142

Byrkjeflot, H., Pedersen, J.S., Svejenova, S., 2013. From label to practice: The process of creating new Nordic cuisine. J. Culin. Sci. Technol. 11, 36-55. https://doi.org/10.1080/154 28052.2013.754296

Cadillo-Benalcazar, J.J., Bukkens, S.G.F., Ripa, M., Giampietro, M., 2020. Why does the European Union produce biofuels? Examining consistency and plausibility in prevailing narratives with quantitative storytelling. Energy Res. Soc. Sci. 71, 101810. https://doi. org/10.1016/j.erss.2020.101810

Callesen, I., Grohnheit, P.E., Østergård, H., 2010. Optimization of bioenergy yield from cultivated land in Denmark. Biomass and Bioenergy 34, 1348-1362. https://doi.org/10.1016/j. biombioe.2010.04.020

Candel, J.J.L., Breeman, G.E., Stiller, S.J., Termeer, C.J.A.M., 2014. Disentangling the consensus frame of food security: The case of the EU Common Agricultural Policy reform debate. Food Policy 44, 47-58. https://doi.org/10.1016/j.foodpol.2013.10.005

Carus, M., Dammer, L., Puente, Á., Raschka, A., Arendt, O., 2017. Bio-based drop-in, smart drop-in and dedicated chemicals 1-3. http://bio-based.eu/downloads/bio-based-drop-insmart-drop-in-and-dedicated-chemicals/

Cashion, T., Le Manach, F., Zeller, D., Pauly, D., 2017. Most fish destined for fishmeal production are food-grade fish. Fish Fish. 18, 837-844. https://doi.org/10.1111/faf.12209

Castro, M.B.G., Remmerswaal, J.A.M., Brezet, J.C., Reuter, M.A., 2007. Exergy losses during recycling and the resource efficiency of product systems. Resour. Conserv. Recycl. 52, 219-233. https://doi.org/10.1016/j.resconrec.2007.01.014

CEPF and ELO, 2007. FP(07)2178:7 Brussels, 23 November 2007. Joint position on the promotion of bioenergy from forests. Available at: https://copa-cogeca.eu/Archive/ Download? $\mathrm{id}=336123$ 
Chae, Y., An, Y.J., 2018. Current research trends on plastic pollution and ecological impacts on the soil ecosystem: A review. Environ. Pollut. 240, 387-395. https://doi.org/10.1016/j. envpol.2018.05.008

Chakravorty, U., Hubert, M.-H., Nøstbakken, L., 2009. Fuel Versus Food. Annu. Rev. Resour. Econ. 1, 645-663. https://doi.org/10.1146/annurev.resource.050708.144200

Chaudhary, A., Kastner, T., 2016. Land use biodiversity impacts embodied in international food trade. Glob. Environ. Chang. 38, 195-204. https://doi.org/10.1016/j. gloenvcha.2016.03.013

Cho, R., 2017. The truth about bioplastics [WWW Document]. Phys.org. URL https://phys.org/ news/2017-12-truth-bioplastics.html (accessed 9.17.19).

Churkina, G., Organschi, A., Reyer, C.P.O., Ruff, A., Vinke, K., Liu, Z., Reck, B.K., Graedel, T.E., Schellnhuber, H.J., 2020. Buildings as a global carbon sink. Nat. Sustain. https://doi. org/10.1038/s41893-019-0462-4

COPA-COGECA, 2020. LONG-TERM VISION FOR RURAL AREAS - THE PERSPECTIVE OF FARMERS AND AGRI-FOOD. https://copa-cogeca.eu/Archive/Download?id=3819012

Costanza, R., Hart, M., Posner, S., Talberth, J., 2009. Beyond GDP : The Need for New Measures of Progress Beyond GDP : The Need for New Measures of Progress. Bost. Univ. 1-47. https://doi.org/0109 970401

Dahiya, S., Kumar, A.N., Shanthi Sravan, J., Chatterjee, S., Sarkar, O., Mohan, S.V., 2018. Food waste biorefinery: Sustainable strategy for circular bioeconomy. Bioresour. Technol. 248, 2-12. https://doi.org/10.1016/j.biortech.2017.07.176

Daioglou, V., Doelman, J.C., Wicke, B., Faaij, A., van Vuuren, D.P., 2019. Integrated assessment of biomass supply and demand in climate change mitigation scenarios. Glob. Environ. Chang. 54, 88-101. https://doi.org/10.1016/j.gloenvcha.2018.11.012

Dale, B., Klein, K., Wright, L., Perlack, R., Downing, M., Graham, R., 2011. Interactions among bioenergy feedstock choices landscape dynamics and land use. Ecol. Appl. 21, 10391054.

Damerau, K., Patt, A.G., van Vliet, O.P.R., 2016. Water saving potentials and possible tradeoffs for future food and energy supply. Glob. Environ. Chang. 39, 15-25. https://doi. org/10.1016/j.gloenvcha.2016.03.014

Dammer, L., Essel, R., (Nova Institute) 2015. Quo vadis , cascading use of biomass ? http://biobased.eu/downloads/quo-vadis-cascading-use-of-biomass/

Davis, K.F., D'Odorico, P., 2015. Livestock intensification and the influence of dietary change: A calorie-based assessment of competition for crop production. Sci. Total Environ. 538, 817-823. https://doi.org/10.1016/j.scitotenv.2015.08.126

Davis, K.F., D'Odorico, P., Rulli, M.C., 2014. Moderating diets to feed the future. Earth's Futur. 2, 559-565. https://doi.org/10.1002/2014EF000254

Daystar, J., Chapman, L., Moore, M., Pires, S., Golden, J., 2019. Quantifying apparel consumer use behavior in six countries: Addressing a data need in life cycle assessment modeling. J. 
Text. Apparel, Technol. Manag. 11.

de Boer, I.J.M., Van Ittersum, M.K., 2018. Circularity in agricultural production. Mansholt lecture 2018 - Royal Flemish Academy of Belgium for Science and the Arts Paleis der Academiën, Brussels, Belgium. https://edepot.wur.n1/470625

de Fazio, F., 2019. Enhancing Consumer Product Repairability: A case study on vacuum cleaners. Master Thesis. Delft University of Technology. http://resolver.tudelft.nl/uuid:810db9a69718-4451-8f8f-67ad0cdccad9

de Olde, E.M., Valentinov, V., 2019. The Moral Complexity of Agriculture: A Challenge for Corporate Social Responsibility. J. Agric. Environ. Ethics 32, 413-430. https://doi. org/10.1007/s10806-019-09782-3

De Schutter, O., Jacobs, N., Clément, C., 2020. A ‘Common Food Policy’ for Europe: How governance reforms can spark a shift to healthy diets and sustainable food systems. Food Policy 96, 101849. https://doi.org/10.1016/j.foodpol.2020.101849

de Visser, C.L.M., Schreuder, R., Stoddard, F., 2014. The EU's dependency on soya bean import for the animal feed industry and potential for EU produced alternatives. Ocl 21, 8. https:// doi.org/10.1051/ocl/2014021

Demartini, E., Gaviglio, A., Gelati, M., Cavicchioli, D., 2016. The effect of biogas production on farmland rental prices: Empirical evidences from Northern Italy. Energies 9, 1-23. https:// doi.org/10.3390/en9110965

Dewulf, A., Craps, M., Bouwen, R., Taillieu, T., Pahl-Wostl, C., 2005. Integrated management of natural resources: Dealing with ambiguous issues, multiple actors and diverging frames. Water Sci. Technol. 52, 115-124. https://doi.org/10.2166/wst.2005.0159

Dewulf, A., Gray, B., Putnam, L., Lewicki, R., Aarts, N., Bouwen, R., Van Woerkum, C., 2009. Disentangling approaches to framing in conflict and negotiation research: A metaparadigmatic perspective, Human Relations. https://doi.org/10.1177/0018726708100356

Di Lucia, L., Ahlgren, S., Ericsson, K., 2012a. The dilemma of indirect land-use changes in EU biofuel policy - An empirical study of policy-making in the context of scientific uncertainty. Environ. Sci. Policy 16, 9-19. https://doi.org/10.1016/j.envsci.2011.11.004

Di Lucia, L., Ahlgren, S., Ericsson, K., 2012b. The dilemma of indirect land-use changes in EU biofuel policy - An empirical study of policy-making in the context of scientific uncertainty. Environ. Sci. Policy 16, 9-19. https://doi.org/10.1016/j.envsci.2011.11.004

Directive 2008/98/EC, 2008. Directive 2008/98/EC on waste (Waste Framework Directive) Environment - European Commission, Last Accessed: 06/03/2017.

Dixon, J. et al. 2010. Feed, food and fuel: Competition and potential impacts on small-scale crop-livestock-energy farming systems Nairobi: ILRI. https://cgspace.cgiar.org/bitstream/ handle/10568/3018/Food_feed_fuel\%20final.pdf?sequence=1\&isAllowed=y

Don, A., Osborne, B., Hastings, A., Skiba, U., Carter, M.S., Drewer, J., Flessa, H., Freibauer, A., Hyvönen, N., Jones, M.B., Lanigan, G.J., Mander, Ü., Monti, A., Djomo, S.N., Valentine, J., Walter, K., Zegada-Lizarazu, W., Zenone, T., 2012. Land-use change to bioenergy 
production in Europe: Implications for the greenhouse gas balance and soil carbon. GCB Bioenergy 4, 372-391. https://doi.org/10.1111/j.1757-1707.2011.01116.x

Doyal, L., Gough, I., 1991. A theory of human need. A theory Hum. need. https://doi. org/10.1016/0016-3287(92)90123-w

Drewnowski, a., Popkin, B.M., 1997. The Nutrition Transition: New Trends in the Global Diet. Nutr. Rev. 55, 31-43. https://doi.org/10.1111/j.1753-4887.1997.tb01593.x

Eickhout, B., 2015. To build a bio-economy, Europe needs to cut bioenergy - EURACTIV.com [WWW Document]. Euractiv. URL https://www.euractiv.com/section/agriculture-food/ opinion/to-build-a-bio-economy-europe-needs-to-cut-bioenergy/ (accessed 11.27.20).

Elbersen, B., Fritsche, U., Petersen, J.-E., Lesschen, J.P., Böttcher, H., Overmars, K., 2013. Assessing the effect of stricter sustainability criteria on EU biomass crop potential. Biofuels, Bioprod. Biorefining 7, 173-192. https://doi.org/10.1002/bbb.1396

Ellen MacArthur Foundation, 2015. Growth within: a circular economy vision for a competitive europe. Ellen MacArthur Found. 100. https://www.ellenmacarthurfoundation.org/assets/ downloads/publications/EllenMacArthurFoundation_Growth-Within_July15.pdf

Emilsson, K., Johansson, H., Wennerhag, M., 2020. Frame disputes or frame consensus? "environment" or "welfare" first amongst climate strike protesters. Sustain. 12, 1-20. https://doi.org/10.3390/su12030882

Erb, K.-H., Lauk, C., Kastner, T., Mayer, A., Theurl, M.C., Haberl, H., 2016. Exploring the biophysical option space for feeding the world without deforestation. Nat. Commun. 7, 11382. https://doi.org/10.1038/ncomms11382

Erb, K.H., Haberl, H., Plutzar, C., 2012. Dependency of global primary bioenergy crop potentials in 2050 on food systems, yields, biodiversity conservation and political stability. Energy Policy 47, 260-269. https://doi.org/10.1016/j.enpol.2012.04.066

Erb, K.H., Krausmann, F., Lucht, W., Haberl, H., 2009. Embodied HANPP: Mapping the spatial disconnect between global biomass production and consumption. Ecol. Econ. 69, 328334. https://doi.org/10.1016/j.ecolecon.2009.06.025

Eriksen, M., Lebreton, L.C.M., Carson, H.S., Thiel, M., Moore, C.J., Borerro, J.C., Galgani, F., Ryan, P.G., Reisser, J., 2014. Plastic Pollution in the World's Oceans: More than 5 Trillion Plastic Pieces Weighing over 250,000 Tons Afloat at Sea. PLoS One 9, 1-15. https://doi. org/10.1371/journal.pone.0111913

Ertl, P., Klocker, H., Hörtenhuber, S., Knaus, W., Zollitsch, W., 2015. The net contribution of dairy production to human food supply: The case of austrian dairy farms. Agric. Syst. 137, 119-125. https://doi.org/10.1016/j.agsy.2015.04.004

Ertl, P., Steinwidder, A., Schönauer, M., Krimberger, K., Knaus, W., Zollitsch, W., 2016. Net food production of different Livestock: A national analysis for Austria including relative occupation of different land categories. Bodenkultur 67, 91-103. https://doi.org/10.1515/ boku-2016-0009

European Commission, 2020. EN Horizon 2020 Work Programme 2018-2020 9 . Food security, 
sustainable agriculture and forestry , marine, maritime and inland water research and the bioeconomy. https://ec.europa.eu/research/participants/data/ref/h2020/wp/2018-2020/ main/h2020-wp1820-food_en.pdf

European Bioeconomy Alliance, 2020. Taxonomy Regulation's draft delegated act on climaterelated objectives and its annexes 1-5.

European Commission, 2018. A sustainable bioeconomy for Europe : strengthening the connection between economy, society and the environment. Updated Bioeconomy Strategy. https://doi.org/10.2777/478385

European Commission 2020: A Farm to Fork Strategy for a fair, healthy and environmentallyfriendly food system COM/2020/381 final

European Commission, 2012a. Innovating for Sustainable Growth: A Bioeconomy for Europe, Official Journal of the European Union. https://doi.org/10.1089/ind.2012.1508

European Commission, 2012b. TFEU The treaty on the functioning of the European Union 1-344.

European Commission, 2011. COMMUNICATION FROM THE COMMISION: A Roadmap for moving to a competitive low carbon economy in 2050. COM(2011) 112 Final 34, 1-34. https://doi.org/10.1002/jsc.572

European Commission, 2000. Green Infrastructure and Rural Abandonment What is Green Green Infrastructure and Rural Abandonment Costs \& benefits of Green Infrastructure in relation to Rural Abandonment. https://doi.org/10.2861/821468

European Court of Auditors, 2017. Greening: a more complex income support scheme, not yet environmentally effective. EU Court Audit. 287, 1977-2017.

European Environmental Agency (EEA), 2018. The circular economy and the bioeconomy Partners in sustainability.

European Environmental Agency (EEA), 2017a. Food in a green light. https://doi. org/10.2800/884986

European Environmental Agency (EEA), 2017b. Landscapes in Transition. https://doi. org/10.2800/81075

European Parliament, 2009. Directive 2009/28/EC of the European Parliament and of the Council of 23 April 2009. Off. J. Eur. Union 140, 16-62. https://doi. org/10.3000/17252555.L_2009.140.eng

European Parliament and Council, 2009. Directive 2009/28/EC of the European Parliament and of the Council of 23 April 2009. Off. J. Eur. Union 140, 16-62. https://doi. org/10.3000/17252555.L_2009.140.eng

Eurostat, n.d. Energy production and imports - Statistics Explained [WWW Document]. 2016. URL http://ec.europa.eu/eurostat/statistics-explained/index.php/Energy_production_and_ imports (accessed 2.2.17).

Executive Office of the President, T., 2013. The President's Climate Action Plan 21.

Fanzo, J., Covic, N., Dobermann, A., Henson, S., Herrero, M., Pingali, P., Staal, S., 2020. A research vision for food systems in the 2020s: Defying the status quo. Glob. Food Sec. 26, 
100397. https://doi.org/10.1016/j.gfs.2020.100397

FAO, 2018. Sustainable food systems. Concept and framework 1-8. http://www.fao.org/3/ ca2079en/CA2079EN.pdf

FAO, 2017. The future of food and agriculture: Trends and challenges. ISBN 978-92-5-109551-5

FAO, 2016. The 10 Elements of agroecology: guiding the transition to sustainable food and agricultural systems. http://www.fao.org/3/i9037en/19037EN.pdf

FAO, 2012. The state of world fisheries and aquaculture 2012. ISBN 978-92-5-107225-7

FAO, 2011. Global food losses and food waste - Extent, causes and prevention., SAVE FOOD: An initiative on Food Loss and Waste Reduction. https://doi.org/10.1098/rstb.2010.0126

FAOSTAT, 2016. FAO Statistical Database [WWW Document]. URL http://faostat3.fao.org/ browse/G1/*/E (accessed 10.7.16).

Fargione, J.E., Plevin, R.J., Hill, J.D., 2010. The ecological impact of biofuels. Annu. Rev. Ecol. Evol. Syst. https://doi.org/10.1146/annurev-ecolsys-102209-144720

Fazeni, K., Steinmüller, H., 2011. Impact of changes in diet on the availability of land, energy demand, and greenhouse gas emissions of agriculture. Energy. Sustain. Soc. 1, 1-14. https://doi.org/10.1186/2192-0567-1-6

Felt, U., Wynne, B., Gonçalves, M.E., Jasanoff, S., Callon, M., Jepsen, M., Joly, P.-B., Konopasek, Z., May, S., Neubauer, C., Rip, A., Siune, K., Stirling, A., Tallacchini, M., 2007. Taking European knowledge society seriously, Office for Official Publications of the European Union

Fereday, J., Muir-Cochrane, E., 2006. Demonstrating Rigor Using Thematic Analysis: A Hybrid Approach of Inductive and Deductive Coding and Theme Development. Int. J. Qual. Methods 5, 80-92. https://doi.org/10.1177/160940690600500107

Fischer, J., Manning, A.D., Steffen, W., Rose, D.B., Daniell, K., Felton, A., Garnett, S., Gilna, B., Heinsohn, R., Lindenmayer, D.B., MacDonald, B., Mills, F., Newell, B., Reid, J., Robin, L., Sherren, K., Wade, A., 2007. Mind the sustainability gap. Trends Ecol. Evol. 22, 621-624. https://doi.org/10.1016/j.tree.2007.08.016

Flick, U., 2014. The SAGE Handbook of Qualitative Data Analysis. SAGE Publications Ltd, 1 Oliver's Yard, 55 City Road, London EC1Y 1SP United Kingdom. https://doi. org/10.4135/9781446282243

Foley, J.A., Ramankutty, N., Brauman, K.A., Cassidy, E.S., Gerber, J.S., Johnston, M., Mueller, N.D., O'Connell, C., Ray, D.K., West, P.C., Balzer, C., Bennett, E.M., Carpenter, S.R., Hill, J., Monfreda, C., Polasky, S., Rockström, J., Sheehan, J., Siebert, S., Tilman, D., Zaks, D.P.M., O'Connell, C., 2011. Solutions for a cultivated planet. Nature 478, 337-42. https:// doi.org/10.1038/nature 10452

Foote, N., 2020. Farm to Fork strategy softens stance on meat but backs alternative proteins [WWW Document]. Euractiv. URL https://www.euractiv.com/section/agriculture-food/ news/farm-to-fork-strategy-softens-stance-on-meat-but-backs-alternative-proteins/ (accessed 11.13.20). 
Forsell, N., Guerassimoff, G., Athanassiadis, D., Thivolle-Casat, A., Lorne, D., Millet, G., Assoumou, E., 2013. Sub-national TIMES model for analyzing future regional use of biomass and biofuels in Sweden and France. Renew. Energy 60, 415-426. https://doi. org/10.1016/j.renene.2013.05.015

Friends of the Earth International, 2010. Jatropha: money doesn't grow on trees ten reasons why jatropha is neither a profitable nor sustainable investment december 2010 | issue 120. https:// www.foei.org/wp-content/uploads/2013/12/jatropha_FoElreport.pdf

Friese, S., 2012. Qualitative Data Analysis with ATLAS.ti. Qual. Res. https://doi. org/10.1177/1468794113475420

Gamborg, C., Millar, K., Shortall, O., Sandøe, P., 2012. Bioenergy and Land Use: Framing the Ethical Debate. J. Agric. Environ. Ethics 25, 909-925. https://doi.org/10.1007/s10806-0119351-1

Gardebroek, C., Reimer, J.J., Baller, L., 2017. The Impact of Biofuel Policies on Crop Acreages in Germany and France. J. Agric. Econ. 68, 839-860. https://doi.org/10.1111/14779552.12218

Garnett, T., 2016. Planting up solutions. Science (80-. ). 353.

Garnett, T., 2009. Livestock-related greenhouse gas emissions: impacts and options for policy makers. Environ. Sci. Policy 12, 491-503. https://doi.org/10.1016/j.envsci.2009.01.006

Garnett, T., Godde, C., Muller, A., Röös, E., Smith, P., De Boer, I., Zu Ermgassen, E., Herrero, M., Van Middelaar, C., Schader, C., Van Zanten, H., Conant, R., Ericsson, N., Falcucci, A., Henderson, B., Johansson, D., Mottet, A., Opio, C., Persson, M., Stehfest, E., Bartlett, H., Godfray, C., 2017. Grazed and confused? Ruminating on Cattle, Grazing Systems, Methane, Nitrous Oxide, the Soil Carbon Sequestration Question-and what it All Means for Greenhouse Gas Emissions. 1-127.

Garnett, T., Roos, E., Little, D., 2015. Lean, green, mean, obscene... ? What is efficiency? And is it sustainable? Animal production and consumption reconsidered.

Gauttier, P., 2004. Horizontal Coherence and the External Competences of the European Union. Eur. Law J. 10, 23-41. https://doi.org/10.1111/j.1468-0386.2004.00201.x

Geels, F.W., Schot, J., 2007. Typology of sociotechnical transition pathways. Res. Policy 36, 399-417. https://doi.org/10.1016/j.respol.2007.01.003

Gerbens-Leenes, P.W., 2017. Bioenergy water footprints , comparing first , second and third generation feedstocks for bioenergy supply in 2040. Eur. Water 373-380.

Gerbens-Leenes, P.W., Nonhebel, S., 2002. Consumption patterns and their effects on land required for food. Ecol. Econ. 42, 185-199. https://doi.org/10.1016/S0921-8009(02)00049-6

Gerbens-Leenes, W., Hoekstra, A.Y., van der Meer, T.H., 2009. The water footprint of bioenergy. Proc. Natl. Acad. Sci. 106, 10219-10223. https://doi.org/10.1073/pnas.0812619106

Gerten, D., Heck, V., Jägermeyr, J., Bodirsky, B.L., Fetzer, I., Jalava, M., Kummu, M., Lucht, W., Rockström, J., Schaphoff, S., Schellnhuber, H.J., 2020. Feeding ten billion people is possible within four terrestrial planetary boundaries. Nat. Sustain. 3, 200-208. https://doi. 
org/10.1038/s41893-019-0465-1

Gerwin, W., Ivanina, V., Repmann, F., Volkmann, C., Baumgarten, W., 2018a. The potential of marginal lands for bioenergy [WWW Document]. BEsustainable. URL http://www. besustainablemagazine.com/cms2/the-potential-of-marginal-lands-for-bioenergy/ (accessed 7.2.18).

Gerwin, W., Repmann, F., Galatsidas, S., Vlachaki, D., Gounaris, N., Baumgarten, W., Volkmann, C., Keramitzis, D., Kiourtsis, F., Freese, D., 2018b. Assessment and quantification of marginal lands for biomass production in Europe using soil-quality indicators. Soil 4, 267290. https://doi.org/10.5194/soil-4-267-2018

Geyer, R., 2012. Can Complexity Move UK Policy beyond "Evidence-Based Policy Making" and the "Audit Culture"? Applying a "Complexity Cascade" to Education and Health Policy.

Polit. Stud. 60, 20-43. https://doi.org/10.1111/j.1467-9248.2011.00903.x

Giampietro, M., 2019. On the Circular Bioeconomy and Decoupling: Implications for Sustainable Growth. Ecol. Econ. 162, 143-156. https://doi.org/10.1016/j.ecolecon.2019.05.001

Giampietro, M., Aspinall, R.J.., Bukkens, S.G.F.., Benalcazar, J.C., Diaz-Maurin, F., Flammini, A., Gomiero, T., Kovacic, Z., Madrid, C., Ramos-Martin, J., Serrano-Tovar, T., 2013. An Innovative Accounting Framework for the Food-Energy-Water Nexus: Application of the MuSIASEM approach to three case studies, Environment and Natural Resources.

Giampietro, M., Aspinall, R.J., Ramos-martin, J., Bukkens, S.G.F., 2014. Resource Accounting for Sustainability Assessment. https://doi.org/10.4324/9781315866895

Gielen, D.J., Fujino, J., Hashimoto, S., Moriguchi, Y., 2002. Biomass strategies for climate policies? Clim. Policy 2, 319-333. https://doi.org/10.1016/S1469-3062(02)00040-2

Gifford, R., Nilsson, A., 2014. Personal and social factors that influence pro-environmental concern and behaviour: A review. Int. J. Psychol. 49, 141-157. https://doi.org/10.1002/ ijop. 12034

Giller, K.E., Leeuwis, C., Andersson, J.A., Andriesse, W., Brouwer, A., Frost, P., Hebinck, P., Heitkönig, I., Van Ittersum, M.K., Koning, N., Ruben, R., Slingerland, M., Udo, H., Veldkamp, T., Van de Vijver, C., Van Wijk, M.T., Windmeijer, P., 2008. Competing claims on natural resources: What role for science? Ecol. Soc. 13. https://doi.org/10.5751/ES02595-130234

Gillingham, K.T., Smith, S.J., Sands, R.D., 2008. Impact of bioenergy crops in a carbon dioxide constrained world: An application of the MiniCAM energy-agriculture and land use model. Mitig. Adapt. Strateg. Glob. Chang. 13, 675-701. https://doi.org/10.1007/s11027-0079122-5

Gissi, E., Gaglio, M., Reho, M., 2016. Sustainable energy potential from biomass through ecosystem services trade-off analysis: The case of the Province of Rovigo (Northern Italy). Ecosyst. Serv. 18, 1-19. https://doi.org/10.1016/j.ecoser.2016.01.004

Godfray, H.C.J., Beddington, J.R., Crute, I.R., Haddad, L., Lawrence, D., Muir, J.F., Pretty, J., Robinson, S., Thomas, S.M., Toulmin, C., Tilman, D., Schmidhuber, J., Tubiello, F.N., 
Piesse, J., Thirtle, C., Pretty, J., Balmford, A., Green, R.E., Scharlemann, J.P.W., Fargione, J., Hill, J., Tilman, D., Polasky, S., Hawthorne, P., Cassman, K.G., Evenson, R.E., Gollin, D., Pretty, J.N., Ball, A.S., Lang, T., Morison, J.I.L., Pretty, J.N., Hazell, P., Wood, S., Deininger, K., Feder, G., Collier, P., Gilbert, R.A., Shine, J.M., Miller, J.D., Rice, R.W., Rainbolt, C.R., Lemaux, P.G., Lea, D., Smith, M.D., Tacon, A.G.J., Metian, M., Hobbs, P.R., Sayre, K., Gupta, R., Day, W., Audsley, E., Frost, A.R., Reij, C.P., Smaling, E.M.A., 2010. Food security: the challenge of feeding 9 billion people. Science 327, 812-8. https:// doi.org/10.1126/science.1185383

Gomes, L., Fernando, A.L., Santos, F., 2018. A toolbox to tackle the technological and environmental constraints associated with the use of biomass for energy from marginal land. ECOS 2018 - Proc. 31st Int. Conf. Effic. Cost, Optim. Simul. Environ. Impact Energy Syst.

Gomiero, T., 2016. Soil degradation, land scarcity and food security: Reviewing a complex challenge. Sustain. 8, 1-41. https://doi.org/10.3390/su8030281

Goodland, R., 1997. Environmental sustainability in agriculture: diet matters. Ecol. Econ. 23, 189-200. https://doi.org/S0921-8009(97)00579-X

Gopalakrishnan, G., Cristina Negri, M., Snyder, S.W., 2011. A Novel Framework to Classify Marginal Land for Sustainable Biomass Feedstock Production. J. Environ. Qual. 40, 1593. https://doi.org/10.2134/jeq2010.0539

Grandell, L., Höök, M., 2015. Assessing rare metal availability challenges for solar energy technologies. Sustain. 7, 11818-11837. https://doi.org/10.3390/su70911818

Grundmann, P., Klauss, H., 2014. The impact of global trends on bioenergy production, food supply and global warming potential - an impact assessment of land-use changes in four regions in Germany using linear programming. J. Land Use Sci. 9, 34-58. https://doi.org/1 0.1080/1747423X.2012.719935

Gurría, P., Ronzon, T., Tamosiunas, S., López, R., Condado, S.G., Guillén, J., Cazzaniga, N.E., Jonsson, R., Banja, M., Fiore, G., Camia, A., M'Barek, R., 2017. Biomass flows in the European Union: The Sankey biomass diagram - towards a cross-set integration of biomass. EUR 28565 EN, doi:10.2760/352412. https://doi.org/10.2760/352412

Haberl, Helmut, Erb, K.-H., Krausmann, F., 2014a. Human Appropriation of Net Primary Production: Patterns, Trends, and Planetary Boundaries. Annu. Rev. Environ. Resour. 39, 363-391. https://doi.org/10.1146/annurev-environ-121912-094620

Haberl, Helmut, Erb, K.-H., Krausmann, F., 2014b. Human appropriation of net primary production: Patterns, trends, and planetary boundaries. Annu. Rev. Environ. Resour. 39, 363-391. https://doi.org/10.1146/annurev-environ-121912-094620

Haberl, H., Erb, K.-H., Krausmann, F., Running, S., Searchinger, T.D., Kolby Smith, W., 2013. Bioenergy: how much can we expect for 2050 ? Environ. Res. Lett. 8, 031004. https://doi. org/10.1088/1748-9326/8/3/031004

Haberl, H., Erb, K.H., Krausmann, F., Bondeau, A., Lauk, C., Müller, C., Plutzar, C., Steinberger, 
J.K., 2011. Global bioenergy potentials from agricultural land in 2050: Sensitivity to climate change, diets and yields. Biomass and Bioenergy 35, 4753-4769. https://doi. org/10.1016/j.biombioe.2011.04.035

Haberl, H., Geissler, S., 2000. Cascade utilization of biomass: strategies for a more efficient use of a scarce resource. Ecol. Eng. 16, 111-121. https://doi.org/10.1016/S09258574(00)00059-8

Hannah, A., 2020. The promises and pitfalls of polysemic ideas : ' One Health ' and antimicrobial resistance policy in Australia and the UK. Policy Sci. 1-24. https://doi.org/10.1007/ s11077-020-09390-3

Hannah, A., Baekkeskov, E., 2020. The promises and pitfalls of polysemic ideas: 'One Health' and antimicrobial resistance policy in Australia and the UK. Policy Sci. 53, 437-452. https://doi.org/10.1007/s11077-020-09390-3

Harahap, F., Silveira, S., Khatiwada, D., 2017. Land allocation to meet sectoral goals in Indonesia-An analysis of policy coherence. Land use policy $61,451-465$. https://doi. org/10.1016/j.landusepol.2016.11.033

Hatfield-Dodds, S., Schandl, H., Adams, P.D., Baynes, T.M., Brinsmead, T.S., Bryan, B.A., Chiew, F.H.S., Graham, P.W., Grundy, M., Harwood, T., McCallum, R., McCrea, R., McKellar, L.E., Newth, D., Nolan, M., Prosser, I., Wonhas, A., 2015. Australia is "free to choose" economic growth and falling environmental pressures. Nature 527, 49-53. https:// doi.org/10.1038/nature16065

Helliwell, R., 2018. Where did the marginal land go? Farmers perspectives on marginal land and its implications for adoption of dedicated energy crops. Energy Policy 117, 166-172. https://doi.org/10.1016/j.enpol.2018.03.011

Hertel, T., Steinbuks, J., Baldos, U., 2013. Competition for land in the global bioeconomy. Agric. Econ. (United Kingdom) 44, 129-138. https://doi.org/10.1111/agec.12057

HLPE, 2013. Biofuels and food security. https://doi.org/10.1094/CFW-53-2-0076

Holman, I.P., Brown, C., Janes, V., Sandars, D., 2017. Can we be certain about future land use change in Europe? A multi-scenario, integrated-assessment analysis. Agric. Syst. 151, 126-135. https://doi.org/10.1016/j.agsy.2016.12.001

Holmatov, B., Hoekstra, A.Y., Krol, M.S., 2019. Land, water and carbon footprints of circular bioenergy production systems. Renew. Sustain. Energy Rev. 111, 224-235. https://doi. org/10.1016/j.rser.2019.04.085

Hoogwijk, M., Faaij, A., van den Broek, R., Berndes, G., Gielen, D., Turkenburg, W., 2003. Exploration of the ranges of the global potential of biomass for energy. Biomass and Bioenergy 25, 119-133. https://doi.org/10.1016/S0961-9534(02)00191-5

Hoppe, R., 1999. Policy analysis, science and politics: from 'speaking truth to power' to 'making sense together. Sci. Public Policy 26, 201-210.

Howden, M., Schroeter, S., Crimp, S., Hanigan, I., 2014. The changing roles of science in managing Australian droughts: An agricultural perspective. Weather Clim. Extrem. 3, 80- 
89. https://doi.org/10.1016/j.wace.2014.04.006

Howe, C., Suich, H., Vira, B., Mace, G.M., 2014. Creating win-wins from trade-offs? Ecosystem services for human well-being: A meta-analysis of ecosystem service trade-offs and synergies in the real world. Glob. Environ. Chang. 28, 263-275. https://doi.org/10.1016/j. gloenvcha.2014.07.005

Huttunen, S., 2015. Farming Practices and Experienced Policy Coherence in Agri-environmental Policies: The Case of Land Clearing in Finland. J. Environ. Policy Plan. 17, 573-592. https://doi.org/10.1080/1523908X.2014.1003348

Huttunen, S., Kivimaa, P., Virkamäki, V., 2014. The need for policy coherence to trigger a transition to biogas production. Environ. Innov. Soc. Transitions 12, 14-30. https://doi. org/10.1016/j.eist.2014.04.002

IEA, 2017. Technology Roadmap: Delivering Sustainable Bioenergy 94. https://www. ieabioenergy.com/wp-content/uploads/2017/11/Technology_Roadmap_Delivering_ Sustainable_Bioenergy.pdf

IFPRI-CGIAR, 2008. BIOFUELS AND FOOD SECURITY: Balancing Needs for Food, Feed, and Fuel, IFPRI Booklets. http://ebrary.ifpri.org/utils/getfile/collection/p15738coll2/id/16395/ filename/16396.pdf

Ignaciuk, A., Vöhringer, F., Ruijs, A., van lerland, E.C., 2006. Competition between biomass and food production in the presence of energy policies: a partial equilibrium analysis. Energy Policy 34, 1127-1138. https://doi.org/10.1016/j.enpol.2004.09.010

Immerzeel, D.J., Verweij, P.A., van der Hilst, F., Faaij, A.P.C., 2014. Biodiversity impacts of bioenergy crop production: A state-of-the-art review. GCB Bioenergy 6, 183-209. https:// doi.org/10.1111/gcbb.12067

International Council for Science, 2017. A guide to SDG interactions: from science to implementation 127-169. https://doi.org/10.24948/2017.01

IPBES (2019): Summary for policymakers of the global assessment report on biodiversity and ecosystem services of the Intergovernmental Science-Policy Platform on Biodiversity and Ecosystem Services. S. Díaz, J. Settele, E. S. Brondízio E.S., H. T. Ngo, M. Guèze, J. Agard, A. Arneth, P. Balvanera, K. A. Brauman, S. H. M. Butchart, K. M. A. Chan, L. A. Garibaldi, K. Ichii, J. Liu, S. M. Subramanian, G. F. Midgley, P. Miloslavich, Z. Molnár, D. Obura, A. Pfaff, S. Polasky, A. Purvis, J. Razzaque, B. Reyers, R. Roy Chowdhury, Y. J. Shin, I. J. Visseren-Hamakers, K. J. Willis, and C. N. Zayas (eds.). IPBES secretariat, Bonn, Germany. 56 pages.

IRENA (2019), Advanced biofuels. What holds them back?, International Renewable Energy Agency, Abu Dhabi.

Isendahl, N., Dewulf, A., Brugnach, M., François, G., Möllenkamp, S., Pahl-Wostl, C., 2009. Assessing framing of uncertainties in water management practice. Water Resour. Manag. 23, 3191-3205. https://doi.org/10.1007/s11269-009-9429-y

Ishangulyyev, R., Kim, S., Lee, S.H., 2019. Understanding food loss and waste-why are we losing 
and wasting food? Foods 8. https://doi.org/10.3390/foods8080297

Jasanoff, S., Kim, S.-H., 2015. Dreamscapes of Modernity, Dreamscapes of Modernity. https:// doi.org/10.7208/chicago/9780226276663.001.0001

Joint Research Centre, 2018. Agricultural Land Abandonment in the EU within 2015-2030. https://ec.europa.eu/jrc/sites/jrcsh/files/jrc113718.pdf

Jørgensen, S.E., Nielsen, S.N., 1996. Application of ecological engineering principles in agriculture. Ecol. Eng. 7, 373-381. https://doi.org/10.1016/S0925-8574(96)00018-3

Jurgilevich, A., Birge, T., Kentala-Lehtonen, J., Korhonen-Kurki, K., Pietikäinen, J., Saikku, L., Schösler, H., 2016. Transition towards circular economy in the food system. Sustain. 8, 1-14. https://doi.org/10.3390/su8010069

Kalaba, F.K., Quinn, C.H., Dougill, A.J., 2014. Policy coherence and interplay between Zambia's forest, energy, agricultural and climate change policies and multilateral environmental agreements. Int. Environ. Agreements Polit. Law Econ. 14, 181-198. https://doi. org/10.1007/s10784-013-9236-z

Karlberg, L., Hoff, H., Flores-L??pez, F., Goetz, A., Matuschke, I., 2015. Tackling biomass scarcity-from vicious to virtuous cycles in sub-Saharan Africa. Curr. Opin. Environ. Sustain. 15, 1-8. https://doi.org/10.1016/j.cosust.2015.07.011

Kastner, T., Erb, K.H., Haberl, H., 2014. Rapid growth in agricultural trade: Effects on global area efficiency and the role of management. Environ. Res. Lett. 9. https://doi.org/10.1088/17489326/9/3/034015

Keegan, D., Kretschmer, B., Elbersen, B., Panoutsou, C., 2013. Cascading use: a systematic approach to biomass beyond the energy sector. Biofuels, Bioprod. Biorefining 7, 193-206. https://doi.org/10.1002/bbb.1351

Kelleher, L., Henchion, M., O'Neill, E., 2019. Policy coherence and the transition to a bioeconomy: The case of Ireland. Sustain. 11, 1-25. https://doi.org/10.3390/SU11247247

Kent, P., 2016. Commission's flip-flop on biofuels puts at risk tens of thousands of jobs EURACTIV.com. Euractiv. https://www.euractiv.com/section/sustainable-dev/opinion/ commissions-flip-flop-on-biofuels-puts-at-risk-tens-of-thousands-of-jobs/

Kim, S., Dale, B.E., 2004. Global potential bioethanol production from wasted crops and crop residues. Biomass and Bioenergy 26, 361-375. https://doi.org/10.1016/j. biombioe.2003.08.002

Kirchherr, J., Piscicelli, L., Bour, R., Kostense-Smit, E., Muller, J., Huibrechtse-Truijens, A., Hekkert, M., 2018. Barriers to the Circular Economy: Evidence From the European Union (EU). Ecol. Econ. 150, 264-272. https://doi.org/10.1016/j.ecolecon.2018.04.028

Kirchherr, J., Reike, D., Hekkert, M., 2017. Conceptualizing the circular economy: An analysis of 114 definitions. Resour. Conserv. Recycl. 127, 221-232. https://doi.org/10.1016/j. resconrec.2017.09.005

Kline, K.L., Msangi, S., Dale, V.H., Woods, J., Souza, G., Osseweijer, P., Clancy, J.S., Hilbert, J.A., Johnson, F.X., McDonnell, P.C., Mugera, H.K., 2017. Reconciling food security 
and bioenergy: priorities for action. GCB Bioenergy 9, 557-576. https://doi.org/10.1111/ gcbb.12366

Klinke, A., Renn, O., 2002. A new approach to risk evaluation and management: Risk-based, precaution-based, and discourse-based strategies. Risk Anal. 22, 1071-1094. https://doi. org/10.1111/1539-6924.00274

Kollenda, E., 2020. How to deliver on the EU Farm to Fork's protein transition objectives [WWW Document]. Inst. Eur. Environ. Policy. URL https://ieep.eu/news/how-to-deliver-on-the-eufarm-to-fork-s-protein-transition-objectives (accessed 11.13.20).

Kollmuss, A., Agyeman, J., 2002. Mind the Gap: Why do people act environmentally and what are the barriers to pro-environmental behavior? Environ. Educ. Res. https://doi. org/10.1080/13504620220145401

Konadu, D.D., Mourão, Z.S., Allwood, J.M., Richards, K.S., Kopec, G., McMahon, R., Fenner, R., 2015. Land use implications of future energy system trajectories-The case of the UK 2050 Carbon Plan. Energy Policy 86, 328-337. https://doi.org/10.1016/j.enpol.2015.07.008

Korhonen, J., Honkasalo, A., Seppälä, J., 2018. Circular Economy: The Concept and its Limitations. Ecol. Econ. 143, 37-46. https://doi.org/10.1016/j.ecolecon.2017.06.041

Kovacic, Z., 2018. Conceptualizing Numbers at the Science-Policy Interface. Sci. Technol. Hum. Values 43, 1039-1065. https://doi.org/10.1177/0162243918770734

Kovacic, Z., Di Felice, L.J., 2019. Complexity, uncertainty and ambiguity: Implications for European Union energy governance. Energy Res. Soc. Sci. 53, 159-169. https://doi. org/10.1016/j.erss.2019.03.005

Kovacic, Z., Jane, L., Felice, D., 2019a. Energy Research \& Social Science Complexity , uncertainty and ambiguity : Implications for European Union energy governance. Energy Res. Soc. Sci. 53, 159-169. https://doi.org/10.1016/j.erss.2019.03.005

Kovacic, Z., Smit, S., Musango, J.K., Brent, A.C., Giampietro, M., 2016. Probing uncertainty levels of electrification in informal urban settlements: A case from South Africa. Habitat Int. 56, 212-221. https://doi.org/10.1016/j.habitatint.2016.06.002

Kovacic, Z., Strand, R., Völker, T., 2019b. The Circular Economy in Europe, The Circular Economy in Europe. Routledge, New York : Routledge, 2020. | Series: Routledge explorations in sustainability and governance. https://doi.org/10.4324/9780429061028

Krausmann, F., Erb, K.-H., Gingrich, S., Haberl, H., Bondeau, A., Gaube, V., Lauk, C., Plutzar, C., Searchinger, T.D., 2013. Global human appropriation of net primary production doubled in the 20th century. Proc. Natl. Acad. Sci. 110, 10324-10329. https://doi.org/10.1073/ pnas. 1211349110

Kubiszewski, I., Costanza, R., Franco, C., Lawn, P., Talberth, J., Jackson, T., Aylmer, C., 2013. Beyond GDP: Measuring and achieving global genuine progress. Ecol. Econ. 93, 57-68. https://doi.org/10.1016/j.ecolecon.2013.04.019

Lajdova, Z., Lajda, J., Kapusta, J., Bielik, P., 2016. Consequences of maize cultivation intended for biogas production. Agric. Econ. Ekon. 62, 543-549. https://doi.org/10.17221/209/2016- 


\section{AGRICECON}

Lambin, E.F., Meyfroidt, P., 2011. Global land use change, economic globalization, and the looming land scarcity. Proc. Natl. Acad. Sci. 108, 3465-3472. https://doi.org/10.1073/ pnas. 1100480108

Langeveld, J.W.A., Dixon, J., van Keulen, H., Quist-Wessel, P.M.F., 2014. Analyzing the effect of biofuel expansion on land use in major producing countries: Evidence of increased multiple cropping. Biofuels, Bioprod. Biorefining 8, 49-58. https://doi.org/10.1002/ bbb. 1432

Lapola, D.M., Schaldach, R., Alcamo, J., Bondeau, A., Koch, J., Koelking, C., Priess, J.A., 2010. Indirect land-use changes can overcome carbon savings from biofuels in Brazil. Proc. Natl. Acad. Sci. U. S. A. 107, 3388-3393. https://doi.org/10.1073/pnas.0907318107

Larsen, S., Bentsen, N.S., Dalgaard, T., Jørgensen, U., Olesen, J.E., Felby, C., 2017. Possibilities for near-term bioenergy production and GHG-mitigation through sustainable intensification of agriculture and forestry in Denmark. Environ. Res. Lett. 12. https://doi. org/10.1088/1748-9326/aa9001

Latour, B., 2018. Down to Earth: Politics in the New Climatic Regime. Polity, p. 140.

Lazarevic, D., Valve, H., 2017. Narrating expectations for the circular economy: Towards a common and contested European transition. Energy Res. Soc. Sci. 31, 60-69. https://doi. org/10.1016/j.erss.2017.05.006

Lenschow, A., Bocquillon, P., Carafa, L., 2018. Understanding coherence between policy spheres. Environ. Policy Gov. 28, 323-328. https://doi.org/10.1002/eet.1818

Lindstad, B.H., Pistorius, T., Ferranti, F., Dominguez, G., Gorriz-Mifsud, E., Kurttila, M., Leban, V., Navarro, P., Peters, D.M., Pezdevsek Malovrh, S., Prokofieva, I., Schuck, A., Solberg, B., Viiri, H., Zadnik Stirn, L., Krc, J., 2015. Forest-based bioenergy policies in five European countries: An explorative study of interactions with national and EU policies. Biomass and Bioenergy 80, 102-113. https://doi.org/10.1016/j.biombioe.2015.04.033

Lomba, A., Moreira, F., Klimek, S., Jongman, R.H.G., Sullivan, C., Moran, J., Poux, X., Honrado, J.P., Pinto-Correia, T., Plieninger, T., McCracken, D.I., 2020. Back to the future: rethinking socioecological systems underlying high nature value farmlands. Front. Ecol. Environ. 18, 36-42. https://doi.org/10.1002/fee.2116

Lotze-Campen, H., Popp, A., Beringer, T., Müller, C., Bondeau, A., Rost, S., Lucht, W., 2010. Scenarios of global bioenergy production: The trade-offs between agricultural expansion, intensification and trade. Ecol. Modell. 221, 2188-2196. https://doi.org/10.1016/j. ecolmodel.2009.10.002

Lotze-Campen, H., von Lampe, M., Kyle, P., Fujimori, S., Havlik, P., van Meijl, H., Hasegawa, T., Popp, A., Schmitz, C., Tabeau, A., Valin, H., Willenbockel, D., Wise, M., 2014. Impacts of increased bioenergy demand on global food markets: An AgMIP economic model intercomparison. Agric. Econ. (United Kingdom) 45, 103-116. https://doi.org/10.1111/ agec.12092 
Low, S., Schäfer, S., 2020. Is bio-energy carbon capture and storage (BECCS) feasible? The contested authority of integrated assessment modeling. Energy Res. Soc. Sci. 60, 101326. https://doi.org/10.1016/j.erss.2019.101326

Lywood, W., Pinkney, J., Cockerill, S., 2009. Impact of protein concentrate coproducts on net land requirement for European biofuel production. GCB Bioenergy 1, 346-359. https://doi. org/10.1111/j.1757-1707.2009.01026.x

Maiteny, P.T., 2010. Mind in the Gap : Summary of research exploring ' inner 'influences on pro-sustainability learning and behaviour Mind in the Gap : summary of research exploring ' inner' in uences on pro-sustainability learning and behaviour 4622, 37-41. https://doi. org/10.1080/1350462022014544

Malins, C., 2017. Thought for food - A review of the interaction between biofuel consumption and food markets, Cerulogy. London. https://doi.org/10.1126/science.1195701

Manceron, S., Tamara, B., Patrice, D., 2014. Proteins Source in animal feeds. Oilseeds Fats Crop. Lipids 21, 1-10. https://doi.org/10.1051/ocl/2014020

Materiom [WWW Document], 2018. URL https://materiom.org/ (accessed 7.16.20).

Matland, R.E., 1995. Synthesizing the implementation literature: The ambiguity-conflict model of policy implementation. J. Public Adm. Res. Theory 5, 145-174. https://doi.org/10.1093/ oxfordjournals.jpart.a037242

Max-Neef, M., 1992. Development and human needs. Real-life Econ. https://doi. org/10.4324/9781315258003-14

Mayer, A., Schaffartzik, A., Haas, W., Rojas-Sepúlveda, A., 2015. Patterns of global biomass trade: Implications for food sovereignty and socio-environmental conflicts 109 .

Mayer, A.L., 2005. Importing Timber, Exporting Ecological Impact. Science (80-. ). 308, 359-360. https://doi.org/10.1126/science.1109476

McCollum, D.L., Echeverri, L.G., Busch, S., Pachauri, S., Parkinson, S., Rogelj, J., Krey, V., Minx, J.C., Nilsson, M., Stevance, A.-S., Riahi, K., 2018. Connecting the sustainable development goals by their energy inter-linkages. Environ. Res. Lett. 13, 033006. https:// doi.org/10.1088/1748-9326/aaafe3

Meadows, D.H., 2009. Thinking in systems : a primer. London ; Sterling, VA : Earthscan

Meehan, P., Burke, B., Doyle, D., Barth, S., Finnan, J., 2017. Exploring the potential of grass feedstock from marginal land in Ireland: Does marginal mean lower yield? Biomass and Bioenergy 107, 361-369. https://doi.org/10.1016/j.biombioe.2017.10.014

Melorose, J., Perroy, R., Careas, S., 2015. World population prospects. United Nations 1, 58792. https://doi.org/10.1017/CBO9781107415324.004

Merckx, T., Pereira, H.M., 2015. Reshaping agri-environmental subsidies: From marginal farming to large-scale rewilding. Basic Appl. Ecol. 16, 95-103. https://doi.org/10.1016/j. baae.2014.12.003

Meyfroidt, P., Rudel, T.K., Lambin, E.F., 2010. Forest transitions, trade, and the global displacement of land use. Proc. Natl. Acad. Sci. 107, 20917-20922. https://doi. 
org/10.1073/pnas.1014773107

Milani, F.X., Nutter, D., Thoma, G., 2011. Invited review: Environmental impacts of dairy processing and products: A review. J. Dairy Sci. 94, 4243-4254. https://doi.org/10.3168/ jds.2010-3955

Millward-Hopkins, J., Steinberger, J.K., Rao, N.D., Oswald, Y., 2020. Providing decent living with minimum energy: A global scenario. Glob. Environ. Chang. 65, 102168. https://doi. org/10.1016/j.gloenvcha.2020.102168

Mirzabaev, A., Guta, D., Goedecke, J., Gaur, V., Börner, J., Virchow, D., Denich, M., von Braun, J., 2015. Bioenergy, food security and poverty reduction: trade-offs and synergies along the water-energy-food security nexus. Water Int. 8060, 1-19. https://doi.org/10.1080/0250 8060.2015.1048924

Moomaw, W., T. Griffin, K. Kurczak, J. Lomax (2012). "The Critical Role of Global Food Consumption Patterns in Achieving Sustainable Food Systems and Food for All, A UNEP Discussion Paper", United Nations Environment Programme, Division of Technology, Industry and Economics, Paris, France

Mooney, P.H., Hunt, S.A., 2009. Food security: The elaboration of contested claims to a consensus frame. Rural Sociol. 74, 469-497. https://doi.org/10.1526/003601109789864053

Mottet, A., de Haan, C., Falcucci, A., Tempio, G., Opio, C., Gerber, P., 2017. Livestock: On our plates or eating at our table? A new analysis of the feed/food debate. Glob. Food Sec. 14, 1-8. https://doi.org/10.1016/j.gfs.2017.01.001

Munroe, D.K., van Berkel, D.B., Verburg, P.H., Olson, J.L., 2013. Alternative trajectories of land abandonment: Causes, consequences and research challenges, in: Current Opinion in Environmental Sustainability. Elsevier B.V., pp. 471-476. https://doi.org/10.2861/821468

Murphy, S., Hansen-Kuhn, K., 2019. The true costs of US agricultural dumping. Renew. Agric. Food Syst. 1-15. https://doi.org/10.1017/S1742170519000097

Muscat, A., de Olde, E.M., de Boer, I.J.M., Ripoll-Bosch, R., 2020. The battle for biomass: A systematic review of food-feed-fuel competition. Glob. Food Sec. 25, 100330. https://doi. org/10.1016/j.gfs.2019.100330

Nalepa, R.A., Bauer, D.M., 2012a. Marginal lands: The role of remote sensing in constructing landscapes for agrofuel development. J. Peasant Stud. 39, 403-422. https://doi.org/10.10 80/03066150.2012.665890

Nalepa, R.A., Bauer, D.M., 2012b. Marginal lands: The role of remote sensing in constructing landscapes for agrofuel development. J. Peasant Stud. 39, 403-422. https://doi.org/10.10 80/03066150.2012.665890

Navarro, L.M., Pereira, H.M., 2012. Rewilding Abandoned Landscapes in Europe. Ecosystems 15, 900-912. https://doi.org/10.1007/s10021-012-9558-7

Naylor, R., Steinfeld, H., Falcon, W., Galloway, J., Smil, V., Bradford, E., Alder, J., Mooney, H., 2005. Losing the Links Between Livectock and Land. Science (80-. ). 310, 1621-1622.

Nebehay, S., 2007. Biofuels could lead to mass hunger deaths -UN envoy [WWW Document]. 
Reuters. URL https://www.reuters.com/article/idUSL14909771._CH_.2400 (accessed 3.15.18).

Nilsson, M., 2017. Important interactions among the sustainable development goals under review at the high-level political forum 2017. Sei-International.Org.

Nilsson, M., Chisholm, E., Griggs, D., Howden-Chapman, P., McCollum, D., Messerli, P., Neumann, B., Stevance, A.S., Visbeck, M., Stafford-Smith, M., 2018. Mapping interactions between the sustainable development goals: lessons learned and ways forward. Sustain. Sci. 0123456789, 1-15. https://doi.org/10.1007/s11625-018-0604-z

Nilsson, M., Zamparutti, T., Petersen, J.E., Nykvist, B., Rudberg, P., Mcguinn, J., 2012. Understanding Policy Coherence: Analytical Framework and Examples of SectorEnvironment Policy Interactions in the EU. Environ. Policy Gov. 22, 395-423. https://doi. org/10.1002/eet.1589

Nonhebel, S., 2012. Global food supply and the impacts of increased use of biofuels. Energy 37 , 115-121. https://doi.org/10.1016/j.energy.2011.09.019

Nonhebel, S., 2007. Energy from agricultural residues and consequences for land requirements for food production. Agric. Syst. 94, 586-592. https://doi.org/10.1016/j.agsy.2007.02.004

Nonhebel, S., 2004. On resource use in food production systems: The value of livestock as "rest-stream upgrading system." Ecol. Econ. 48, 221-230. https://doi.org/10.1016/j. ecolecon.2003.09.013

Nyborg, K., Anderies, J.M., Dannenberg, A., Lindahl, T., Schill, C., Schlüter, M., Adger, W.N., Arrow, K.J., Barrett, S., Carpenter, S., Chapin, F.S., Crépin, A.S., Daily, G., Ehrlich, P., Folke, C., Jager, W., Kautsky, N., Levin, S.A., Madsen, O.J., Polasky, S., Scheffer, M., Walker, B., Weber, E.U., Wilen, J., Xepapadeas, A., De Zeeuw, A., 2016. Social norms as solutions. Science (80-. ). 354, 42-43. https://doi.org/10.1126/science.aaf8317

O’Neill, D.W., Fanning, A.L., Lamb, W.F., Steinberger, J.K., 2018. A good life for all within planetary boundaries. Nat. Sustain. 1, 88-95. https://doi.org/10.1038/s41893-018-0021-4

Obersteiner, M., Walsh, B., Frank, S., Havlik, P., Cantele, M., Liu, J., Palazzo, A., Herrero, M., Lu, Y., Mosnier, A., Valin, H., Riahi, K., Kraxner, F., Fritz, S., van Vuuren, D., 2016. Assessing the land resource-food price nexus of the Sustainable Development Goals. Sci. Adv. 2, e1501499-e1501499. https://doi.org/10.1126/sciadv.1501499

Odegard, I., Croezen, H., Bergsma, G., 2012. Cascading of Biomass: 13 Solutions for a Sustainable Bio-based Economy-Making Better Choices for Use of Biomass Residues, Byproducts and Wastes. Delft, CE Delft, August 2012. Publication code: 12.2665.52. https://www. cedelft.eu/en/publications/download/1326

OECD/FAO, 2018. Chapter 9. Biofuels. OECD-FAO Agric. Outlook 2018-2027 191-206.

OECD, 2016. Better Policies for Sustainable Development 2016: a new framework for policy coherence. OECD Publishing. https://doi.org/10.1787/9789264256996-en

OECD, 2004. A Comparative Analysis of Institutional Mechanisms to Promote Policy Coherence for Development: Case Study Synthesis The European Community, United States and 
Japan. Paris, France.

Diakosavvas, D. and C. Frezal (2019-09-12), "Bio-economy and the sustainability of the agriculture and food system: Opportunities and policy challenges", OECD Food, Agriculture and Fisheries Papers, No. 136, OECD Publishing, Paris. http://dx.doi. org/10.1787/d0ad045d-en

Ölander, F., Thøgersen, J., 2014. Informing Versus Nudging in Environmental Policy. J. Consum. Policy 37, 341-356. https://doi.org/10.1007/s10603-014-9256-2

Orsini, A., Le Prestre, P., Haas, P.M., Brosig, M., Pattberg, P., Widerberg, O., Gomez-Mera, L., Morin, J.-F., Harrison, N.E., Geyer, R., Chandler, D., 2019. Forum: Complex Systems and International Governance. Int. Stud. Rev. 1-31. https://doi.org/10.1093/isr/viz005

Özdemir, E.D., Härdtlein, M., Eltrop, L., 2009. Land substitution effects of biofuel side products and implications on the land area requirement for EU 2020 biofuel targets. Energy Policy 37, 2986-2996. https://doi.org/10.1016/j.enpol.2009.03.051

Parajuli, R., Dalgaard, T., Birkved, M., 2018. Can farmers mitigate environmental impacts through combined production of food, fuel and feed? A consequential life cycle assessment of integrated mixed crop-livestock system with a green biorefinery. Sci. Total Environ. 619620, 127-143. https://doi.org/10.1016/j.scitotenv.2017.11.082

Parodi, A., Leip, A., De Boer, I.J.M., Slegers, P.M., Ziegler, F., Temme, E.H.M., Herrero, M., Tuomisto, H., Valin, H., Van Middelaar, C.E., Van Loon, J.J.A., Van Zanten, H.H.E., 2018. The potential of future foods for sustainable and healthy diets. Nat. Sustain. 1, 782-789. https://doi.org/10.1038/s41893-018-0189-7

PBL Netherlands Environmental Assessment Agency, 2014. Biomass. Wishes and limitations - PBL Netherlands Environmental Assessment Agency [WWW Document]. URL http:// infographics.pbl.nl/biomass/ (accessed 10.10.16).

Pelletier, N., Audsley, E., Brodt, S., Garnett, T., Henriksson, P., Kendall, A., Kramer, K.J., Murphy, D., Nemecek, T., Troell, M., 2011. Energy Intensity of Agriculture and Food Systems. Annu. Rev. Environ. Resour 36, 223-46. https://doi.org/10.1146/annurev-environ-081710-161014

Persson, M., 2015. The Impact of Biofuel Demand on Agricultural Commodity Prices:

A Systematic Review. Adv. Bioenergy Sustain. Chall. 4, 465-482. https://doi. org/10.1002/9781118957844.ch30

Persson, U.M., 2013. SOCIO-ECONOMIC CONSEQUENCES OF INCREASED BIOMASS DEMAND, in: Sandén, B.A., Pettersson, K. (Eds.), System Perspectives on Biorefineries. Chalmers University of Technology, Göteborg, pp. 56-67.

Petersen, B., Snapp, S., 2015. What is sustainable intensification? Views from experts. Land use policy 46, 1-10. https://doi.org/10.1016/j.landusepol.2015.02.002

Pielke, R.A., 2004. When scientists politicize science: Making sense of controversy over The Skeptical Environmentalist. Environ. Sci. Policy 7, 405-417. https://doi.org/10.1016/j. envsci.2004.06.004

Pilgrim, S., Harvey, M., 2010. Battles over biofuels in Europe: NGOs and the politics of markets. 
Sociol. Res. Online 15. https://doi.org/10.5153/sro.2192

Pirgmaier, E., 2021. The value of value theory for ecological economics. Ecol. Econ. 179, 106790. https://doi.org/10.1016/j.ecolecon.2020.106790

Plantinga, A.J., 2015. Integrating Economic Land-Use and Biophysical Models. Annu. Rev. Resour. Econ. 7, 233-249. https://doi.org/10.1146/annurev-resource-100814-125056

Poore, J., Nemecek, T., 2018. Reducing food's environmental impacts through producers and consumers. Science (80-. ). 360, 987-992. https://doi.org/10.1126/science.aaq0216

Popp, A., Dietrich, J.P., Lotze-Campen, H., Klein, D., Bauer, N., Krause, M., Beringer, T., Gerten, D., Edenhofer, O., 2011. The economic potential of bioenergy for climate change mitigation with special attention given to implications for the land system. Environ. Res. Lett. 6. https://doi.org/10.1088/1748-9326/6/3/034017

Popp, J., Lakner, Z., Harangi-Rákos, M., Fári, M., 2014. The effect of bioenergy expansion: Food, energy, and environment. Renew. Sustain. Energy Rev. 32, 559-578. https://doi. org/10.1016/j.rser.2014.01.056

Porkka, M., Kummu, M., Siebert, S., Varis, O., 2013. From food insufficiency towards trade dependency: A historical analysis of global food availability. PLoS One 8. https://doi. org/10.1371/journal.pone.0082714

Potting, J., Hekkert, M., Worrell, E., Hanemaaijer, A., 2016. Circular Economy: Measuring innovation in the product chain - Policy report. PBL Netherlands Environ. Assess. Agency 42.

Prestele, R., Alexander, P., Rounsevell, M.D.A., Arneth, A., Calvin, K., Doelman, J., Eitelberg, D.A., Engström, K., Fujimori, S., Hasegawa, T., Havlik, P., Humpenöder, F., Jain, A.K., Krisztin, T., Kyle, P., Meiyappan, P., Popp, A., Sands, R.D., Schaldach, R., Schüngel, J., Stehfest, E., Tabeau, A., Van Meijl, H., Van Vliet, J., Verburg, P.H., 2016. Hotspots of uncertainty in land-use and land-cover change projections: a global-scale model comparison. Glob. Chang. Biol. 22, 3967-3983. https://doi.org/10.1111/gcb.13337

Priefer, C., Jörissen, J., Bräutigam, K.R., 2016. Food waste prevention in Europe - A causedriven approach to identify the most relevant leverage points for action. Resour. Conserv. Recycl. 109, 155-165. https://doi.org/10.1016/j.resconrec.2016.03.004

Ranganathan, J., Vennard, D., Waite, R., Dumas, P., Lipinski, B., Searchinger, T., 2016. Shifting diets Toward a sustainable food future. Creat. a Sustain. Food Futur. 11, 90. https://doi. org/10.2499/9780896295827_08

Rao, N.D., Min, J., 2018. Decent Living Standards: Material Prerequisites for Human Wellbeing. Soc. Indic. Res. 138, 225-244. https://doi.org/10.1007/s11205-017-1650-0

Raworth, K., 2017. A Doughnut for the Anthropocene: humanity's compass in the 21st century. Lancet Planet. Heal. 1, e48-e49. https://doi.org/10.1016/s2542-5196(17)30028-1

Ray, D.K., Mueller, N.D., West, P.C., Foley, J.A., 2013. Yield Trends Are Insufficient to Double Global Crop Production by 2050. PLoS One 8. https://doi.org/10.1371/journal. pone.0066428 
Richter, B., 2017. Knowledge and perception of food waste among German consumers. J. Clean. Prod. 166, 641-648. https://doi.org/10.1016/j.jclepro.2017.08.009

Rico-Campà, A., Martínez-González, M.A., Alvarez-Alvarez, I., De Deus Mendonça, R., De La Fuente-Arrillaga, C., Gómez-Donoso, C., Bes-Rastrollo, M., 2019. Association between consumption of ultra-processed foods and all cause mortality: SUN prospective cohort study. BMJ 365. https://doi.org/10.1136/bmj.11949

Ritchie, H., Roser, M., 2019. Crop Yields [WWW Document]. Our World Data. URL https:// ourworldindata.org/crop-yields\#citation (accessed 6.11.20).

Ronzon, T., Sanjuán, A.I., 2020. Friends or foes? A compatibility assessment of bioeconomyrelated Sustainable Development Goals for European policy coherence. J. Clean. Prod. 254. https://doi.org/10.1016/j.jclepro.2019.119832

Rood, T., Muilwijk, H., Westhoek, H., 2017. Food for the circular economy. https://doi. org/10.1145/3236112.3236125

Röös, E., Bajželj, B., Smith, P., Patel, M., Little, D., Garnett, T., 2017. Greedy or needy? Land use and climate impacts of food in 2050 under different livestock futures. Glob. Environ. Chang. 47, 1-12. https://doi.org/10.1016/j.gloenvcha.2017.09.001

Ros, J., Koelemeijer, R., Elzenga, H., Peters, J., Hekkenberg, M., Bosch, P., 2011. Exploration of pathways towards a clean economy by 2050:

Rosegrant, M.W., Msangi, S., 2014. Consensus and Contention in the Food-Versus-Fuel Debate. Annu. Rev. Environ. Resour. 39, 271-294. https://doi.org/10.1146/annurevenviron-031813-132233

Rossi, A., Lambrou, Y., 2008. Gender and equity issues in liquid biofuels production: Minimizing the risks to maximize the opportunities. East.

Rothgerber, H., 2013. Real men don't eat (vegetable) quiche: Masculinity and the justification of meat consumption. Psychol. Men Masculinity 14, 363-375. https://doi.org/10.1037/ a0030379

Rulli, M.C., Bellomi, D., Cazzoli, A., De Carolis, G., D’Odorico, P., 2016. The water-land-food nexus of first-generation biofuels. Sci. Rep. 6, 1-10. https://doi.org/10.1038/srep22521

Rulli, M.C., Saviori, A., Odorico, P.D., 2012. Global land and water grabbing. Pnas 110, 892897. https://doi.org/10.1073/pnas.1213163110/-/DCSupplemental.www.pnas.org/cgi/ doi/10.1073/pnas.1213163110

Russi, D., 2008. An integrated assessment of a large-scale biodiesel production in Italy: Killing several birds with one stone? Energy Policy 36, 1169-1180. https://doi.org/10.1016/j. enpol.2007.11.016

Saavedra, Y.M.B., Iritani, D.R., Pavan, A.L.R., Ometto, A.R., 2018. Theoretical contribution of industrial ecology to circular economy. J. Clean. Prod. 170, 1514-1522. https://doi. org/10.1016/j.jclepro.2017.09.260

Saltelli, A., Giampietro, M., 2017. What is wrong with evidence based policy, and how can it be improved? Futures 91, 62-71. https://doi.org/10.1016/j.futures.2016.11.012 
Sandin, G., Peters, G.M., 2018. Environmental impact of textile reuse and recycling - A review. J. Clean. Prod. 184, 353-365. https://doi.org/10.1016/j.jclepro.2018.02.266

Sarker, A., Deepo, D.M., Nandi, R., Rana, J., Islam, S., Rahman, S., Hossain, M.N., Islam, M.S., Baroi, A., Kim, J.E., 2020. A review of microplastics pollution in the soil and terrestrial ecosystems: A global and Bangladesh perspective. Sci. Total Environ. 733, 139296. https://doi.org/10.1016/j.scitotenv.2020.139296

Saunders, B., Sim, J., Kingstone, T., Baker, S., Waterfield, J., Bartlam, B., Burroughs, H., Jinks, C., 2018. Saturation in qualitative research: exploring its conceptualization and operationalization. Qual. Quant. 52, 1893-1907. https://doi.org/10.1007/s11135-017-0574-8

Scarlat, N., Blujdea, V., Dallemand, J.F., 2011. Assessment of the availability of agricultural and forest residues for bioenergy production in Romania. Biomass and Bioenergy 35, 19952005. https://doi.org/10.1016/j.biombioe.2011.01.057

Scarlat, N., Dallemand, J.-F., Taylor, N., Banja, M., Sanchez Lopez, J., Avraamides, M., 2019. Brief on biomass for energy in the European Union. https://doi.org/10.2760/546943

Scarlat, N., Dallemand, J.F., Banja, M., 2013. Possible impact of 2020 bioenergy targets on European Union land use. A scenario-based assessment from national renewable energy action plans proposals. Renew. Sustain. Energy Rev. 18, 595-606. https://doi. org/10.1016/j.rser.2012.10.040

Scarlat, N., Dallemand, J.F., Monforti-Ferrario, F., Nita, V., 2015. The role of biomass and bioenergy in a future bioeconomy: Policies and facts. Environ. Dev. 15, 3-34. https://doi. org/10.1016/j.envdev.2015.03.006

Schader, C., Muller, A., Scialabba, N.E.-H., Hecht, J., Isensee, A., Erb, K.-H., Smith, P., Makkar, H.P.S., Klocke, P., Leiber, F., Schwegler, P., Stolze, M., Niggli, U., 2015. Impacts of feeding less food-competing feedstuffs to livestock on global food system sustainability. J. R. Soc. Interface 12, 20150891. https://doi.org/10.1098/rsif.2015.0891

Schanes, K., Dobernig, K., Gözet, B., 2018. Food waste matters - A systematic review of household food waste practices and their policy implications. J. Clean. Prod. 182, 978991. https://doi.org/10.1016/j.jclepro.2018.02.030

Schebesta, H., Candel, J.J.L., 2020. Game-changing potential of the EU's Farm to Fork Strategy. Nat. Food 1, 586-588. https://doi.org/10.1038/s43016-020-00166-9

Scherhaufer, S., Moates, G., Hartikainen, H., Waldron, K., Obersteiner, G., 2018. Environmental impacts of food waste in Europe. Waste Manag. 77, 98-113. https://doi.org/10.1016/j. wasman.2018.04.038

Schmidt, J., Schönhart, M., Biberacher, M., Guggenberger, T., Hausl, S., Kalt, G., Leduc, S., Schardinger, I., Schmid, E., 2012. Regional energy autarky: Potentials, costs and consequences for an Austrian region. Energy Policy 47, 211-221. https://doi.org/10.1016/j. enpol.2012.04.059

Searchinger, T.D., Beringer, T., Holtsmark, B., Kammen, D.M., Lambin, E.F., Lucht, W., Raven, P., van Ypersele, J.P., 2018. Europe's renewable energy directive poised to harm global 
forests. Nat. Commun. 9, 10-13. https://doi.org/10.1038/s41467-018-06175-4

Searchinger, T.D., Moomaw, W., Booth, M., Norton, M., 2020. Comment on Strengers \& Elzenga , Availability and Applications of Sustainable Biomass ( PBL 2020 ) 1-27.

Semetko, H.A., Valkenburg, P.M., 2000. Framing European politics: A content analysis of press and television news. J. Commun. 50, 93-109. https://doi.org/10.1111/j.1460-2466.2000. tb02843.x

Sexton, A.E., Garnett, T., Lorimer, J., 2019. Framing the future of food: The contested promises of alternative proteins. Environ. Plan. E Nat. Sp. 2, 47-72. https://doi. org/10.1177/2514848619827009

Shortall, O.K., 2013. "Marginal land" for energy crops: Exploring definitions and embedded assumptions. Energy Policy 62, 19-27. https://doi.org/10.1016/j.enpol.2013.07.048

Shortall, O.K., Anker, H.T., Sandøe, P., Gamborg, C., 2019a. Room at the margins for energycrops? A qualitative analysis of stakeholder views on the use of marginal land for biomass production in Denmark. Biomass and Bioenergy. https://doi.org/10.1016/j. biombioe.2019.01.042

Shortall, O.K., Anker, H.T., Sandøe, P., Gamborg, C., 2019b. Room at the margins for energycrops? A qualitative analysis of stakeholder views on the use of marginal land for biomass production in Denmark. Biomass and Bioenergy 123, 51-58. https://doi.org/10.1016/j. biombioe.2019.01.042

Shove, E., Watson, M., Spurling, N., 2015. Conceptualizing connections: Energy demand, infrastructures and social practices. Eur. J. Soc. Theory 18, 274-287. https://doi. org/10.1177/1368431015579964

Shurson, G.C., 2017. The Role of Biofuels Coproducts in Feeding the World Sustainably. Annu. Rev. Anim. Biosci. 5, 229-254. https://doi.org/10.1146/annurev-animal-022516-022907

Simon, S., Wiegmann, K., 2009. Modelling sustainable bioenergy potentials from agriculture for Germany and Eastern European countries. Biomass and Bioenergy 33, 603-609. https:// doi.org/10.1016/j.biombioe.2008.10.001

Sirkin, T., Houten, M. ten, 1994. The cascade chain. A theory and tool for achieving resource sustainability with applications for product design. Resour. Conserv. Recycl. 10, 213-276. https://doi.org/10.1016/0921-3449(94)90016-7

Skevas, T., Hayden, N.J., Swinton, S.M., Lupi, F., 2016. Landowner willingness to supply marginal land for bioenergy production. Land use policy 50, 507-517. https://doi. org/10.1016/j.landusepol.2015.09.027

Skogstad, G., Wilder, M., 2019. Strangers at the gate: the role of multidimensional ideas, policy anomalies and institutional gatekeepers in biofuel policy developments in the USA and European Union. Policy Sci. 52, 343-366. https://doi.org/10.1007/s11077-019-09351-5

Smeets, E.M.W., Faaij, A.P.C., Lewandowski, I.M., Turkenburg, W.C., 2007. A bottom-up assessment and review of global bio-energy potentials to 2050. Prog. Energy Combust. Sci. 33, 56-106. https://doi.org/10.1016/j.pecs.2006.08.001 
Smil, V., 2012. Harvesting the biosphere: What we have taken from nature[M]. Mit Press, 2012. https://doi.org/10.1017/CBO9781107415324.004

Smith, P., Gregory, P.J., van Vuuren, D., Obersteiner, M., Havlík, P., Rounsevell, M., Woods, J., Stehfest, E., Bellarby, J., 2010. Competition for land. Philos. Trans. R. Soc. Lond. B. Biol. Sci. 365, 2941-57. https://doi.org/10.1098/rstb.2010.0127

Söderholm, P., 2011. Taxing virgin natural resources: Lessons from aggregates taxation in Europe. Resour. Conserv. Recycl. 55, 911-922. https://doi.org/10.1016/j. resconrec.2011.05.011

Sorda, G., Banse, M., 2011. The response of the German agricultural sector to the envisaged biofuel targets in Germany and abroad: A CGE simulation. Ger. J. Agric. Econ. 60, 243258.

Spierling, S., Venkatachalam, V., Behnsen, H., Herrmann, C., Endres, H., 2019. Bioplastics and Circular Economy-Performance Indicators to Identify Optimal Pathways Sebastian. Springer International Publishing. https://doi.org/10.1007/978-3-319-92237-9

Srour, B., Fezeu, L.K., Kesse-Guyot, E., Allès, B., Méjean, C., Andrianasolo, R.M., Chazelas, E., Deschasaux, M., Hercberg, S., Galan, P., Monteiro, C.A., Julia, C., Touvier, M., 2019. Ultra-processed food intake and risk of cardiovascular disease: Prospective cohort study (NutriNet-Santé). BMJ 365. https://doi.org/10.1136/bmj.l1451

Steffen, W., Richardson, K., Rockström, J., Cornell, S.E., Fetzer, I., Bennett, E.M., Biggs, R., Carpenter, S.R., Vries, W. De, Wit, C.A. De, Folke, C., Gerten, D., Heinke, J., Mace, G.M., Persson, L.M., Ramanathan, V., Reyers, B., Sörlin, S., 2015. Planetary boundaries : Guiding changing planet. Science (80-. ). 347, 1-10. https://doi.org/10.1126/ science. 1259855

Steg, L., Vlek, C., 2009. Encouraging pro-environmental behaviour: An integrative review and research agenda. J. Environ. Psychol. 29, 309-317. https://doi.org/10.1016/j. jenvp.2008.10.004

Stegmann, P., Londo, M., Junginger, M., 2020. The circular bioeconomy: Its elements and role in European bioeconomy clusters. Resour. Conserv. Recycl. X 6, 100029. https://doi. org/10.1016/j.rcrx.2019.100029

Steinbuks, J., Hertel, T.W., 2016. Confronting the Food???Energy???Environment Trilemma: Global Land Use in the Long Run. Environ. Resour. Econ. 63, 545-570. https://doi. org/10.1007/s10640-014-9848-y

Steubing, B., Zah, R., Waeger, P., Ludwig, C., 2010. Bioenergy in Switzerland: Assessing the domestic sustainable biomass potential. Renew. Sustain. Energy Rev. 14, 2256-2265. https://doi.org/10.1016/j.rser.2010.03.036

Stirling, A., 2010. Keep it complex. Nature 468, 1029-1031. https://doi.org/10.1038/4681029a

Stirling, A., 2007. Risk, precaution and science: towards a more constructive policy debate. EMBO Rep. 8, 309-315. https://doi.org/10.1038/sj.embor.7400953

Strand, R., 2002. Complexity, Ideology, and Governance. Emergence. https://doi.org/10.1207/ 
s15327000em041\&2-14

Strapasson, A., Woods, J., Chum, H., Kalas, N., Shah, N., Rosillo-Calle, F., 2017. On the global limits of bioenergy and land use for climate change mitigation. GCB Bioenergy 9, 17211735. https://doi.org/10.1111/gcbb.12456

Stürmer, B., Schmidt, J., Schmid, E., Sinabell, F., 2013. Implications of agricultural bioenergy crop production in a land constrained economy - The example of Austria. Land use policy 30, 570-581. https://doi.org/10.1016/j.landusepol.2012.04.020

Styles, D, Gibbons, J., Williams, A.P., Stichnothe, H., Chadwick, D.R., Healey, J.R., 2015. Cattle feed or bioenergy? Consequential life cycle assessment of biogas feedstock options on dairy farms. GCB Bioenergy 7, 1034-1049. https://doi.org/10.1111/gcbb.12189

Styles, David, Gibbons, J., Williams, A.P., Stichnothe, H., Chadwick, D.R., Healey, J.R., 2015. Cattle feed or bioenergy? Consequential life cycle assessment of biogas feedstock options on dairy farms. GCB Bioenergy 7, 1034-1049. https://doi.org/10.1111/gcbb.12189

Sumter, D., de Koning, J., Bakker, C., Balkenende, R., 2020. Circular economy competencies for design. Sustain. 12, 1-16. https://doi.org/10.3390/su12041561

Suominen, T., Kunttu, J., Jasinevičius, G., Tuomasjukka, D., Lindner, M., 2017. Trade-offs in sustainability impacts of introducing cascade use of wood. Scand. J. For. Res. 32, 588597. https://doi.org/10.1080/02827581.2017.1342859

Taheripour, F., Hertel, T.W., Tyner, W.E., 2011. Implications of biofuels mandates for the global livestock industry: A computable general equilibrium analysis. Agric. Econ. 42, 325-342. https://doi.org/10.1111/j.1574-0862.2010.00517.x

Taheripour, F., Hertel, T.W., Tyner, W.E., 2010. Implications of the biofuels boom for the global livestock industry: a computable general equilibrium analysis. GTAP Work. Pap. 3194, 1-46. https://doi.org/10.1111/j.1574-0862.2010.00517.x

Teigiserova, D.A., Hamelin, L., Thomsen, M., 2019. Review of high-value food waste and food residues biorefineries with focus on unavoidable wastes from processing. Resour. Conserv. Recycl. 149, 413-426. https://doi.org/10.1016/j.resconrec.2019.05.003

Termeer, C.J.A.M., Metze, T.A.P., 2019. More than peanuts: Transformation towards a circular economy through a small-wins governance framework. J. Clean. Prod. 240, 118272. https://doi.org/10.1016/j.jclepro.2019.118272

The European Parliament and the Council of the European Union, 2018. Directive (EU) 2018/2001 of the European Parliament and of the Council on the promotion of the use of energy from renewable sources. Off. J. Eur. Union 2018.

Thornton, P.K., 2010. Livestock production: recent trends, future prospects. Philos. Trans. R. Soc. London.Series B, Biol. Sci. 365, 2853-2867. https://doi.org/10.1098/rstb.2010.0134 [doi]

Thrän, D., Seidenberger, T., Zeddies, J., Offermann, R., 2010. Global biomass potentials Resources, drivers and scenario results. Energy Sustain. Dev. 14, 200-205. https://doi. org/10.1016/j.esd.2010.07.004 
Tilman, D., Balzer, C., Hill, J., Befort, B.L., 2011. Global food demand and the sustainable intensification of agriculture. Proc. Natl. Acad. Sci. United States Am. United States Am. 108, 20260-20264. https://doi.org/10.1073/pnas.1116437108

Timilsina, G.R., Beghin, J.C., van der Mensbrugghe, D., Mevel, S., 2012. The impacts of biofuels targets on land-use change and food supply: A global CGE assessment. Agric. Econ. 43, 315-332. https://doi.org/10.1111/j.1574-0862.2012.00585.x

Tonini, D., Hamelin, L., Astrup, T.F., 2016. Environmental implications of the use of agroindustrial residues for biorefineries: application of a deterministic model for indirect landuse changes. GCB Bioenergy 8, 690-706. https://doi.org/10.1111/gcbb.12290

Tosun, J., Leininger, J., 2017. Governing the Interlinkages between the Sustainable Development Goals: Approaches to Attain Policy Integration. Glob. Challenges 1700036, 1700036. https://doi.org/10.1002/gch2.201700036

Treesilvattanakul, K., Taheripour, F., Tyner, W.E., 2014. Application of US and EU sustainability criteria to analysis of biofuels-induced land use change. Energies 7, 5119-5128. https:// doi.org/10.3390/en7085119

Trink, T., Schmid, C., Schinko, T., Steininger, K.W., Loibnegger, T., Kettner, C., Pack, A., Töglhofer, C., 2010. Regional economic impacts of biomass based energy service use: A comparison across crops and technologies for East Styria, Austria. Energy Policy 38, 5912-5926. https://doi.org/10.1016/j.enpol.2010.05.045

Tufvesson, L.M., Lantz, M., Börjesson, P., 2013. Environmental performance of biogas produced from industrial residues including competition with animal feed - Life-cycle calculations according to different methodologies and standards. J. Clean. Prod. 53, 214-223. https:// doi.org/10.1016/j.jclepro.2013.04.005

Tukker, A., Bulavskaya, T., Giljum, S., de Koning, A., Lutter, S., Simas, M., Stadler, K., Wood, R., 2016. Environmental and resource footprints in a global context: Europe's structural deficit in resource endowments. Glob. Environ. Chang. 40, 171-181. https://doi.org/10.1016/j. gloenvcha.2016.07.002

Tukker, A., Bulavskaya, T., Giljum, S., de Koning, A., Lutter, S., Simas, M., Stadler, K., Wood, R., 2014. The global resource footprint of nations, Carbon, water, land and materials embodied in trade and final consumption calculated with EXIOBASE. https://repository. tno.nl//islandora/object/uuid:213c00d4-c342-42fd-b93e-a07b06d44f0c

UN General Assembly, 2015. Transforming our world: the 2030 Agenda for Sustainable Development.

UNEP, 2014. Decoupling 2: technologies, opportunities and policy options. A Report of the Working Group on Decoupling to the International Resource Panel. E.U. von Weizsäcker, J. de Larderel, K. Hargroves, C.Hudson, M. Smith and M. Rodrigues.

Usubiaga-Liaño, A., Mace, G.M., Ekins, P., 2019. Limits to agricultural land for retaining acceptable levels of local biodiversity. Nat. Sustain. 2, 491-498. https://doi.org/10.1038/ s41893-019-0300-8 
Valentine, J., Clifton-Brown, J., Hastings, A., Robson, P., Allison, G., Smith, P., 2012. Food vs. fuel: The use of land for lignocellulosic "next generation" energy crops that minimize competition with primary food production. GCB Bioenergy 4, 1-19. https://doi. org/10.1111/j.1757-1707.2011.01111.x

van Berkum, S., Dengerink, J., Ruben, R., 2018. The food systems approach: sustainable solutions for a sufficient supply of healthy food. Wageningen Econ. Res. 064, 32.

van den Bos Verma, M., de Vreede, L., Achterbosch, T., Rutten, M.M., 2020. Consumers discard a lot more food than widely believed: Estimates of global food waste using an energy gap approach and affluence elasticity of food waste. PLoS One 15, 1-14. https://doi. org/10.1371/journal.pone.0228369

Van Der Sluijs, J.P., Craye, M., Funtowicz, S., Kloprogge, P., Ravetz, J., Risbey, J., 2005. Combining quantitative and qualitative measures of uncertainty in model-based environmental assessment: The NUSAP system. Risk Anal. 25, 481-492. https://doi. org/10.1111/j.1539-6924.2005.00604.x

Van Eijk, F., 2015. Barriers \& Drivers towards a Circular Economy - Literature Review 1-138. Van Gorp, B., 2006. The Constructionist Approach to Framing: Bringing Culture Back In. J. Commun. 56, 869-870. https://doi.org/10.1111/j.1460-2466.2006.00329.x

Van Gorp, B., van der Goot, M.J., 2012. Sustainable Food and Agriculture: Stakeholder's Frames. Commun. Cult. Crit. 5, 127-148. https://doi.org/10.1111/j.17539137.2012.01135.x

Van Hal, O., de Boer, I.J.M., Muller, A., de Vries, S., Erb, K.H., Schader, C., Gerrits, W.J.J., van Zanten, H.H.E., 2019a. Upcycling food leftovers and grass resources through livestock: Impact of livestock system and productivity. J. Clean. Prod. 219, 485-496. https://doi.org/ https://doi.org/10.1016/j.jclepro.2019.01.329

Van Hal, O., Weijenberg, Boer, D., van Zanten, 2019b. Accounting for feed-food competition in environmental impact assessment: Towards a resource efficient food-system. J. Clean. Prod. 240, 118241. https://doi.org/10.1016/j.jclepro.2019.118241

Van Kernebeek, H.R.J., Oosting, S.J., Van Ittersum, M.K., Bikker, P., De Boer, I.J.M., 2016. Saving land to feed a growing population: consequences for consumption of crop and livestock products. Int. J. Life Cycle Assess. 21, 677-687. https://doi.org/10.1007/s11367015-0923-6

Van Kernebeek, H.R.J., Oosting, S.J., van Ittersum, M.K., Ripoll-Bosch, R., de Boer, I.J.M., 2018. Closing the phosphorus cycle in a food system: insights from a modelling exercise. Animal 12, 1755-1765. https://doi.org/10.1017/s1751731118001039

Van Stappen, F., Mathot, M., Decruyenaere, V., Loriers, A., Delcour, A., Planchon, V., Goffart, J.P., Stilmant, D., 2016. Consequential environmental life cycle assessment of a farm-scale biogas plant. J. Environ. Manage. 175, 20-32. https://doi.org/10.1016/j. jenvman.2016.03.020

Van Zanten, H, Meerburg, B.G., Bikker, P., Herrero, M., de Boer, I.J.M., 2016a. Opinion paper : 
The role of livestock in a sustainable diet : a land-use perspective. Animal 10, 547-549. https://doi.org/10.1017/S1751731115002694

Van Zanten, H, Mollenhorst, H., Klootwijk, C.W., van Middelaar, C.E., de Boer, I.J.M., 2016b. Global food supply: land use efficiency of livestock systems. Int. J. Life Cycle Assess. 21, 747-758. https://doi.org/10.1007/s11367-015-0944-1

Van Zanten, H.H.E., Herrero, M., Van Hal, O., Röös, E., Muller, A., Garnett, T., Gerber, P.J., Schader, C., De Boer, I.J.M., 2018. Defining a land boundary for sustainable livestock consumption. Glob. Chang. Biol. 24, 4185-4194. https://doi.org/10.1111/gcb.14321

Van Zanten, H.H.E., Mollenhorst, H., De Vries, J.W., Van Middelaar, C.E., Van Kernebeek, H.R.J., De Boer, I.J.M., 2014. Assessing environmental consequences of using co-products in animal feed. Int. J. Life Cycle Assess. 19, 79-88. https://doi.org/10.1007/s11367-0130633-x

Van Zanten, H.H.E., van Ittersum, M.K., de Boer, I.J.M., 2019. The role of farm animals in a circular food system. Press 21, 18-22. https://doi.org/10.1016/j.gfs.2019.06.003

Velenturf, A.P.M., Archer, S.A., Gomes, H.I., Christgen, B., Lag-Brotons, A.J., Purnell, P., 2019. Circular economy and the matter of integrated resources. Sci. Total Environ. 689, 963969. https://doi.org/10.1016/j.scitotenv.2019.06.449

Verkerk, P.J., Fitzgerald, J.B., Datta, P., Dees, M., Hengeveld, G.M., Lindner, M., Zudin, S., 2019. Spatial distribution of the potential forest biomass availability in europe. For. Ecosyst. 6 , 1-11. https://doi.org/10.1186/s40663-019-0163-5

Verschraegen, G., Vandermoere, F., Braeckmans, L., Segaert, B., 2017. Imagined Futures in Science, Technology and Society, Imagined Futures in Science, Technology and Society. https://doi.org/10.4324/9781315440842

Vidal, O., Goffé, B., Arndt, N., 2013. Metals for a low-carbon society. Nat. Geosci. 6, 894-896. https://doi.org/10.1038/ngeo1993

Villas-Bôas, S.G., Esposito, E., Mitchell, D.A., 2002. Microbial conversion of lignocellulosic residues for production of animal feeds. Anim. Feed Sci. Technol. 98, 1-12. https://doi. org/10.1016/S0377-8401(02)00017-2

Vis, M., Mantau, U., Allen, B., 2016. CASCADES. Study on the optimised cascading use of wood. https://doi.org/10.2873/827106

Voelker, T., Blackstock, K., Kovacic, Z., Sindt, J., Strand, R., Waylen, K., 2019. The role of metrics in the governance of the water-energy-food nexus within the European Commission. J. Rural Stud. 1-9. https://doi.org/10.1016/j.jrurstud.2019.08.001

Walker, W.E., Harremoes, P., Rotmans, J., Van Der Sluijs, J.P., Van Asselt, M.B.A., Janssen, P., Krayer Von Krauss, M.P., 2003. Defining Uncertainty. Integr. Assess. 00.

Ward, J.D., Sutton, P.C., Werner, A.D., Costanza, R., Mohr, S.H., Simmons, C.T., 2016. Is decoupling GDP growth from environmental impact possible? PLoS One 11, 1-14. https:// doi.org/10.1371/journal.pone.0164733

Ward, S.M., Holden, N.M., White, E.P., Oldfield, T.L., 2016. The ' circular economy ' applied to 
the agriculture ( livestock production ) sector - discussion paper The ' Circular ' v . ' Linear 'Economy : The ' circular economy' is a generic term for an industrial economy that is producing no waste and pollution. Work. Sustain. EU's Livest. Prod. Syst. 11.

Warner, E., Inman, D., Kunstman, B., Bush, B., Vimmerstedt, L., Peterson, S., Macknick, J., Zhang, Y., 2013. Modeling biofuel expansion effects on land use change dynamics. Environ. Res. Lett. 8. https://doi.org/10.1088/1748-9326/8/1/015003

Weinzettel, J., Hertwich, E.G., Peters, G.P., Steen-Olsen, K., Galli, A., 2013. Affluence drives the global displacement of land use. Glob. Environ. Chang. 23, 433-438. https://doi. org/10.1016/j.gloenvcha.2012.12.010

Weitz, N., Strambo, C., Kemp-Benedict, E., Nilsson, M., 2017. Closing the governance gaps in the water-energy-food nexus: Insights from integrative governance. Glob. Environ. Chang. 45, 165-173. https://doi.org/10.1016/j.gloenvcha.2017.06.006

Welfle, A., Gilbert, P., Thornley, P., 2014. Securing a bioenergy future without imports. Energy Policy 68, 1-14. https://doi.org/10.1016/j.enpol.2013.11.079

WHO, 2019. Obesity and Overweight [WWW Document]. URL https://www.who.int/news-room/ fact-sheets/detail/obesity-and-overweight (accessed 4.10.20).

Willett, W., Rockström, J., Loken, B., Springmann, M., Lang, T., Vermeulen, S., Garnett, T., Tilman, D., DeClerck, F., Wood, A., Jonell, M., Clark, M., Gordon, L., Fanzo, J., Hawkes, C., Zurayk, R., Rivera, J.A., Vries, W. De, Sibanda, L., Afshin, A., Chaudhary, A., Herrero, M., Agustina, R., Branca, F., Lartey, A., Fan, S., Crona, B., Fox, E., Bignet, V., Troell, M., Lindahl, T., Singh, S., Cornell, S., Reddy, S., Narain, S., Nishtar, S., Murray, C., 2019. Food in the Anthropocene: the EAT-Lancet Commission on healthy diets from sustainable food systems. Lancet 6736, 3-49. https://doi.org/10.1016/S0140-6736(18)31788-4

Winchester, N., Ledvina, K., 2017. The impact of oil prices on bioenergy, emissions and land use. Energy Econ. 65, 219-227. https://doi.org/10.1016/j.eneco.2017.05.008

Wirsenius, S., 2003. The Biomass Metabolism of the Food System: A Model-Based Survey of the Global and Regional Turnover of Food Biomass. J. Ind. Ecol. 7, 47-80. https://doi. org/10.1162/108819803766729195

Wise, M., Dooley, J., Luckow, P., Calvin, K., Kyle, P., 2014. Agriculture, land use, energy and carbon emission impacts of global biofuel mandates to mid-century. Appl. Energy 114, 763-773. https://doi.org/10.1016/j.apenergy.2013.08.042

Zabaniotou, A., 2018. Redesigning a bioenergy sector in EU in the transition to circular wastebased Bioeconomy-A multidisciplinary review. J. Clean. Prod. 177, 197-206. https://doi. org/10.1016/j.jclepro.2017.12.172

Zahariadis, N., 2008. Ambiguity and choice in European public policy. J. Eur. Public Policy 15, 514-530. https://doi.org/10.1080/13501760801996717

Zhang, C., Chen, X., Li, Y., Ding, W., Fu, G., 2018. Water-energy-food nexus: Concepts, questions and methodologies. J. Clean. Prod. 195, 625-639. https://doi.org/10.1016/j. jclepro.2018.05.194 
Zhao, C., Liu, B., Piao, S., Wang, X., Lobell, D.B., Huang, Y., Huang, M., Yao, Y., Bassu, S., Ciais, P., Durand, J.L., Elliott, J., Ewert, F., Janssens, I.A., Li, T., Lin, E., Liu, Q., Martre, P., Müller, C., Peng, S., Peñuelas, J., Ruane, A.C., Wallach, D., Wang, T., Wu, D., Liu, Z., Zhu, Y., Zhu, Z., Asseng, S., 2017. Temperature increase reduces global yields of major crops in four independent estimates. Proc. Natl. Acad. Sci. U. S. A. 114, 9326-9331. https://doi. org/10.1073/pnas.1701762114

Zhou, S., Kolding, J., Garcia, S.M., Plank, M.J., Bundy, A., Charles, A., Hansen, C., Heino, M., Howell, D., Jacobsen, N.S., Reid, D.G., Rice, J.C., van Zwieten, P.A.M., 2019. Balanced harvest: concept, policies, evidence, and management implications. Rev. Fish Biol. Fish. 29, 711-733. https://doi.org/10.1007/s11160-019-09568-w 
The Battle for Biomass | Abigail Muscat Bibliography 


\section{Summary}

Humanity's growing demand for food, feed, bioenergy and biomaterials put pressure on agroecosystems and the biosphere. If these trends continue, the capacity of agroecosystems to feed the planet while also providing for humanity's energy and material needs is at risk. This demand cause interactions and trade-offs between different biomass uses, competition for biomass and other natural and economic resources. Governing these interactions is difficult, because of the inherent complexity of these interactions but also due to the diversity of biomass resources, the diversity of policy domains and institutions that are needed to govern them. However, there is limited knowledge on the interactions between different biomass uses and how these may result in trade-offs and synergies. Furthermore, little is known how these trade-offs and synergies may affect policy coherence and what solutions are needed to achieve more sustainable biomass use. With its leading role in bioenergy and bioeconomy policy, the European Union (EU) plays a key role in debates surrounding biomass. This thesis, therefore, aims to advance the theoretical and empirical understanding of the governance of biomass with the ultimate aim of improving the governance process at the science-policy interface, taking the EU as a case study.

Chapter 2 provides an overview of the driving factors behind the growing demands for biomass as well as the trade-offs and synergies across different biomass uses. To do this, we conducted a systematic review of 75 studies that looked at competition between biomass uses and the resources that support them (i.e. water, land, labour and capital). We found seven factors that drive the availability of biomass and resources namely: increased bioenergy demand, increased crop yields, increase of human-edible feed, amount of animal-source food in human diets, efficiency of food supply chains, type of bioenergy feedstock and implementation of land-use policies. These shaped the biophysical option-space, determining which interactions (neutral), trade-offs (negative) and synergies (positive) between food, feed, fuel goals. We found that the majority of the effects implied trade-offs. For example, the factor of increasing bioenergy demand resulted in trade-offs with other natural resources such as increased land-use and land-use change, increased water consumption, and increased nitrogen demand. It also resulted in tradeoffs with economic resources, leading to increasing food prices and higher land rents. A diversity of solutions was recommended by the literature to deal with these trade-offs and these ranged from production-side, governance, losses and wastes and consumption-side solutions. We found that these different types of solutions came from different disciplinary perspectives, each setting different priorities for biomass. To connect these perspectives, we suggested a framework where priority is given to basic human needs for the consumption of biomass.

Given the many trade-offs between biomass uses, it is difficult for policies to manage issues that cut across different policy domains. Given these trade-offs, biomass will become an increasingly 
important resource in the bioeconomy and will require careful and sustainable management. The bioeconomy will therefore require coherence between many different policy domains. In chapter 3 we conducted a study of policy coherence between these policy domains. To do this we conducted a qualitative content analysis of $41 \mathrm{EU}$ policy documents across 5 policy domains, namely agrofood, bio-based industry, waste, energy and environment. Coherency was measured by using a survey and focus groups based on expert opinion across scientific fields. We utilised both a coherency score using a 7-point Likert scale and measures of confidence and disagreement. The results of the survey indicate that bioeconomy policy goals and agro-food policy goals are largely considered to be consistent and that synergies outweigh trade-offs, both in quantity and in strength. However, there was disagreement and mixed confidence among respondents on whether different goals were synergistic or conflicting. Digging further into the results using focus groups, we found uncertainty and context dependencies in the scientific knowledge-base, particularly concerning waste and bio-based industry. We categorised these uncertainties into five types, and distinguish between ambiguity, which arises from different incommensurable ways of framing a problem and vagueness which leaves concepts undefined. We conclude that a shift towards a bioeconomy will have to acknowledge the interactions between different policy goals across the different sectors and avoid 'silo-thinking'. This can be achieved through overcoming vagueness in policies, such as having clear cascading guidelines for biomass.

Building on the findings of chapter 2, where we found that marginal lands was recommended as a solution to food-feed-fuel competition, in chapter $\mathbf{4}$ we conducted a framing analysis of the narrative frames surrounding marginal lands in EU science and policy-making. We wanted to know how different scientific and policy stakeholders looked at marginal lands and what problems and solutions marginal lands address. We found a total of eight frames utilised by a diversity of actors: i) the Sustainable Bioenergy frame ii) the Precautionary Principle frame iii) the Marginal Land Critique frame iv) the Food Security frame v) the Land Rights frame vi) the Rural Development frame vii) the Ecosystem Restoration frame and viii) the Low-Cost Livestock frame. We related these to four debates taking place in the EU related to land use; discussions about the effect of indirectland use change, biofuels, rural development and the sustainability of food systems. Rather than overcoming debates about land use, marginal lands are subject to the same competing claims as productive land. We argued that the ambiguity of the term 'marginal land' is a type of uncertainty that results from multiple ways of framing an issue, leaving no clear idea of what is the problem or what should be done about it. Deliberative approaches are needed where framing debates can form the starting point.

Given the many trade-offs that arise due to growing demands, a sustainable way of utilising biomass is needed. In chapter 5 we suggested that a circular bio-based economy could provide a pathway to more sustainable use of biomass. Here we presented five ecological principles to guide biomass use towards a more circular bioeconomy: 1) safeguarding and regenerating the 
health of our agroecosystems; 2) avoiding the production of non-essential products and waste of essential ones; 3) using biomass streams for basic human needs; 4) utilising and recycling all byproducts of agroecosystems, and 5) prioritising renewable energy and minimising energy use. We also identified institutional, technological, organisational, behavioural, cultural and market barriers that may halt the required transformation. For each set of barriers, we identified opportunities for change which were leverage points that can bring about transformative change. By involving stakeholders, leaving room for ambiguity, having an ambitious vision for change and a mix of topdown and bottom-up governance approaches, these principles can be operationalised.

Chapter 6 brings the insights of the preceding chapters together by answering three questions. First, what are the key interactions, trade-offs and synergies in biomass uses in both science and policy? I argued that high demands, particularly for bioenergy and animal-source food, limit the biophysical option space, resulting in multiple trade-offs. Bioenergy and agricultural systems are closely interconnected and the diversion of high-value biomass streams to bioenergy can cause negative environmental impacts. Furthermore, the solutions recommended for biomass competition, such as marginal lands, remain unclear. By looking at policy coherence, I showed a policy of biomass cascading and renewable energy policies are a source of trade-offs as well as key synergies. My second question was, how can science and policy deal with complexity, ambiguity and uncertainty? Here I suggested that defining between different types of uncertainty can lead to understanding which uncertainties can be reduced and which require different approaches. These approaches include changing models of scientific advice and changing modes of governance. Third, what practical steps can be made towards more sustainable use of biomass? I suggested practical ways forward in relation to more sustainable use of biomass, such as taking a more integrated view of biomass and defining a cascading principle for biomass emerging from our ecological principles in Chapter 5. Moving towards a more sustainable use of biomass will not be easy and will require a societal transition. By redefining what we value, directing biomass towards human needs and paying as much attention to the social foundation as to the biophysical boundaries, humanity can change its relationship with the biosphere and continue to develop and thrive for generations to come. 


\section{Acknowledgements}

It takes a village to raise a $\mathrm{PhD}$.

I would like to first thank my supervisors without whom there would be no PhD book. I was incredibly lucky to have such a supportive supervisory team at APS. First, Raimon, whose critical thinking kept us all on our toes. Your interdisciplinarity allowed us to think in ways we wouldn't have otherwise and though growth is painful, it's also the most valuable thing a PhD student can achieve. You balanced this with support and advice that went beyond papers, presentations and projects. In difficult times, you were the first to offer support and for this I am forever grateful. APS is lucky to have you. Gràcies per tot Raimon, sincerament.

To Evelien, who was always more than a supervisor but also a mentor and a friend. The care you display for your students is one of the many reasons they always love you so much and something I wish to emulate in the future with my own students. You are an inspiration and it was my great luck that you joined the supervision team. Undoubtedly the award for coolest supervisor ever goes to you.

To Imke, an inspiring boss and leader. In every sense you are a trailblazer: in your management and leadership, in your research area, not to mention the countless trails you must have blazed all across Europe on your bike. Few chairholders manage the kind of toughness needed to make difficult decisions with the care, support and cooperation that is needed for fruitful science. You really are an inspiration for others.

I would like to thank my co-authors who hitched a ride with us on the PhD journey and made the interdisciplinary papers in this book possible: thank you Zora (who attended a meeting with a newborn); Jeroen for believing in our framing paper and beyond; Tamara, Martin, Katrien and Hannah for giving advice on how to achieve a circular bio-based society!

Thanks also goes to all my colleagues from the MAGIC project and UAB. Thank you for contributing and participating in my research in meaningful ways.

Grazie Maddalena (e Remo) per averci fatto stare nel tuo appartamento e per esserti preso cura del mio fratellino! Siamo stati benissimo a Barcellona. Grazie mille!

To my brother and sister from another mother, Loekie and Titis, who always made sure I didn't get stuck in my head by making me laugh. I miss you guys and hope to feed you again soon. 
This PhD would have been a lot less fun without the atmosphere at APS, where colleagues are also friends. Thank you to Akke for the much-needed hugs and occasionally helping me set up a bookcase. We need another Ghibli night. Ollie for being my buddy in radical honesty and social justice. I look forward to more weird talks over coffee. Knuffels! Gracias Alejandro por la música y por las charlas sobre familia, amigos y inmigración. Aunty Sally for the dances and the late night advice. President Brain, for your faith that I would be Prime Minister of Malta some day! To my auntie/sister Windi for late-night commiserations at our desks. Heleen for the dancing and the singing. Aisling for heart-to-heart talks over drinks in Cologne. Louise (see I didn't forget you!), Margret, Cecilia, Ben, Simon F and Simon O (my bandmates), Bhavana, Cindy, Pim 1+2, Laura, Corina, Hannah, Pablo, Eddie, Iris, Aart: dank je voor de gezelligheid/so long and thanks for the laughs. Fokje, Theo and Lia; a special shout-out to you for the patient support!

To S, without whom I wouldn't have moved to the Netherlands in the first place. I wish you happiness wherever you are.

Kiki, thank you for listening to my whining at peak PhD in the darkness of winter and for the long discussions about politics, immigrant life and God. Here's to many more (coupled with drinkies).

Grazzi lil Julian tal-qoxra inkredibbli! Kieku ma iddeciidejtx li nabbanduna festival letterarju ghal gig tal-metal, abbli ma kontx nispićċa b'qoxra tal-ġenn. Grazzi talli fhimtni u ghamilt qoxra sabiћa ghal 4 snin tbatija!

A note to the anthropologists in my life and in the afterlife. I thought a lot about what shaped me and the further I move away from anthropology in my career, the more I think about its insights. First, to the dearly departed Paul Clough who was probably one of the greatest anthropologists I've ever met. Most of us get into anthropology because we love theory or we love fieldwork but Paul loved both. Above all he loved people...in his misanthropic sort of way. Hearing about your death in 2019 was a blow to me both academically and personally. Paul, I hope to meet you somewhere in the afterlife where we can ask Levinas directly what the heck he was on about.

A bond between anthropologists is never broken. Though many years have passed now, and we meet at multi-year gaps, I still feel connected to my Durham friends. A special thanks goes to Diana and Taras for hosting me in Cambridge during a difficult time. That trip really was the beginning of my reboot. Nolite te bastardes carborundorum $D$.

Lil familja tieghi, b'mod spećjali liz-zija Angele u z-ziju John li kienu hemm f'mumenti diffićli. Lil Francesca, li ersaqna flimkien iktar ma' morna 'I boghod minn Malta. Nispera li dejjem nersqu iktar vićin fil-futur (u din tapplika ghal kuġini kollha). Liz-ziju Ray li tlifna fis-sajf...ghadni niftakar meta

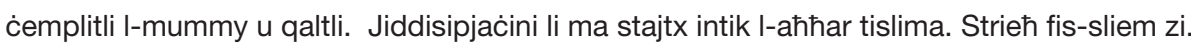




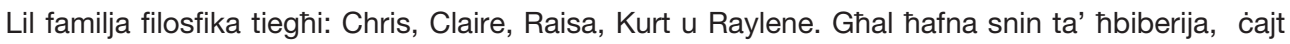
hażin, qrid fuq politika, ritratti inkriminanti u New Years Eve epiċi. Minkejja li konna kultant il-

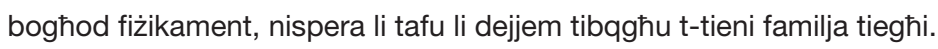

To Sammy, the coolest brother a sister could have. You genuinely are my hero: you're more courageous than me with your opinions, you are more open and curious to learning new things and you constantly master new skills with your razor-sharp attention. I hope both of us manage to achieve the greener, fairer world we want. Thank you for being my best friend and keeping me updated with memes. Grazzi bro.

To Ali, without whose generosity of spirit and love, I would be nowhere at all.

مدىسر ىمن اجنى هب نم ،وت قشع و منادنمتو اخس مىعور نودب مزعزع

Finalment ghal iktar persuna importanti u tal-ġenn fid-dinja: il-mama'. Inti l-iktar bniedma kuraġġuża, qalbiena u ġeneruża li naf. Qalb tad-deheb. Ftit huma nies daqsek komplew jiżvilluppaw u jikbru matul iż-żmien. Ghallimt lili u lis-Sammy l-iktar lezzjoni importanti: kif inћobbu u kif dejjem ikollna empatija ghal haddieћor, anki (anzi iktar) jekk qed inbatu aћna stess. M'hawn hadd fid-dinja li haqqu iktar kuntentizza minnek. Kompli bić-ćajt hażin, ibqa' certa li jien dejjem inkun hemm indawwar ghajnejja. 


\section{About the Author}

\section{Abigail Muscat was born on $9^{\text {th }}$ January 1991 in Pieta', Malta. In 2012, she obtained a BA in Anthropology and Philosophy from the University of Malta.}

In 2015, she obtained her MSc in Sustainability, Culture and Development from Durham University, UK where she conducted fieldwork and wrote a thesis on conservation conflicts in Malta surrounding hunting and migratory birds. After briefly completing an internship with a human rights NGO in Malta, she worked for the Maltese Ministry of Sustainable Development, Environment and Climate Change, following EU and international environmental policy and sustainable development issues. Here, she attended EU Council meetings and the United Nations Environment Assembly in Kenya as part of a Ministerial delegation.

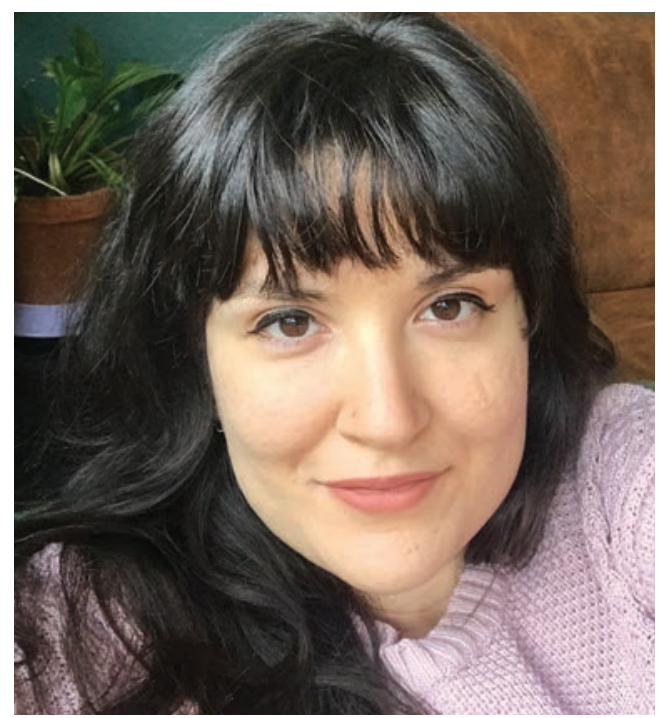

In 2016 she joined the Animal Production Systems group to work on her PhD as part of the project "Moving Towards Adaptive Governance in Complexity: Informing Nexus Security" (MAGIC). Here she worked on the complex issue of food-feed-fuel competition from both a policy and ecological lens. The findings of this thesis were presented at international conferences, graduate school days as well as invited lectures and published in peer-reviewed scientific journals. During her time in MAGIC, Abigail formed part of the social media team as well as producing policy briefs and deliverables. Passionate about the science-policy interface and science communication, Abigail continues to follow policy developments, share her work while writing about environmental and policy issues. She currently coordinates and teaches in an international PhD course on circular bio-based systems entitled 'A bio-based society: from principles to practice' at the Animal Production Systems group. 


\section{Publications}

\section{Refereed scientific journals}

Muscat, A., de Olde, E.M., de Boer, I.J.M., Ripoll-Bosch, R., 2019. The battle for biomass: A systematic review of food-feed-fuel competition. Global Food Security 25, 100330. https://doi. org/10.1016/j.gfs.2019.100330

Muscat, A., de Olde, E.M., Ripoll-Bosch, R., van Zanten, H.H.E., Mezte, T.A.P., Termeer, C.J.A.M., van Ittersum, M.K., de Boer, I.J.M., Towards a circular, bio-based society: principles, barriers and opportunities, Under Review.

Muscat, A., de Olde, E.M., de Boer, I.J.M., Kocacic, Z., Ripoll-Bosch, R.

Energy, food or biomaterials? Policy coherence across agro-food and bioeconomy policy domains in the EU. Under Review.

Muscat, A., de Olde, E.M., Candel J.J.L; de Boer, I.J.M., Ripoll-Bosch, R., The Promised Land: Contrasting frames of marginal land in the European Union. Submitted.

\section{Conference proceedings}

2020. Muscat, A., de Olde, E. M., van Zanten, H. H. E., Ripoll Bosch, R. \& de Boer, I. J. M., Principles for the use of biomass in a circular economy 13 Feb 2020, WIAS Annual Conference 2020: Frontiers in Animal Sciences. WIAS, p. 34-34 1 p. https://edepot.wur.nl/517930

2019. Muscat, A., de Olde, E. M., de Boer, I. J. M., \& Ripoll Bosch, R. (2019). Livestock in the Bioeconomy: are EU policies coherent. In Trade-Offs in Science - Keeping the balance: Abstracts of the WIAS Science Day 2019 (pp. 44-45). Wageningen University \& Research. https:// research.wur.nl/en/publications/livestock-in-the-bioeconomy-are-eu-policies-coherent

2018. Muscat, A., Ripoll Bosch, R., \& de Boer, I. J. M. (2018). A systematic review of food-feedfuel competition. 39-39. Abstract from WIAS Science Day 2018, Wageningen, Netherlands.

2018. Muscat, A., de Olde, E. M., de Boer, I. J. M., \& Ripoll Bosch, R. (2018). Balance trade-offs and synergies between food, feed and bioenergy production: a systematic review. In SDG Conference "Towards Zero Hunger: Partnerships for Impact" (pp. 15-16),

2017. Muscat, A., Ripoll Bosch, R., \& de Boer, I. J. M. (2017). A systematic review of trade-offs between food-feed-bioenergy as result of biomass competition. In Book of Abstracts of the 68th 
Annual Meeting of the European Federation of Animal Science (pp. 210-210). (Book of abstracts; No. 23). Wageningen: Wageningen Academic Publishers. http://www.wageningenacademic.com/ doi/pdf/10.3920/978-90-8686-859-9\#page=211

\section{Scientific reports}

Krol MS, Cabello Villarejo V, Cadillo-Benalcazar J, de Olde E, Di Felice L, Giampietro M, Muscat A, Renner A, Ripa M, Ripoll Bosch R, Serrano-Tovar T and Verburg CCA (2018). Report on exploratory applications of the MuSIASEM Toolbox in Quantitative Story Telling for anticipation. MAGIC (H2020-GA 689669), Project Deliverable 4.3, 31 March 2018. http://magic-nexus.eu/ sites/default/files/files_documents_repository/magic_d4.3.pdf

Ripoll-Bosch and Giampietro (Editors). (2019). Report on EU socio-ecological systems (Revision). MAGIC (H2020-GA 689669) Project Deliverable 4.2. First submitted 31 March 2018, revised 30 June 2019 http://magic-nexus.eu/sites/default/files/files_documents_repository/magic_689669_ d4.2_revised.pdf

Kok A., Ripoll Bosch R., de Olde E.M., Muscat A., de Boer I.J.M. (2020), ıntervention directed towards environmental protection: Biodiversity conservation on agricultural land, MAGIC (H2020-GA 689669) Project Deliverable 6.4, 24 February 2020. https://magic-nexus.eu/sites/default/files/files_documents_repository/magic_deliverable_6.4_report_final.pdf 
The Battle for Biomass | Abigail Muscat Publications 


\section{Education Certificate \\ Completed training and supervision plan ${ }^{1}$}

\begin{tabular}{|c|c|}
\hline Basic Package & 2 ECTS \\
\hline WIAS Introduction Day & 2016 \\
\hline Research integrity and ethics in animal sciences & 2017 \\
\hline Disciplinary Competences & 20 ECTS \\
\hline WIAS PhD proposal & 2016 \\
\hline $\begin{array}{l}\text { Multi-Scale Integrated Analysis of Societal and Ecosystem } \\
\text { Metabolism (MuSIASEM) }\end{array}$ & 2016 \\
\hline Future of Food: Environmental Sustainability & 2016 \\
\hline Environmental Impact Assessment of Livestock Systems & 2017 \\
\hline Systematic Approaches to Reviewing Literature & 2017 \\
\hline Shaping future animal systems: exploring practices through dialogue & 2017 \\
\hline $\begin{array}{l}\text { Towards a Bio-Based Economy: Science, Innovation, Economics, } \\
\text { Education }\end{array}$ & 2018 \\
\hline Professional Competences & 6 ECTS \\
\hline Scientific Publishing & 2017 \\
\hline Presenting with Impact & 2017 \\
\hline Mobilising your Scientific Network & 2017 \\
\hline Scientific Writing & 2019 \\
\hline Career orientation & 2020 \\
\hline Presentation Skills & 4 ECTS $^{2}$ \\
\hline Poster, WIAS Science Day, Wageningen, The Netherlands & $2017-2019$ \\
\hline Oral, EAAP, Tallin, Estonia & 2017 \\
\hline $\begin{array}{l}\text { Oral, Towards Zero Hunger: Partnerships for Impact, Wageningen, } \\
\text { The Netherlands }\end{array}$ & 2018 \\
\hline Poster, EMP-E, Brussels, Belgium & 2019 \\
\hline Teaching competences & 6 ECTS $^{2}$ \\
\hline Thesis supervisor, $3 \mathrm{BSc}$ thesis & $2017-2018$ \\
\hline Thesis supervisors, 2 MSc thesis & $2018-2020$ \\
\hline Practical supervisor, System Approach to Animal Sciences & 2018 \\
\hline Education and Training Total & 38 \\
\hline
\end{tabular}

${ }^{1}$ With the listed activities, the $\mathrm{PhD}$ candidate complied with the educational requirements of Wageningen Institute of Animal Sciences (WIAS) a Wageningen University \& Research graduate school. One ECTS equals a study load of 28 hours.

${ }^{2}$ Listed activities provided more ECTS than granted by WIAS regulations 


\section{Colophon}

The research described in this thesis was financially supported by the European Union's Horizon 2020 Research and Innovation Programme under grant agreement No.689669. The present work reflects only the authors' views and the Funding Agency cannot be held responsible for any use that may be made of the information it contains.

Cover Illustration by Julian ‘Julinu’ Mallia (www.julinu.com)

Printed by ProefschriftMaken 
